\title{
ANÁLISE E INTEGRAÇÃO DE DADOS GEOQUÍMICOS E DE SENSORIAMENTO REMOTO EM UM SETOR DO CRISTALINO URUGUAIO
}

\author{
JOSÉ MARIA FILIPPINI ALBA
}

Orientadora: Prof. Dr ${ }^{\text {a. }}$ Sonia Maria Barros de Oliveira

\section{TESE DE DOUTORAMENTO}

COMISSÃO JULGADORA

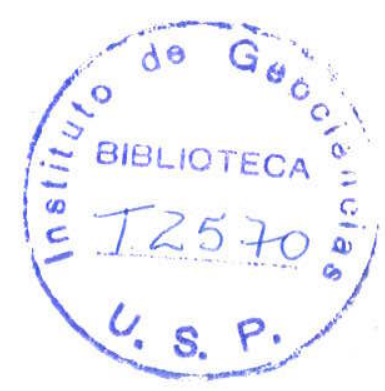

Nome

Assinatura

Presidente: $\quad$ Prof $^{\text {a. }}$ Dr $^{\text {a. }}$ Soria Maria Barros de Oliveira

Examinadores: Prof. Dr. Gilberto Amaral

Prof. Dr. Paulo Roberto Menezes

Prof. Dr. Romulo Angelica Simões

Prof. Dr. Waldir Renato Paradella

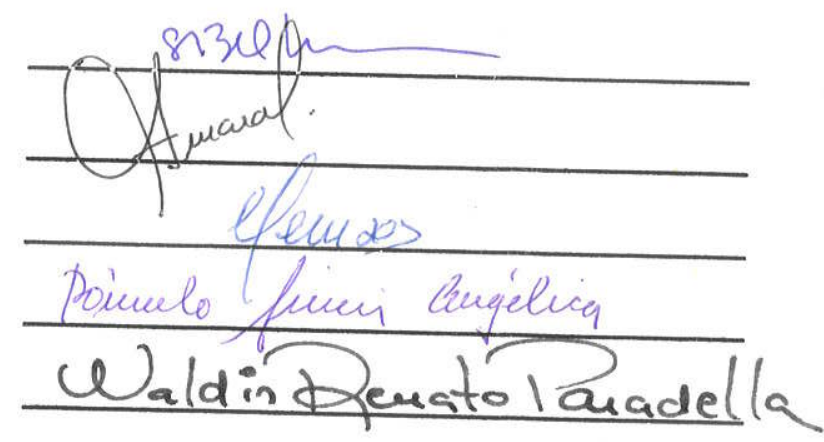


UNIVERSIDADE DE SÃO PAULO

INSTITUTO DE GEOCIENNCIAS

\section{ANÁLISE E INTEGRAÇÃO DE DADOS GEOQUÍMICOS E DE SENSORIAMENTO REMOTO EM UM SETOR DO CRISTALINO URUGUAIO}

José Maria Filippini Alba

Orientadora: Profa. Dra. Sonia M. B. de Oliveira

Co-orientador: Prof. Dr. Alvaro P. Crósta

TESE DE DOUTORAMENTO

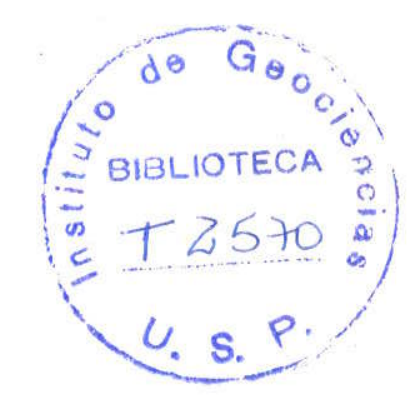

Programa de Pós-Graduação em Geoquímica e Geotectônica

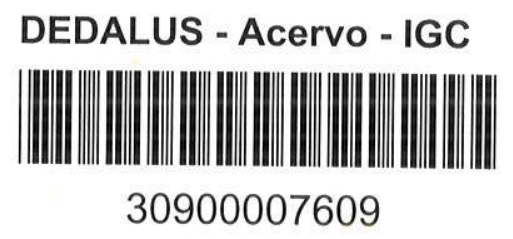

SÃO PAULO

1998 
Dedico este trabalho a minha esposa Vanderleia e ao meu filho Lenin. 


\section{AGRADECIMENTOS}

- autor agradece a valorosa contribuição de todas as pessoas e instituições mencionadas na lista a seguir:

À Dra. Sônia M. B. de oliveira, na função de orientadora, pelo seu apoio incondicional e incentivo nos quatro anos de duração do projeto, e pela sua dedicação e senso crítico na otimização do documento final.

Ao Dr. Álvaro P. Crósta do Departamento de Metalogênese e Geoquímica do IG-UNICAMP, na função de co-orientador, por apoiar - projeto, permitindo o uso dos recursos computarizados do Laboratório de Informação Geo-referênciada-LAPIG do IG-UNICAMP, e pela sua cooperação no processamento dos dados e na discussão dos resultados.

Ao Dr. Alf Björklund do Departamento de Mineralogia e Geologia da Universidade Acadêmica de Ảbo que foi coordenador do estágio na Finlândia (outubro/95-março/96), cooperando no tratamento dos dados geoquímicos e discussão dos resultados, em especial na avaliação dos erros e na produção de mapas.

Também no Departamento de Mineralogia e Geologia da Universidade Acadêmica de Ảbo (Finlândia) ao Dr. Carl Eblers (Diretor), a Sra. Marja Puumala, ao Dr. Leif Bergman, ao Dr. Bo Linaberg, ao Dr. Mats Àström $e$ ao Dr. Peter Edén, que colaboraram em diversos aspectos durante o estágio na Finlândia.

Ao Dr. Nils Gustavsson do Serviço Geológico da Finlândia que foi coordenador do estágio nessa instituição, pelo seu apoio incondicional durante e depois da permanência na Finlândia.

Também no serviço Geológico da Finlândia, ao Iic. Tech. Eero Lampio, ao Sr. Heimo Savolainen e ao Sr. Jukka Laitinen pela elaboração de mapas, a M.Sc. Ilkka Arkima, ao Geof. Hilkka Arkima e ao Sr. Matti Lehtonen pela sua ajuda no uso de computadores e softwares. 
Continuando no Serviço Geológico da Finlândia, ao Diretor Ph.D. Veikko Lappalainen, ao Vice-Diretor Dr. Pentti Noras e ao M.Sc. Toni Eerola da Divisão Internacional por permitir o estágio nessa instituição e por colaborar nas gestões envolvidas.

Ao Dr. Ardemirio Barros Silva do LAPIG-IG-UNICAMP que atuou como coordenador do projeto no LAPIG no período janeiro/95dezembro/96. Aproveita-se o espaço para agradecer a Gerente do Sistema Sra. Patrícia sirquiera leite e aos demais colegas do LAPIG-IG-UNICAP pelo intercâmbio de idéias e bons momentos compartilhados (Amintas, Enrico, Enrique, Irian, Giorgio, Julio, Liliana, Marcelo, Marcia, Neivaldo, Paulão, Solange, Ricardo, Rigoberto, ...).

Ao Dr. Daniel Cersócimo ex-Sub-Secretário do Ministério de Industrias, Energia e Mineração (Uruguai), ao Sr. Francisco Sequeiros Sub-Director da Direção Nacional de Mineração e Geologia-DINAMIGE (Uruguai) e ao Dr. Gustavo Corrêa Calcagno, ex-Diretor da DINAMIGE, que apoiaram ao autor do presente trabalho, na época em que era funcionário da DINAMIGE.

Ao Diretor da Coordenadoria de Comunicação Social da USP Dr. Celso Barros Gómes e ao Diretor da Divisão Gráfica de essa instituição, Sr. Valtemir $\mathbf{T}$. Sasso, pela reprodução dos mapas coloridos incluídos na tese.

Ao Dr. Manuel s. Pinto da Universidade de Aveiro pelas gestões relacionadas ao estágio na finlândia e pelo seu apoio através de material bibliografico.

Na Biblioteca do Instituto de Geociências - USP, à sra. Maria A. Bezerra e ao pessoal do setor de Atendimento pela normalização da bibliografia e pela boa disposição demonstrada.

No Departamento de Geologia Geral, ao Dr. Marcos E. Silva pelo apoio oferecido, ao Dr. Ian McReath pela sua ajuda na 
elaboração do Abstract e as Secretárias, Sra. Nicia Maria B. zalaf e sra. Sonia G.C. Vieira pela sua ótima disposição em todo momento.

Ao Conselho Nacional de Pesquisa pela atribuição de uma bolsa de estudos e à Fundação de Apoio a Pesquisa do Estado de são paulo que financiou a compra dos dados de satélite e outros materiais.

Aos Colegas da Pós-graduação do IG-USP pela troca de ideias e conhecimentos.

Ao pessoal da Gráfica do IG-Jsp pela confecção do documento final. Ao $\mathrm{Sx}$. Jaime $\mathrm{S}$. Marcos pela preparação de diapositivas.

A minha esposa vanderleia, que colaborou nas tarefas de digitação e correção de dados, e pelo seu apoio incondicional.

Aos meus Pais, Blanca R. Alba e Elbio P. Filippini pela ajuda e compreensão demonstradas. 
Resumo

Abstract

Lista de legendas dos mapas

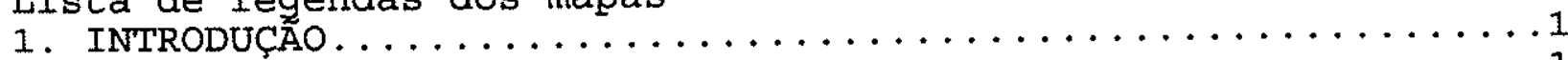

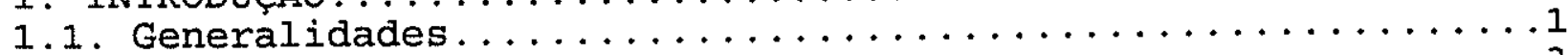

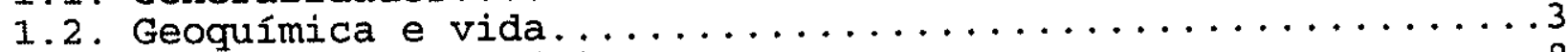

1.3. Mapeamento geoquímico $\ldots \ldots \ldots \ldots \ldots \ldots \ldots \ldots \ldots \ldots \ldots$

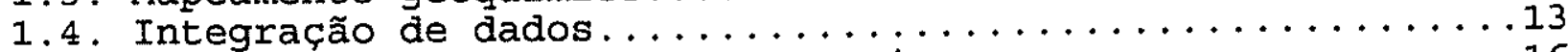

1.5. Prospecção geoquímica no Uruguai 16

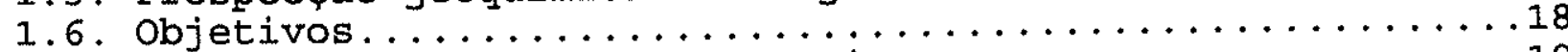

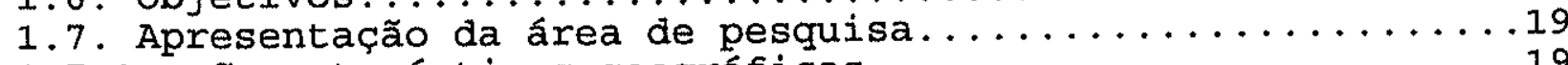

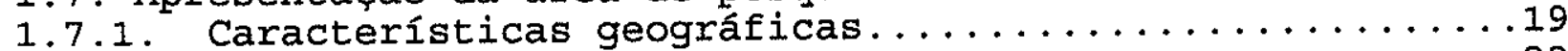

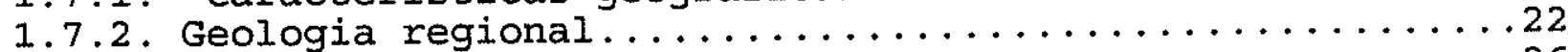

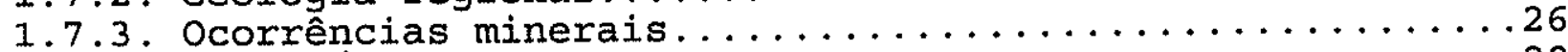

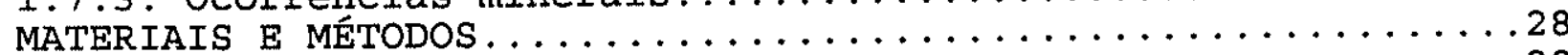

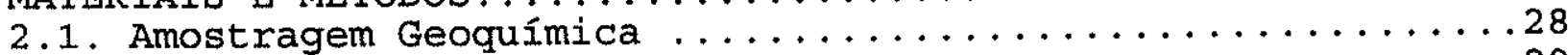

2.2. Analises químicas. . . . . . . . . . . . . . . . . . 29

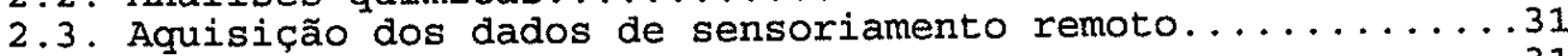

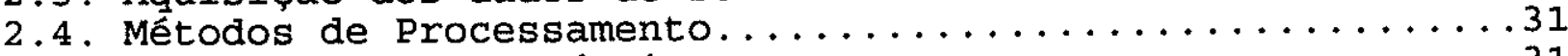

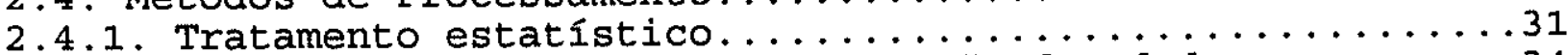

2.4.2. Processamento digital e integração dos dados .......34

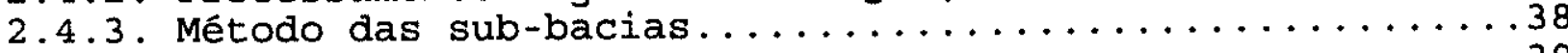

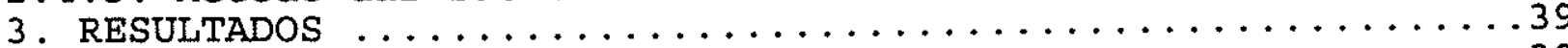

3.1. Avaliação dos erros geoquímicos . . . . . . . . . . . . . 39

3.2. Tratamento estatístico dos dados geoquimicos originais...54

3.2.1. Parâmetros das distribuições univariadas............54

3.2.2. Análise de variância-ANOVA..................60

3.2.3. Distribuição espacial univariada..............64

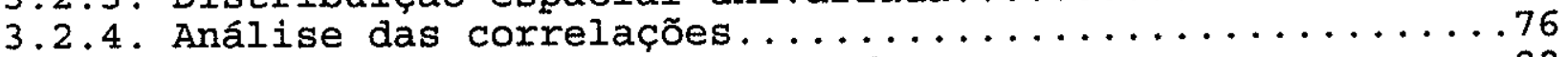

3.2.5. Regressão em função de $F e$ e $M n \ldots \ldots \ldots \ldots \ldots \ldots . \ldots \ldots 8$

3.2 .6 . Definição das outliers....................

3.2.7. Procedimentos que usam os autovetores (ACP e AFR) . ...93

3.2.7.1 Aplicação da ACP-AFR sobre a população total ........95

3.2 .7 .2 Aplicação da ACP sobre sub-populações............. 103

3.2.8. Regressão em função dos fatores..................107

3.3. Processamento digital das imagens Landsat-TM..........108

3.4. Integração dos dados . . . . . . . . . . . . . . . . . 116

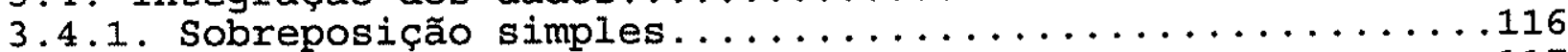

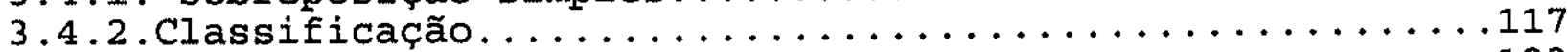

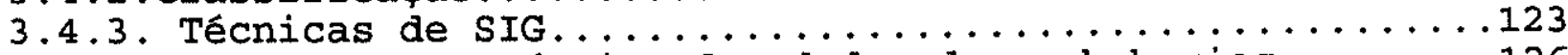

3.5. Tratamento estatístico dos dados das sub-bacias......126

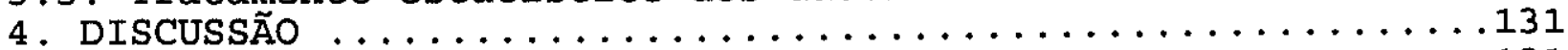

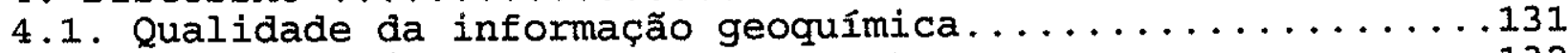

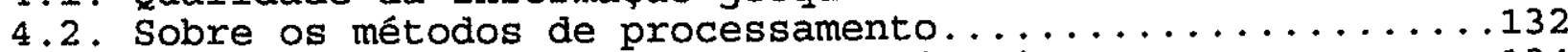

4.3 . Fundo geoquímico e anomalias regionais............................

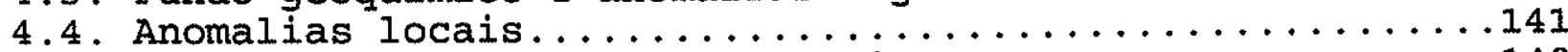

4.5. Aspectos relacionados à geologia................148

4.6. Aspectos relacionados aos recursos minerais...........150

4.7 . Aspectos relacionados ao meio ambiente. . . . . . . . . . 154

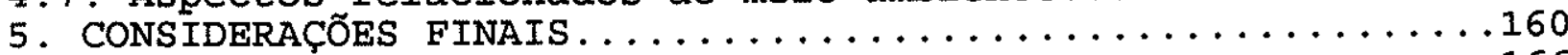

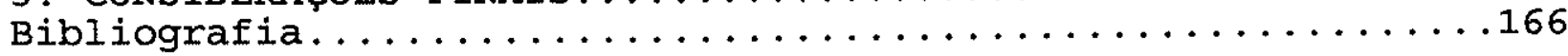




\section{Resumo}

Informações extraídas de mapas geológicos, antigos dados geoquímicos e dados digitais Landsat-TM de um setor no cristalino uruguaio foram integrados utilizando pacotes estatísticos, sistemas de processamento digital de imagens e SIGs. Foram consideradas 2172 amostras de sedimentos de correntes e solos que foram analisadas para 22 elementos por espectrometria DCP. Fe, Mn, P, Ba, Co, Cr, Cu, Ni, Pb, v, $\mathbf{Y}$ e $\mathbf{z n}$ apresentaram variância adequada e erros analíticos inferiores a $10 \%$. Ag, As, $\mathbf{B}, \mathbf{B e}, \mathbf{C d}, \mathbf{M o}, \mathbf{M b}, \mathbf{S b}, \mathbf{S n}$ e $\mathbf{W}$ apresentaram muitas amostras com teores abaixo dos limites de deteç̧ão analíticos e erros analíticos superiores a 15\%. Por esse motivo, o primeiro grupo de elementos foi utilizado para o tratamento estatístico e o segundo grupo, apenas para aqueles valores próximos ou acima dos limites de detecção.

Houve alguns problemas relacionados à metodologia de amostragem, aos materiais amostrados e à existência de outliers estatísticas. Esses problemas foram corrigidos de duas formas principais: (1) Usando as medianas dos grupos segundo o material amostrado. (2) Eliminando as outliers. Foi obtido um conjunto de dados de características mais homogêneas.

A resposta geoquímica foi controlada por variaços relacionadas às unidades geológicas, aos litotipos e à ocorrência de mineralizações. Foram definidas várias anomalias regionais e nove setores anômalos, alguns dos quais foram considerados anomalias litológicas.

A informação de satélite associada aos mapas geoquímicos permitiu destacar o interesse prospectivo de alguns dos setores anômalos, pela visualização de relações espaciais de lineamentos ou corpos aflorantes.

Um outro nível de integração da informação geoquímica e de feições extraídas dos dados Landsat, usando técnicas de classificação permitiu discriminar anomalias regionais, litológicas e associadas a mineralizações, e evidenciou novos alvos prospectivos. As técnicas de SIG reduziram o tamanho dos alvos e hierarquizaram seu potencial mineral. A medida da distância entre anomalia e ocorrência conhecida para os diversos procedimentos aplicados mostrou uma distância mínima média de 1,7 quilômetros. Nesse sentido, os mapas de círculos foram um pouco mais precisos que os mapas gridados.

Uma das anomalias regionais mais importantes, localizada nas proximidades da vila Zapicán, apresentou teores elevados para elementos tóxicos (Fe, $\mathbf{m}, \mathbf{C r}, \mathbf{N i}, \mathbf{v} . .$.$) , constituindo um eventual alvo para$ estudos ambientais. Outras duas zona urbanas mostraram comportamento oposto, com empobrecimento nos teores da maioria dos traços. 


\section{Abstract}

Geological map information, old geochemical data and digital Landsat-TM data in a portion of the Precambriam basement of Uruguay were integrated using statistical packages, image processing data systems and GIS strategy. Stream sediments and soil samples were collected at 2,172 sites and analysed for 22 elements by DCP spectrometry. Fe, Mn, P, Ba, Co, $\mathbf{C r}, \mathbf{C u}, \mathbf{N i}, \mathbf{P b}, \mathbf{v}, \mathbf{Y}$ and $\mathrm{zn}_{\mathbf{n}}$ showed adequate variance and analytical errors lower than $10 \%$. Ag, $\mathbf{A s}, \mathbf{B}, \mathbf{B e}, \mathbf{C d}, \mathbf{M o}, \mathbf{N b}, \mathbf{S b}$ and $\mathbf{W}$ in several samples had contents lower than the analytical detection limits and analytical errors greater than $15 \%$. For these reasons, the first group of elements was used for the statistical data treatment and the second group was used in restricted applications.

Some problems were related to sampling methodology, sampling materials and statistical outliers. These problems were corrected in two principal ways: (1) Using mediams for groups of elements. Elimination of outliers. The final data set was more homogeneous.

Several regional anomalies and nine anomalous sectors were defined, related to lithological phenomena or mineralization. Landsat-TM data showed some structural features and outcrops spacially related to geochemical anomalies in some anomalous sectors, improving their prospective interest.

Classification techniques using geochemical data and features extracted from Landsat-TM data discriminated regional, lithological and mineralization anomalies and some new prospects were detected. GIS approach reduced the size of prospects and priorities were estimated. The mean minimum distance between anomalies and the known mineral occurrences was $1.7 \mathrm{~km}$ according to a comparative study with four anomaly detection procedures used in this work. In that sense, dot maps were a little more precise than grid maps.

The anomaly region near zapicán village presented high contents of toxic metals (Fe, $\mathbf{M n}, \mathbf{C r}, \mathbf{N i}, \mathbf{V}$...) and future environmental studies might be done. Pirarajá and J.P. Varela urban zones showed an opposite environment with low contents of most trace metals. 


\section{IISTA DE LEGENDAS DOS MAPAS}

MAPA 1. Mapa de círculos do Fe para os dados sem transformação (2144 amostras). As linhas finas indicam os contatos geológicos, as linhas intermediárias as principais falhas e as linhas mais grossas (cor cinza) as ocorrências de anfibolitos.

MAPA 2. Mapa de círculos do $\mathbf{P}$ para os dados sem transformação (2144 amostras). As Iinhas finas indicam os contatos geológicos, as linhas intermediárias as principais falhas e as linhas mais grossas (cor cinza) as ocorrências de anfibolitos.

MAPA 3. Mapa de círculos do Ba para os dados sem transformação (2144 amostras). As linhas finas indicam os contatos geológicos, as linhas intermediárias as principais falhas e as linhas mais grossas (cor cinza) as ocorrências de anfibolitos.

MAPA 4. Mapa de círculos do Cr para os dados sem transformação (2144 amostras). As linhas finas indicam os contatos geológicos, as linhas intermediárias as principais falhas e as linhas mais grossas (cor cinza) as ocorrências de anfibolitos.

MAPA 5. Mapa gridado do fator $1(\mathrm{Fe}+\mathrm{Cr}+\mathrm{Cu}+\mathrm{N} \mathbf{i}+\mathrm{V} \ldots)$ para os dados em logaritmos, sem outliers e corrigidos pelo efeito do material amostrado (2128 amostras). Mapa de círculos para a Distância de Mahalanobis-DM. As linhas finas indicam os contatos geológicos e as linhas intermediárias as principais falhas. As linhas grossas azuis indicam as ocorrências de anfibolitos. $\mathbf{0}=$ Ocorrência de Fe-Cu ou Au. 1 = Ocorrência de $\mathbf{P b}$.

MAPA 6. Mapa gridado da $D^{2} \mathrm{cp} 1-5$ e de círculos para a $\mathrm{D}^{2} \mathrm{cp} 6-11$. Dados em logaritmos, sem outliers e corrigidos pelo efeito do material amostrado $(2128$ amostras). As linhas finas 
indicam os contatos geológicos e as linhas intermediárias as principais falhas. As linhas grossas azuis indicam as ocorrências de anfibolitos. 0 = Ocorrência de $\mathrm{Fe}-\mathrm{Cu}$ ou Au. 1 = Ocorrência de $\mathbf{P b}$.

MAPA 7. Mapa gridado do fator $3(\mathbf{M n}+\mathrm{Co}+\mathrm{Fe})$ e de círculos para o Mn. Dados em logaritmos, sem outliers e corrigidos pelo efeito do material amostrado (2128 amostras). As linhas finas indicam os contatos geológicos $e$ as linhas intermediárias as principais falhas. As linhas grossas cinzas indicam as ocorrências de anfibolitos.

MAPA 8. Mapa gridado do fator $4(\mathrm{~Pb}-\mathrm{P})$ e de círculos para $0 \mathrm{~Pb}$. Dados em logaritmos, sem outliers e corrigidos pelo efeito do material amostrado (2128 amostras). As linhas finas indicam os contatos geológicos e as linhas intermediárias as principais falhas. As linhas grossas cinzas indicam as ocorrências de anfibolitos.

MAPA 9. Mapa gridado do Cu estimado em função dos fatores e de círculos para as residuais de $\mathrm{Cu}$ (Cu real - Cu estimado). Dados em logaritmos, sem outliers e corrigidos pelo efeito do material amostrado (2128 amostras). 0 = Ocorrência de Fe$\mathrm{Cu}$ ou Au. 1 = Ocorrência de $\mathrm{Pb}$. 


\section{INTRODUÇÃO}

\subsection{Generalidades}

$\mathrm{Na}$ sua concepção moderna, a Geoquímica estuda a distribuição e a circulação dos elementos químicos e seus isótopos nos materiais terrestres e nos processos naturais. Trata-se de uma ciência recente, que possui suas raízes na geologia e na química, mas integra princípios da biologia, da mineralogia e da petrologia. Esse fato, junto à necessidade de que fosse completada e sistematizada a Tabela Periódica dos Elementos, demorou seu surgimento como subdivisão cientifica. GOLDSCHMIDT é reconhecido como o precursor da disciplina na sua visão contemporânea, através da sua obra póstuma "Geoquímica" (GOLDSCHMIDT, 1958) .

Do ponto de vista aplicado, a Prospeç̧ão Geoquímica, ou seja a utilização dos métodos geoquímicos na pesquisa de recursos minerais (GRANIER, 1973; LEVINSON, 1974; BEUS \& GRIGORIAN, 1977; ROSE ET AL., 1979; BOYLE, 1982a,b; GOVETT, 1983...), teve um papel preponderante no decorrer do século. Assim foram realizados estudos da distribuição geográfica dos elementos traças à escala regional e da sua variação espacial a nível de detalhe. Por outro lado, no século passado e durante a segunda guerra mundial foram desenvolvidos trabalhos de geoquímica de solos orientados a melhorar a produtividade agrícola (apud DARNLEY, 1990).

Nas últimas décadas foi retomado o enfoque ambientalista da Prospecção Geoquímica, visando incrementar seu campo de aplicação na resolução de problemas relacionados à agricultura, contaminação antrópica, ciência florestal, medicina, pecuária e veterinária. Os elementos químicos interagem com os seres vivos através dos processos que ligam as camadas superficiais da Terra, dando lugar a efeitos benéficos ou lesivos, em função das suas características e teores (THORNTON, 1983).

Esses conceitos demonstram a utilidade dos mapas geoquímicos, realizados através do levantamento sistemático de materiais superficiais, visando detectar anomalias relacionadas à ocorrências minerais, zonas contaminadas com elementos lesivos 
e regiões com baixos teores de elementos benéficos. Em 1988 foi criado o Projeto "Mapeamento Geoquímico Internacional". A Fase I desse Projeto (IGCP 259) realizou uma revisão dos métodos de mapeamento geoquímico nacionais e regionais, discutindo os resultados obtidos (DARNLEY et al., 1995). Dessa maneira, foram estabelecidas as bases para a Fase II (IGCP 360), que pretende realizar uma malha geoquímica mundial de referência com 5000 locais de amostragem homogeneamente distribuídos e multicoleta de materiais (DARNLEY, 1993).

Paralelamente, tem acontecido uma revolução na administração e utilização dos recursos naturais, incluindo a pesquisa mineral, pela disponibilidade de dados de sensoriamento remoto a nível mundial, em função da comercialização das imagens obtidas pelos satélites LANDSAT-TM, SPOT e outros (DRURY, 1990), e a possibilidade de integrar e analisar informações diversas, através da utilização de sistemas de informação geográficos ou geo-referênciados-SIG (PLUMMER, 1992) e o processamento digital de imagens-PDI (CRÓSTA, 1993a). Nos últimos anos surgiram várias publicações sobre a integração de dados de sensoriamento remoto, geoquímicos, geofísicos e geográficos obtidos em diferentes épocas, usando sIGs, programas de PDI ou sistemas de gerenciamento de banco de dados-SGBD (BONHAM-CARTER et al., 1988; GAÁL, 1988; CRÓSTA, 1991 e BARROS SILVA, 1993).

Na década passada foram executados vários programas de prospecção geoquímica no Uruguai. Dois deles foram desenvolvidos pela Dirección Nacional de Minería e Geología-DINAMIGE em cooperação com instituições européias e possuem particular importância pela quantidade de informação gerada, que em alguns casos mantém ainda caráter inédito. Foram realizados estudos regionais e de detalhe, com amostragem de sedimentos, solos e rochas, e análises multielementares por espectrometria de emissão, sendo cobertos $15 \frac{\%}{\%}$ do território uruguaio, principalmente no pré-Cambriano.

os tópicos mencionados acima constituem as causas que motivaram este trabalho e podem ser classificados da seguinte forma: (1) Geoquímica e vida.

(2) Mapeamento geoquímico.

(3) Integração de dados. 
(4) Prospecção geoquímica no Uruguai.

\subsection{Geoquímica e vida}

A relação geoquímica-vida é estabelecida através dos processos que ligam a litosfera, a pedosfera, a hidrosfera, a biosfera e a atmosfera, e reflete-se em diversos fatos ligados aos elementos que constituem a crosta:

(1) As necessidades de $\mathbf{P}, \mathbf{K}, \mathbf{C a}$ e $\mathbf{M g}$ do solo para uso agrícola, que são bem entendidas e projetadas na atualidade.

(2) As propriedades curativas de alguns elementos. Por exemplo, existem registros de que na antigüidade já eram usados produtos marinhos, ricos em I, para a cura do bócio.

(3) A ocorrência de doenças ou lesões em seres tratados com elementos específicos durante períodos prolongados ou que foram contaminados com produtos industriais.

(4) A observação de efeitos específicos em populações de seres vivos relacionados a padrões geoquímicos característicos. BOWIE \& THORNTON (1985) e THORNTON (1983) indicam a ocorrência de solos contaminados por $\mathrm{Ni}$ derivado de rochas máficas ou por $\mathbf{A s}, \mathbf{C d}, \mathbf{C u}, \mathbf{P b}$ y $\mathbf{Z n}$ de mineralizações, que geraram níveis tóxicos em produtos agrícolas e gado. Solos contaminados com Mo ou se derivados de xistos enriquecidos provocaram doenças em bois e cavalos.

o tópico (4) seria o diretamente envolvido no assunto aqui tratado, mas devem ser realizadas algumas considerações, por problemas de terminologia, fatores econômicos ou de aspectos vinculados à relação solo-plantas-animais-homem.

Existem algumas confusões geradas pelos termos "essencial", "metal pesado", "micro-nutriente" e "traço". Um "elemento essencial" é indispensável no metabolismo dos seres vivos, mas sua definição possui diferenças, ao serem consideradas plantas ou animais. Nesse sentido os "micro-nutrientes" e os "macronutrientes" são elementos essenciais, discriminados por um fator de escala. São necessarias poucas miligramas/dia de micronutientes e mais de 100 miligramas/dia de macro-nutrientes. Os "metais pesados" são aqueles elementos que possuem densidade maior que 5,0 gramas/mililitro. O termo "traço" resulta 
complicado ao considerar elementos como $\circ \mathrm{Fe} e \circ \mathbf{S i}$, que são elementos maiores na crosta porém "traços" na biosfera. Em geoquímica são considerados "traços" aqueles elementos cuja abundância na litosfera é inferior a $0,1 \%$.

ADRIANO (1986) define o conceito de elemento essencial para as plantas superiores, em função das seguintes conđições:

(1) A ausência do elemento provoca crescimento anormal, falhas para completar o ciclo de vida ou senilidade prematura e morte.

(2) $O$ efeito deve ser específico e 0 elemento insubstituível.

(3) O efeito deve ser direto em alguns aspectos do crescimento ou do metabolismo.

Efeitos benéficos indiretos ou secundários, como reversão ou inibição da ação de outro elemento, não outorgam o caráter de essencial. Do ponto de vista de nutrição animal, o conceito de essencial inclui:

(1) Crescimento significativo em resposta a dieta incluindo o elemento.

(2) Desenvolvimento de estado deficiente com dietas sem 0 elemento, que de outra maneira seriam adequadas.

(3) Correlação do estado de deficiência com a ocorrência de níveis anormais do elemento em sangue ou tecidos de animais afetados.

$\mathrm{Na}$ Tabela 1 indica-se o caráter essencial-benéfico ou tóxico de 30 elementos traço, em relação as plantas, animais experimentais ou de criação e o homem. Não foram incluídos aqueles elementos que superam teores de $0,1 \%$ na biosfera ou na litosfera e que possuem caráter de macro-nutrientes (C, H, $\mathbf{O}, \mathbf{N}$, P, K, Na, Ca e Mg). O caráter dual de alguns elementos (As, Co, Cr, Cu, F...) seria explicado em função da concentração ou da espécie química envolvida. $0 \mathrm{Cr}^{+6}$ é altamente tóxico, porém outras espécies do $\mathbf{C r}$ são relativamente não tóxicas. Ba, Bi, Ni, $\mathbf{S b}, \mathbf{S n}$ e $\mathbf{z n}$ também são elementos pouco tóxicos. O caráter fitotóxico do $\mathrm{Mn}$ tem lugar somente em solos de $\mathrm{pH}$ ácido ( $\mathrm{pH}<5$ ). As, Be, Cd, Co, Cr, Ni, Ti e $\mathbf{V}$ são indicados como possíveis cancerígenos. Au, $\mathbf{B r}$ e $\mathrm{LI}$ tem sido usados em tratamentos terapêticos. 
BOWIE \& THORNTON (1985) consideram que os materiais ideais para avaliar o comportamento geoquímico dos elementos no sistema pedosfera-biosfera, são o solo, os vegetais e os alimentos. As águas representam uma opção interessante, mas sofrem mudanças estacionais, que dificultam sua interpretação. Há bastante informação sobre geoquímica de sedimentos de correntes a nível mundial, o que representa uma alternativa barata e rápida, cuja resposta está relacionada as variações na composição geoquímica das rochas superficiais e dos solos. No entanto, eles são de utilidade na escala regional e não para estudos de detalhe.

Tabela 1. Caráter dos elementos traça segundo seus efeitos nas plantas, nos animais $e$ no homem. Foram inclusdos os elementos citados pelo menos uma vez em ADRIANO (1986), BOWIE \& THORNTON (1985) e CROUNSE et aI. (1983). Os parênteses indicam dúvidas.

\begin{tabular}{|c|c|c|c|c|c|c|}
\hline \multirow{2}{*}{ Elemento } & \multicolumn{3}{|c|}{ Essenciais-benteficos } & \multicolumn{3}{|c|}{ Tбxicos } \\
\hline & Plantas & Animats & Homem & Plantas & Animats & Homem \\
\hline Ag & - & - & & & + & \\
\hline $\begin{array}{l}A 1 \\
\text { AB }\end{array}$ & - & + & $(+)$ & + & + & $\begin{array}{l}+ \\
+\end{array}$ \\
\hline B & + & - & & + & & + \\
\hline $\mathbf{B a}$ & - & $(+)$ & & & & + \\
\hline Be & - & - & & + & + & + \\
\hline Bi & - & - & & + & + & \\
\hline cd & - & - & & + & + & + \\
\hline $\mathrm{Cl}$ & + & & + & & & \\
\hline Co & + & + & + & + & + & \\
\hline $\mathbf{C r}$ & - & + & + & + & & \\
\hline $\mathrm{Cu}$ & + & + & + & + & & \\
\hline $\mathbf{F}$ & - & + & + & + & $\begin{array}{l}+ \\
+\end{array}$ & \\
\hline Fe & + & & + & & $\begin{array}{l}+ \\
+\end{array}$ & + \\
\hline $\begin{array}{l}\mathrm{Hg} \\
\mathrm{I}\end{array}$ & - & - & + & + & + & + \\
\hline in & + & + & + & $\mathbf{p H}<5$ & & \\
\hline so & + & + & + & + & + & \\
\hline Ni & - & + & $(+)$ & + & + & \\
\hline $\mathbf{P b}$ & - & $(+)$ & & + & + & + \\
\hline sb & - & - & & & + & \\
\hline $\mathbf{s}$ & + & + & + & & & \\
\hline Se & + & + & + & + & + & \\
\hline si & $(+)$ & + & $(+)$ & & + & \\
\hline $\begin{array}{l}S n \\
T 1\end{array}$ & - & $\stackrel{+}{(+)}$ & $(+)$ & & + & \\
\hline TI & - & - & & & + & \\
\hline v & + & + & $(+)$ & + & + & \\
\hline w & - & - & & 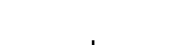 & 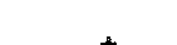 & \\
\hline $\mathbf{Z n}$ & + & + & + & + & + & \\
\hline
\end{tabular}

THORNTON (1983) indicou que a disponibilidade dos elementos para as plantas e animais não depende somente do seu conteúdo no solo. O mecanismo de absorção dos elementos traço pelas plantas 
não é bem entendido ainda. Por exemplo, nos solos, o cu pode ocorrer em forma mineral ou complexado por substâncias orgânicas; mas só a fração orgânica estaria disponível para as plantas. Alguns avanços nesse sentido foram obtidos trabalhando com extrações parciais, ou seja, atacando os solos com reagentes moderados $\left(\mathrm{CH}_{3} \mathrm{COOH}, \mathrm{EDTA}, \mathrm{HCl} . ..\right)$ e comparando com a fração total.

KRYUSKOV (1991) descreveu um halo de degradação de pinheiros, cobrindo uma área de cerca de $20.000 \mathrm{~km}^{2}$, devida à poluição do ar por siderúrgicas de Al, Ni e apatita, em Kola Norte, um distrito industrializado da URSS. Foram caracterizadas cinco regiões de degradação vegetal, mostrando teores de $\mathbf{N i}$, Cu e $\mathrm{SO}_{2}$ no ar, diminuindo com o grau de degradação dos pinheiros.

LÅG (1983) introduziu a expressão "Geomedicina" para denominar a ciência que estuda a influência dos fatores ambientais na distribuição geográfica dos problemas patológicos e nutricionais em saúde animal e humana. Foi mencionado um antigo caso de doença óssea em gado na Noruega, que foi atribuído à ocorrência de rochas empobrecidas em $\mathbf{P}$, refletindo essa deficiência em solos e pastagens. Também foram citados solos contaminados com metais pesados $(\mathrm{Cu}, \mathrm{Pb} . .$.$) e deficiência$ de se em plantas e alimentos na Finlândia, um dos primeiros países no mundo que autorizou a adição de se em forragens. LÅG (1991) mencionou a existência de renas afetadas por fluorose nas vizinhanças de uma planta de Al na Noruega. THORNTON (1983) indicou que no processo de pastagem o gado costuma ingerir solo em forma involuntária, atingindo valores de $10 \% \mathrm{em}$ bovinos e de $30 \%$ em ovinos, em relação ao consumo diário; isso pode conduzir à toxicidade em regiões contaminadas ou ao aporte de elementos essenciais, como Co, Cu, se e zn.

Existem quatro casos bem registrados de relação causal da saúde humana com a abundância de traços no ambiente circundante (CROUNSE et al., 1983). Populações com solos deficientes em I mostram um alto predomínio de crescimento da tireóide (bócio). A adição de NaI no sal de mesa reduz drasticamente o problema. Em regiões com teores adequados de $\mathbf{F}$ na agua de consumo observou-se $50 \%$ de redução da velocidade de decadência dentária, sendo que o excesso de $\mathbf{F}$ gera a doença bucal fluorose. A adição de pequenas 
quantias de se em meninos chineses de regiões com solos empobrecidos em se evitou a evolução de uma peculiar miocardite. Quase a totalidade de indivíduos que beberam água de poços contaminados com As em Taiwan desenvolveram sinais de toxicidade em As ou câncer.

LÄG $(1983,1991)$ confirmou casos semelhantes para o I e o $F$ em regiões da Escandinávia, entre eles, ocorrência de fluorose relacionada a emanações vulcânicas na Islânđia. Na Finlândia tem sido realizados estudos geoquímicos com materiais diversos, que ajudaram na detecção de problemas como os citados acima ou de outros, relacionados com acidez em solos, contaminação por metais (Co, Cr, Cu, $\mathbf{N i}, \mathbf{V} e \mathbf{z n}$ ) ou qualidade das águas superficiais e subterrâneas (TARVAINEN, 1996).

SHACKLETTE et al. (1970) estudaram a influência da geoquímica na velocidade de mortalidade por doenças cardíacas no estado de Georgia-uSA. Foram coletadas amostras de solos, hortaliças e árvores em condados com alta e baixa velocidade de mortalidade por doenças cardíacas. Concluíram que as diferenças nos índices de mortalidade seriam devidas a deficiências de elementos essenciais e não à existência de elementos tóxicos. As árvores seriam mais sensíveis que as hortaliças para esse tipo de estudo. BOWIE \& THORNTON (1986) mencionam uma correlação negativa entre a dureza da água de consumo $e$ os índices de mortalidade por doenças cardíacas em extensas áreas, porém os resultados são contraditórios na escala local. Um estudo em 253 cidades da Grã Bretanha identificou cinco fatores que explicariam as variações geográficas desse índice: dureza, precipitações, temperatura, porcentagem de trabalhadores manuais e carro próprio.

No texto acima, foram expostos vários casos que demonstram uma relação, pelo menos indireta, entre a geoquímica e a vida. Porém, resulta complicado estabelecer as causas reais devido à falta de informação e à participação de múltiplos fatores, que dificilmente serão explicados pelas variações de um único elemento. No caso do homem, a situação é mais complexa, pois as fontes de alimentação e os reservatórios de agua potável podem estar realmente afastados, principalmente nas grandes cidades. Para avançar nesse sentido, serão necessários estudos 
detalhados, levando em consideração métodos analíticos precisos e multi-coleta de materiais, sendo incluídas amostras de sangue, cabelos, etc., de animais superiores e seres humanos. SCHROEDER (apud CROUNSE et al., 1983) realizou um significativo comentário em relação aos elementos traços e a vida, que pode ser traduzido da seguinte forma: "Os elementos traços são mais importantes para a vida que as vitaminas, pois não podem ser sintetizados como as vitaminas e ocorrem no ambiente em um intervalo de concentrações relativamente estreito... Sua única fonte são a crosta e a água do mar, e sem eles, a vida deixará de existir".

\subsection{Mapeamento geoquímico}

Na Grã Bretanha já foram elaborados atlas geoquímicos a diferentes escalas, considerando amostras de sedimentos de correntes e águas e levando em consideração elementos maiores e traços. Os resultados foram discutidos por PLANT \& RAISWELL (1983) e HOWARTH \& THORNTON (1983) e podem ser resumidos como segue :

As três grandes unidades geológico-fisiográficas da Grã Bretanha apresentam resposta geoquímica característica, porém as feições mais contrastantes são mostradas pela unidade coberta por sedimentos devonianos e terciários, em relação às outras duas unidades, onde predominam rochas cristalinas mais antigas. Dependendo da escala considerada, as referidas unidades possuem um controle em função dos litotipos das rochas basais, que é refletido nas feições do solo, na vegetação e nas águas. As vezes, esse controle falha pelas condições de drenagem, pelos valores de $\mathrm{Eh} / \mathrm{pH}$ ou por outros fatores. Cu, Co, Fe, Mn, Mo e $\mathrm{Zn}$ são elementos essenciais para agricultura, sendo que a existência de teores exagerados de As, Cd, Cr, Cu, Mo, Ni, Pb ou zn poderia prejudicar a produção agrícola. As anomalias de Cd e $\mathbf{P b}$ evidenciaram regiões contaminadas pela indústria ou mineração. Nesses casos, alguns estudos detalhados em populações humanas descartaram a possibilidade de problemas sanitários. Em relação aos levantamentos de baixa densidade em solos, somente seriam adequados para regiões com unidades geológicas, pedológicas ou ambientais relativamente homogêneas e não no caso 
do Reino Unido, onde esses fatores mudam rapidamente em pequena escala.

DARNLEY (1990) fez referência ao Projeto IGCP 259, "Mapa geoquímico internacional", destacando que a geoquímica superficial é um componente essencial de qualquer descrição compreensível do ambiente natural. Porém, esse fato não é amplamente reconhecido pela sociedade nem por entidades governamentais. Nas últimas décadas foram realizados mapas geológicos da Terra à escala $1 / 10$ milhões ou $1 / 20$ milhões e mapas de solos à escala $1 / 500 \mathrm{mil}$. Vários satélites realizaram levantamentos magnéticos e gravimétricos do planeta, porém não existem hoje informações globais de geoquímica. Segundo os dados compilados, menos de $10 \%$ da superfície terrestre teria sido coberta por programas de prospeção geoquímica, sendo que somente quatro elementos seriam comuns a todos os estudos (Co, $\mathbf{N i}, \mathbf{P b} e$ Zn) e outros oito são determinados com freqüência (As, Ba, Cr, Cu, un, sn, sr e v).

XIE XUEJING (1990) discute os problemas do mapeamento geoquímico internacional, relacionados à coleta e à análise das amostras, e ao tratamento de dados. As maiores dificuldades estão relacionadas à parte analítica, devido aos limites de detecção e à integração da informação. Considerando programas de prospeç̧̃̃o geoquímica no Alasca, na Alemanha, no Canada, na Escandinávia, na Grã Bretanha e na sumatra, foram observados limites de detecção superiores à abundância na crosta para vários elementos indicadores de utilidade em prospeção e estudos ambientais. Esse problema poderia ser resolvido utilizando técnicas alternativas para os elementos menos abundantes, como é realizado na China, ou pelo uso de uma técnica mais sofisticada, como por exemplo a integração da espectrometria de plasma induzido por corrente e a espectrografia de massas. o outro problema é conseqüência dos erros gerados pelas análises interlotes e inter-laboratórios. Na China, esse problema foi resolvido pelo uso de padrões de análise primários e secundários, para solos, sedimentos e rochas, que são alternados periodicamente com fins comparativos.

o atlas geoquímico da Finlândia para tilitos foi desenvolvido com densidade de amostragem de uma amostra a cada 
$300 \mathrm{~km}^{2}$, sendo analisados elementos maiores e traços (KOLJONEN, 1992). Foram definidos dois grandes domínios geoquímicos, um relacionado ao Arqueano e o outro ao Proterozóico, separados por uma zona tectônica, que apresentou resposta típica de depósitos hidrotermais, com enriquecimento em Ag, $\mathbf{A s}, \mathbf{B a}, \mathbf{C o}, \mathbf{C u}, \mathbf{S b}$ e $\mathbf{Z n}$. o domínio Arqueano mostrou enriquecimento em Ca, Na e Si, devido à ocorrência de gnaisses a plagioclásio, e anomalias locais de elementos compatíveis relacionados a rochas máficas verdes. 0 domínio proterozóico mostrou enriquecimento nos voláteis As-Sb e em elementos típicos de granitos e pegmatitos (Cs , $\mathbf{K}, \mathbf{L i}, \mathbf{P b}$, Rb, REE, Si, Ta, Th, $\boldsymbol{T}, \mathbf{Y} \in \mathbf{Z r}$ ).

DARNLEY (1993) mencionou a continuação do Mapeamento geoquímico internacional, na fase II (IGCP 360), com o título "Transectos de geoquímica global". O objetivo atual é realizar uma malha geoquímica global com 5.000 locais de amostragem, correspondendo a uma amostra cada $25.600 \mathrm{~km}^{2}$ (celas de $160 \mathrm{~km}$ de lado). Essa malha seria reduzida posteriormente para uma amostra cada $6400 \mathrm{~km}^{2}$ (celas de $80 \mathrm{~km}$ de lado), cada $1600 \mathrm{~km}^{2}$ (celas de $40 \mathrm{~km}$ de lado), cada $400 \mathrm{~km}^{2}$ (celas de $20 \mathrm{~km}$ de lado) etc., em função dos interesses dos programas de prospeção a nível nacional, que também seriam responsáveis pelos materiais coletados.

DAVENPORT (1993) apresentou resultados de prospecções regionais na Alemanha, no Canada, na China, na Escandinávia, na Groenlândia e no Pais de Gales, sendo cobertos territórios da ordem dos $1000 \mathrm{~km}^{2}$ (Pais de Gales), de $180.000-250.000 \mathrm{~km}^{2}$ (Canada, Escandinávia e Groenlândia) ou até dos cinco milhões de $\mathrm{km}^{2}$ (China). Em geral, foram amostrados sedimentos de correntes, sendo em ocasiões comparados com aguas de cursos (Alemanha) ou de lagos (Canada), ou com tilitos (Escandinávia). O número de elementos analisados foi em geral superior a 30 , sendo incluídas outras variáveis no caso de águas (alcalimetria, condutimetria e pH). No Pais de Gales foram coletadas só amostras de cursos hídricos e analisados menos de 20 elementos. A densidade de amostragem variou de uma amostras $/ \mathrm{km}^{2}$, na Alemanha e no Pais de Gales, até uma amostra cada $30 \mathrm{~km}^{2}$ na Groenlândia e na Escandinávia. A maior parte dos estudos indicou a influência de 
aspectos geológicos e ocorrências minerais sobre a resposta geoquímica, porém devem-se destacar três situações especiais:

(1) Associações multielementares relacionadas à litologia, à mineralizações, ao ambiente ( $\mathbf{m}$-Co-Ni-Zn) ou às atividades do homem (condutimetria-pH-zn) foram identificadas na Alemanha.

(2) A ocorrência de doenças graves na China, relacionadas aos teores de Cr e Mo em sedimentos de corrente.

(3) A resposta dos cursos hídricos foi sensível as tormentas, com desvio do comportamento do background durante um curto período no pais de Gales.

EDÉN (1994) realizou um levantamento geoquímico de baixa densidade (uma amostra/23.000 $\mathrm{km}^{2}$ ) considerando sedimentos em terraços, tilitos, húmus e água de rios, como projeto piloto do IGCP 259/360. Para os sedimentos em flat e os tilitos, os resultados foram comparáveis aos de outros estudos que utilizaram maior densidade de amostragem. Nesses casos, a resposta geoquímica foi controlada pelo litotipo das rochas proximais e pela atividade antrópica; o húmus foi afetado pela deposição atmosférica e a agua dos rios pelo conteúdo de sedimentos finos e em forma indireta, pela atividade agrícola. Cada meio amostrado apresentou mudanças em função de diferentes reservatórios (fontes).

DARNLEY (1995) reitera a necessidade do mapeamento geoquímico global como outra forma de analisar os problemas ambientais do planeta. No principal documento publicado até a presente data pelo IGCP 259, DARNLEY et al. (1995) descreveram os objetivos e os conceitos fundamentais do Projeto, sendo estabelecidos os critérios para a segunda fase. Foram discutidas varias formas de amostragem, levando em consideração os diversos climas e paisagens que ocorrem no planeta. Por exemplo, para países de clima temperado foram recomendadas amostragens de aguas superficiais, sedimentos de corrente ou solos. Cabe destacar que foram discriminados três tipos de materiais sedimentares a ser coletados: floodplain sediments, overbank sediments e stream sediments. Os floodplain sediments são sedimentos aluviais acumulados nas margens dos cursos hídricos de alta ordem (grandes rios), representativos de bacias maiores de $1000 \mathrm{~km}^{2}$ e relevantes à escala continental ou global. Os 
overbank sediments são análogos aos anteriores, porém para cursos hídricos de baixa ordem, representando bacias pequenas, de $100 \mathrm{~km}^{2}$, e são adequados para prospeç̧ão regional. Por último, os stream sediments também são úteis à escala regional e diferenciam-se por serem coletados no leito dos cursos de baixa ordem.

DARNLEY et al. (1995) também mencionaram algumas aplicações de geoquímica superficial bem sucedidas, como 0 caso das anomalias de se na China (seção 1.2.) e descreveram os métodos mais adequados de tratamento dos dados, incluindo a avaliação dos exros de precisão. Um exemplo muito interessante, é constituído por dois mapas do conteúdo de $\mathbf{K}$ em regolitos nos USA com densidades de amostragem diferentes. Um dos mapas foi elaborado considerando 1314 amostras que foram analisadas por métodos convencionais e o outro mapa foi realizado considerando transectos de $10 \mathrm{~km}$ de largura, por espectrometria aérea de raios gama. Se bem que o último apresenta um melhor nivel de detalhamento, os grandes domínios são bem caracterizados pelos dois mapas, mostrando a utilidade da amostragem de baixa densidade. Nesse sentido, O IGCP 259 incorporou o conceito da "natureza fractal das paisagens geoquímicas" (BÖLVIKEN et al., 1992), onde "paisagem" possui o significado de "padrão de distribuição". Os "objetos fractais" são estruturas espaciais (figuras geométricas) que parecem basicamente iguais em diferentes escalas de magnitude. Um exemplo clássico é a acidentada costa da Noruega. BÖLVIKEN et al.(1992) aplicaram a teoria fractal a dados geoquímicos de tilitos da Finlândia, através de variogramas e medidas de áreas em mapas de isolinhas. Dos 21 elementos considerados, 50\% apresentaram resultados aceitáveis, sendo os restantes inconsistentes. Os autores concluíram que, se as paisagens geoquímicas fossem verdadeiros fractais, existiria a possibilidade de conseguir caracterizar o comportamento geoquímico de extensos domínios, efetuando amostragens de baixa densidade.

Em particular, LICHT \& TARVAINEN (1997) integraram dados geoquímicos de vários estudos prospectivos no paraná, elaborando mapas multi-propósito cobrindo a metade do estado. A resposta geoquímica não apresentou problemas de integração no total do 
mosaico, em função da semelhança dos materiais levantados e o bom padrão de qualidade interna dos três Laboratórios brasileiros que efetuaram as análises. Em geral a geoquímica mostrou correlação com a geologia e alguns mapas apresentaram feições, possivelmente, relacionadas com saúde pública (As e F) ou com produtividade agrícola (Fe, $\mathbf{M n}, \mathbf{C u}$ e $\mathbf{Z n}$ ).

Alguns ambiciosos projetos de mapeamento geoquímico surgiram nos últimos anos. Na Rússia foram desenvolvidos diferentes tipos de mapas geoquímicos, porém a informação contida neles é irregular e inapropriada para os atuais requerimentos da sociedade. Por esse motivo, está sendo desenvolvido o programa "Mapeamento geoquímico multi-propósito da Rússia" (KOVAL et al., 1995). Esse programa pretende monitorar a distribuição dos elementos químicos em diferentes meios e estudar sua relação com os processos naturais e antrópicos. Na primeira etapa foram preparados mapas de revisão, com antigos dados geológicos, geofísicos, litogeoquímicos e de geoquímica superficial. A segunda etapa consiste na realização de projetos piloto, a serem desenvolvidos em seis regiões selecionadas pelas suas características geográficas contrastantes ("polígonos da Rússia"), abrangendo as diversas paisagens e feições ocupacionais do país. o outro projeto, "Mapeamento geoquímico da Europa Ocidental", também encontra-se em estágio de revisão e vem sendo impulsionado pelos Diretores do Serviços Geológicos da Europa Ocidental (BÖLVIKEN et al., 1996).

\subsection{Integração de dados}

$\mathrm{Na}$ década de 80 os computadores ganharam velocidade de processamento e capacidade de armazenagem, gerando maior desenvolvimento de aplicativos para $\circ$ manuseio de dados espaciais. Assim surgiram os programas de Desenho Assistido por Computador, conhecidos como CADs, pela sua denominação em inglês Computer Aided Drawing, os de Processamento Digital de ImagensPDI, os Sistemas Gerenciadores de Base de Dados-SGBD e os Sistemas de Informação Geográficos (ou Geo-referenciados)-SIGs. Cada um desses aplicativos possui um campo de abrangência 
específico, porém existem relações de dependência entre eles e, às vezes, sobreposição de tarefas.

Os CADs permitem desenhar figuras, mapas, etc., mas possuem pouca capacidade analítica. O PDI envolve um conjunto de operações para facilitar a extração de informação que foi originalmente captada, ou transformada no decorrer do processo, segundo uma malha regular (CRÓSTA, 1993a). Os SGBD permitem armazenar, pesquisar ou extrair informações sobre assuntos especificos. PLUMMER (1992) indicou que os SIGs possuem quatro componentes fundamentais: (1) entrada de dados, (2) base de dados, (3) operações de manipulação e análise, e (4) saída de dados. A entrada de dados é a etapa que consome mais tempo, possivelmente $75 \%$ do total do projeto. Os conceitos fundamentais dos SIGs, os processos envolvidos $e$ as relações com outros sistemas, como os antes mencionados, com um enfoque orientado às Geociências, são detalhados por BONHAM-CARTER (1994).

$\mathrm{Na}$ região de New Scotia (Canadá) ocorrem vários veios quartzo-carbonáticos concordantes, mineralizados com Au e sulfetos. A produção de Au declarada é de treze toneladas. o mecanismo de mineralização não é bem entendido, razão pela qual foram utilizados SIGs para integrar dados de sensoriamento remoto, os mapas geológico-estruturais, a geoquímica multielemento e a localização das ocorrências (BONHAM-CARTER et al., 1988; HARRIS, 1989). Ambos os estudos utilizaram dados e estratégias semelhantes, considerando probabilidades de ocorrência de Au por relações de áreas, efetuando corredores em lineamentos, contatos ou litotipos, e integrando a informação através de mapas de sobreposição, com e sem critérios de ponderação. Em ambos os casos foi mencionado que o uso do SIG oferece vantagens devido à sua versatilidade e capacidade analítica. BARROS SILVA (1990) realizou um enfoque semelhante para dados de uma região mineralizada no estado da Bahia. Entre suas conclusões indica que o coração do SIG é um conjunto de dados muito bem organizado, dividido em arquivos de formatos diferentes (ASCII, binário e raster). 0 método utilizado reduziu, em forma significativa, a área dos alvos de exploração. $\begin{aligned} \text { CRÓSTA } & (1991) \text { discriminou limonitas derivadas de } \\ \text { ultramáficas } & \text { estéreis daquelas indicativas de rochas }\end{aligned}$ 
mineralizadas, através da integração de dados digitais das seis bandas refletidas Landsat-TM e da geoquímica de solos para As, Cr, Cu, Ni e $\mathbf{z n}$, no prospecto de Mombuca (Minas Gerais). O método foi eficiente na deteç̧ão de um depósito conhecido e de dois novos alvos.

KUOSMANEN et al. (1988) realizaram a integração da geofísica aérea, de dados geológico-estruturais, da geoquímica de tilitos e de dados Landsat MSS em uma região no centro da Finlândia, onde ocorrem mineralizações de $\mathbf{C u}-\mathbf{z n}, \mathrm{Ni}-\mathrm{Cu}-\mathrm{Co}$, sulfetos e $\sigma$. As anomalias geofísicas foram destacadas utilizando componentes principasi-CPs, classificação e composições coloridas. Técnicas fatoriais foram aplicadas para determinar associações multi-elementares relacionadas às mineralizações para os dados geoquímicos. A integração foi realizada pelo cálculo de coeficientes de similaridade com mapas gridados a $1 \times 1 \mathrm{~km}^{2}$, em função de modelos teóricos ou considerando a resposta de depósitos conhecidos. A metodologia foi eficiente, pois reduziu a área de maior favorabilidade, que representou $\circ 0,033 \%$ da área de pesquisa. A integração por pixels foi realizada com cuidado, devido à existência de dados de várias fontes e com níveis de resolução diferentes. Por outra parte, o processo de gridagem pode conduzir a erros inesperados, como perda de feições ligadas à estrutura espacial dos dados. Cada fonte de informação apresentou uma resposta própria derivada da soma de uma grande quantidade de componentes relacionados às unidades geológicas, à ocorrência de depósitos ou de feições estratigráficas. A geoquímica de tilitos com uma densidade de amostragem de 1 amostras cada $4 \mathrm{~km}^{2}$ foi mais eficiente para descrever as províncias metalogenéticas, que a ocorrência de depósitos minerais. TIAIMEN \& VIITA (1994) realizaram um enfoque semelhante para uma região mineralizada no SW da Finlândia. 


\subsection{Prospecção geoquímica no Uruguai}

- Uruguai é um país tradicionalmente agropecuário, com muito pouca mineração, em particular de minerais metálicos. Porém, na década de 80 foram desenvolvidos alguns projetos prospectivos para metais (FESEFELDT, 1988), mostrando uma transformação nesse sentido. Na esfera estatal, o projeto mais abrangente foi desenvolvido no período 1981-1987 pela DINAMIGE, assessorada pelo BRGM (França) e considerou Au, $\boldsymbol{U}$ e metais de base, sendo denominado Inventario Minero del Uruguay-IMU (IGUBRGM， 1982).

- IMU foi um programa de prospecção geoquímica regional com coleção de amostras de sedimentos de correntes e solos, e a análise da fração menor que 80 mesh, depois de digestão total para 22 elementos: Fe, Mn, P, Ag, As, B, Ba, Be, Cd, Co, Cr, Cu, Mo, Nb, $\mathbf{N i}, \mathbf{S b}, \mathbf{S n}, \mathbf{P b}, \mathbf{v}, \mathbf{w}, \mathbf{Y}$ e $\mathbf{z n}$. As determinações foram efetuadas por espectrometria de plasma de corrente direta-DCP, em uma primeira etapa no BRGM e posteriormente na DINAMIGE. No total foram cobertos $15 \%$ do território uruguaio, considerando fundamentalmente terrenos cristalinos. As determinações de Au e $\checkmark$ foram realizadas em forma independente e muitas vezes sem sobreposição com os dados multielementares. Paralelamente foram elaborados os esboços geológicos à escala $1 / 50.000$ das folhas prospectadas e desenvolvidos estudos de detalhe em setores com antigas minas $\mathbf{P b - C u - z n}$ (MIDOT, 1984), incluindo transectos pedogeoquímicos, geofísica, estudos geologicos e perfurações.

SPANGENBERG (1986) descreveu os métodos de amostragem, análise e tratamento da informação adotados pelo IMU, enfatizando os aspectos relacionados aos métodos estatísticos e de definição de anomalias, considerando os resultados do tratamento de 13357 amostras correspondentes a $11356 \mathrm{~km}^{2}$ (dezoito folhas). Mencionou que nos países de clima temperado a dispersão geoquímica é fundamentalmente controlada por aspectos mecânicos e que, devido as condições de baixo relevo e vegetação uniforme que predominam na paisagem uruguaia, ocorreria baixo contraste teor de fundo-anomalia. Isso provocou a seleção de falsas anomalias, nos casos de ausência de assinaturas polimetálicas ou por problemas de precisão. 
Os resultados alcançados pelo IMU para prospecção de Au foram inexpressivos. Isso conđuziu à realização de uma prospecção aluvionar para Au na região de Isla Patrulla (Pérez, $1984 a, b)$ e ao desenvolvimento de um método para prospeç̧ão de Au em veios de quartzo com a cooperação do BGR da Alemanha (FESEFELDT, 1988). Esses trabalhos evidenciaram a ocorrência de veios de quartzo auríferos na região de Isla Patrulla e vizinhanças, porém espalhados e de dimensões pequenas, apresentando pouco interesse do ponto de vista econômico.

FESEFELDT (1988) sobrepôs a geologia à escala 1/200.000 de uma parte do cristalino uruguaio, às anomalias setoriais e pontuais determinadas pelo IMU $e$ as ocorrências metálicas conhecidas. Foi observado que:

(1) Pelo menos $44 \%$ das anomalias estariam associadas ao Grupo Lavalieja, sendo que as outras nove unidades repartiriam as adicionais, em porcentagens variando entre $1 \frac{0}{6} 14 \%$.

(2) Aproximadamente metade das ocorrências minerais foram identificadas pelas anomalias geoquímicas.

Considerando uma pequena área na região de Isla Patrulla, FILIPPINI ALBA (1992) integrou os dados de Au e multielementares para os filões de quartzo, com os dados de sedimentos de correntes do IMU. Foi observado enriquecimento em $\mathbf{P b}$ e $\mathbf{Z n}$ nas amostras de sedimentos relacionadas ao Grupo Lavalleja, e houve correspondência quase de $100 \%$ entre os veios auríferos e as anomalias de sedimentos de correntes.

FIIIPPINI ALBA (1991) processou em forma conjunta 3100 amostras de sedimentos de correntes do IMU, cobrindo quatro folhas $1 / 50.000$. A análise fatorial permitiu representar a resposta do fundo geoquímico através de associações típicas, sendo caracterizados litotipos e unidades geológicas a nível regional.

Os trabalhos de FILIPPINI ALBA (1991, 1992) sugerem que a metodologia utilizada pelo IMU foi adequada à escala regional, contrastando com os problemas apresentados em estudos de detalhe, que mostraram resultados pobres. Segundo FESEFELDT (1988), isso seria explicado em função de erros de amostragem, de diferenças de escala entre os dados geofísicos, geológicos e geoquímicos, da ausência de bases topográficas adequadas e de 
carências na interpretação conjunta da informação. A falta de documentação apropriada, por vezes inexistente, foi outro dos problemas que afetaram os trabalhos realizados pelo IMU, tanto à escala regional, como de detalhe.

\subsection{Objetivos}

Nas seções precedentes, mostrou-se a utilidade da prospeção geoquímica regional, não somente considerando aspectos geológico-minerais, mas também do ponto de vista ambiental, de geomedicina e da produção agrícola. Os dados de geoquímica de sedimentos e solos existentes no uruguai seriam adequados para evidenciar alguns desses aspectos a nível regional, ao menos em forma indireta, ao serem sobrepostos com outras fontes de informação. O processamento dos dados digitais das seis bandas refletidas Landsat-TM5 permitiria extrair informações sobre diversas feições da área e proporcionaria uma visão sinóptica da região. A análise e integração dos dados seria realizada através de pacotes estatisticos, SIGs ou sistemas de PDI.

Do ponto de vista geoquímico, é fundamental caracterizar o comportamento de cada litotipo ou domínio geológico, para poder discriminar entre o fundo regional e as anomalias locais. Em tal sentido, a área de pesquisa deveria possuir dimensões médias, com variedade de litotipos e quantidade de amostras suficientes, para gerar sub-populações estatisticamente significativas. Dessa forma seria checado o problema da pobre integração entre as ocorrência minerais $e$ as anomalias geoquímicas do IMU (FESEFELDT, 1988), que seria explicado como conseqüência da definição errática da relação fundo geoquímico-anomalias.

$\mathrm{Em}$ forma seqüencial podem ser enumerados os seguintes objetivos :

(1) Elaboração de uma pequena base de dados para a área de pesquisa, com a geoquímica de sedimentos e informações extraídas das cartas topográficas e dos mapas geológicos. Devido ao custo operacional da etapa de digitalização, deverá ser analisada cuidadosamente a informação a ser considerada, em função da relação custo/benefício. 
(2) Tratamento estatístico dos dados geoquímicos, procurando determinar as fontes de erro, os fatores que controlam a variância geoquímica, caracterizar o comportamento de fundo dos principais domínios, discriminar as anomalias regionais das anomalias locais $e$, na mediada do possível, das falsas anomalias.

(3) Processamento dos dados digitais das seis bandas refletidas Landsat-TM5, na área de pesquisa, para extrair informação relacionada aos lineamentos, à vegetação e ao conteúdo de argilas ou óxidos que ocorrem nas formações superficiais.

(4) A integração da geoquímica, da geologia, das feições geográficas e dos dados orbitais, seja por simples sobreposição, seja utilizando SIG ou métodos multivariados, como componentes principais ou classificação.

o IGCP 259/360 é um Projeto multimídia a escala global, com normas metodológicas especificas e objetivos ambiciosos (DARNLEY et al., 1995), que o afastam das possibilidades do presente trabalho, de características bem mais restritas. Mas este, pode constituir-se num antecedente positivo para mostrar a importância do IGCP $259 / 360$ e abrir as portas para futuros desenvolvimentos em tal sentido.

\subsection{Apresentação da área de pesquisa}

\subsubsection{Características geográficas}

A região considerada (Figura 1) possui forma poligonal e está integrada pelas quatro folhas 1/50.000: Gutiérrez (orientesul), José $P$. Varela (oriente-norte), Pirarajá (ocidente-sul) e zapicán (ocidente-norte). Na Tabela 2 incluem-se algumas das principais feições geográficas da área, extraídas por cálculos aproximativos das Cartas topograficas de cada folha (SERVIÇO GEOGRÁFICO MILITAR, 1982, 1989, 1990a,b) .

As principais zonas urbanas dentro da área são: José $P$. Varela com aproximadamente 2000 habitantes, Pirarajá e Zapicán com menos de 500 habitantes cada uma e María Albina com menos de 200. Em três casos, os nomes das zonas urbanas coincidem com os 


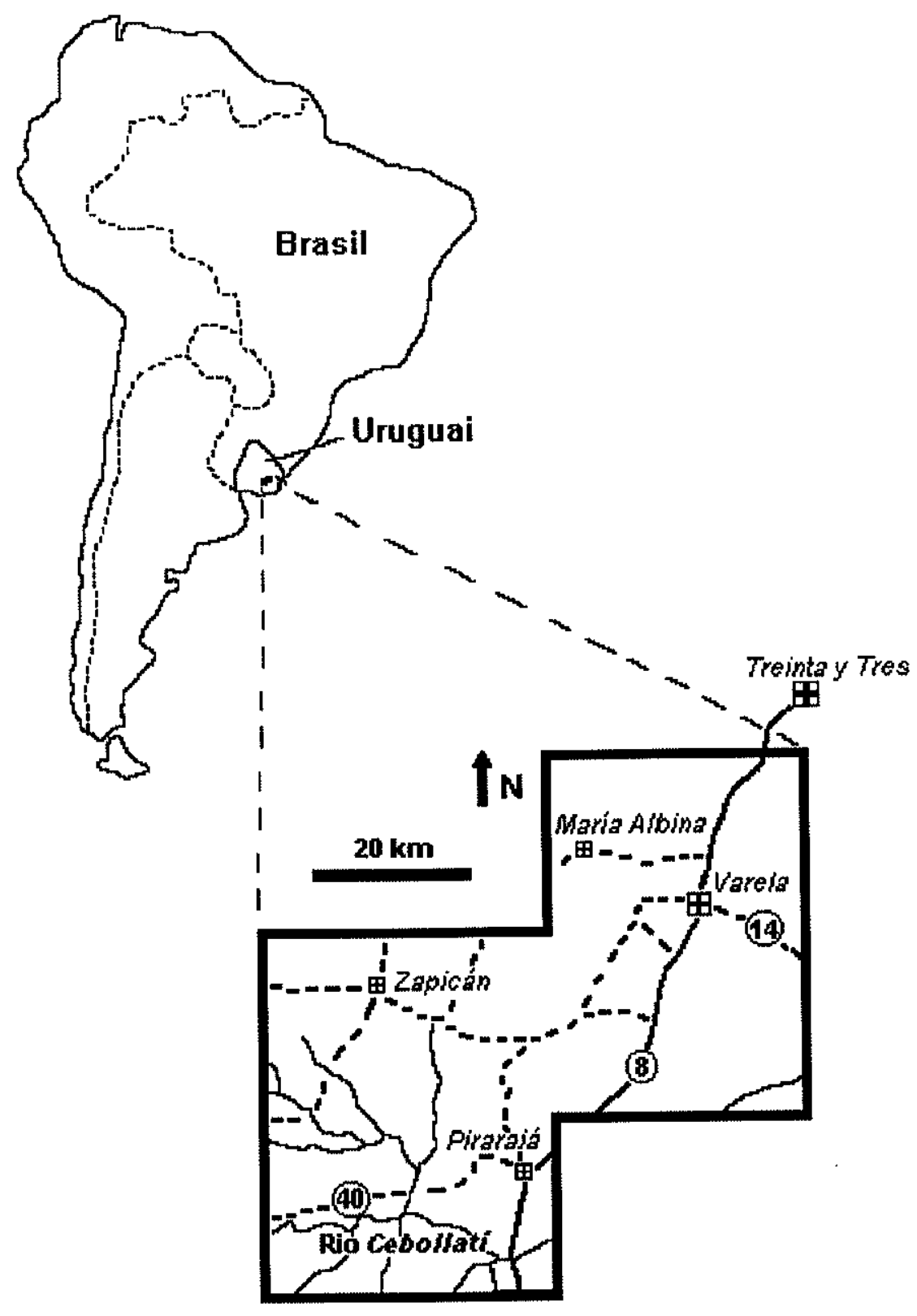

Figura 1. Localização da área de pesquisa. Os quadrados indicam as principais zonas urbanas e os círculos as estradas e seus números. Traço cheio = estrada pavimentada e traço pontilhado $=$ estrada de balastro. 
das folhas $1 / 50.000$ nas quais estão localizadas. Existem também alguns povoados, típicos de regiões rurais, constituídos por 10 a 40 construções mais ou menos espalhađas.

As florestas autóctones concentram-se nas margens dos cursos hídricos mais importantes, em faixas de 100 a 500 metros de largura. As florestas artificiais encontram-se espalhadas e suas dimensões são pequenas, variando entre 1 e 150 hectares, com média de 3 hectares. Não há dados sobre a extensão ocupada por outros cultivos, mas são conhecidos plantios de soja nas vizinhanças da vila José. P. Varela. As zonas de ervas altas e inundações encontram-se geralmente sobrepostas, coincidindo com os setores de relevo baixo (média de 40 metros), como nas proximidades do rio Cebollatí (folha Pirarajá) e no setor oriental das folhas Gutiérrez e José $P$. Varela. As pradarias constituem a paisagem predominante no território uruguaio, sendo sua extensão apenas estimada, considerando os setores com ausência de informação (Tabela 2). O relevo em geral aumenta no sentido $\mathrm{E}-\mathrm{W}$, alcançando 260 metros no setor $\mathrm{NW}$ da folha Zapicán.

o Uruguai é um país de clima temperado com quatro estações mais ou menos bem definidas no decorrer do ano, chuvas moderadas e temperaturas quentes no verão e frias no inverno. Para ter uma idéia concreta dos aspectos meteorológicos, foram considerados dados de temperatura da cidade de Treinta y Tres (Figura 1) e dados de precipitações nas cidades sul-riograndenses Bagé, Porto Alegre, Rio Grande, Santa Maria e Santa Vitória do Palmar, localizadas em um raio de $700 \mathrm{~km}$ em relação ao centro da área de pesquisa. Esses dados foram levantados do Jornal zero Hora (RS), com frequência semanal ou quinzenal, durante o período abril/97janeiro/98, sendo obtidos 32 registros no total. As temperaturas diárias variaram entre $0^{\circ} \mathrm{C}(06 / 07 / 97)$ e $31^{\circ} \mathrm{C}(18 / 01 / 98)$ e as precipitações médias diárias oscilaram entre $0 \mathrm{~mm}$ (vários registros) e $7,6 \mathrm{~mm}(03 / 08 / 97)$. Em função das temperaturas médias extremas, o mês mais frio foi junho/97 com $5-16^{\circ} \mathrm{C}$ e o mês mais quente janeiro/98 com $17-31^{\circ} \mathrm{C}$. Para as precipitações, extrapolando os dados para 30 dias, o mês mais seco foi Julho/97 com $0 \mathrm{~mm}$ e o mês mais chuvoso foi Agosto/97 com $76 \mathrm{~mm}$, sendo a estimava anual de $300 \mathrm{~mm}$. 
Tabela 2. Caracteristicas geograficas da área de pesquisa. Dados aproximados, extraidos das folhas do Plano Cartográfico Nacional (SERVIÇO GEOGRÁFTCO MILITAR, 1982, 1989, $1990 \mathrm{a}, \mathrm{b})$.

\begin{tabular}{|c|c|c|c|c|}
\hline Item & Sub-1tem & Quant 1 dade & Area $\left(\mathrm{km}^{2}\right)$ & Area (z) \\
\hline $\begin{array}{l}\text { Área } \\
\text { Zonas urbanas }\end{array}$ & $\begin{array}{l}\text { Pesquisa } \\
\text { Vilas }\end{array}$ & $\begin{array}{l}1 \\
4\end{array}$ & $\begin{array}{r}2.206 \\
4\end{array}$ & $\begin{array}{l}100 \\
0,2\end{array}$ \\
\hline & Povoados & 4 & & \\
\hline Afloramentos & Rocha & 50 & 42 & 1,6 \\
\hline Águas & $\begin{array}{l}\text { Lagoas } \\
\text { Zonas inundaveis }\end{array}$ & 12 & $\begin{array}{r}5 \\
34\end{array}$ & $\begin{array}{l}1,2 \\
0,2\end{array}$ \\
\hline Vegetação & $\begin{array}{l}\text { Mata autoctone } \\
\text { Mata artificial } \\
\text { Ervas altas } \\
\text { Cultivos } \\
\text { Pradarias }\end{array}$ & $\begin{array}{r}30 \\
70 \\
20 \\
? \\
?\end{array}$ & $\begin{array}{r}89 \\
5 \\
135 \\
? \\
>2112\end{array}$ & $\begin{array}{c}3,4 \\
0,2 \\
5 \\
? \\
>80\end{array}$ \\
\hline
\end{tabular}

\subsubsection{Geologia regional}

A Carta Geológica do Uruguai à escala 1/500.000 (PRECIOzzI et al., 1985, 1988) foi concebida considerando dois ciclos orogênicos: um ciclo mais antigo representado pelo Cráton do Río de la Plata, e o ciclo Brasiliano relacionado ao Cinturão Dom Feliciano (FRAGOSO CESAR et al., 1987). Mas, na zona de transição das rochas desses ciclos, houve incertezas, que geraram controvérsias e novas definições nessa região: Formação Isla patrulla (VAz et al., 1985), Formação de AnfibolitasLeptitas (FESEFELDT, 1988) e Formação Pavas (PRECIOZZI \& FAY, 1988).

BOSSI (1987, 1989) e BOSSI et al. (1993) propuseram a existência de um nưcleo primitivo de mais de 2.000 ma, localizado na região de transição dos ciclos orogênicos conhecidos. GóMEZ-RIFAS (1995) considera essa região como parte do craton do Río de la Plata, com cobertura e deformação brasilianas.

A área de pesquisa localiza-se na referida zona de transição. A geologia exposta no mapa da Figura 2 foi sintetizada da compilação realizada por FESEFELDT et al. (1988), respeitando-se a seqüencia estratigráfica por eles estabelecida, e considerando a informação dos mapas das folhas à escala 1/50.000 (FAY, 1982a,b,c; ILLANES, 1982) e à escala 1/100.000 (PRECIOZZI, 1987a,b; PRECIOZZI \& FAY, 1988). 


\section{Legenda}

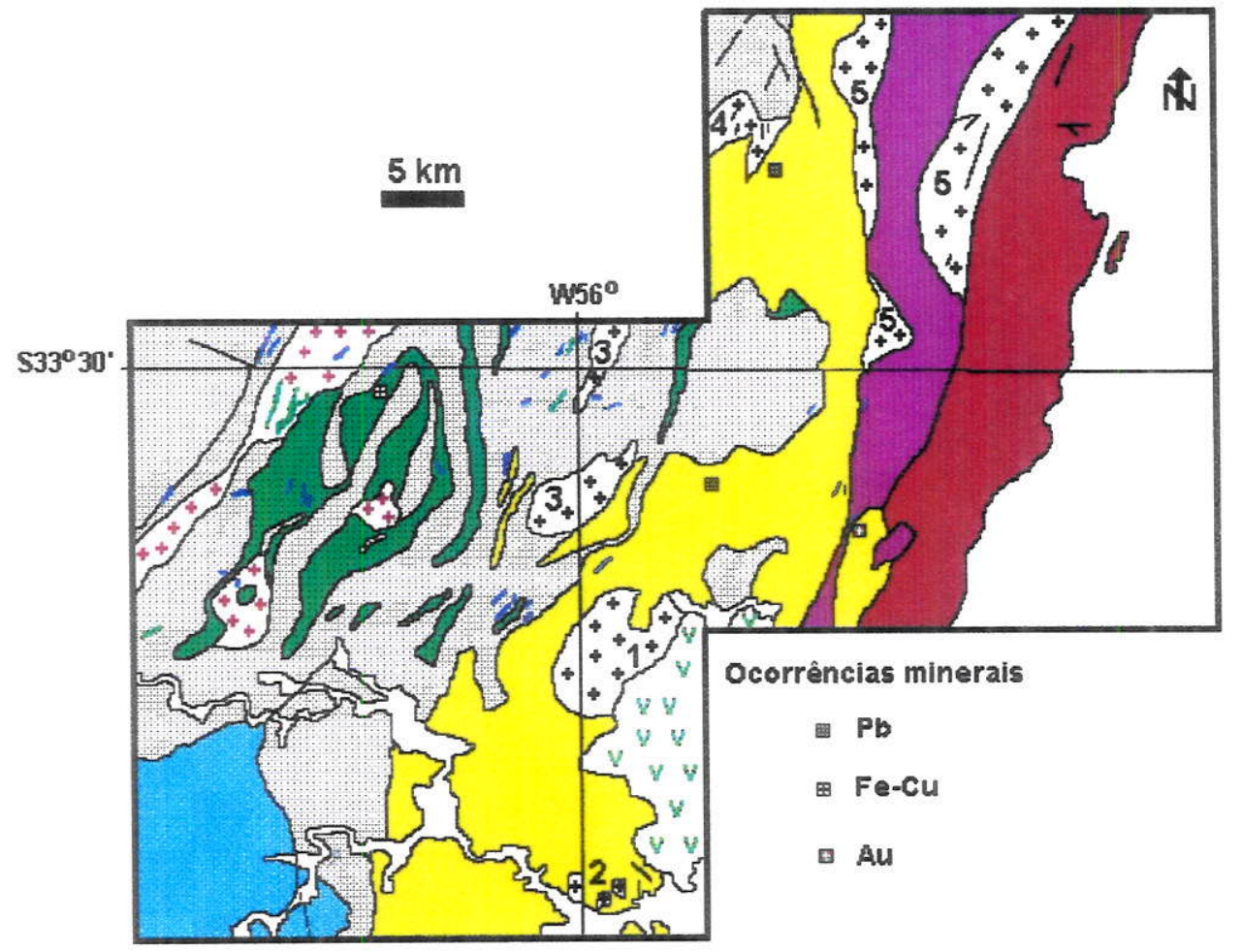

Figura 2. Feições geológicas da área de pesquisa. Compilado de Fay (1982a, b, c), Illanes (1982), Preciozzi (1987 a, b), Fesefeldt (1988) e Preciozzi \& Fay (1988).

\section{Cenozóico}

Cobertura sedimentar indiferenciada Jurássico

Vप Formação Puerto Gómez

Cambriano-Proterozóico Superior

+ 1. Granito Pirarajá. 2. Leuco-granitos 3. Granito-K 4. Granito María Albina 5. Granito Zócalo del Este

Veios máficos

Proterozóico Superior

$\square$ Grupo Barriga Negra

$\square$ Grupo Lavalleja

Proterozóico Médio-Inferior

Formação Sierra Ballena

Formação de Anfibolitas-Leptitas

Rochas máfico-ultramáficas (Formação Pavas)

Granito-gnaisses (Formação Pavas)

+** Granito a anfibólio (Formação Pavas) 
A cobertura sedimentar indiferenciada inclui várias formações do Cenozóico que ocorrem nas proximidades do rio Cebollatí (folha Pirarajá) e no oriente das folhas Gutiérrez e J.P. Varela. Os basaltos jurássicos vacuolares da Formação Puerto Gómez, ocorrem no oriente da folha Pirarajá. Nessa região também existem pequenos corpos e diques de vulcânicas félsicas da Formação Arequita, que não foi mapeada, devido às suas pequenas dimensões.

Os granitóides ocorrem com diferentes composições e formas de colocação (emplacement). O Granito de Pirarajá é um batólito com textura variando de equigranular a porfirítica e composição intermediária granito-granodiorito. A alguns quilômetros ao sul, ocorrem pequenos corpos de leuco-granitos microgranulares, com escassa mica. Ao norte do Granito de Pirarajá afloram dois corpos graníticos de textura granular, com microclinio abundante e escassa biotita, que foram caracterizados como Rapakiwi por FAY (1982b). O Granito de María Albina é um corpo arredondado com xistosidade nas bordas, que contém microclínio pertítico com pequenos cristais de plagioclásio, quartzo com duas texturas diferentes e biotita abundante. Os outros três corpos (Granito zócalo del Este), dois deles de dimensões consideráveis, foram descritos como granitos xistosos por FAY (1982c) e ILLANES (1982). PRECIOZZI (1987a) os considerou como um Complexo Granito-gnáissico, sendo descrito como um granito provavelmente sub-alcalino, granular ou microgranular, que devido à xistosidade intensa transformou-se em granito-gnaisse nas bordas. Onde foram observadas bandas alongadas de biotita alternadas com níveis quartzo-feldspaticos.

Encaixados no Grupo Lavalleja ou nas unidades mais antigas, ocorrem diques de rochas porfiríticas de largura inferior aos $20 \mathrm{~m}$ e direção preferencial N30E, com matriz máica e fenocristais de anfibólio e olivina, que foram mapeados como veios máficos.

- Grupo Barriga Negra é discordante com relação ao Grupo Lavalleja e está integrado por rochas sedimentares com inclinação quase horizontal, incluindo calcário, siltitos, arenitos, conglomerados e brechas. As ultimas são de dois tipos, umas com clastos de quartzitos do Grupo Lavalleja, e as outras 
com clastos de granitos, vulcânicas e metasedimentos. Assim, são caracterizados dois paleo-ambientes de sedimentação, um calmo e - outro agitado.

- Grupo Lavalleja no Uruguai estende-se por uma faixa de 5$20 \mathrm{~km}$ de largura, com direção aproximada $\mathrm{N} 20 \mathrm{E}$, que nasce nas proximidades do Río de la plata e desaparece embaixo da cobertura gondwânica ao Norte, para aflorar novamente no sul do Brasil. Na região estudada predominam calcário e calcofilitos, com intercalações de filitos sericítico-cloritosos, quartzitos e arenitos. Ocorrem ainda rochas vulcânicas máficas.

A Formação Sierra Ballena é uma zona de cisalhamento sinistral de grandeza continental que controla a geologia estrutural do Escudo Uruguaio-Sul-Riograndense e sua cobertura fanerozóica, determinando a distribuição, a natureza e a idade das litologias adjacentes (GOMEZ-RIFAS, 1995). Esse autor acrescenta que a ocorrência de milonitos quentes $\left(550{ }^{\circ} \mathrm{C}\right)$ retomados em níveis crustais rasos indica um amplo espectro de evolução temporal, envolvendo o momento da colisão até períodos tardi a pós-orogênicos. PRECIOzzI (1987a) caracterizou a zona de cisalhamento por blastomilonitos de textura variável, entre oftalmítica e muito fina (ultramilonitos). No primeiro caso, os fenocristais de feldspato- $\mathrm{K}$ foram alongados em função da direção da tensão principal e estão circundados por uma rede microcristalina de quartzo, plagioclásio e biotita. Os dois últimos foram transformados pelos processos metamórficos, gerando sericita, clorita e óxidos de Fe.

A Formação de Anfibolitas-Leptitas foi definida por FESEFELDT (1988), que a interpretou como o piso do Grupo Lavalleja, em função do metamorfismo mais elevado e da relação de proximidade entre ambas. PRECrOzzI (1987a) a incluiu dentro do Grupo Lavalleja, indicando as diferenças no grau do metamorfismo. A unidade está integrada basicamente por anfibolitos e leptinitos, mas também foram descritos gnaisses diversos (PRECIOZZI, 1987a). Os anfibolitos são em geral microgranulares, podendo apresentar xistosidade, e constituídos por hornblenda, plagioclásio, epídoto, actinolita e quartzo. Os leptinitos são de granulação fina e estão compostos por feldspatos e quartzo. 
$\mathrm{Na}$ Formação Pavas ocorrem faixas alternadas de rochas máficas e de rochas félsicas, de largura quilométrica e direção NOE-N3OE, afetadas por metamorfismo de grau médio a alto. Os litotipos escuros são caracterizados por anfibolitos e xistos anfibólicos $e$ os claros, por gnaisses leucocráticos e leptinitos. Com menor expressão, ocorrem basaltos, doleritos, mármores, ortognaisses e piroxenitos. Os anfibolitos, os basaltos, os doleritos, os piroxenitos e os xistos verdes foram mapeados conjuntamente como "Rochas máfico-ultramáficas" (Figura 2). O Granito a anfibólio é um corpo alongado que atravessa quase a totalidade da folha zapicán em direção N20E, sendo constituído por rochas graníticas compostas por plagioclásio, microclina, quartzo, biotita e anfibólio.

\subsubsection{Ocorrências minerais}

Existem quatro ocorrências minerais na região (Figura 2), uma relacionada à Formação pavas e as outras três ao Grupo Lavalieja. Próximo do povoado de zapicán ocorre um veio de quartzo encaixado em gnaisses félsicos da Formação Pavas, mineralizado a pirita e calcopirita. Na década de 80 , uma empresa argentina prospectou duas ocorrências de galena, uma localizada no setor oriental da folha zapicán e a outra na folha J.P.Varela, próxima a Maria Albina. Nos dois casos a rocha encaixante é calcário e a mineralização está associada a níveis silicificados e ferruginosos (PRECIOZZI, 1987a,b).

Na porção sudoeste da folha Gutiérrez encontra-se uma antiga mina de Au, que foi explorada nas décadas de 30-40. Trata-se de um veio quartzoso de cor violacea e largura inferior a um metro, com teor médio de Au de 7 ppm, sendo a pirita e calcopirita minerais acessorios. o veio está localizado no limite entre o Grupo Lavalleja e a Formação de AnfibolitosLeptitos, mas a encaixante é desconhecida. Segundo FESEFELDT (1988) a quantidade de Au já extraída foi da ordem dos $200 \mathrm{~kg}$. Três transectos pedogeoquímicos mostraram uma anomalia positiva de largura métrica no horizonte $C$, relacionada à mineralização (FILIPPINI ALBA, 1990). A relação anomalia/teor médio foi superior a 1,5 para $\mathbf{A u}, \mathbf{B a}, \mathbf{C o}, \mathbf{C u}, \mathbf{M n}, \mathbf{P}, \mathbf{P b}$ e para a 
radiometria gama total. Os outros elementos analisados não apresentaram comportamento característico nas proximidades do veio (Fe, Ag, As, B, Be, Cd, Co, Cr, Mo, Nb, Ni, Sb, V, W, Y e zn) . 


\section{MATERIAIS E MÉTODOS}

\subsection{Amostragem Geoquímica}

A coleta de amostras foi realizada em quatro etapas, considerando uma folha cada vez, segundo a relação da Tabela 3 . Para checar a precisão da informação geoquímica, foram coletadas 29 duplicatas de amostragem, ou seja, duas amostras separadas 100-200 metros uma da outra em um mesmo local. Nas folhas Gutiérrez e José $P$. Varela realizaram-se duas determinações analíticas para cada segunda duplicata de amostragem (duplicatas de análise). Foram considerados 2172 locais de amostragem, sendo coletados 32 sedimentos em leito, 1935 sedimentos em terraços, 176 solos aluviais e 29 solos autóctones. Os sedimentos em leito e os sedimentos em terraços correspondem, respectivamente, aos stream sediments e overbank sediments, segundo a definição de DARNLEY et al. (1995). A amostragem de solos constituiu uma opção alternativa, devido à ausência de cursos hídricos ativos.

Tabela 3. Detalhes sobre a amostragem geoquímica, incluindo o número de locais de coleta, a quantidade de duplicatas de amostragem e o total de amostras.

\begin{tabular}{llccc}
\multicolumn{1}{c}{ Folha } & \multicolumn{1}{c}{ Data } & Locais & Duplicatas & Amostras \\
Piraraja & Agosto/982 & 640 & 8 & 648 \\
Zapican & Fevereiro/985 & 601 & 5 & 606 \\
Gutierrez & Dezembro/985 & 412 & 7 & 419 \\
J.P.Varela & Dezembro/986 & 519 & 9 & 528 \\
Totais & & 2172 & 29 & 2201
\end{tabular}

A área pesquisada foi de $2206 \mathrm{~km}^{2}$ (Tabela 2), o que representa $84 \%$ da área total das quatro folhas. Isso foi consequência de que os setores cobertos pelos sedimentos cenozóicos, nas folhas Gutiérrez, J.P.Varela e Pirarajá, não foram quase amostrados. A densidade média de amostragem foi de uma amostra $/ \mathrm{km}^{2}$. Também foram levantados o $\mathrm{pH}$ dos cursos hídricos ativos com papel indicador, a radiometria gama total (Rad- $\gamma$ ) com detectores de mão e algumas feições representativas das amostras (cor e granulação) ou dos locais de coleta (litotipo e vegetação 
predominantes, possíveis fontes de contaminação, relevo...). Parte da informação de campo não foi aproveitada.

\subsection{Análises químicas}

As amostras foram secas em ambiente aquecido a $40-50^{\circ} \mathrm{C}$, peneiradas a 80 mesh e analisadas no Laboratóxio da DINAMIGE. A digestão das amostras realizou-se em duas etapas: (1) $\mathrm{HClO}_{4}$ a $140^{\circ} \mathrm{C}$. (2) Adição de $\mathrm{HCl-HF}$ a $80^{\circ} \mathrm{C}$. As determinações foram efetuadas por espectrometria de emissão por plasma de arco de corrente contínua, segundo a definição de DUTRA (1984). Essa técnica é também conhecida por direct coupled plasma-atomic emission spectrometry/DCP-AES (JARVIS \& JARVIS, 1992).

Na Tabela 4 apresentam-se os 22 elementos analisados, O limite inferior e o limite superior de deteç̧ão analítica (LIDA e LSDA), a precisão analítica (PREAN) e o grau de correlação entre as analises feitas pela DINAMIGE e pelo BRGM. A PREAN foi calculada considerando o semi-intervalo de confiança 95\% médio das replicatas de três amostras padrões secundários, e expressa como percentagem da média geral.

Constataram-se dois problemas relacionados à RREAN (FILIPPINI ALBA, 1992): (1) Ausência de estimativas para Be, Cd, Co, Mo, $\mathbf{M b}, \mathrm{Sb}, \mathrm{Sn} e \mathrm{~W}$, que mostraram valores constantes, pelo fato dos dados originais serem cortados no LIDA. (2) As estimativas para $\mathbf{F e}, \mathbf{B a}, \mathbf{C r}, \mathbf{C u}, \mathbf{N i}, \mathbf{v}, \mathbf{Y}$ e $\mathbf{Z n}$ mostraram valores superiores aos da precisão de amostragem-PAM. A PAM foi calculada em função da variância residual de um modelo de análise de variância aplicado sobre sete duplicatas de amostragem e considera a dispersão entre cada par de duplicatas. Assim, a PAM inclui à PREAN, pelo que seria de esperar que fosse maior ou igual, contrariamente ao mencionado em (2). Uma explicação possível estaria relacionada a diferente forma como foram calculadas a PREAN e a PAM.

Por esses motivos, foram realizados novos cálculos, adotando um modelo de análise de variância-ANOVA a 2 níveis (GARRETT, 1983) e utilizando as duplicatas de amostragem e de análise do presente trabalho, que foram intercaladas junto com as amostras da folha correspondente. As formulas utilizadas para 
os cálculos serão apresentadas junto com os resultados no próximo capítulo.

Tabela 4. Parametros analíticos das determinaçסes multielementares da DINAMIGE. LIDA/LSDA = Limites inferior/superior de detecçă analíticos. PREAN= precisão analıtica.

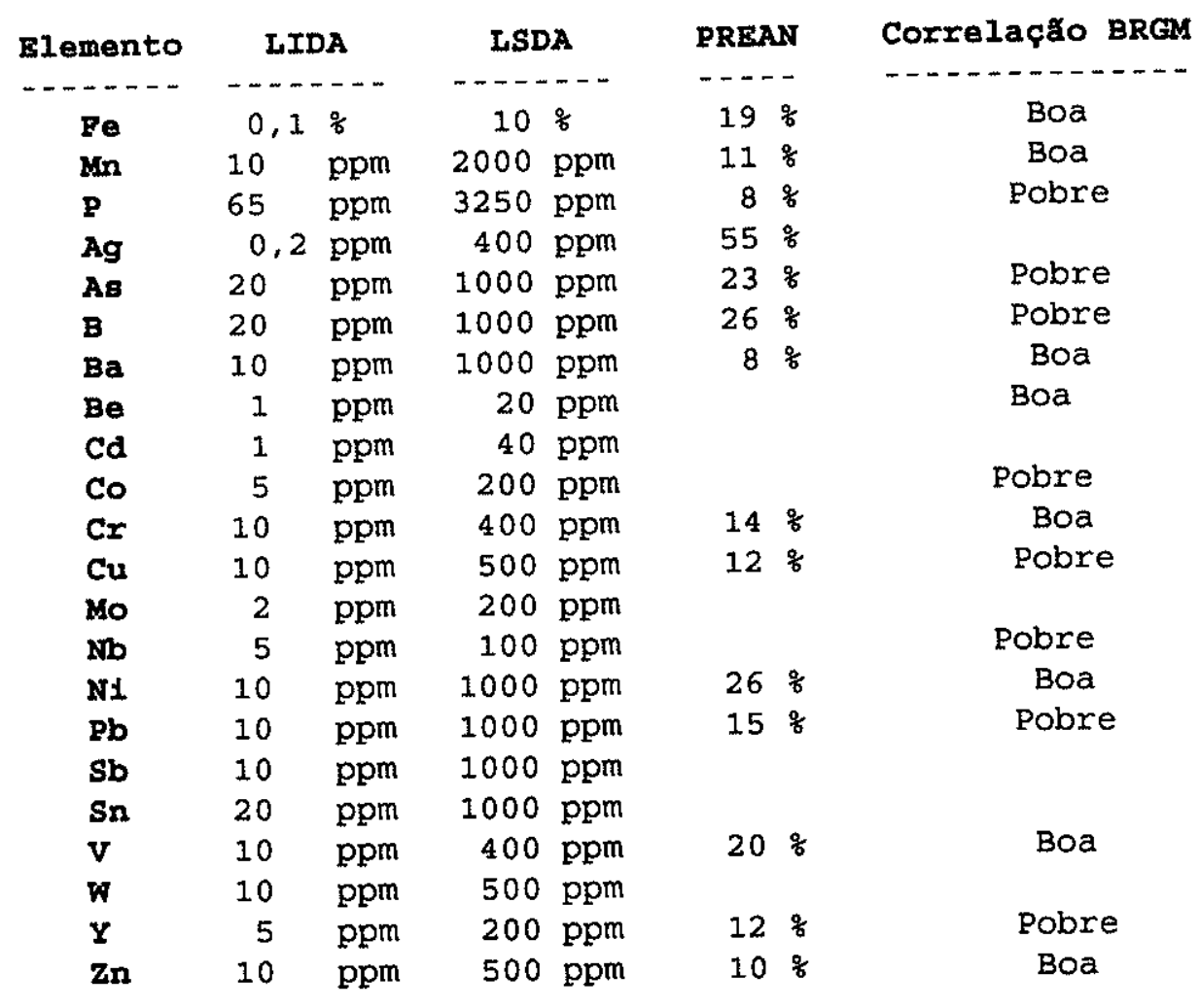

Os dados analíticos das replicatas foram ordenados em um arquivo com 3 variáveis para cada elemento, por exemplo Fe1, Fe2 e Fe3 no caso do Fe. Em Fel guardaram-se os dados de Fe no primeiro local de amostragem, em Fe2 os dados no segundo local e em Fe3 a repetição da analise para o segundo local. Ou seja, para $\circ$ Fe, Fe1-Fe2 representaram as duplicatas de amostragem e Fe2-Fe3 as duplicatas de analise. Esse esquema pode ser generalizado para todas as variáveis. Também utilizaram-se métodos gráficos para visualizar os pađrões de comportamento das duplicatas e a distribuição espacial das diferenças relativas entre as duplicatas de amostragem. 


\subsection{Aquisição dos dados de sensoriamento remoto}

As fitas-cartucho com os dados digitais das seis bandas refletidas Landsat-TM5 da Órbita 223, Ponto 83, Quadrante D foram adquiridas no Instituto Nacional de Pesquisas EspaciasINPE. Entre as cenas do período 01/01/1990-27/10/1994, escolheuse a cena de 16/10/1990, devido às excelentes condições de visibilidade e de qualidade da gravação. A partir da leitura das fitas-cartucho, foi gerado um arquivo para cada uma das seis bandas, sendo importados para ER-MAPPER (1995) na forma de um único arquivo. posteriormente, cortou-se a imagem para restringir os dados à área de pesquisa e procedeu-se à sua retificação. Com esse objetivo, foram escolhidos 44 pontos de controle (Ground control points-GCPs) das folhas cartográficas 1/50.000 (SERVIÇO GEOGRÁFICO MILITAR-URUGUAI, 1982, 1989, 1990a,b) e extraídas suas coordenadas, com apoio de uma mesa digitalizadora e do programa AUTOCAD (AUTODESK, 1990). O método de interpolação foi o do "vizinho próximo" e o erro obtido para cada GCP foi inferior a 3 metros. O ponto de referência foi o Córrego Alegre, com o esferóide International-1924 e a projeção UTM Sul 21 (ER-MAPPER, 1995).

\subsection{Métodos de Processamento}

\subsubsection{Tratamento estatístico}

A expressão "tratamento estatístico" será usada em relação aos métodos estatísticos e graficos aplicados sobre os dados geoquímicos originais, ordenados segundo um padrão irregular. o termo "processamento" será usado em sentido global ou em relação aos procedimentos aplicados sobre dados digitais ou seja, ordenados em uma malha regular. o tratamento estatistico foi realizado com a colaboração da Universidade Acadêmica de Ảbo e o Serviço Geológico da Finlândia. Foram aplicados métodos univariados, multivariados e gráficos, incluindo algumas formas simples de mapeamento. A maioria desses métodos foi descrita por HOWARTH (1983). 
Os métodos univariados foram usados para reconhecer as características das distribuições das variáveis disponíveis: 22 elementos, radiometria gama $(\operatorname{Rad}-\gamma)$ e $\mathbf{p H}$. Assim, foram calculadas as estatísticas basicas, observados os histogramas de freqüências e executado o teste de Kolgomorov-Smirnov. A maioria das variáveis apresentou distribuição assimétrica e deformada, havendo um melhor ajuste ao comportamento log-normal, em comparação ao normal. Por isso, os dados foram log-transformados quando aplicaram-se os métodos paramétricos.

para analisar a influência do material amostrado e do litotipo das rochas de procedência sobre os dados geoquímicos, foi efetuada a ANOVA pelo método de Kruskal-Wallis e realizaramse os gráficos de box, que já foram utilizados por FILIPPINI ALBA (1992) no mesmo sentido. A classificação em função do litotipo das rochas de procedência foi realizada considerando os esboços geológicos à escala 1/50.000 (FAY 1982a,b,c; ILLANES, 1982), com correções segundo os mapas à escala 1/100.000 (PRECIOZZI, 1987a,b; PRECIOZZI \& FAY, 1988), e tomando como base a compilação à escala $1 / 200.000$ de FESEFELDT et al. (1988). 0 critério adotado para a classificação foi $\circ$ de aproximação inferior a 250 metros entre a amostra e o litotipo predominante na maior parte do curso hídrico, no sentido da correnteza.

os métodos multivariados utilizados foram: o cálculo dos coeficientes de correlação e elaboração de diagramas de dispersão, a análise de regressão, a análise em componentes principais-ACP e a análise fatorial-AF e, e o cálculo das Distâncias de Mahalanobis-DMs. Usaram-se diferentes formas de tratamento: (1) Transformação logarítmica. (2) Correção pelas medianas segundo o material amostrado. (3) Eliminação das outliers. (4) $O$ número de fatores na AF. Também aplicaram-se combinações dos métodos, como no caso de AR com ACP ou AF. As DMs foram utilizadas para detectar as outliers, segundo 0 procedimento descrito por AFIFI \& AZEN (1983) ou GARRETT (1989).

As outliers são amostras inconsistentes com o comportamento geral da população, que foram denominadas como amostras "aberrantes", "afastadas" ou "distantes" por ALECRTM \& ROYER (1991). Segundo GNANADESIKAN \& KETTENRING (1972), a detecção das 
outliers multivariadas é bem mais complexa que no caso univariado, indicando três motivos fundamentais:

(1) Uma outlier multivariada pode distorcer, não somente as medidas de escala, mas também as de orientação. Por exemplo, imagine-se que em uma população de amostras de sedimentos de composição mineralógica semelhante, dois elementos A e $\mathbf{L}$ estão correlacionados. Assim o diagrama de dispersão para os teores de A e I mostrará uma nuvem de pontos em forma elíptica, com o eixo maior alongado $e$ o eixo menor estreito. Se na amostra " $y$ " acontece uma alta percentagem de um mineral inerte, como o quartzo, o teor de $\mathbf{A}$ e I em " $y$ " será reduzido em forma mais ou menos proporcional ao aumento do conteúdo do mineral inerte. Assim " $y$ " aparecerá afastada da nuvem de pontos, perto da origem (concentração de A e I nulas) e sobreposta ao eixo de correlação (eixo maior da elipse). Essa é uma distorção de escala, pois a outlier (amostra " $y$ ") não produzira desvio de orientação (correlação). Por outro lado, se ocorresse um aumento no conteúdo de um argilo-mineral na amostra " $z$ ", que adsorbe ao elemento A preferencialmente ao elemento $L$, A aumentará seu teor na amostra "z" em forma não proporcional em relação a I. Assim a amostra " $z$ " será uma outlier de escala e orientação, pois estará afastada da nuvem de pontos e do eixo maior da elipse.

(2) As outliers univariadas podem ser definidas como "as amostras nos extremos da distribuição", o que não é possível no caso multivariado.

(3) Existe uma grande diversidade de outliers multivariadas, pois pode ocorrer um desvio apreciável em uma das variáveis, ou uma sucessão de "erros" moderados em várias delas. Considere-se o exemplo apresentado em (1), mas com um maior número de elementos (variáveis).

os programas utilizados no tratamento estatístico foram StatView em Apple-Macintosh (ABACUS CONCEPTS, 1992) e SPSS for windows (SPSS, 1993). As DM foram calculadas pelo Dr. N. GUSTAVSSON do Serviço Geológico da Finlândia com um programa próprio, elaborado segundo a definição de AFIFI \& AZEN (1972).

Mapas de círculos foram elaborados com um microcomputador Apple na Universidade Acadêmica de Ảbo, com o auxílio de três programas: i. O StatView (ABACUS CONCEPTS, 1992), para os 
cálculos. ii. o systat for Macintosh (SYSTAT, 1992) para elaborar os gráficos. iii. O superpaint (ALDUS, 1993) para edição. Nessa forma foram mapeados alguns elementos, a Radiometria gama $(\operatorname{Rad}-\gamma)$ ) o pH, as CPs, os fatores, as DMs e as residuais da $A R$ em função do conteúdo de $F e$ e de $\mathbf{M n}$, das CPs ou dos fatores (40 mapas).

Mapas incluindo feições geológicas, uma variável geoquímica representada por círculos cujo raio varia proporcionalmente ao teor, e em alguns casos, uma segunda componente variando em função de uma escala de cores foram realizados no serviço Geológico da Finlândia, através do programa ALKEMIA (AHLSVED et al., 1991) com a assistência do Departamento de Geoquímica. Os dados geoquímicos originais foram gridados e suavizados segundo uma malha regular de $100 \mathrm{~m} \times 100 \mathrm{~m}$, pelo método das medianas móveis ponderadas. A interpolação foi efetuada considerando uma janela circular com raio de influência de $6 \mathrm{~km}$ centrada na cela e calculando o peso $w$ de cada amostra pela função de Butterworth (LICHT \& TARVAINEN, 1996).:

$$
w=1 /\left(1+d / d_{0}\right)^{2}
$$

Nessa fórmula "d" representa a distância entre a amostra e - centro da janela circular, e " $\mathbf{d}_{0}$ " é um parâmetro de ajuste, que no caso foi de $1200 \mathrm{~m}$.

\subsubsection{Processamento digital e integração dos dados}

Esta etapa foi desenvolvida junto ao Laboratório de Processamento de Informações Georreferênciadas-LAPIG do IGUNICAMP, nos períodos outubro/94-setembro/95 e junho/96julho/97. No primeiro período foram digitalizados os dados geoquímicos, os mapas geológicos e outras feições da área. No segundo período foram processados e integrados os dados disponíveis.

Os métodos aplicados para o PDI dos dados Landsat-TM foram

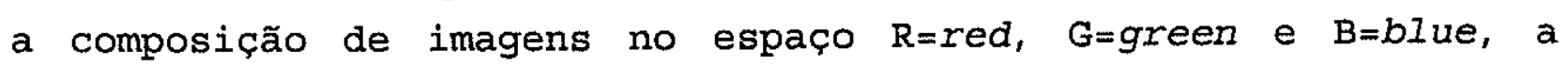
técnica de Abrams (ABRAMS et al., 1977), a ACP e as técnicas de classificação (ER-MAPPER, 1995). Isso envolveu a técnica Feature -oriented Principal Component Selection-FPCS (CRÓSTA \& MC MOORE, 1989; LOUGHLIN, 1991; CRÓSTA \& RABELO, 1993), que permite 
visualizar a distribuição do conteúdo de óxidos e hidróxidos de Fe (Fator-F) e a distribuição dos minerais que contém o grupo-OH (Fator-H), considerando a ACP sobre dois conjuntos independentes de bandas Landsat-TM (TM1-TM3-TM4-TM5 e TM1-TM4-TM5-TM7). Alunita, buddingtonita, caulinita, clorita, dickita, epidoto, montmorillonita, pirofilita e sericita são alguns dos minerais que contém o grupo-OH (CRósTA, 1993b). As técnicas de classificação foram usadas na sua forma supervisionada e não supervisionada. A primeira permite definir grupos teste em forma de polígonos $e$, na segunda, o computador define os grupos em função dos parâmetros iniciais (distância mínima entre centróides, variância máxima, etc.).

Os dados geoquímicos originais foram digitalizados em formato Lotus e transformados para formato ExCel ou ASCII quando necessário. Os setores anômalos definidos pelo tratamento estatístico dos dados $e$ as principais falhas $e$ limites geológicos foram digitalizados em AUTOCAD (AUTODESK, 1990), em arquivos vetoriais, sendo importados para o ER-MAPPER (1995) e para o GRASS (1991), que foi o SIG utilizado.

os dados geoquímicos foram gridados através do programa Surfer, utilizando o método de "Curvatura mínima" prévio à sua importação para o ER-MAPPER (1995). KECKLER (1994) menciona que esse procedimento é rápido e possui nível de qualidade semelhante aos dos métodos de "Krigagem" e do "Inverso do Quadrado da Distância"-IQD, quando são processados mais de 1000 pontos. 0 tamanho da cela foi de 150-200m, dependendo do elemento e foram gerados arquivos ASCII-grid. No GRASS (1991) os dados foram gridados no próprio sistema, pelo método do IQD, sendo interpoladas sete amostras por cela. Os métodos de interpolação foram otimizados por comparação das malhas geradas variando os parâmetros de interpolação para as celas (tamanho ou número de pontos). Para o método da "Curvatura mínima" também foram observados os gráficos da média geral em função do tamanho da cela. Os resultados foram comparados com os mapas de círculos das variáveis geoquímicas originais, procurando-se manter uma distribuição espacial semelhante.

Foram usados três métodos de integração dos dados geoquímicos e de sensoriamento remoto: (1) Superposição das 
anomalias geoquímicas definidas pelo tratamento estatístico e digitalizadas em formato vetorial, sobre composições RGB, considerando três bandas Landsat-TM ou CPs no ER-MAPPER (1995). (2) Classificação não supervisionada incluindo dez elementos (Ba, Co, Cu, Mn, $\mathbf{N i}, \mathbf{P b}, \mathbf{P}, \mathbf{V}, \mathbf{Y}$ e $\mathbf{Z n}$ ), a $\operatorname{Rad}-\gamma$, a banda TM4, 0 Fator-F e o Fator-H. As variáveis foram escolhidas em função do tratamento estatístico dos dados geoquímicos e do préprocessamento, sendo gridadas a $200 \mathrm{~m} \times 200 \mathrm{~m}$, usando o procedimento de interpolação "mapa a mapa", quando necessario. (3) Utilização de SIG, considerando modelos exploratórios teóricos.

Os teores dos elementos foram transformados em logaritmos e expressos como porcentagem da mediana, para cada conjunto de amostras agrupadas segundo o tipo de material amostrado. A Rad- $\gamma$ foi expressa como porcentagem da mediana geral, pois sua resposta não dependeu do material amostrado. Quando foram usados elementos afetados por erros analíticos (Ag, As e $\mathbf{S n} .$. ), foram expressos como porcentagem do LIDA, de maneira que os valores superiores a 100 representassem teores possivelmente anômalos.

os modelos exploratórios teóricos foram elaborados em função dos critérios litoquímicos de GOVETT (1983) e GOVETT \& ATHERDEM (1988). Eles indicam que alguns depósitos minerais ou rochas associadas a minérios, possuem teores característicos para certos elementos. Em função do contexto da área, foram consideradas duas situações preferencialmente: os depósitos de sulfetos maciços e os granitos especializados. Os depósitos vulcano-sedimentares de sulfetos maciços geralmente apresentam anomalias positivas de $\mathbf{F e}$, $\mathbf{M g}$ e $\mathbf{z n}$, às vezes $\mathbf{M n}$, e anomalias negativas de Na e Ca, da ordem dos 100-1000 metros. Anomalias positivas de dimensões menores estão relacionadas aos traços do minério ( $\mathbf{C u}, \mathbf{P b}, \mathbf{z n} . .$.$) e, nessa escala, fatos pouco entendidos$ são o enriquecimento em $\mathrm{Co}, \mathrm{H}_{2} \mathrm{O}$ e $\mathbf{R b}$, e O empobrecimento em $\mathrm{Ni} e$ Sr. Os granitos especializados estão enriquecidos em $\mathrm{Li}$ e Rb, e empobrecidos em $\mathbf{M g}, \mathbf{B a}$ e $\mathbf{S r}$, sendo a relação $\mathbf{R b} / \mathbf{K}$ elevada. Os elementos associados à mineralização são $\mathbf{S n}, \boldsymbol{U}$, Th $e \mathbf{W}$, e as vezes, $\mathbf{C u}, \mathbf{M o}, \mathbf{P b}$ ou $\mathbf{Z n}$, sendo que $\mathrm{Sn}$ e $\mathbf{0}$ estão relacionados ao grau de especialização do granito. Os depósitos de veios e substituição mostram anomalias regionais positivas de $\mathbf{A s}, \mathbf{S b}, \mathbf{T e}$ ou Bi, e anomalias locais positivas de $\mathbf{A g}, \mathbf{A u}, \mathbf{C u}, \mathbf{P b}$ e $\mathbf{z n}$. 
Deve-se levar em conta que essas condições foram adaptadas para geoquímica de sedimentos de corrente e que não foi possível contar com a totalidade dos elementos. Assim, foram elaboradas seqüências de análise lógica executadas no programa GRASS (1991), através do uso de operadores booleanos (AND-OR), tentando contemplar as feições acima mencionadas. O operador AND selecionou os pixels que conferiram ambas condições, e o operador OR, os pixels que verificaram só uma delas. As principais seqüencia lógicas consideradas foram:

\section{(1) Depósitos de sulfetos maciços}

i. $\mathrm{Fe}>105$ AND $\mathbf{z n}>105$

ii. Resultado de $i$ AND $\mathrm{Ni}<85$

iii. As > 80 OR Cu > 120 OR $\mathrm{Mn}>105$ OR Pb > 120

iv. Fusão de ii. e iii. com AND

v. Cu > 120 AND $\mathrm{Zn}>105$

vi. $\mathbf{P b}>120$ AND $\mathbf{z n}>105$

vii. Fusão de v. e vi com OR

viii. Resultado de vii. AND Ni $<85$

ix. Resultado de viii. AND Fe $>105$

x. Fusão de iv. e ix. com or

\section{(2) Granitos especializados}

i. Rad- $\gamma>105$ AND Ba<96.

ii. Ba<96 AND $\mathbf{S n}>80$.

iii. Fusão de $i$ e ii com OR.

iv. $\mathrm{Cu}>120$ OR $\mathrm{Pb}>120$ OR $\mathbf{z n}>105$.

v. Fusão de iii e iv com AND.

Os valores acima foram escolhidos em função dos histogramas dos dados gridados. Para As e Sn foi selecionado o valor 80\% em relação ao LIDA, considerando que para valores superiores, pelo menos um dos sete pontos gridados teria teor acima do LIDA. Observe-se que para os sulfetos maciços foram integradas duas seqüências lógicas, uma incluindo As e kn, e a outra não. Para os granitos especializados, a proximidade de intrusões foi avaliada pela sobreposição das feições geológicas em arquivo vetorial. A radiometria gama representou os teores de $\mathrm{U}$ e Th. 
Finalmente foi aplicada uma seqüência lógica incluindo fatores de ponderação, de maneira a classificar os pixels da área de pesquisa segundo uma escala de prioridades. A base foi o modelo de sulfetos maciços, que foi o mais eficiente entre os testados, tendo sido introduzidas algumas modificações em função da experiência prévia. Por exemplo, a inclusão de $c o$ e mn nas sequências lógicas foi inexpressiva em relação ao resultado final, não tendo sido, portanto, considerada no modelo ponderado. O Fator-F e o Fator-H foram importados do ER-MAPPER (1995) e incluídos no processamento.

\subsubsection{Método das sub-bacias}

BONHAM-CARTER (1994) definiu o método dos polígonos como uma forma de transformar informação pontual em formato de área. Uma aplicação desse método para dados geoquímicos de sedimentos ou águas é o método das sub-bacias, no qual é estabelecida uma relação recíproca entre sub-bacias e amostras geoquímicas. As sub-bacias foram definidas em função da hidrografia, do mapa de localização e da topografia, de maneira de que foram incluídas 3-10 amostras na área delimitada. A cada polígono foi atribuído - valor da média das amostras interiores, representado o teor de uma variável.

Este método permitiria uma melhora na interpretação da informação, pois as sub-bacias representariam amostras compostas, cobrindo áreas de $3-10 \mathrm{~km}^{2}$, e possíveis erros gerados na gridagem dos dados poderiam ser verificados por comparação.

Sobre os dados das médias das sub-bacias foram aplicados procedimentos estatísticos univariados, para calcular as estatísticas básicas e analisar a variância geoquímica em relação à variância interna de cada polígono através da ANOVA. Sub-populações características das sub-bacias foram identificadas classificando os teores dos elementos em função dos limiares, definidos pela média e o desvio padrão, e estabelecendo relações por comparação. 


\section{RESULTADOS}

\subsection{Avaliação dos erros geoquímicos}

Na Tabela 5 são apresentadas as fórmulas utilizadas para o cálculo dos parâmetros da ANOVA segundo um modelo não balanceado de dois níveis. Como ja foi mencionado, em 29 locais de amostragem foram coletadas duas amostras separadas por 100-200 metros (duplicatas de amostragem). Em 16 locais, uma dessas amostras foi dividida em duas porções, dando lugar a duas análises (duplicatas de análise). Observe-se que $\sigma_{i}{ }^{2}, \sigma_{\mathrm{m}}{ }^{2}$ e $\sigma_{\mathrm{a}}{ }^{2}$ são estimativas independentes, respectivamente, da variância inter-locais (ou geoquímica), da variância de amostragem e da variância analítica. Esses valores são obtidos igualando a SQDM com sua estimativa, para a primeira, segunda e terceira linhas da tabela.

Tabela 5. Formulas usadas para o cálculo da ANOVA segundo um modelo não balanceado de dois níveis (GARRETT, 1983).

\begin{tabular}{|c|c|c|c|c|}
\hline N.V. & GI & Termos da SQD & SQDM & Estimativas \\
\hline$\cdots$ & -- & 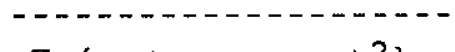 & & \\
\hline I & 28 & $\Sigma_{i}\left\{N_{i}\left(\mu_{\star \star \star}-\mu_{i \star \star}\right)^{2}\right\}$ & $(S Q D)_{I} / 28$ & $\sigma_{a}{ }^{2}+c$ \\
\hline $\mathrm{M}$ & 29 & $\Sigma_{i j}\left\{N_{i j}\left(\mu_{i * *}-\mu_{i j *}\right)^{2}\right\}$ & $(\mathrm{SQD})_{\mathrm{M}} / 29$ & $\sigma_{a}^{2}+a \cdot \sigma_{m}^{2}$ \\
\hline A & 16 & $\Sigma_{i j k}\left(\mu_{i j *-}-\mu_{i j k}\right)^{2}$ & $(S Q D)_{A} / 16$ & $\sigma_{a}{ }^{2}$ \\
\hline
\end{tabular}

N.V. = Nivel de variação ( $I=$ inter-locais; $M=$ inter-amostra; $A=$ interanalises).

GL = Graus de liberdade

$\mathrm{N}_{i}=$ Número de amostras no local $i$

$N_{i j}=$ Número de análises para a amostra $j$ do local $i$

SQD = Somatoria dos quadrados das diferenças

SQDM = SQD media (SQD dividida pelos GL)

$\sigma_{a}^{2}=$ Estimativa da variância analitica

$\sigma_{i}^{2}=$ Estimativa da variancia inter-locais (ou geoquímica)

$\sigma_{\mathrm{m}}^{2}=$ Estimativa da variancia inter-amostras

$\mu_{* \star *}=$ Media geral

$\mu_{i \star *}=$ Media do local $i$

$\mu_{i j *}=$ Media da amostra $j$ no local $i$

$\mu_{i j k}=$ Teor da variável $x$ para $\circ$ local $i$, a amostra $j$ e a analise $k$ 
$a=(G L)_{I}^{-1} \Sigma_{i j k}\left[n_{i j *^{2}}\left(1 / n_{i j k}-1 / n_{i j *}\right)\right]=1,1$

$b=(G L)_{M}^{-1}, \Sigma_{i j k}\left[n_{i * *}{ }^{2}\left(1 / n_{i j *}-1 / n_{i * *}\right)\right]=1,8$

$\mathrm{n}_{i * *}=$ número de amostras por local

$\mathrm{n}_{i j *}=$ número de análises por amostra

$\mathrm{n}_{i j k}=$ número de repetições por análise

Posteriormente foram calculados os coeficientes $F$ as variâncias relativas interlocais (VIL), de amostragem (VAM) e de análise (VAN) em função das seguintes equações:

$$
\begin{aligned}
& \mathrm{F}_{1}=\mathrm{SQDM}_{\mathrm{i}} / \mathrm{SQDM}_{\mathrm{m}} \\
& \mathrm{F}_{2}=\mathrm{SQDM}_{\mathrm{m}} / \mathrm{SQDM}_{\mathrm{a}} \\
& \mathrm{VIL}=100 \cdot \sigma_{i}{ }^{2} /\left(\sigma_{\mathrm{a}}{ }^{2}+\mathrm{a} \cdot \sigma_{\mathrm{m}}{ }^{2}+\mathrm{b} \cdot \sigma_{\mathrm{i}}{ }^{2}\right) \\
& \mathrm{VAM}=100 \cdot \sigma_{\mathrm{m}}{ }^{2} /\left(\sigma_{\mathrm{a}}{ }^{2}+\mathrm{a} \cdot \sigma_{\mathrm{m}}{ }^{2}+\mathrm{b} \cdot \sigma_{\mathrm{i}}{ }^{2}\right) \\
& \mathrm{VAN}=100 \cdot \sigma_{\mathrm{a}}{ }^{2} /\left(\sigma_{\mathrm{a}}{ }^{2}+\mathrm{a} \cdot \sigma_{\mathrm{m}}{ }^{2}+\mathrm{b} \cdot \sigma_{\mathrm{i}}{ }^{2}\right)
\end{aligned}
$$

Os coeficientes $F\left(F_{1}\right.$ e $\left.F_{2}\right)$ foram comparados com os valores críticos extraídos de tabelas da distribuição $F$ (DAVIS, 1986), em função dos GL e com nível de significância de 5\%. Valores inferiores ou iguais aos do $F$ critico significam que as estimativas de variância no numerador e no denominador são estatisticamente equivalentes (hipótese nula). De outra forma, a estimativa no numerador é estatisticamente maior que a no denominador.

Na Tabela 6 são apresentados os coeficientes $F_{1}$ e $F_{2}$, e os percentuais das variâncias relativas do presente trabalho: VIL, VAM e VAN. Na Figura 3 foram apresentados alguns diagramas de dispersão para as replicatas analíticas, e nas Figuras 4 e 5 foram incluídos os das replicatas de amostragem.

$\mathbf{A g}, \mathbf{A s}, \mathbf{B}, \mathbf{B e}, \mathbf{C d}, \mathbf{M o}, \mathbf{M b}, \mathbf{S b}, \mathbf{S n} \mathrm{e} \mathbf{W}$ apresentam erros analíticos elevados, superiores a $15 \% \mathrm{em}$ todos os casos. Os valores negativos para Ag, Cd e Mo seriam um caso extremo de desajuste ao modelo. Como exemplo dos gráicos de dispersão típicos, são apresentados os de $\mathbf{A s}, \mathbf{S b}$ e $\mathbf{S n}$. Observe-se que, para os três elementos, existe um padrão análogo no gráfico das replicatas de análise (Figura 3 ) e no gráfico das replicatas de amostragem (Figuras 4 e 5 ). Isso sugere problemas, em particular de ordem analítica, que seriam explicados pela existência de 

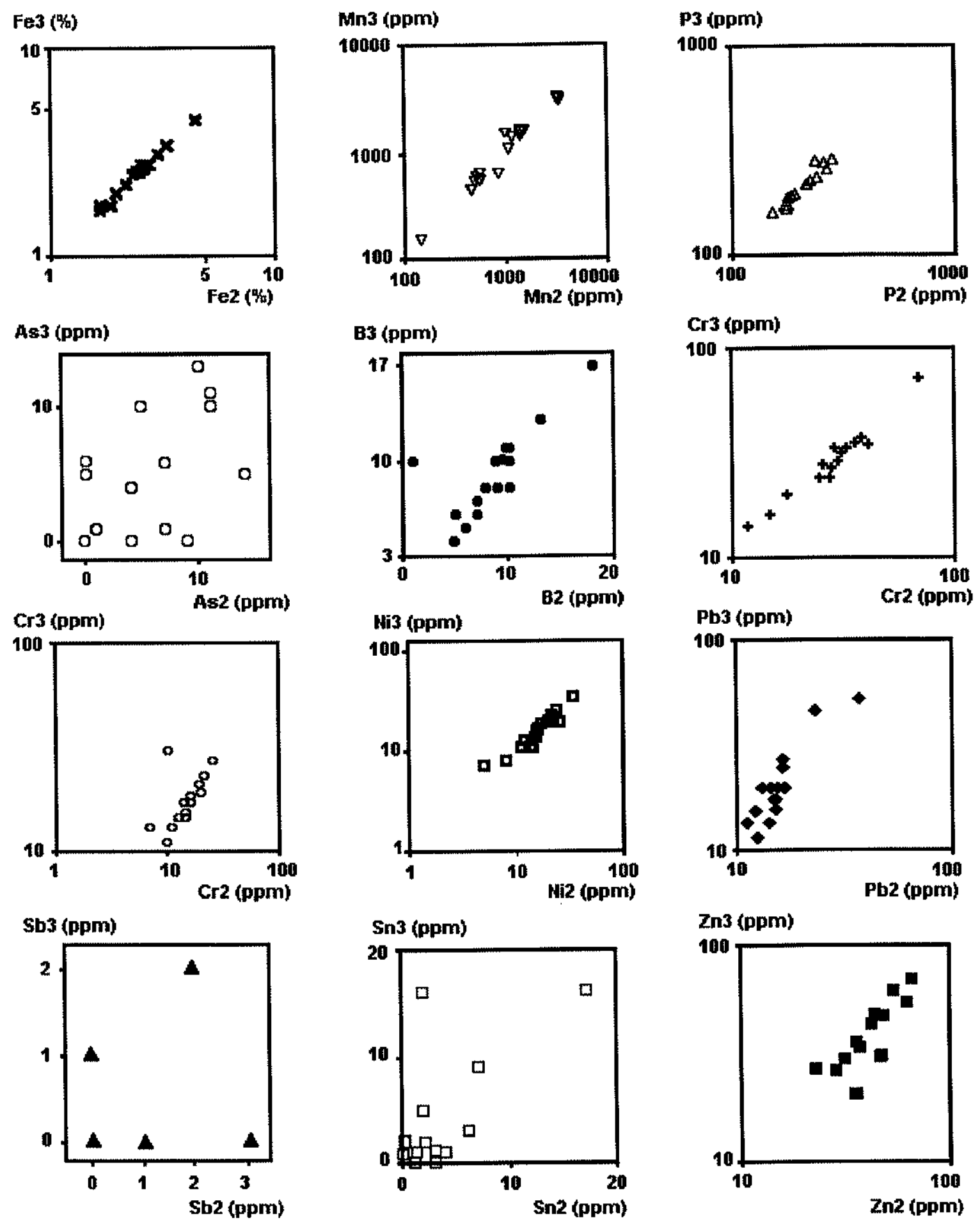

Figura 3. Diagramas de dispersão das duplicatas de análise para $\mathbf{F e}, \mathbf{M n}, \mathbf{P}, \mathbf{A s}, \mathbf{B}, \mathbf{C r}, \mathbf{C u}, \mathbf{N i}$, $\mathbf{P b}, \mathbf{S b}, \mathbf{S n}$ e $\mathbf{Z n}$. Os gráficos de As, B, Sb e Sn em escala linear, os outros em escala logarítmica. 


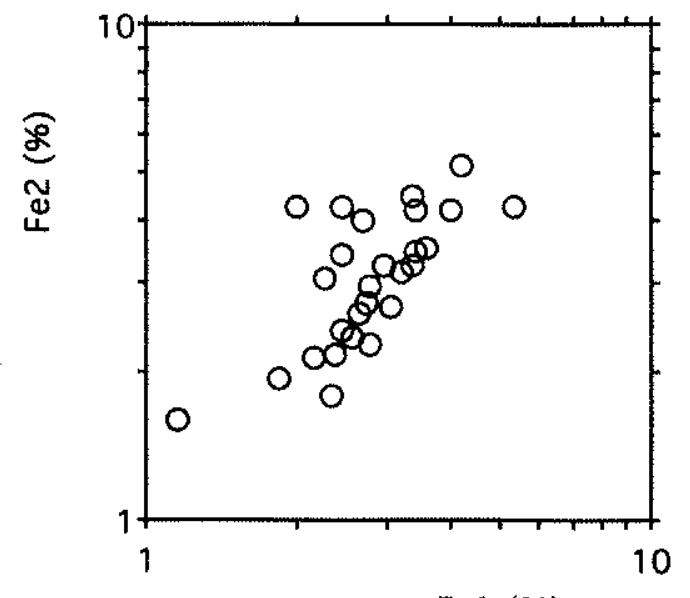

Fel (\%)
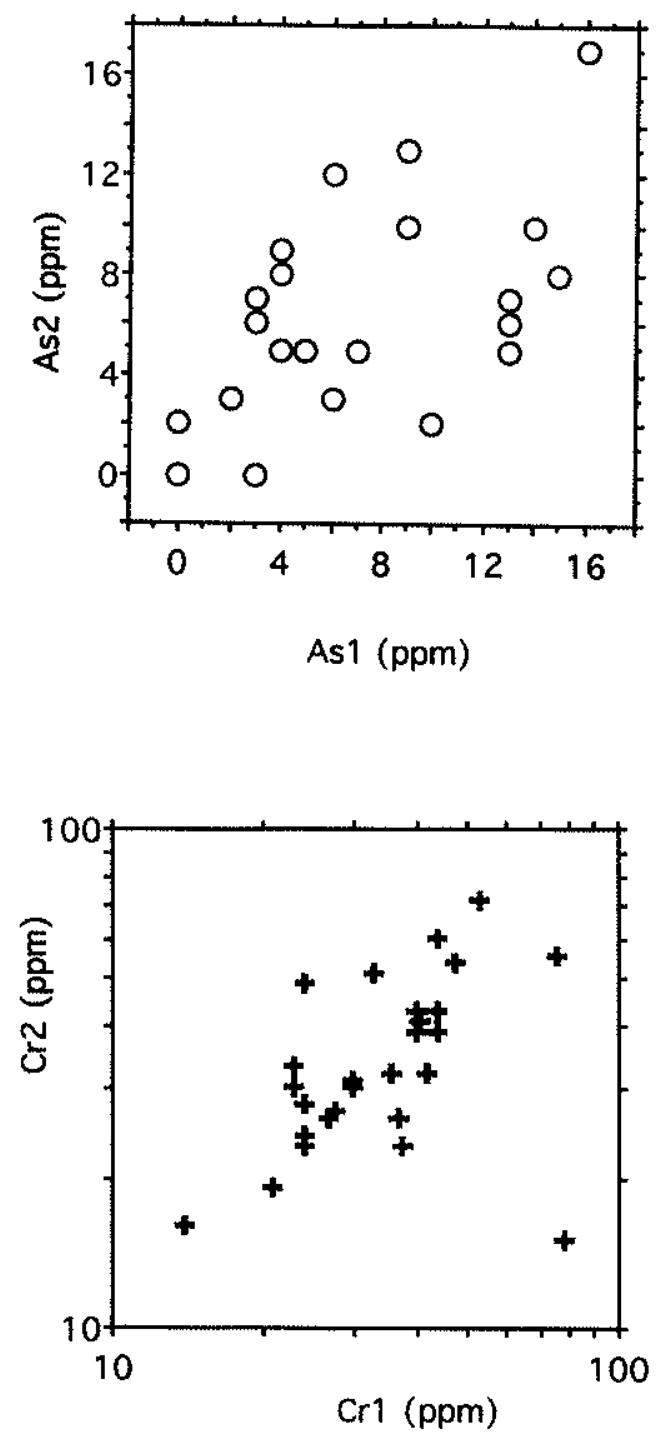
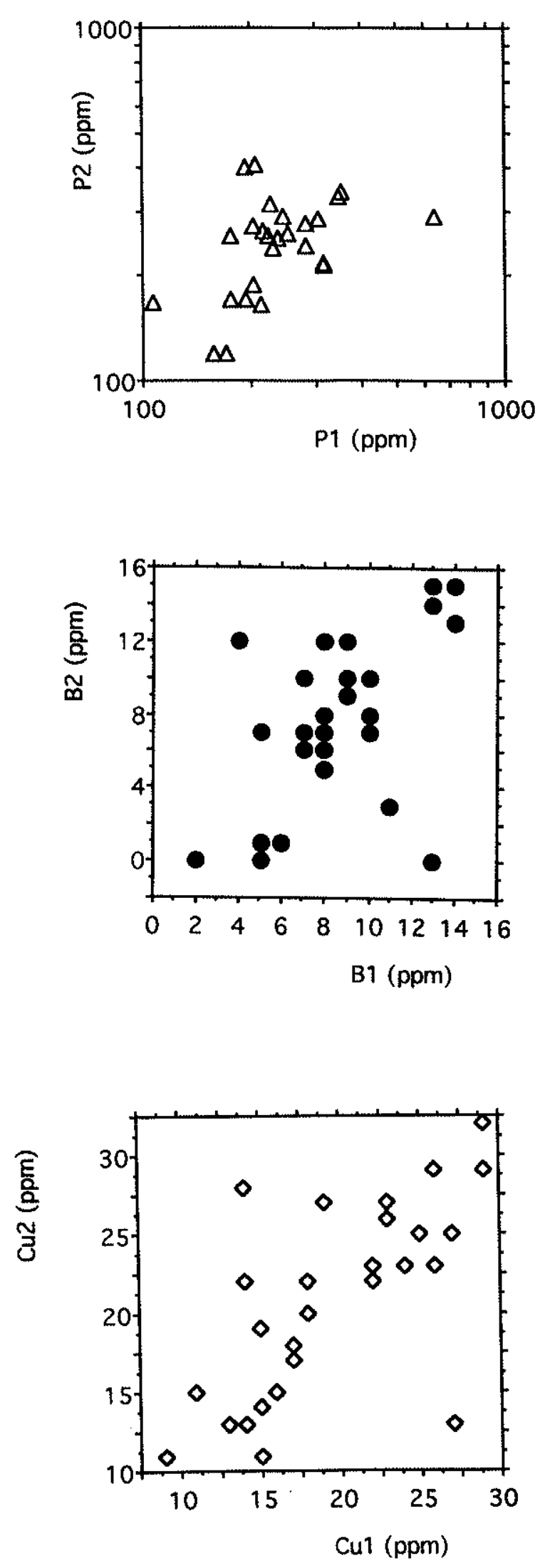

Figura 4. Diagramas de dispersão das duplicatas de amostragem para Fe, $\mathbf{P}, \mathbf{A s}, \mathbf{B}, \mathbf{C r}$ e Cu. Os gráficos de As, B e $\mathbf{C u}$ em escala linear, os outros em escala logarítmica. 

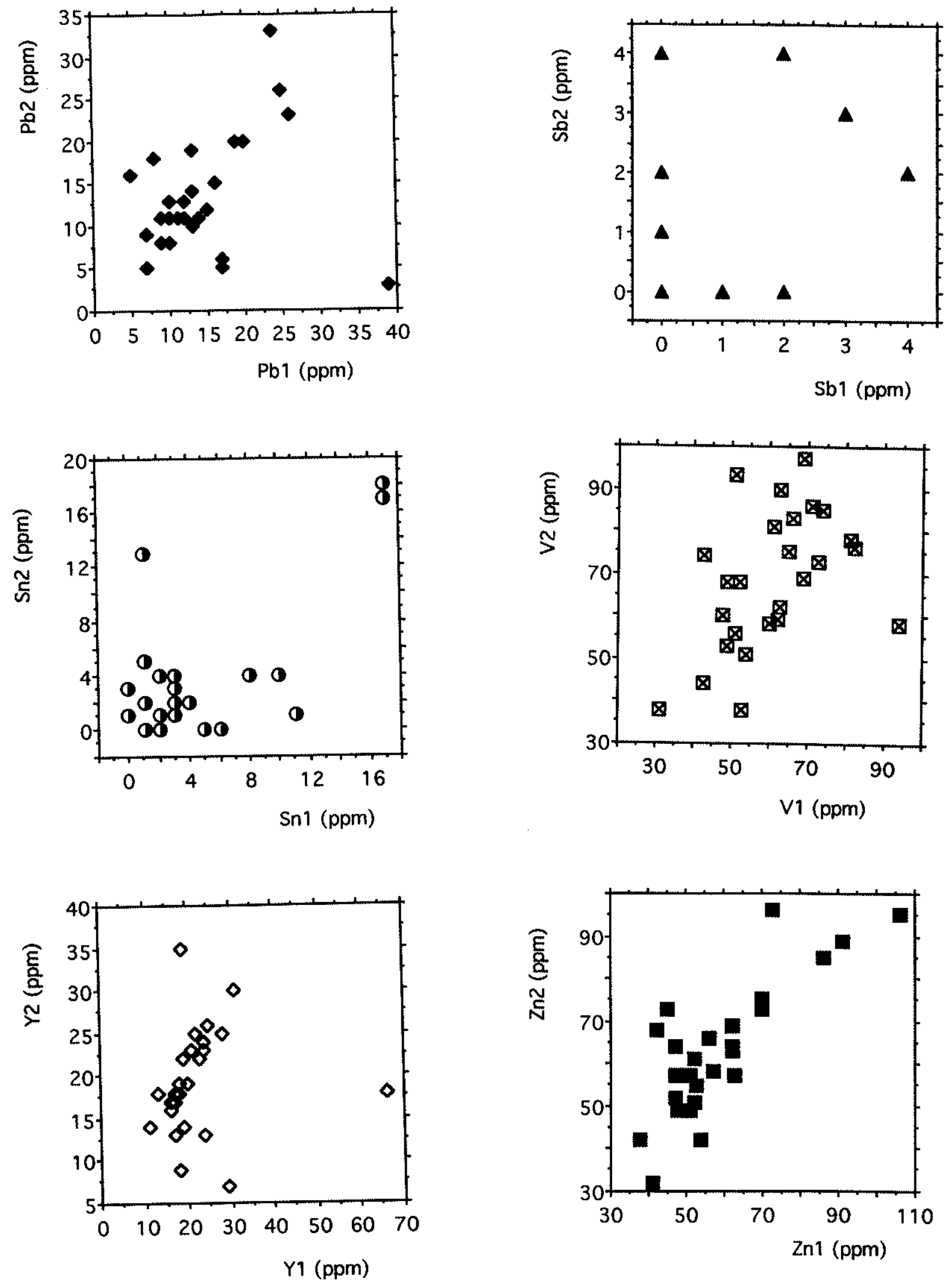

Figura 5. Diagramas de dispersão das duplicatas de amostragem para $\mathbf{P b}, \mathbf{S b}, \mathbf{S n}, \mathbf{V}, \mathbf{Y}$ e Zn em escala logarítmica. 
muitos teores abaixo ou próximos aos LIDAs. O B apresentou certa linearidade no gráfico de dispersão das replicatas de análise (Figura 3), porém foi incluído nesse grupo pelos valores da Tabela 6 e seus antecedentes (Tabela 4).

$\mathbf{F e} \mathbf{m}, \mathbf{P}, \mathbf{B a}, \mathbf{C o}, \mathbf{C r}, \mathbf{C u}, \mathbf{N i}, \mathbf{P b}, \mathbf{V}, \mathbf{Y}$ e $\mathbf{Z n}$ apresentaram erros analíticos baixos, a VAN máxima foi para o $\mathrm{Pb}$, próximo aos $10 \%$. Os diagramas de dispersão típicos para as duplicatas de análise são exemplificados pelos do Fe, $\mathbf{M n}, \mathbf{P}, \mathbf{C r}, \mathbf{C u}, \mathbf{N i}, \mathbf{P b}$ e zn, mostrando uma boa aproximação com o comportamento linear (Figura 3). Porém, o erro de amostragem (VAM) foi elevado para vários elementos $(\mathbf{P}, \mathbf{B a}, \mathbf{C o}, \mathbf{V}, \mathbf{Y} . .$.$) . Isso também reflete-se na$ falta de linearidade dos diagramas de dispersão para as replicatas de amostragem do $\mathbf{P}, \mathbf{C r}$ e $\mathbf{C u}$ (Figura 4 ) e do $\mathbf{P b}, \mathbf{V}$ e $\mathbf{Y}$ (Figura 5).

Tabela 6. Resultados da ANOVA segundo um modelo não balanceado de dois nIveis (GARRETT, 1983).

\begin{tabular}{cccccrr} 
Variável & Amplitude & $\mathbf{F}_{1}$ & $\mathbf{F}_{2}$ & VII, & VAM, & VAN, \\
\hline Fe & $1-5$ & 5,2 & 193 & 65,9 & 33,9 & 0,2 \\
Mn & $149-3265$ & 3,9 & 24 & 57,0 & 40,9 & 2,1 \\
P & $106-636$ & 2,0 & 52 & 31,6 & 66,8 & 1,5 \\
Ag & $0-0,2$ & 0,7 & 5,7 & $-15,9$ & 92,6 & 23,3 \\
AB & $0-17$ & 2,6 & 1,5 & 40,0 & 16,8 & 43,2 \\
B & $0-18$ & 3,8 & 2,7 & 55,3 & 26,4 & 18,3 \\
Ba & $362-1075$ & 3,3 & 150 & 51,3 & 48,3 & 0,4 \\
Be & $0-3$ & 3,3 & 3,0 & 50,1 & 31,5 & 18,3 \\
Cd & $0-1$ & 5,4 & 0,7 & 62,2 & $-10,9$ & 48,7 \\
Co & $3-25$ & 2,2 & 23 & 36,2 & 60,6 & 3,3 \\
Cr & $12-79$ & 3,5 & 31 & 53,3 & 45,0 & 1,8 \\
Cu & $9-32$ & 15,0 & 2,2 & 73,0 & 21,0 & 5,4 \\
Mo & $0-2$ & 1,7 & 0,6 & 19,4 & $-41,5$ & 122,1 \\
Mb & $0-5$ & 1,4 & 5,9 & 13,8 & 69,5 & 16,7 \\
Ni & $4-46$ & 3,6 & 15 & 54,0 & 42,5 & 3,6 \\
Pb & $0-33$ & 3,1 & 6,1 & 48,7 & 41,6 & 9,6 \\
Sb & $0-4$ & 5,1 & 1,0 & 61,8 & 0,0 & 38,2 \\
Sn & $0-18$ & 3,5 & 1,2 & 50,4 & 8,0 & 41,7 \\
V & $31-97$ & 2,5 & 23 & 40,8 & 56,1 & 3,1 \\
W & $0-6$ & 2,7 & 1,4 & 40,9 & 14,1 & 45,0 \\
Y & $11-66$ & 1,4 & 60,1 & 14,9 & 83,4 & 1,8 \\
Zn & $32-106$ & 8,9 & 4,2 & 77,9 & 16,1 & 6,0 \\
& & & & & & \\
F & & 1,9 & 2,2 & & & \\
GL & & $(28 ; 29)$ & $(29 ; 16)$ & & &
\end{tabular}


Nas Figuras 6 a 12 são mostradas as distribuições espaciais das diferenças relativas entre duplicatas de amostragem para Fe, Mn, As, Ba, Co, Cu e Ni. Observe-se que os graficos para o Fe (Figura 6) e para o kn (Figura 7) sugerem comportamentos diferentes para as amostras no setor oriental e no setor ocidental, em relação à Iinha imaginária da coordenada UTM-X = $600 \mathrm{~km}$. O Fe apresentou as maiores diferenças relativas na região ocidental (Figura 6 ), sendo que para o kn aconteceu 0 contrário (Figura 7), com as maiores diferenças na região oriental. O As (Figura 8) e $O$ Co (Figura 10) mostraram diferenças relativas elevadas em toda a area. Ba (Figura 9), Cu (Figura 11) e Ni (Figura 12) apresentam padrões de distribuição semelhantes ao do $\mathbf{F e}$. Pb mostrou comportamento semelhante ao do As-Co e, para $\mathbf{P}, \mathbf{C r}, \mathbf{v}, \mathbf{Y}$ e $\mathbf{z n}$, a distribuição das diferenças relativas foi semelhante à do $\mathbf{F e}$.

Assim, elementos como As, que apresentaram erros analíticos consideráveis, mostraram diferenças relativas elevadas em toda a área, pois sua variância foi controlada por efeitos aleatórios relacionados ao ruido analitico. Por esse motivo, somente os valores acima do LIDA poderiam ser considerados. Os diagramas de dispersão do As e o Sn sugerem linearidade acima de 15ppm, valor inferior ao IIDA desses elementos, que é de $20 \mathrm{ppm}$. Esse fato representa uma situação especial, que deve ser considerada com cuidado, em função do baixo número de amostras envolvidas.

Os erros de amostragem elevados para os elementos com bom comportamento analítico, em especial $\mathbf{P}, \mathbf{B a}, \mathbf{C o}, \mathbf{V}$ e $\mathbf{Y}$, seriam explicados por dois fatores: (1) Devido a erros na metodologia de coleta das amostras ou na sua preparação. (2) por contrastes fortes dos tipos litológicos ou de fenômenos superficiais, em distâncias curtas.

o primeiro fator estaria associado a uma escolha inadequada da área de influência nos locais de amostragem. As amostras de sedimentos são, na realidade, amostras compostas de 4-5 pontos, coletados em uma distância de 30 metros no longo do curso hídrico. Essa distância parece pequena pois, em função da densidade de amostragem, a área a ser representada é de mais ou menos $1 \mathrm{~km}^{2}$. Assim, deveria ter sido considerada uma distância mínima de 100 metros ao longo do curso hídrico. 


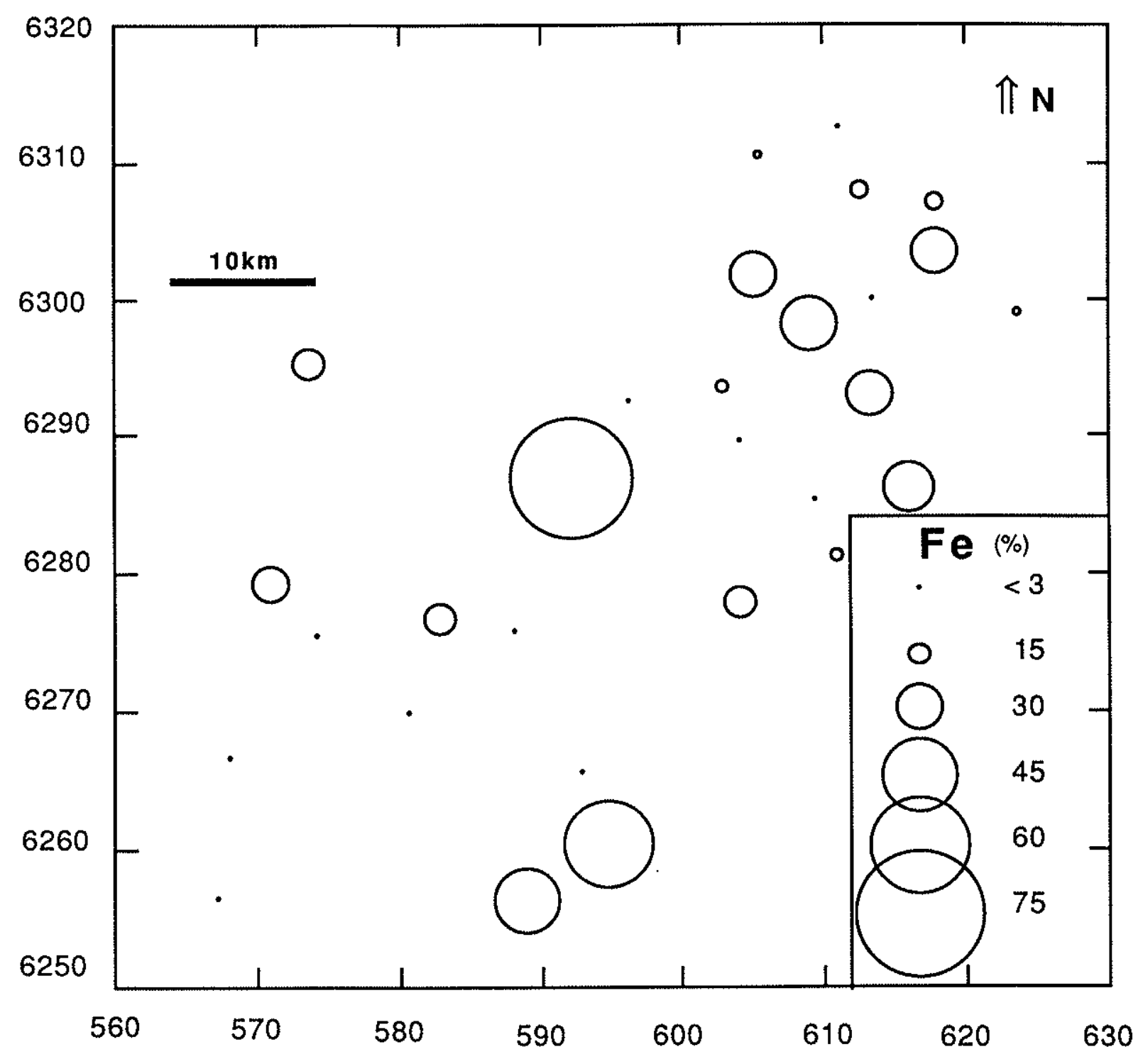

Figura 6. Diferenças relativas entre as duplicatas de amostragem para o Fe. Diferença relativa $=$ Valor absoluto $\{2($ Fe1-Fe2 $) /($ Fe1 + Fe2 $)\}$. 


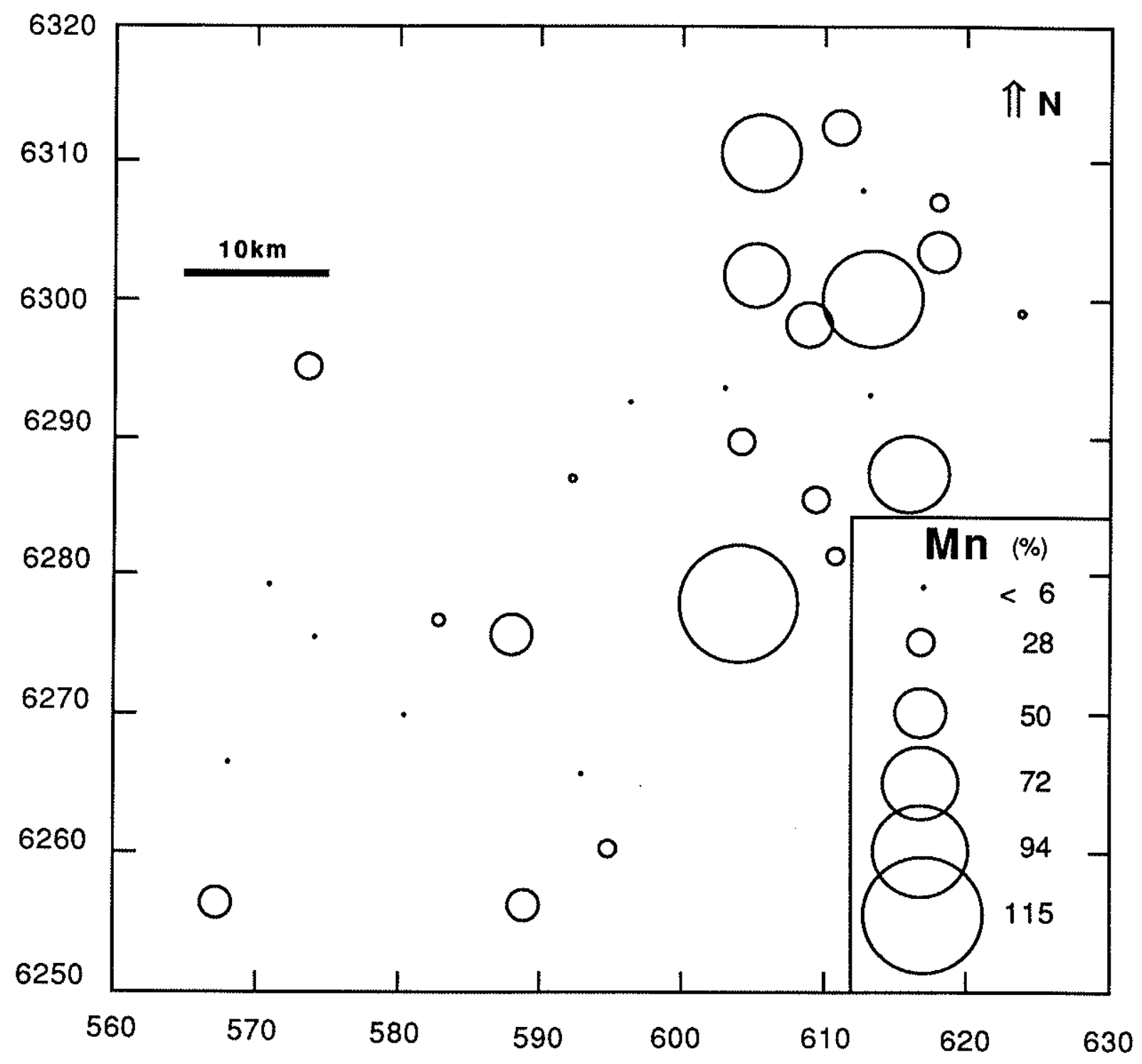

Figura 7. Diferenças relativas entre as duplicatas de amostragem para o Mn. Diferença relativa $=$ Valor absoluto $\{2(\mathbf{M n 1 - M n 2}) /(\mathbf{M n 1}+\mathbf{M n} 2)\}$. 


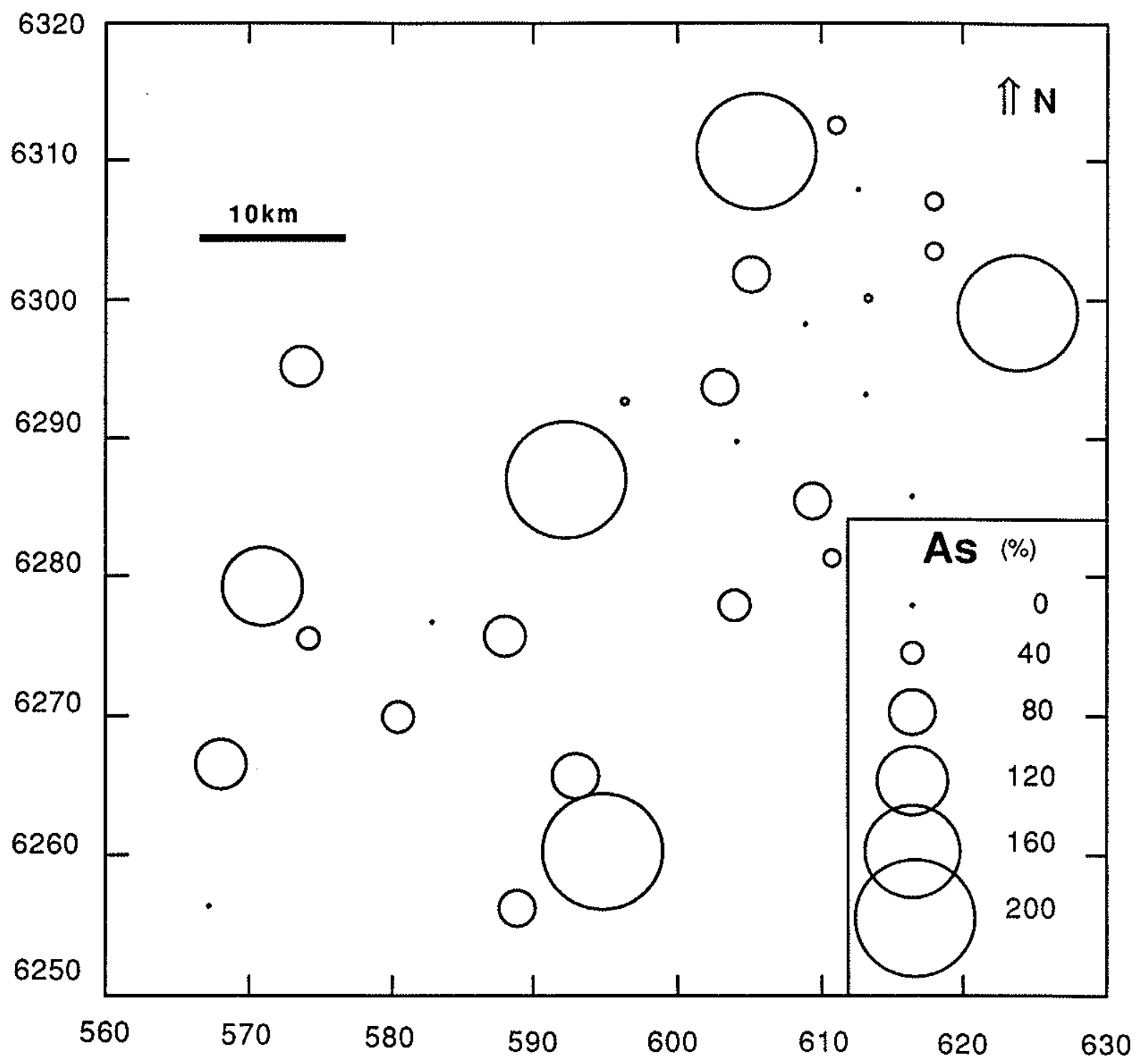

Figura 8. Diferenças relativas entre as duplicatas de amostragem para o As. Diferença relativa $=$ Valor absoluto $\{2($ As1-As2) $/(\mathbf{A s 1}+\mathbf{A s 2})\}$. 


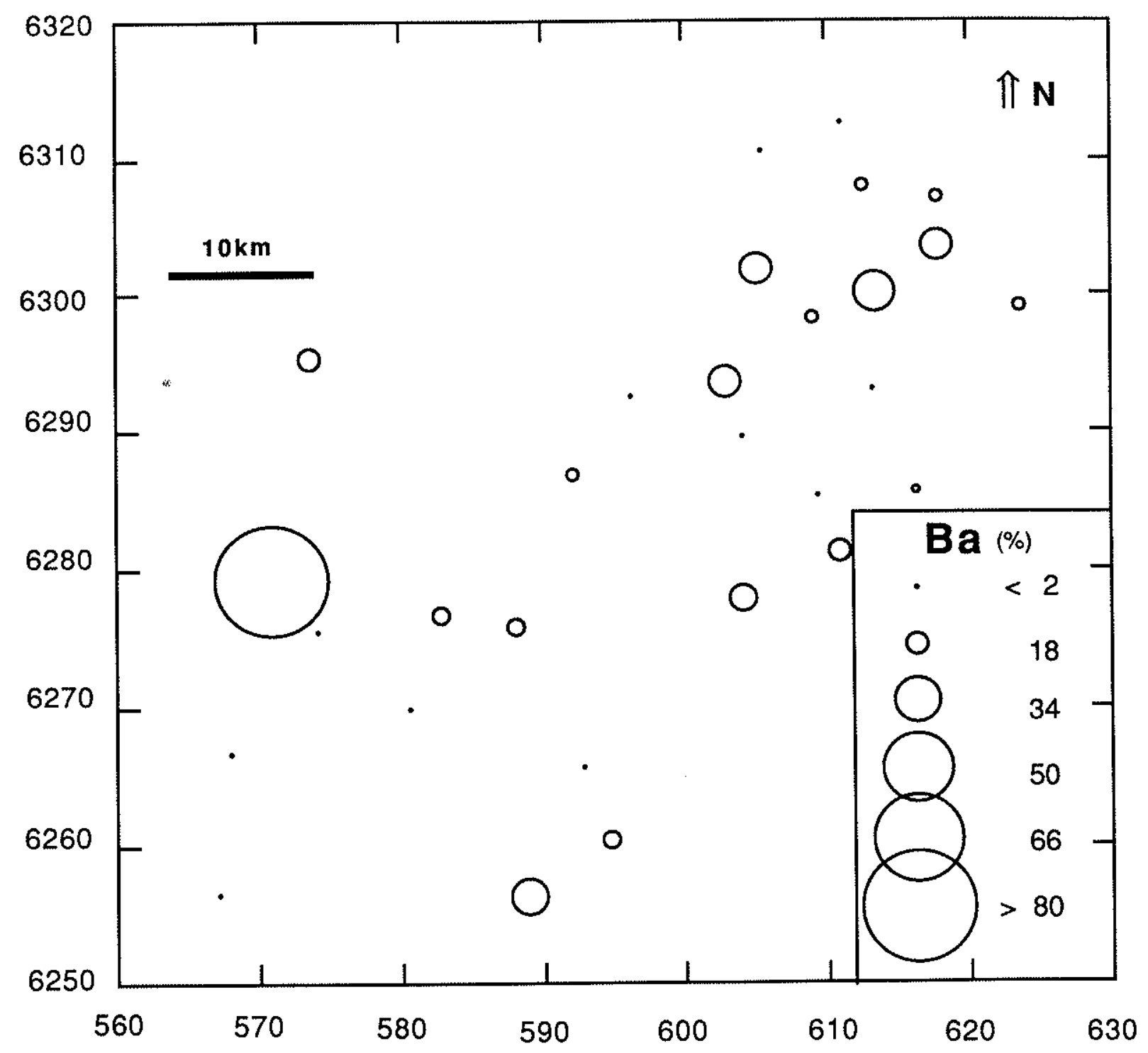

Figura 9. Diferenças relativas entre as duplicatas de amostragem para o Ba. Diferença relativa $=$ Valor absoluto $\{2(\mathbf{B a 1}-\mathbf{B a} 2) /(\mathbf{B a 1}+\mathbf{B a 2})\}$. 


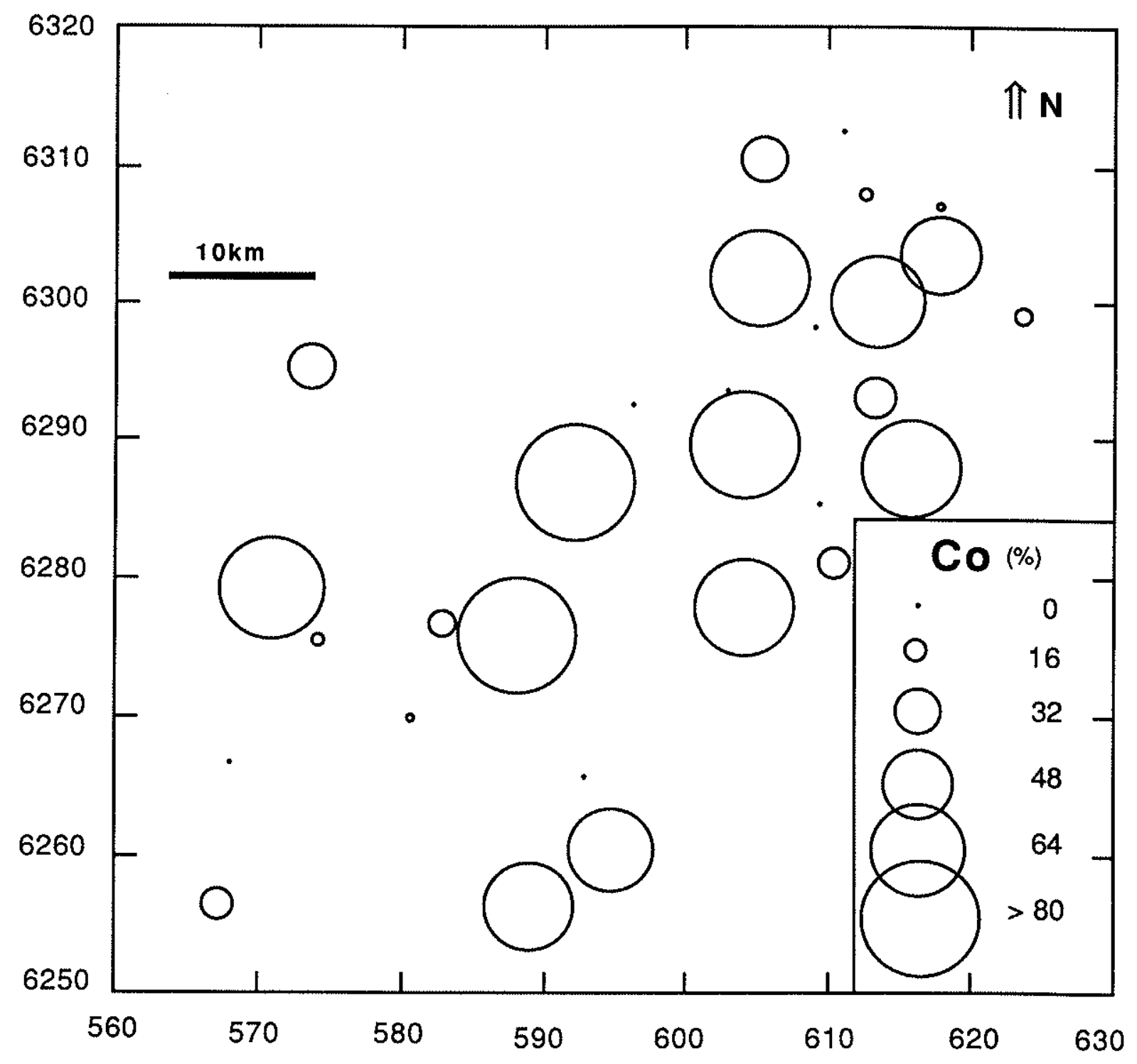

Figura 10. Diferenças relativas entre as duplicatas de amostragem para o Co. Diferença relativa $=$ Valor absoluto $\{2(\mathbf{C o 1 - C o 2}) /(\mathbf{C o 1}+\mathbf{C o 2})\}$. 


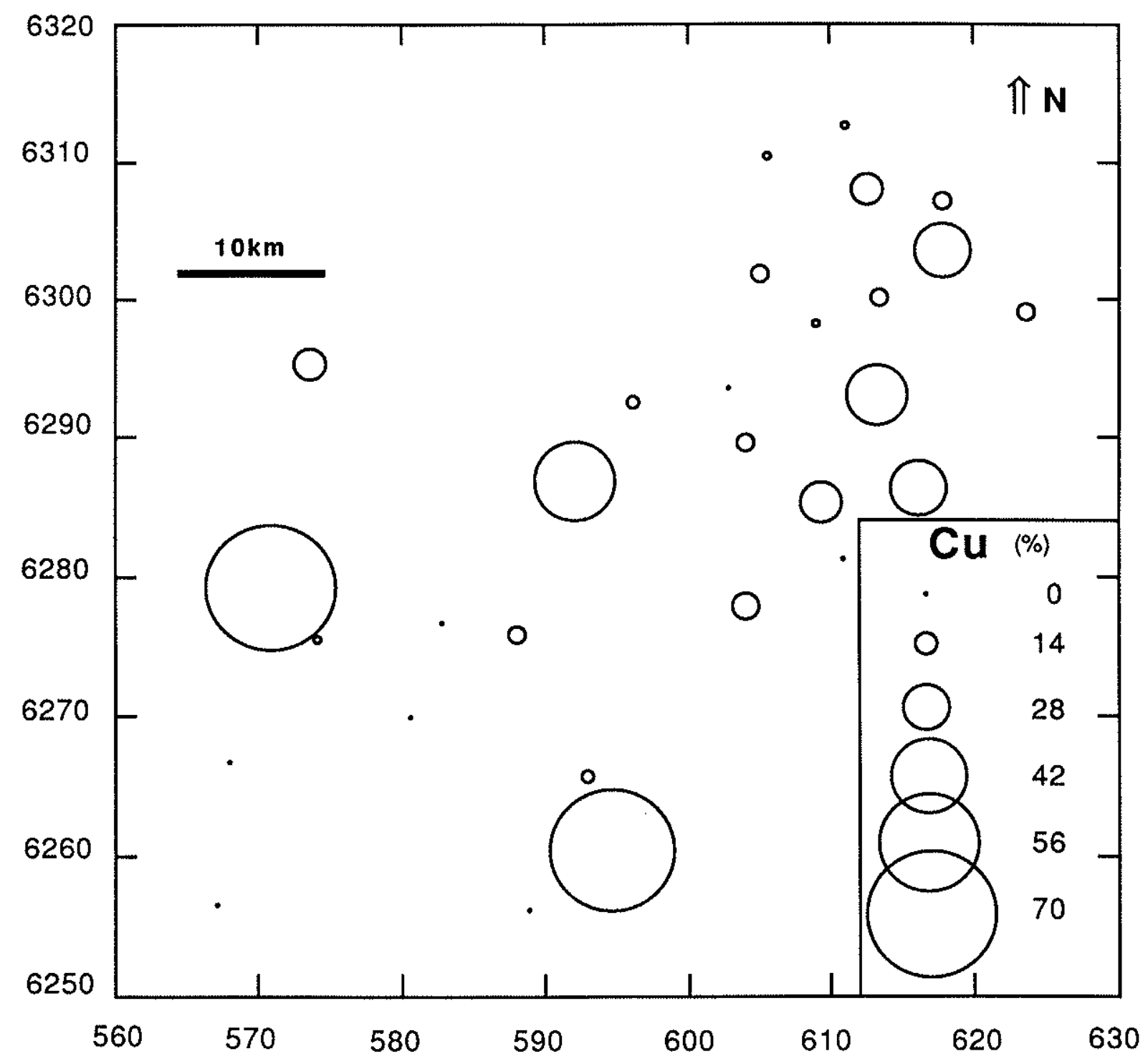

Figura 11. Diferenças relativas entre as duplicatas de amostragem para o $\mathbf{C u}$. Diferença relativa $=$ Valor absoluto $\{2(\mathbf{C u 1}-\mathbf{C u} 2) /(\mathbf{C u} 1+\mathbf{C u} 2)\}$. 


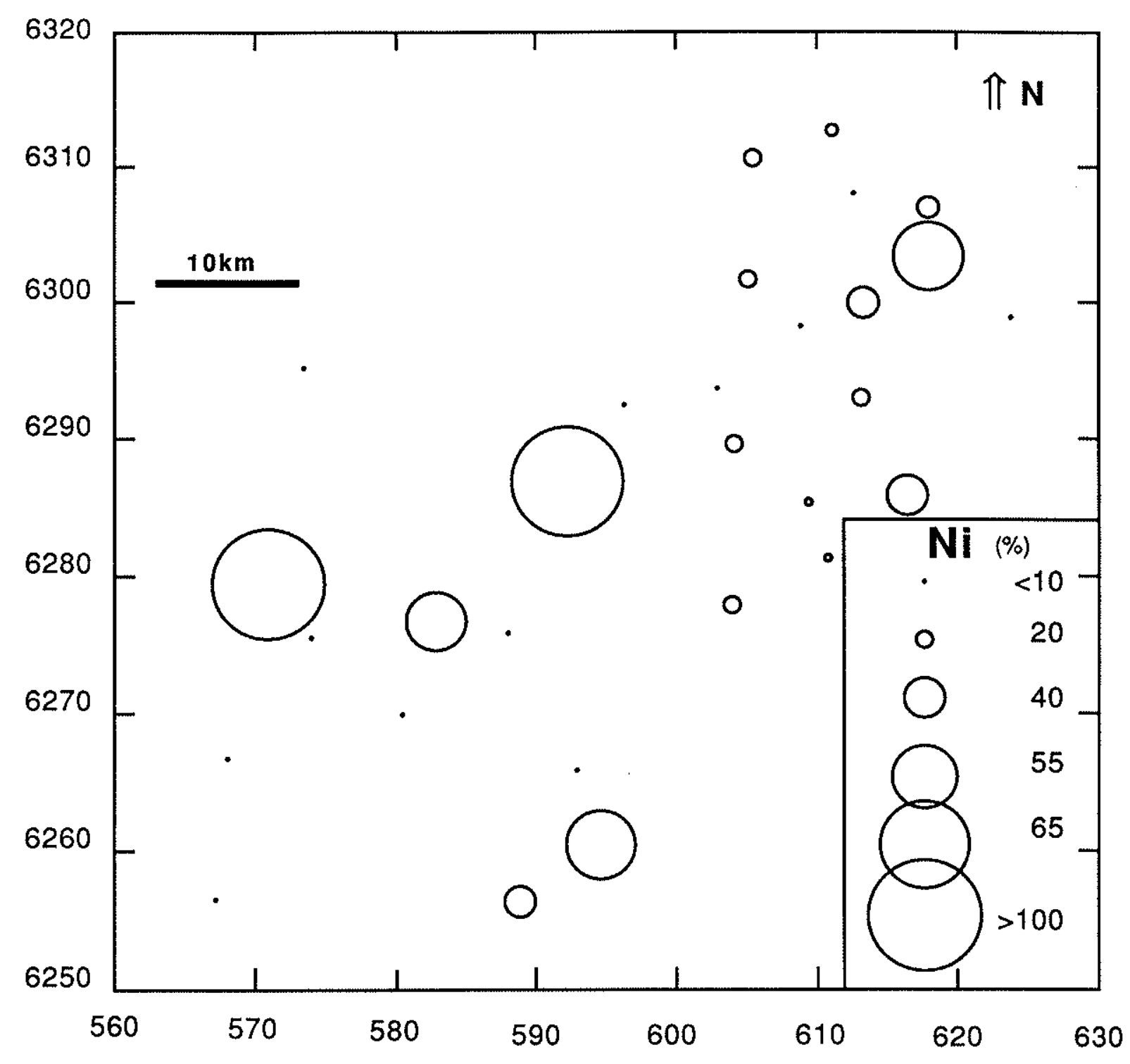

Figura 12. Diferenças relativas entre as duplicatas de amostragem para o Ni. Diferença relativa $=$ Valor absoluto $\{2(\mathbf{N i 1}-\mathbf{N i 2}) /(\mathbf{N i 1}+\mathbf{N i 2})\}$. 
Posteriormente as amostras eram secas, moídas manualmente e peneiradas, sendo armazenada a fração inferior a 80 mesh. A ocorrência de concreções duras poderia provocar uma situação semelhante ao "efeito pepita", por falta de moagem mais enérgica. Ou seja, em algumas amostras as concreções seriam parcialmente moídas, podendo atravessar ou não a peneira, incrementando assim a variância de amostragem. A variância analítica é pouco afetada pois, nesse caso, as duplicatas são divididas depois de serem peneiradas.

Fe, Co, Cr, Cu, Ni e v possuem caráter femáfilo, isto é, concentram-se nos minerais ferromagnesianos, que predominam nas rochas máfico-ultramáficas (SHAW, 1966). No setor NW da área, existe uma alternância de rochas félsicas e máfico-ultramáficas, que mudam em curta distância (PRECIOZZI, 1987b). Por esse motivo Fe, Co, Cr, Ni e V apresentaram erros de amostragem elevados. Os desvios para $\mathbf{P}$, $\mathbf{B a}$ e $\mathbf{P b}$ nesse setor estariam relacionados ao mesmo fenômeno.

Co e Pb também apresentam dịferenças relativas altas no setor oriental da área, conjuntamente com un. A associação mnco é típica de óxidos de mo (PLANT \& RAISWELL, 1983). SALOMONS \& FÖRSTNER (1984) indicam a formação de fases autígenas nodulares de Mn e Fe-kn no fundo oceânico, sendo que nódulos ricos em Co ocorreriam em ambientes oxidantes. MIDOT (1984) caracterizou paleo-ambiente marinho no Grupo Lavalleja, que predomina na região oriental da área de pesquisa. Esse autor descreveu níveis de jaspe relacionados às rochas carbonatadas do Grupo Lavalleja, onde ocorrem lentes ferro-manganesiferas centimétricas. PRECIOZZI (1987a) menciona a ocorrência de mineralizações de Mn (psilomelano) em jaspes, relacionadas aos calcários da folha J.P. Varela. Esses fatos poderiam explicar os desvios elevados em Co e mn para as duplicatas de amostragem no setor oriental, em função da ocorrência de nódulos ou micronódulos de kn ou Femn. FILIPPINT ALBA (1992) detectou anomalias de $\mathrm{Pb}$ associadas a teores elevados de Fe-Mn-Co, em amostras de sedimentos de correntes do Grupo Lavalleja na região de Isla Patrulla, alguns quilômetros ao Norte da área atual. Assim, as diferenças relativas elevadas entre duplicatas de amostragem para 0 Pb 
poderiam estar também relacionadas à formação de nódulos ou micronódulos de mn ou Fe-mn.

O uso dos coeficientes $F$ como único critério de avaliação poderia gerar controvérsias, pois vários elementos com problemas analíticos poderiam ser aceitos. O valor de $F_{2}$ para o Nb (Tabela 5) sugere a ausência de problemas analíticos, o que é imediatamente questionado ao se observarem os valores de VIL, VAM $\mathrm{e}$ VAN.

Resumindo, foram definidos dois grupos de elementos:

(A) Ag, As, B, Be, Cd, Mo, $\mathrm{Nb}, \mathbf{S b}, \mathrm{Sn} \in \mathrm{W}$.

(B) Fe, Mn, P, Ba, Co, Cr, Cu, $\mathrm{Ni}, \mathrm{Pb}, \mathrm{V}, \mathrm{Y}$ e Zn.

o grupo A esta integrado por elementos com problemas analíticos. Muitas amostras foram afetadas pelo LIDA, de forma que somente serão considerados os teores próximos ou acima desse limite. Os elementos do grupo $\mathrm{B}$ apresentaram erros analíticos inferiores a $10 \% \mathrm{e}$, em alguns casos, erros de amostragem elevados. Isso seria explicado em função do ambiente geológico e de possíveis erros nos métodos de coleta do material. Apenas os elementos do grupo $B$ foram selecionados para o tratamento estatístico.

Finalmente, é importante mencionar que, como as replicatas de cada folha foram processadas junto com as amostras da folha, - modelo assumido não considerou as variações inter-processos (inter-folhas). Assim, as estimativas de erros de amostragem estariam sub-avaliadas. Por outra parte, como foi mencionado acima, alguns dos fatores que provocaram valores elevados para os exros de amostragem (VAM) estariam superavaliados, pois incorporariam também a variabilidade geoquímica natural.

\subsection{Tratamento estatístico dos dados geoquimicos originais}

\subsubsection{Parâmetros das distribuições univariadas}

Na Tabela 7 são apresentadas algumas estatísticas para o total da população. Os valores das medianas indicam que Ag, As, B, Be, Cd, Mo, No, Sb, Sn e $\mathbf{W}$ apresentam muitos valores abaixo dos LIDAs. Seus coeficientes de variação são usualmente elevados devido à existência de máximos muito afastados da média. Como 
foi mencionado antes, esses elementos são inadequados para o processamento estatístico.

Tabela 7. Extremos, médias, desvios padróes-D.P. e coeficientes de variação-C.v. para os 22 elementos analisados $(2172$ amostras), Rad- $\gamma(2170$ mediçôes) e pH (1525 medidas em cursos hidricos ativos).

\begin{tabular}{lrrrrrr} 
Vartável & Minimo & Maximo & Média & Mediana & D.P. & C.V. \\
\hline Fe $\%$ & 0,8 & 8,4 & 2,9 & 2,7 & 1,0 & $34 \%$ \\
Mn ppm & 74 & 15610 & 998 & 863 & 704 & $71 \%$ \\
P ppm & 99 & 2528 & 292 & 242 & 217 & $74 \%$ \\
Ag ppm & 0 & 0,9 & 0,0 & 0 & 0,1 & $500 \%$ \\
As ppm & 0 & 80 & 6 & 5 & 5 & $96 \%$ \\
B ppm & 0 & 19 & 8,5 & 8 & 4 & $43 \%$ \\
Ba ppm & 174 & 2272 & 557 & 506 & 194 & $35 \%$ \\
Be ppm & 0 & 6 & 1,6 & 1 & 0,7 & $43 \%$ \\
Cd ppm & 0 & 1 & 0,1 & 0 & 0,2 & $400 \%$ \\
Co ppm & 1 & 78 & 12 & 11 & 6 & $50 \%$ \\
Cr ppm & 8 & 1980 & 42 & 31 & 61 & $146 \%$ \\
Cu ppm & 2 & 60 & 19 & 18 & 6 & $33 \%$ \\
Mo ppm & 0 & 4 & 0,2 & 0 & 0,5 & $242 \%$ \\
Nb ppm & 0 & 13 & 0,6 & 0 & 1,5 & $243 \%$ \\
N1 ppm & 0 & 940 & 22 & 17 & 29 & $133 \%$ \\
Pb ppm & 0 & 116 & 14 & 13 & 7 & $50 \%$ \\
Sb ppm & 0 & 11 & 0,8 & 0 & 1,3 & $174 \%$ \\
Sn ppm & 0 & 77 & 3,6 & 3 & 4,2 & $118 \%$ \\
V ppm & 18 & 240 & 65 & 62 & 20 & $30 \%$ \\
W ppm & 0 & 13 & 0,5 & 0 & 1,4 & $281 \%$ \\
Y ppm & 8 & 266 & 24 & 20 & 13 & $54 \%$ \\
Zn ppm & 17 & 176 & 59 & 56 & 19 & $33 \%$ \\
pH & 2 & 8,5 & 6,5 & 6,5 & 0,7 & $11 \%$ \\
Rad $\gamma$ C/s & 30 & 200 & 79 & 80 & 20 & $25 \%$ \\
& & & & & &
\end{tabular}

A maioria das variáveis apresentaram medianas inferiores às médias, sugerindo assimetria positiva nas distribuições, o que foi confirmado pelos histogramas. Como exemplos de histogramas são apresentados os de Fe (Figura 13), Ni (Figura 14), $\mathrm{Pb}$ (Figura 15) e zn (Figura 16) em escala linear e logarítmica. Fica claro da observação das figuras que os histogramas se ajustam melhor a uma distribuição log-normal. Para continuar o estudo das distribuições, foi aplicado o teste não paramétrico de Kolgomorov-Smirnov (Tabela 8). Considerando um nível de significância de 2\%, somente $\circ$ Fe $e \circ$ Mn, ajustaram-se à distribuição log-normal. porém $\mathbf{P}, \mathrm{Ba}, \mathrm{Co}, \mathrm{Cr}, \mathrm{Cu}, \mathrm{Ni}, \mathrm{V}$ e $\mathbf{Y}$ mostraram diminuição das estatísticas para os dados log- 


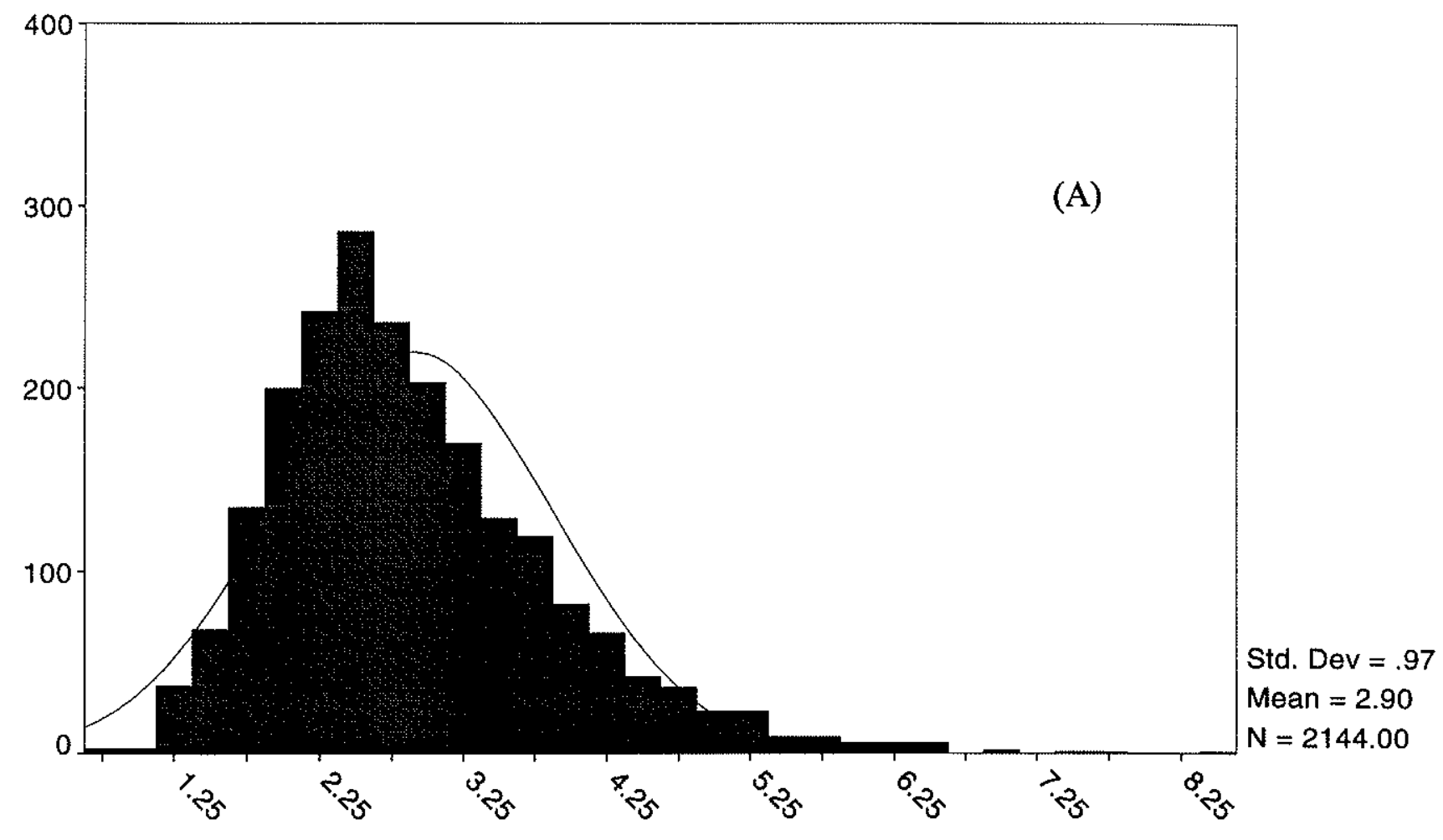

Fe $(\%)$

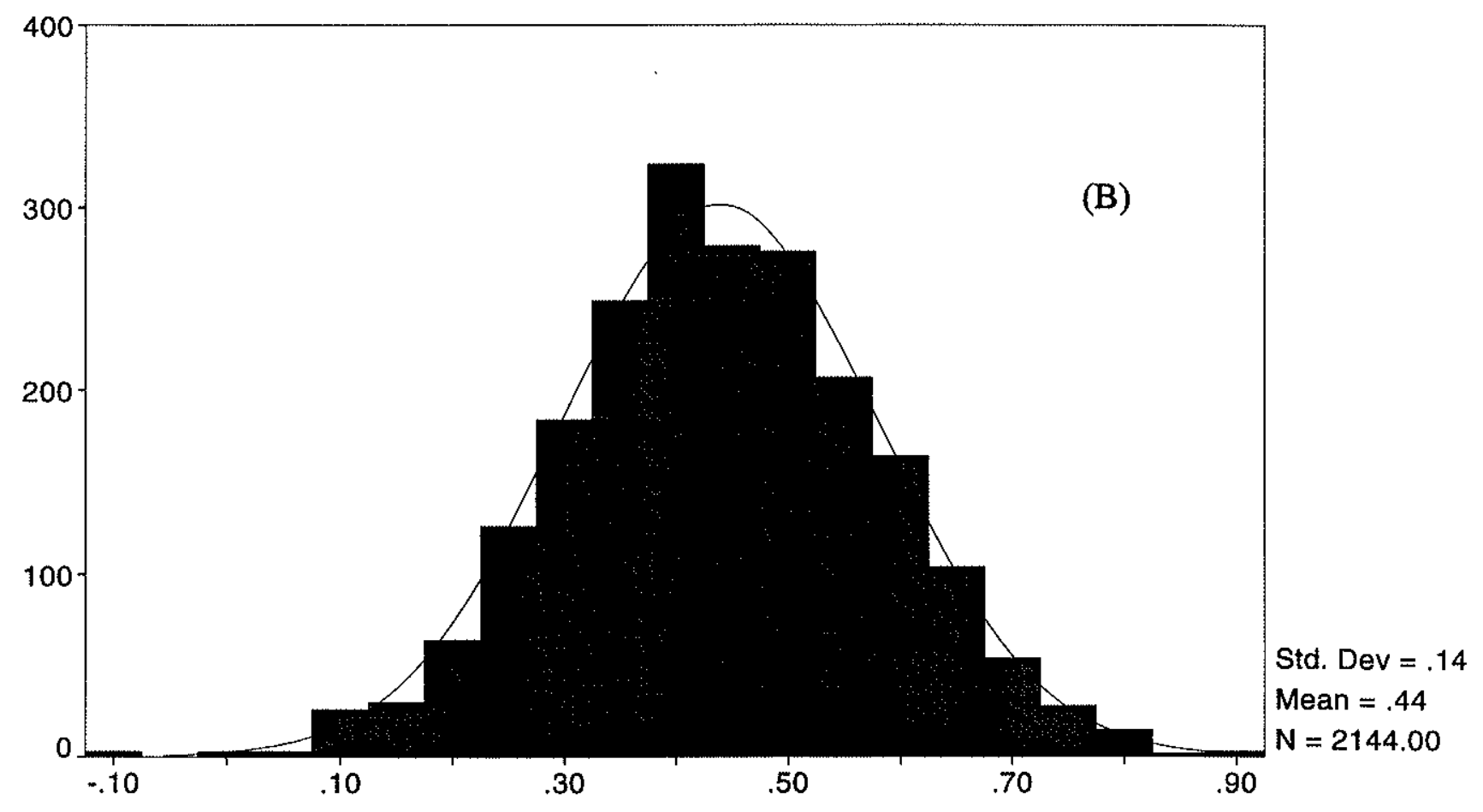

$\log \mathrm{Fe}(\%)$

Figura 13. Histograma do Fe em escala linear (A) e em escala logarítmica (B). 

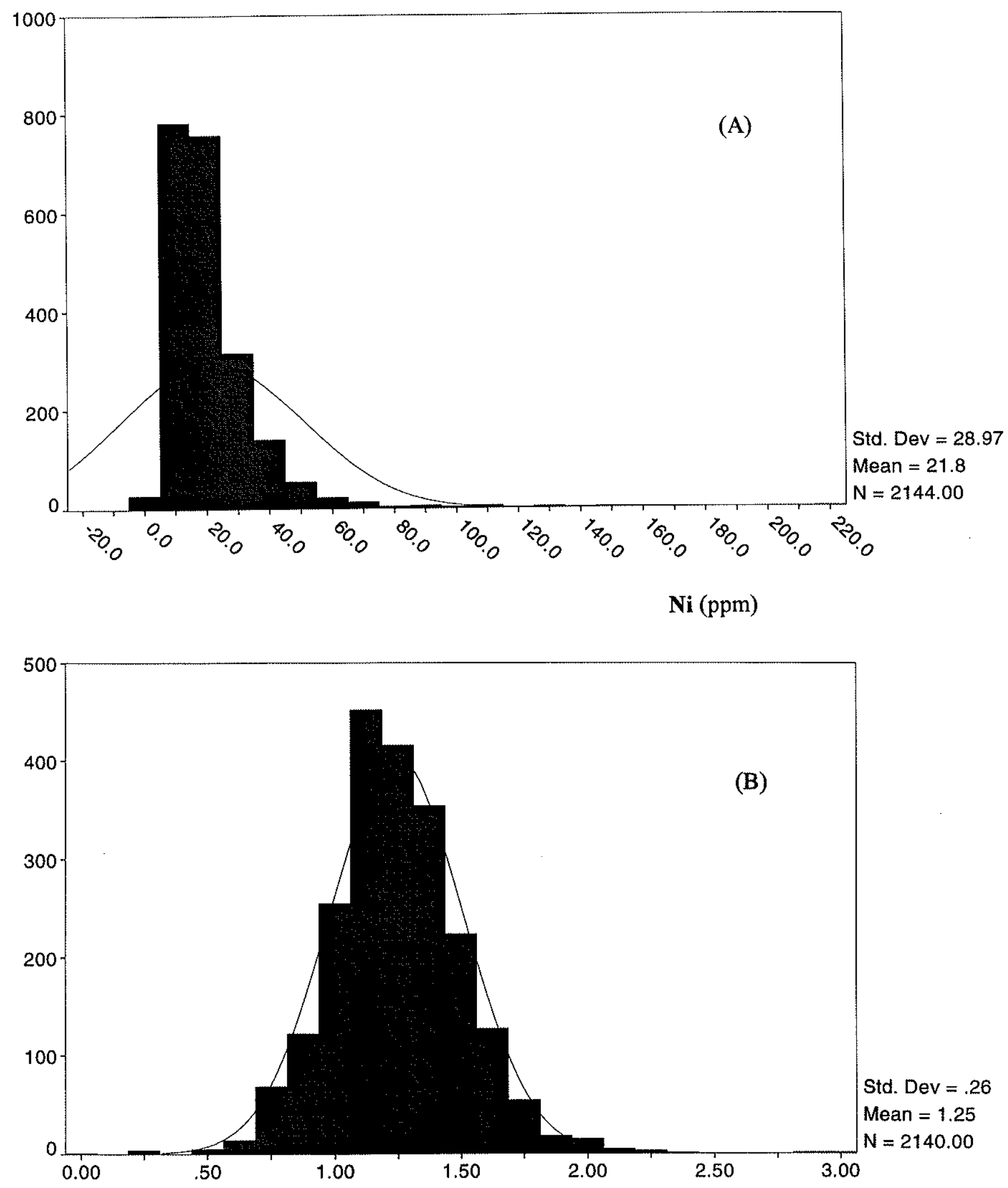

$\log \mathbf{N i}(\mathrm{ppm})$

Figura 14. Histograma do Ni em escala linear (A) e em escala logarítmica (B). 


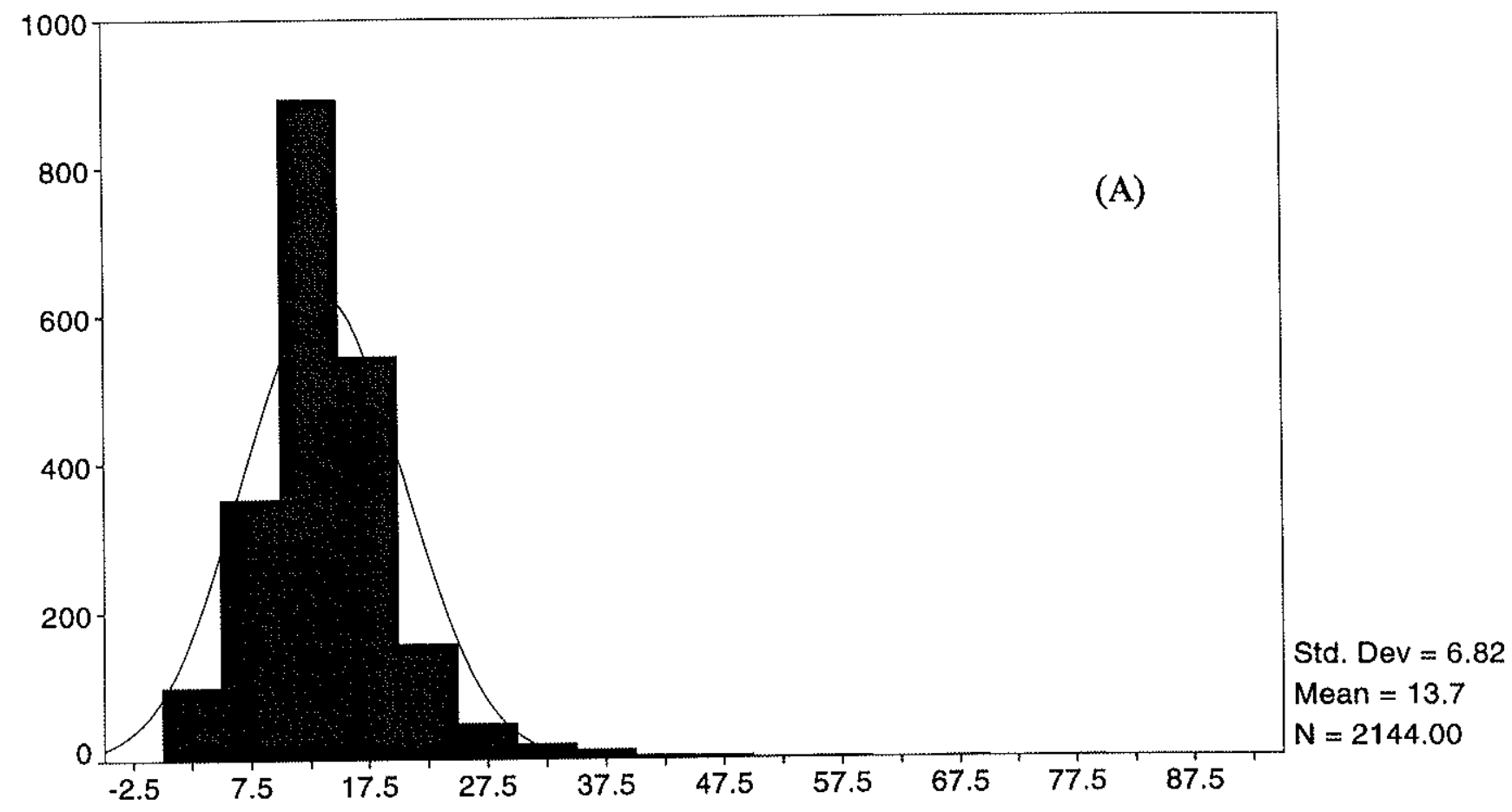

Pb (ppm)

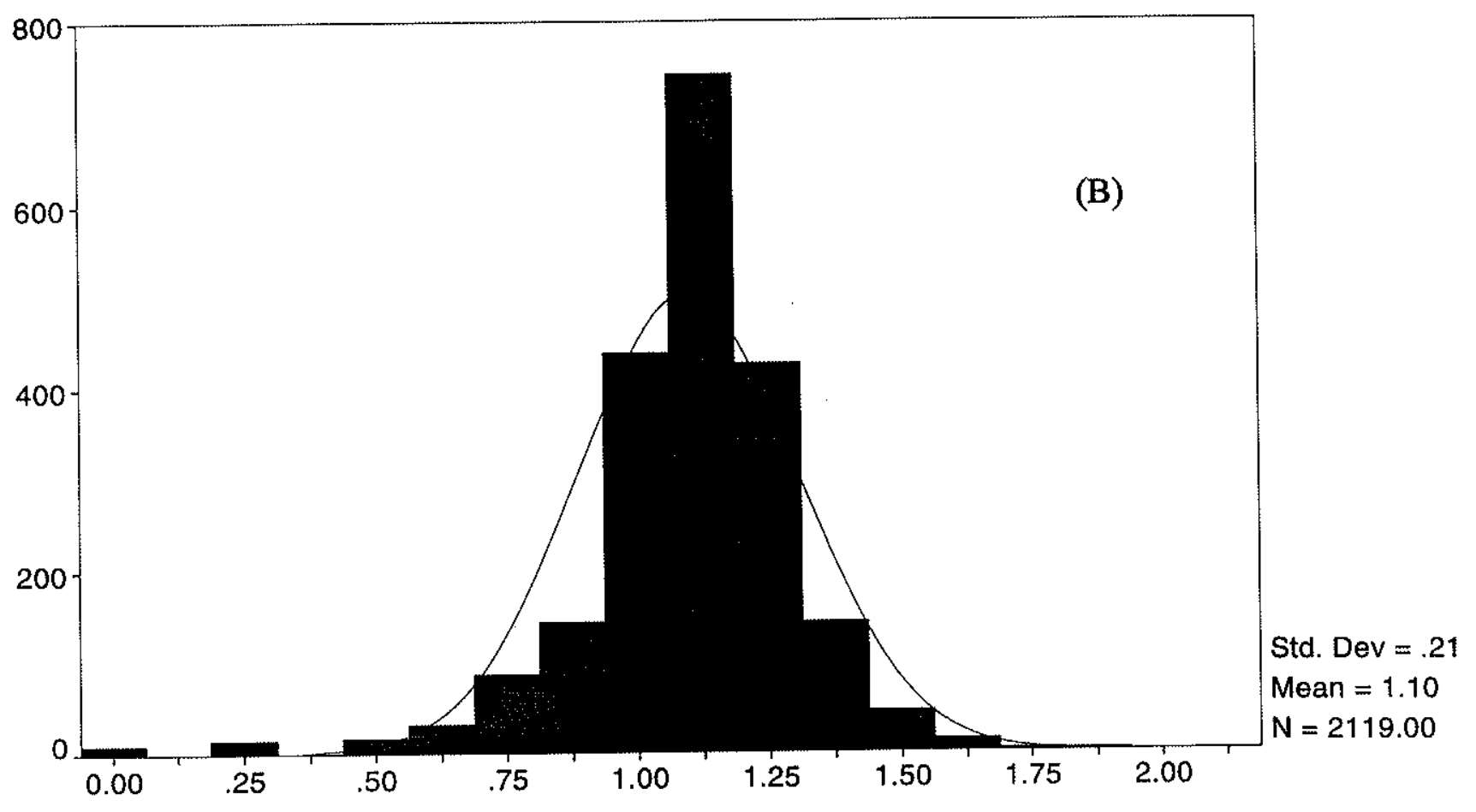

\section{$\log \mathbf{P b}(\mathrm{ppm})$}

Figura 15. Histograma do $\mathbf{P b}$ em escala linear (A) e em escala logarítmica (B). 


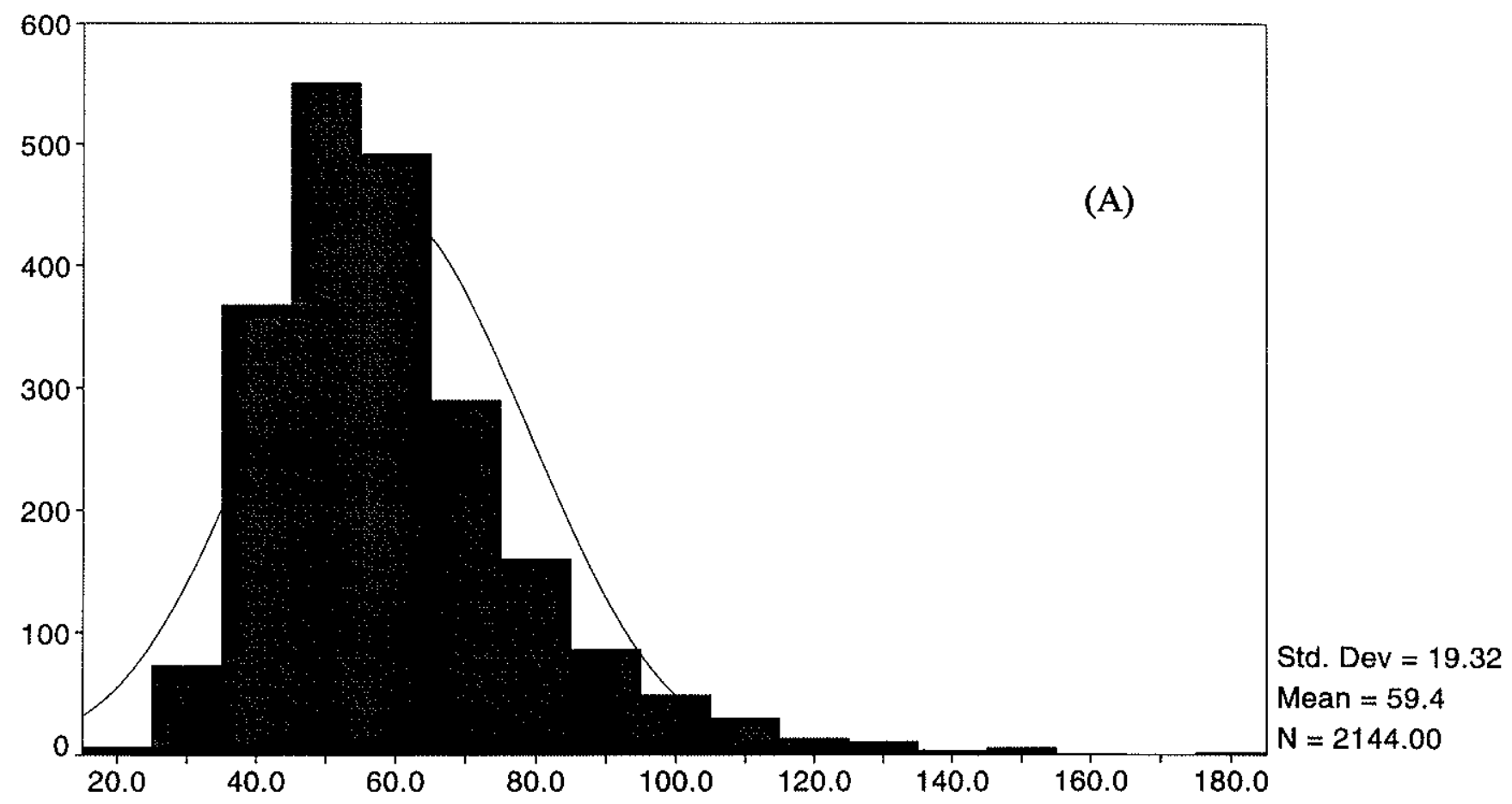

$\mathbf{Z n}(\mathrm{ppm})$

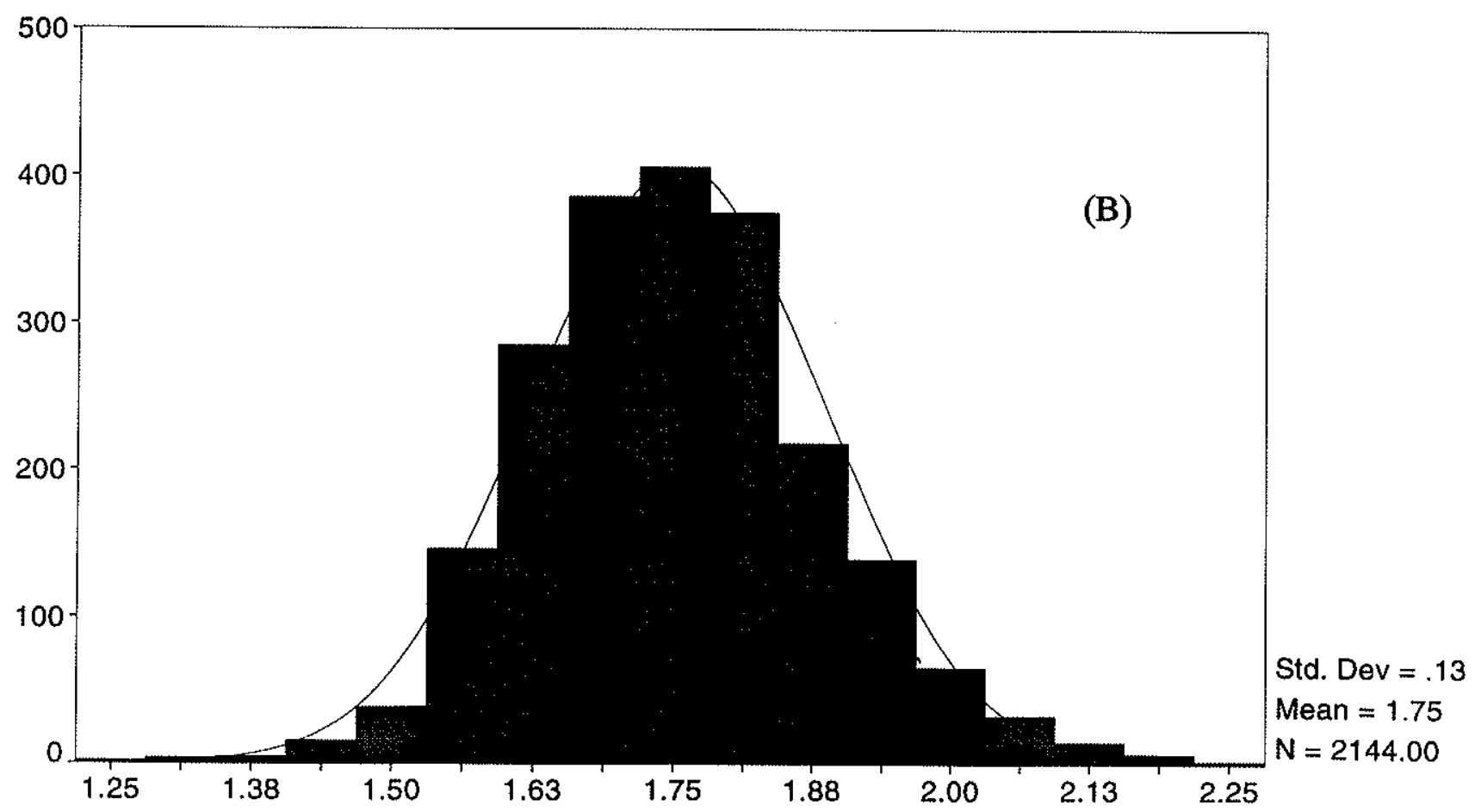

$\log \mathbf{Z n}(\mathrm{ppm})$

Figura 16. Histograma do $\mathbf{Z n}$ em escala linear (A) e em escala logarítmica (B). 
transformados. O teste de Wilconxon mostrou que $\mathbf{m}, \mathbf{C u}, \mathbf{V}$ e $\mathbf{z n}$ apresentam distribuições semelhantes às do $F e$, com uma significância de 10-50\%. A distribuição desses elementos apresenta comportamento próximo ao log-normal, porém com certo grau de deformação devido à ocorrência de pelo menos duas subpopulações com distribuições semelhantes. A distribuição das outras variáveis mostra maior afastamento do comportamento normal ou log-normal, em função da ocorrência de sub-populações com distribuições diferentes (P, Ba, Co, $\mathbf{C r}, \mathbf{N i}, \mathbf{P b}, \mathbf{Y}, \mathbf{p H}$ e $\operatorname{Rad}-\gamma$ ).

Tabela 8. Resultados do teste de Kolgomorov-Smirnov para os dados originais e log-transformados.

\begin{tabular}{|c|c|c|c|c|}
\hline & \multicolumn{2}{|c|}{ Dados origtnats } & \multicolumn{2}{|c|}{ Dados log-transformados } \\
\hline \multirow[t]{2}{*}{ Vartável } & $\cdots-\cdots \cdots-1$ & - & $-\cdots-\cdots-\cdots-1$ & 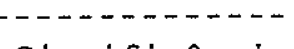 \\
\hline & Estatistica & Significância & Estatistica & Significância \\
\hline Fe $\%$ & 3,5 & $0 \%$ & 0.7 & $-1------$ \\
\hline sn ppm & 6,2 & $0 \div$ & 1,4 & $4,9 \%$ \\
\hline P ppm & 11,6 & $0 \div$ & 5,4 & $\begin{array}{l}4, y \\
0,0 \%\end{array}$ \\
\hline Ba ppm & 6,7 & $0 \%$ & 3,6 & $0,0 \%$ \\
\hline Co ppm & 5,7 & $0 \%$ & 3,4 & $0,0 \%$ \\
\hline Cr ppm & 14,2 & $0 \%$ & 3,7 & $0,0 \%$ \\
\hline Cu ppm & 4,8 & $0 \div$ & 2,3 & $0,0 \%$ \\
\hline s1 $\mathrm{ppm}$ & 12,4 & $0 \%$ & 2,4 & $0,0 \%$ \\
\hline $\mathrm{Pb}$ ppm & 6,6 & $0 \%$ & 7,1 & $0,0 \%$ \\
\hline v ppm & 3,8 & $0 \%$ & 2,0 & $0,0 \%$ \\
\hline $\mathbf{Y} \mathrm{ppm}$ & 9,5 & $0 \div$ & 5,6 & $0,0 \%$ \\
\hline zn ppm & 4,8 & $0 \%$ & 1,9 & $0,1 \%$ \\
\hline pH & 7,7 & $0 \%$ & 7,2 & $0,0 \%$ \\
\hline $\operatorname{Rad}-\gamma \mathrm{c} / \mathrm{s}$ & 8,7 & $0 \%$ & 9,3 & $0,0 \%$ \\
\hline
\end{tabular}

\subsubsection{Análise de variância-ANova}

Nesta seção, a ANOVA foi utilizada de maneira diferente da discutida acima. Foi avaliado um único efeito segundo o teste não paramétrico de Kruskall-Wallis. O referido fator foi o material amostrado ou o litotipo das rochas de procedência.

Na Tabela 9 são expostas as medianas e as estatísticas do teste para os grupos definidos segundo o material amostrado. 0 efeito também foi ilustrado pelos diagramas de box para Fe e Mn (Figura 17) e para Co, $\mathrm{Cr}, \mathrm{Cu}$ e $\mathrm{Ni}$ (Figura 18). P, pH e Rad- $\gamma$ 


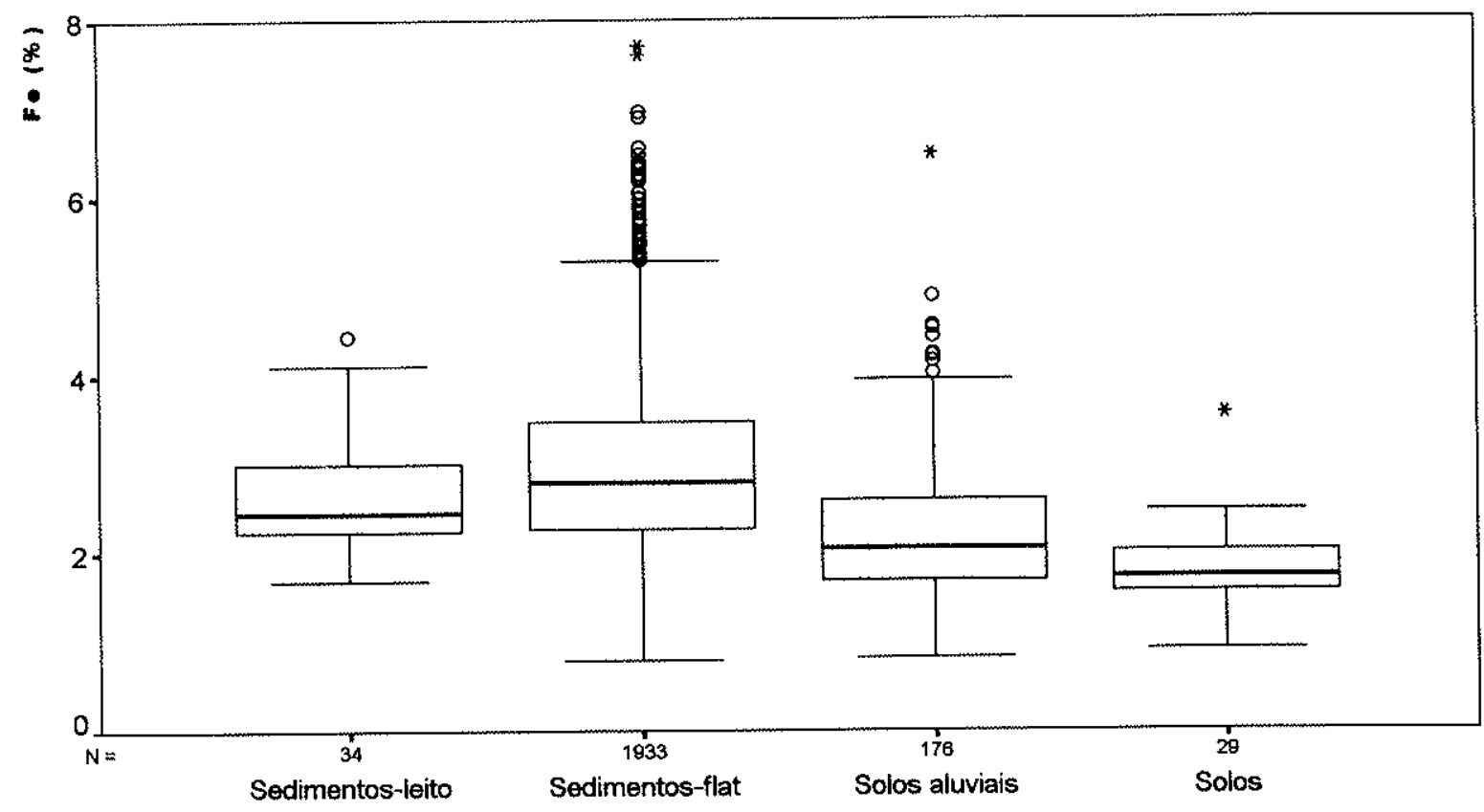

Material amostrado

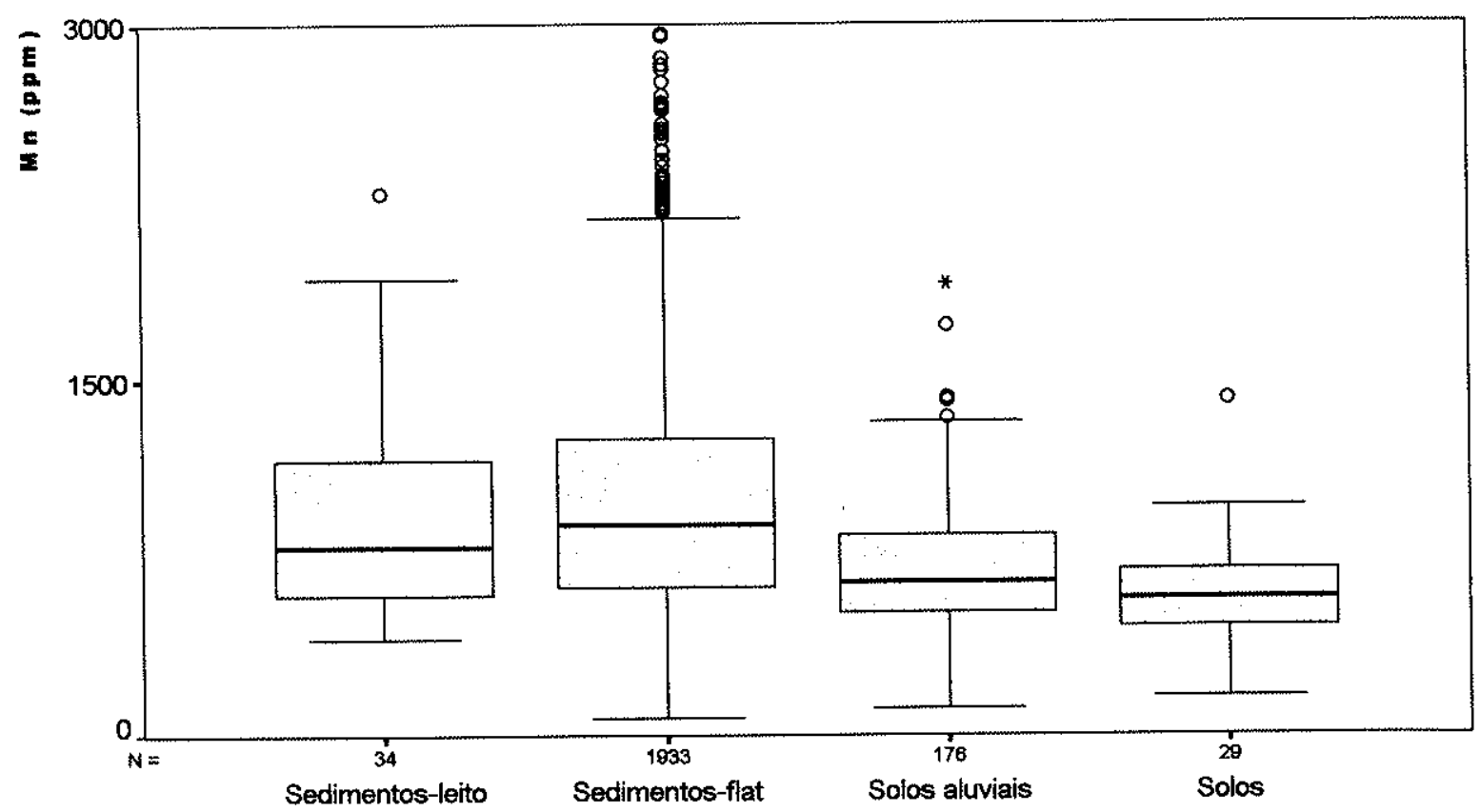

Material amostrado

Figura 17. Gráfico de box para o Fe (acima) e para o Mn (abaixo). As barras horizontais na base, no centro e no topo de cada retângulo representam os quartis $25 \%, 50 \%$ (mediana) e $75 \%$ de cada grupo. As barras horizontais nos extremos das linhas verticais indicam o mínimo e o máximo das sub-populações sem outliers (círculos), nem amostras extremas (asteriscos). As outliers são definidas pelo próprio procedimento, como as amostras que localizam-se entre 1,5 - 3 vezes a distância inter-quartis, tomando como origem os quartis $25 \%$ e $75 \%$. De maneira análoga, as amostras extremas são aquelas que superam 3 vezes a distância inter-quartis. 


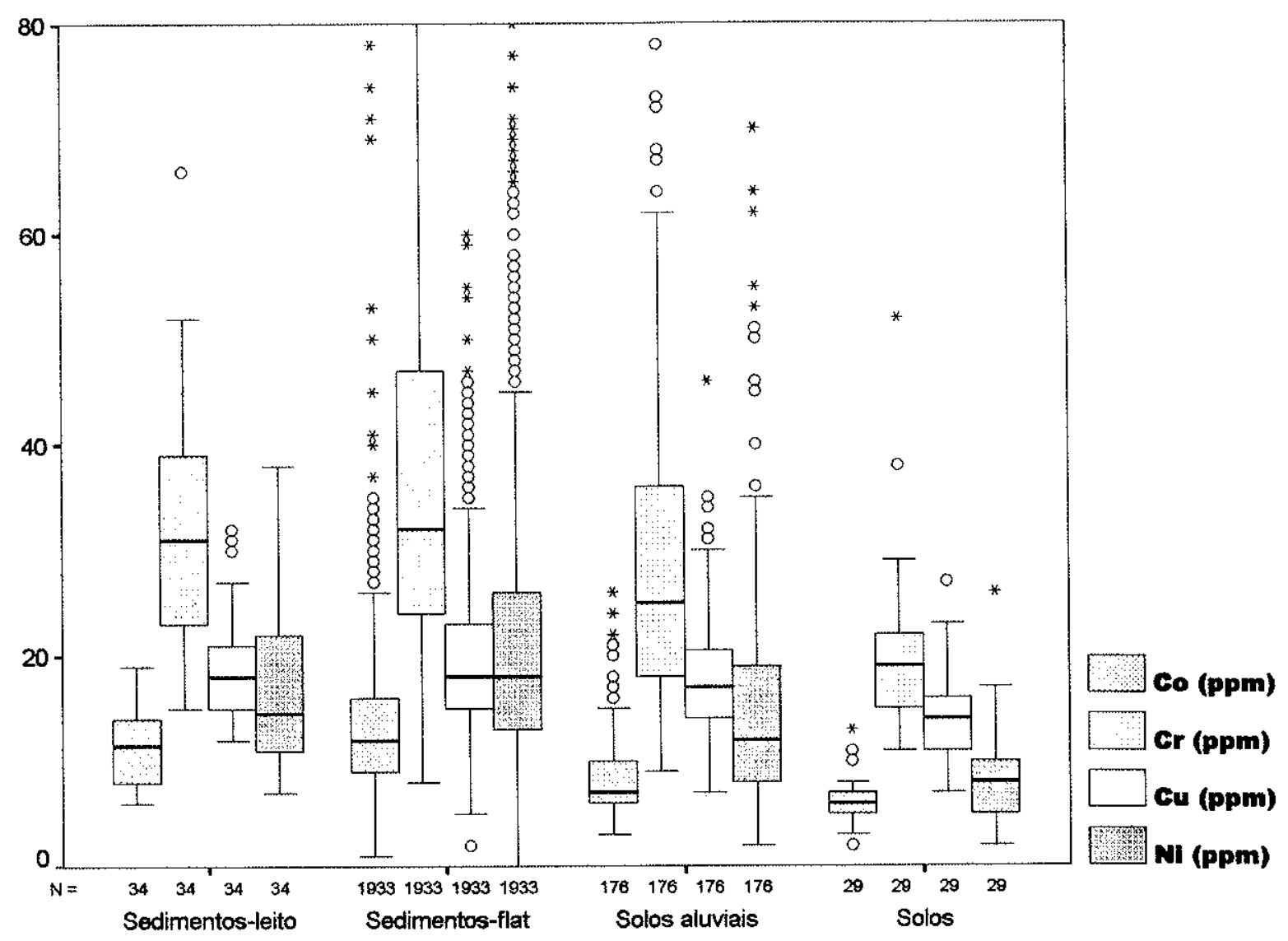

Material amostrado

Figura 18. Gráfico de box para o Co, o $\mathbf{C r}$, o $\mathbf{C u}$ e o Ni.. As barras horizontais na base, no centro e no topo de cada retângulo representam os quartis $25 \%, 50 \%$ (mediana) e $75 \%$ de cada grupo. As barras horizontais nos extremos das linhas verticais, indicam o mínimo e o máximo das sub-populações sem outliers (círculos), nem amostras extremas (asteriscos). Nesse caso, as outliers \{amostras extremas\} são aquelas amostras afastadas mais de $1,5\{3,0\}$ vezes a distância inter-quartis em relação ao quartil $25 \%$ ou $75 \%$. Algumas amostras foram descartadas para melhorar a expressão do gráfico. 
apresentaram estatísticas baixas, sem significação para a Rad- $\gamma$. Isso constitui um resultado óbvio, pois essa variável não depende do material coletado, mas do teor de elementos radioativos do embasamento. Os demais elementos apresentaram estatísticas altamente significativas. Em geral, as amostras de sedimentos mostraram-se enriquecidas em relação aos solos, sendo os solos autóctones o grupo mais empobrecido. A magnitude das diferenças extremas entre medianas foram da ordem de grandeza ou maiores que os erros de amostragem (Tabela 6). Por esse motivo, a comparação direta entre amostras de sedimentos e de solos não seria possível, senđo necessário antes corrigir os dados, eliminando esse efeito.

Tabela 9. Medianas e resultados do teste de Kruskall-Wallis para os grupos definidos pelo material coletado. (A)=Sedimentos em leito, (B) $=$ Sedimentos em terraços, (C) =Solos aluviais e (D)=Solos autoctones.

\begin{tabular}{lcccccc} 
Variavel & (A) & (B) & (C) & (D) & Estatibtica & Significância \\
\hline Fe $\%$ & 2,4 & 2,8 & 2,1 & 1,7 & 154 & $0,0 \%$ \\
Mn ppm & 799 & 893 & 722 & 550 & 90 & $0,0 \%$ \\
P ppm & 250 & 240 & 261 & 241 & 10 & $1,6 \%$ \\
Ba ppm & 531 & 515 & 437 & 390 & 94 & $0,0 \%$ \\
Co ppm & 12 & 12 & 7 & 6 & 168 & $0,0 \%$ \\
Cr ppm & 30 & 32 & 25 & 19 & 77 & $0,0 \%$ \\
Cu ppm & 18 & 18 & 17 & 14 & 32 & $0,0 \%$ \\
Ni ppm & 15 & 18 & 12 & 8 & 109 & $0,0 \%$ \\
Pb ppm & 13 & 13 & 11 & 10 & 37 & $0,0 \%$ \\
V ppm & 58 & 63 & 53 & 47 & 78 & $0,0 \%$ \\
Y ppm & 18 & 20 & 16 & 14 & 103 & $0,0 \%$ \\
Zn ppm & 54 & 57 & 47 & 38 & 88 & $0,0 \%$ \\
pH & 7 & 6,5 & 6,5 & -- & 8 & $2,2 \%$ \\
Rad- $\gamma \mathrm{q} / \mathrm{s}$ & 80 & 80 & 80 & 80 & 1 & $88 \%$
\end{tabular}

A correção foi efetuada dividindo os teores das amostras de cada grupo definido pelo material coletado, pela mediana do grupo. Posteriormente foi efetuado um novo Teste de Kruskallwallis, sendo obtida uma sensível queda dos valores das estatísticas para os 12 elementos. O Co apresentou a maior estatística, com um valor de 7,4 e significância de $6 \%$, seguido pelo Cu com um valor de 2,2 e significância de $54 \%$.

Uma vez corrigido o efeito do material amostrado, o teste de Kruskall-Wallis foi aplicado sobre a classificação em função 
dos tipos litológicos dos mapas na escala $1 / 50.000$ ou 1/100.000. os resultados são apresentados na Tabela 10 e nos gráficos de box para Fe (Figura 19), Mn (Figura 20), Ni (Figura 21), Pb (Figura 22) e $\mathbf{Y}$ (Figura 23). Nessas Figuras são expostos os quartis, a amplitude e o número de amostras para cada litotipo considerado. As diferenças entre as medianas dos grupos extremos sugerem a validade do teste, mesmo para os elementos com erros de amostragem importantes, como $\mathbf{P}$, Co $\mathrm{e} \mathbf{Y}$. Observe-se que somente seis dos dezoito grupos definidos pelo litotipo das rochas de procedência mostraram valores extremos (Tabela 10). Os litotipos enriquecidos são, em geral, termos máficos da Formação Pavas (AXV, MUM e GRAN).

Tabela 10. Resultados do teste de Kruskall-Wallis considerando 0 efeito do litotipo da rocha de procedência. As diferenças relativas-D.R. foram calculadas em função dos postos medios extremos (Máximo-minimo/Máximo). Os "Litotipos extremos" correspondem ao posto medio inferior e superior respectivamente. SCEN= Sedimentos Cenozoicos, GRAMA= Granito Marfa Albina, $\mathrm{AXV}=$ Anfibolitos-Xistos verdes, $\mathrm{MUM}=$ Rochas mafico-ultramáficas e GRAN= Granito a anfibolio.

$\begin{array}{ccccc}\text { Variável } & \text { Estatistica } & \text { Significâncla } & \text { D.R. } & \text { Iltotipos extremos } \\ \text { Fe } & 702 & 0,0 \% & 86 \% & \text { SCEN - MUM } \\ \text { Mn } & 66 & 0,0 \% & 49 \% & \text { GRAMA - GRAN } \\ \text { P } & 279 & 0,0 \% & 64 \% & \text { SCEN - GRAN } \\ \text { Ba } & 277 & 0,0 \% & 69 \% & \text { GRAMA - GRAN } \\ \text { Co } & 235 & 0,0 \% & 69 \% & \text { GRAMA - MUM } \\ \text { Cr } & 789 & 0,0 \% & 92 \% & \text { SCEN - MUM } \\ \text { Cu } & 575 & 0,0 \% & 80 \% & \text { SCEN - MUM } \\ \text { Ni } & 717 & 0,0 \% & 89 \% & \text { SCEN - MUM } \\ \text { Pb } & 233 & 0,0 \% & 74 \% & \text { AXV - GRAMA } \\ \text { V } & 531 & 0,0 \% & 78 \% & \text { SCEN - AXV } \\ \mathbf{Y} & 866 & 0,0 \% & 80 \% & \text { SCEN - AXV } \\ \text { Zn } & 500 & 0,0 \% & 78 \% & \text { SCEN - GRAN }\end{array}$

\subsubsection{Distribuição espacial univariada}

Para analisar a distribuição geográfica das variáveis foram elaborados mapas de círculos simples, como os de pH (Figura 24) e de $\operatorname{Rad}-\gamma$ (Figura 25), ou aqueles que incluíram as feições geológicas sobrepostas, como os de Fe (Mapa 1), P (Mapa 2), Ba (Mapa 3) e Cr (Mapa 4). Esses últimos, desenvolvidos no Serviço 


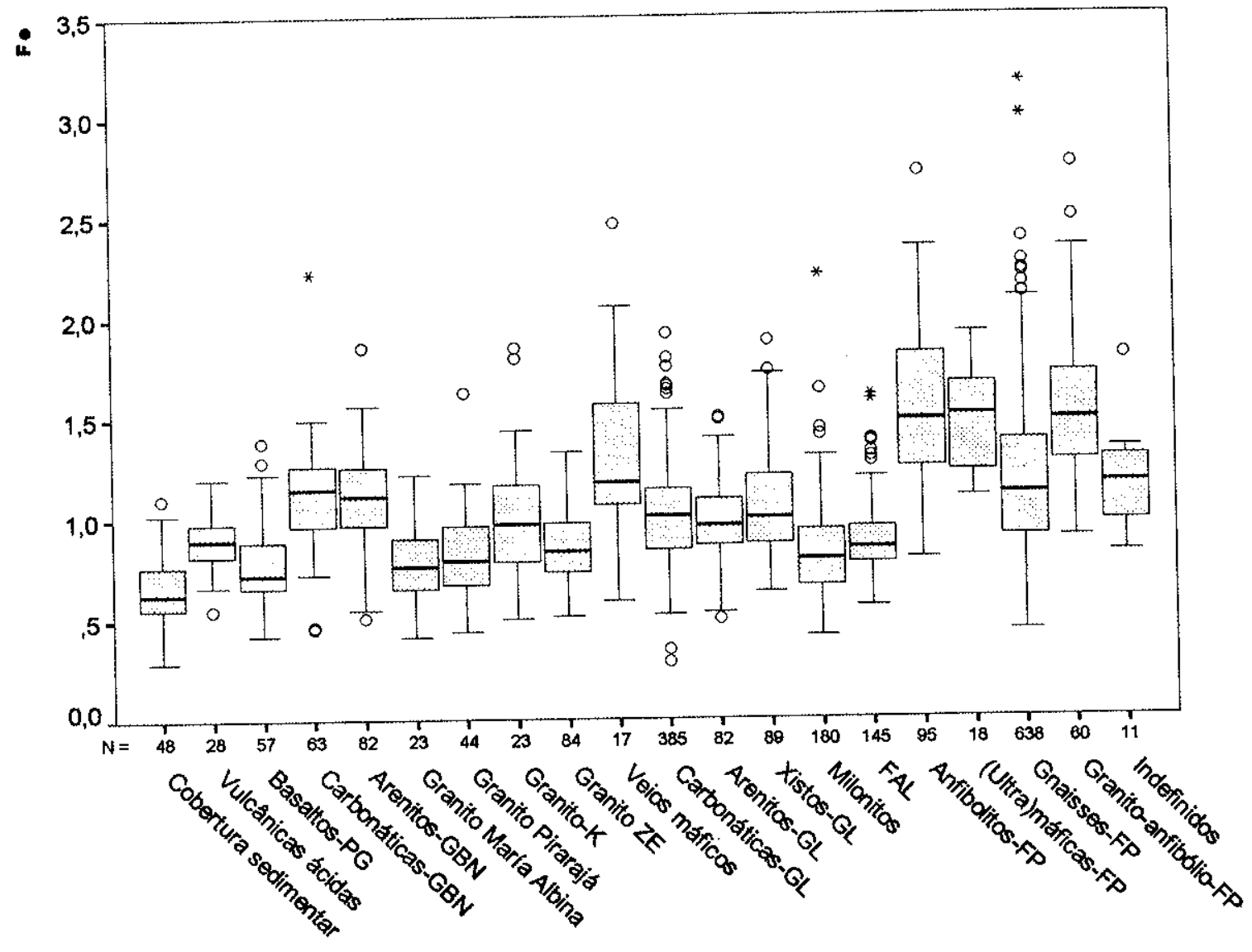

Lltotipo assoclado (mapa)

Figura 19. Gráfico de box para o Fe, dividido pela mediana de cada grupo definido pelo material amostrado, mostrando a influência do litotipo associado. As barras horizontais na base, no centro e no topo de cada retângulo representam os quartis $25 \%, 50 \%$ (mediana) e $75 \%$ de cada grupo. As barras horizontais nos extremos das linhas verticais, indicam o mínimo e o máximo das sub-populações sem outliers (círculos), nem amostras extremas (asteriscos). Nesse caso, as outliers \{amostras extremas\} são aquelas amostras afastadas mais de $1,5\{3,0\}$ vezes a distância inter-quartis em relação ao quartil $25 \%$ ou $75 \%$. Algumas amostras foram descartadas para melhorar a expressão do gráfico. $\mathrm{PG}=$ Puerto Gómez, GBN = Grupo Barriga Negra, $\mathrm{ZE}=$ Zócalo del Este, GL = Grupo Lavalleja, FAL $=$ Formação de Anfibolitas-Leptitas e FP $=$ Formação Pavas. 


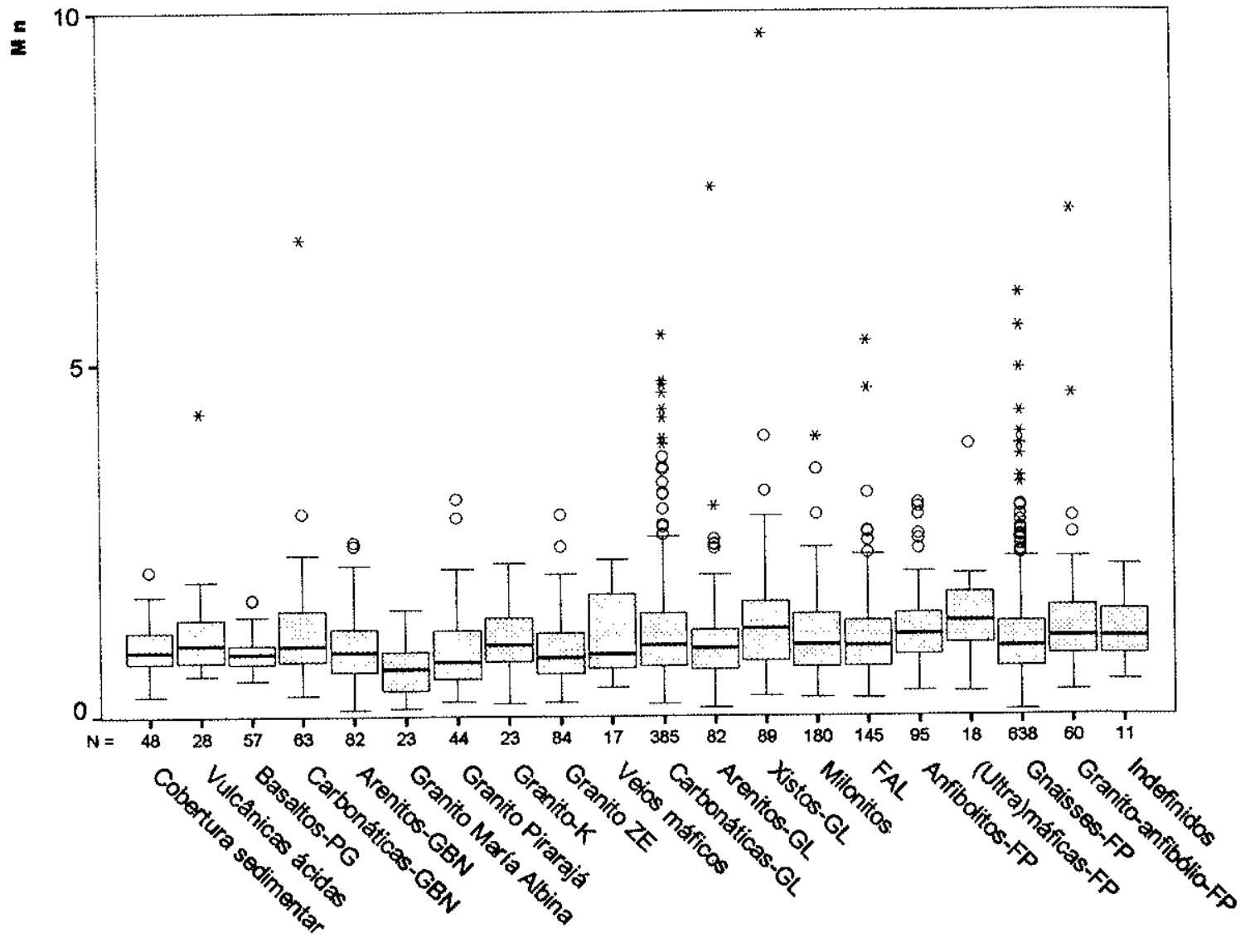

Litotipo associado (mapa)

Figura 20. Gráfico de box para o Mn, dividido pela mediana de cada grupo definido pelo material amostrado, mostrando a influência do litotipo associado. As barras horizontais na base, no centro e no topo de cada retângulo representam os quartis $25 \%, 50 \%$ (mediana) e $75 \%$ de cada grupo. As barras horizontais nos extremos das linhas verticais, indicam o mínimo e o máximo das sub-populações sem outliers (círculos), nem amostras extremas (asteriscos). Nesse caso, as outliers \{amostras extremas\} são aquelas amostras afastadas mais de $1,5\{3,0\}$ vezes a distância inter-quartis em relação ao quartil $25 \%$ ou $75 \%$. Algumas amostras foram descartadas para melhorar a expressão do gráfico. $\mathrm{PG}=$ Puerto Gómez, GBN = Grupo Barriga Negra, $\mathrm{ZE}=$ Zócalo del Este, GL $=$ Grupo Lavalleja, FAL = Formação de Anfibolitas-Leptitas e FP = Formação Pavas. 


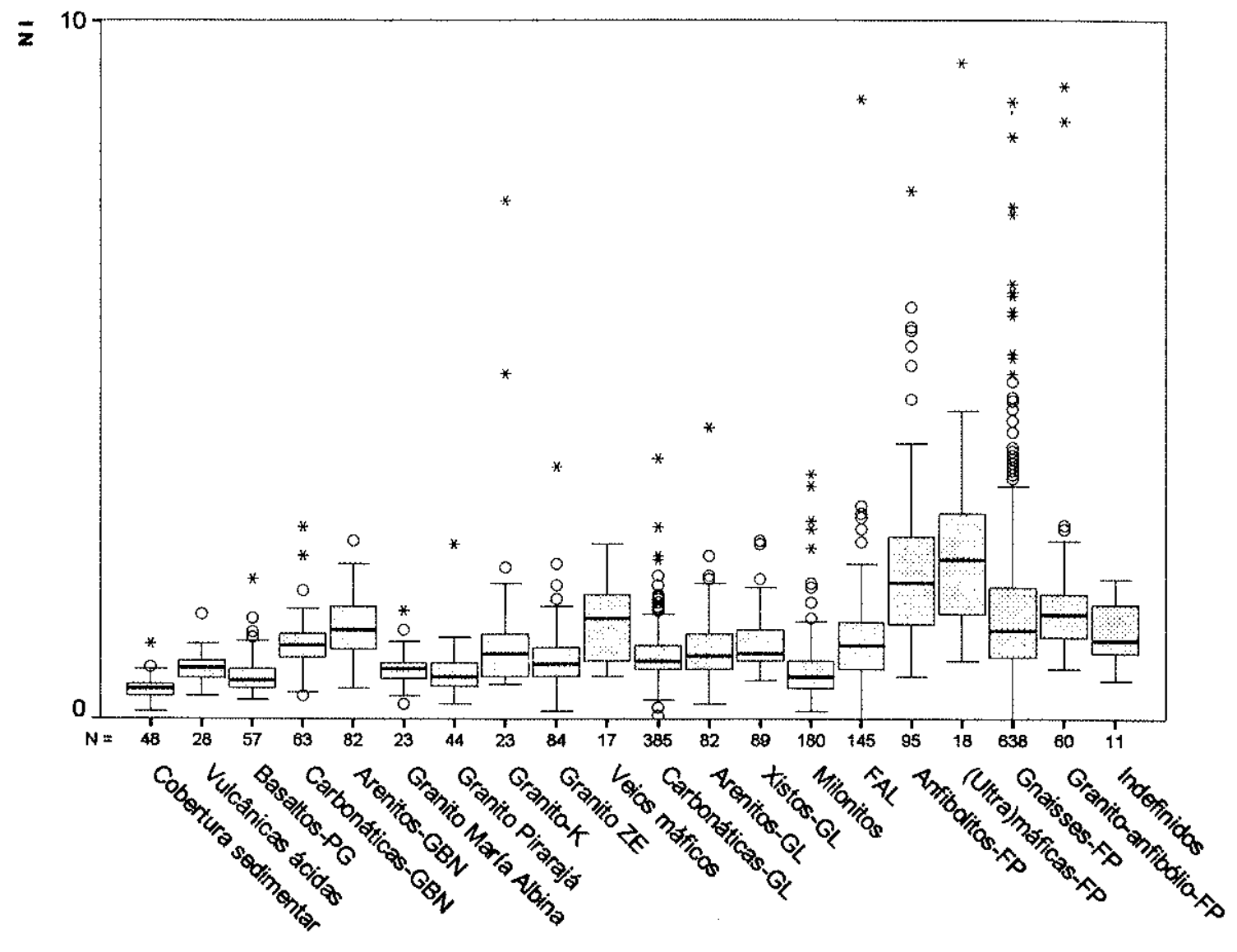

Litotipo associado (mapa)

Figura 21. Gráfico de box para o Ni, dividido pela mediana de cada grupo definido pelo material amostrado, mostrando a influência do litotipo associado. As barras horizontais na base, no centro e no topo de cada retângulo representam os quartis $25 \%, 50 \%$ (mediana) e $75 \%$ de cada grupo. As barras horizontais nos extremos das linhas verticais, indicam o mínimo e o máximo das sub-populações sem outliers (círculos), nem amostras extremas (asteriscos). Nesse caso, as outliers \{amostras extremas\} são aquelas amostras afastadas mais de $1,5\{3,0\}$ vezes a distância inter-quartis em relação ao quartil $25 \%$ ou $75 \%$. Algumas amostras foram descartadas para melhorar a expressão do gráfico. $\mathrm{PG}=$ Puerto Gómez, GBN = Grupo Barriga Negra, $\mathrm{ZE}=$ Zócalo del Este, GL = Grupo Lavalleja, FAL $=$ Formação de Anfibolitas-Leptitas e FP = Formação Pavas. 


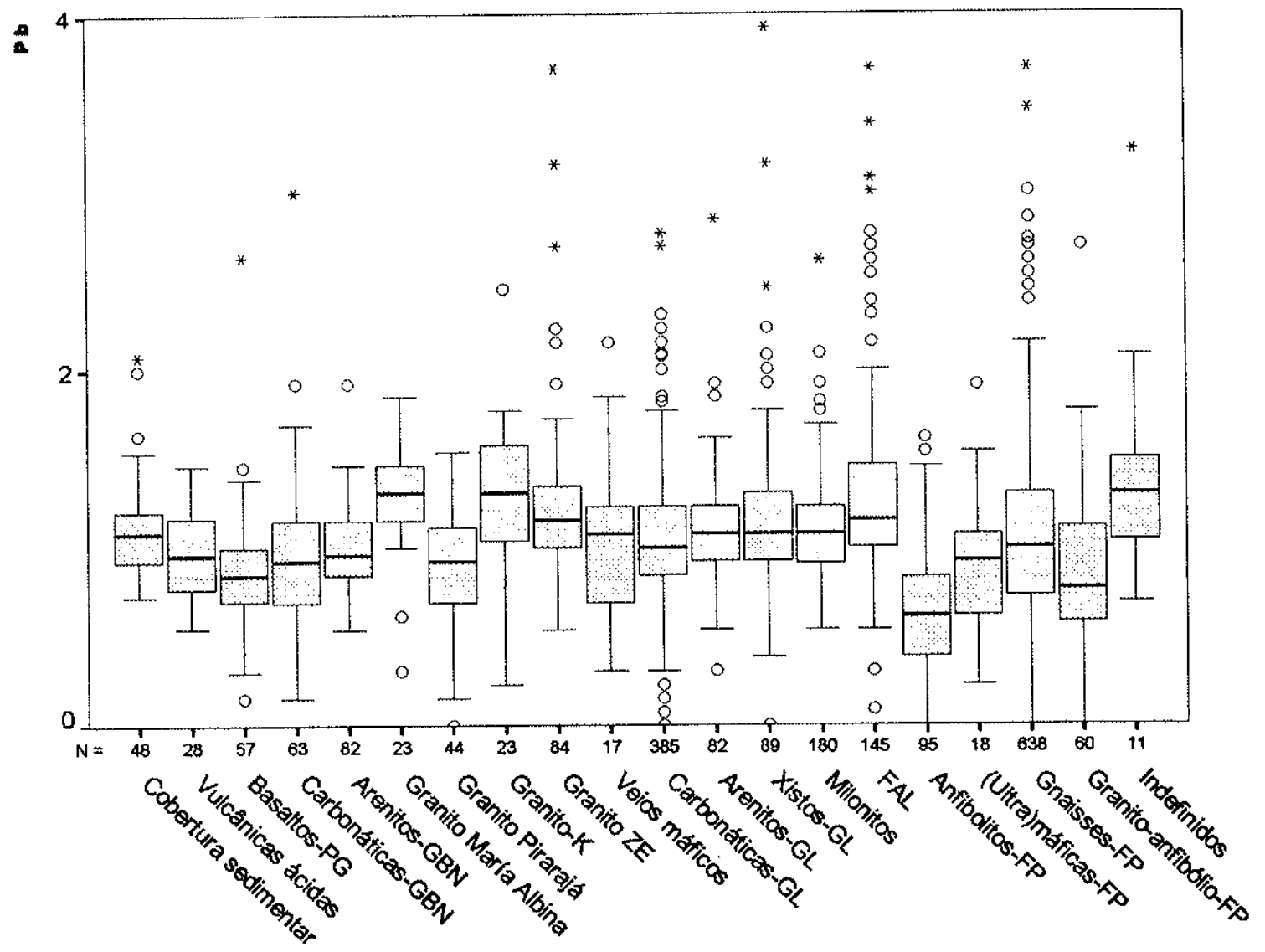

Litotipo associado (mapa)

Figura 22. Gráfico de box para o $\mathbf{P b}$, dividido pela mediana de cada grupo definido pelo material amostrado, mostrando a influência do litotipo associado. As barras horizontais na base, no centro e no topo de cada retângulo representam os quartis $25 \%, 50 \%$ (mediana) e $75 \%$ de cada grupo. As barras horizontais nos extremos das linhas verticais, indicam o mínimo e o máximo das sub-populações sem outliers (círculos), nem amostras extremas (asteriscos). Nesse caso, as outliers \{amostras extremas\} são aquelas amostras afastadas mais de $1,5\{3,0\}$ vezes a distância inter-quartis em relação ao quartil $25 \%$ ou $75 \%$. Algumas amostras foram descartadas para melhorar a expressão do gráfico. $\mathrm{PG}=$ Puerto Gómez, GBN = Grupo Barriga Negra, $\mathrm{ZE}=$ Zócalo del Este, GL = Grupo Lavalleja, FAL = Formação de Anfibolitas-Leptitas e FP = Formação Pavas. 


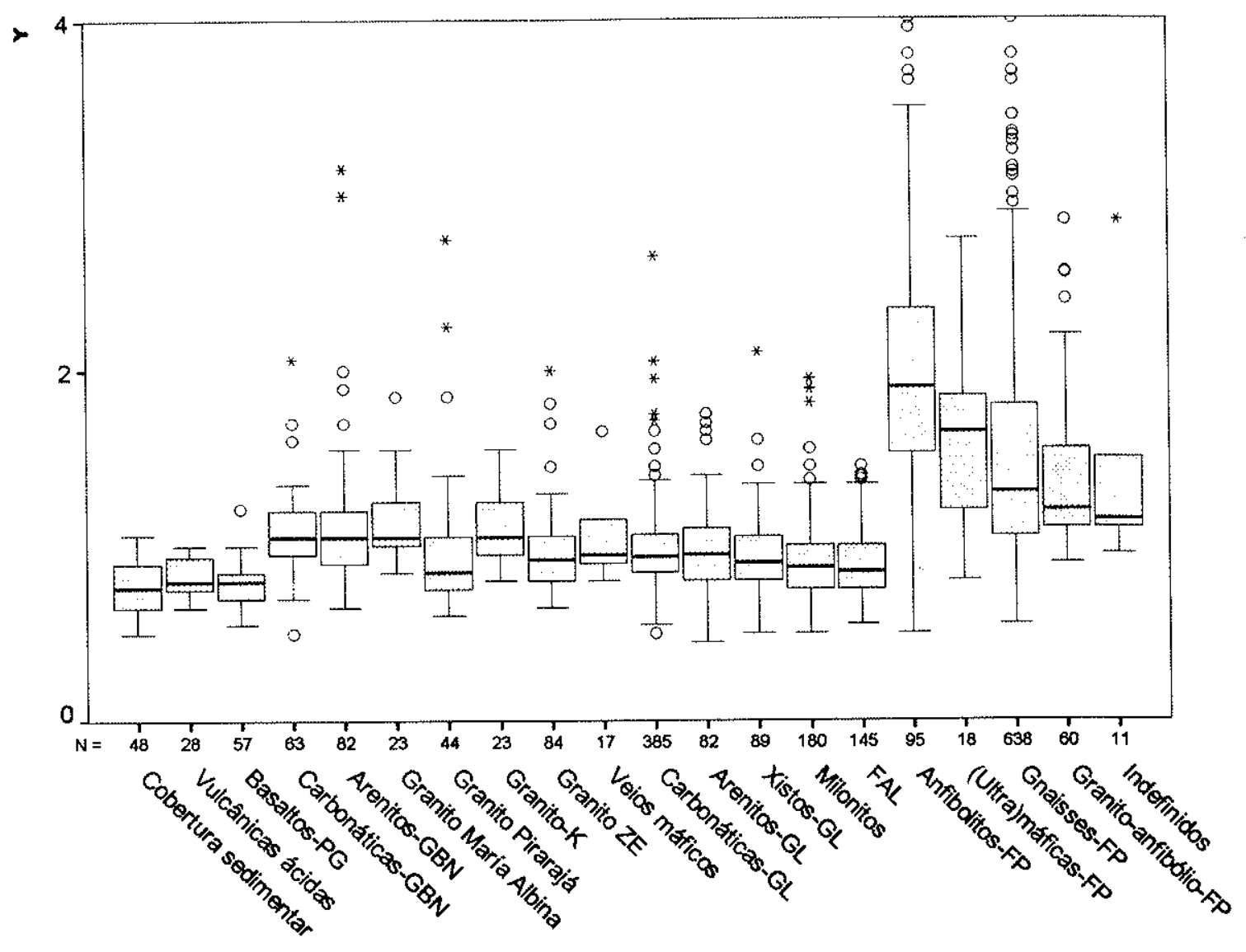

Litotipo associado (mapa)

Figura 23. Gráfico de box para o $\mathbf{Y}$, dividido pela mediana de cada grupo definido pelo material amostrado, mostrando a influência do litotipo associado. As barras horizontais na base, no centro e no topo de cada retângulo representam os quartis $25 \%, 50 \%$ (mediana) e $75 \%$ de cada grupo. As barras horizontais nos extremos das linhas verticais, indicam o mínimo e o máximo das sub-populações sem outliers (círculos), nem amostras extremas (asteriscos). Nesse caso, as outliers \{amostras extremas\} são aquelas amostras afastadas mais de $1,5\{3,0\}$ vezes a distância inter-quartis em relação ao quartil $25 \%$ ou $75 \%$. Algumas amostras foram descartadas para melhorar a expressão do gráfico. PG $=$ Puerto Gómez, GBN = Grupo Barriga Negra, $\mathrm{ZE}=$ Zócalo del Este, GL = Grupo Lavalleja, FAL = Formação de Anfibolitas-Leptitas e FP = Formação Pavas. 


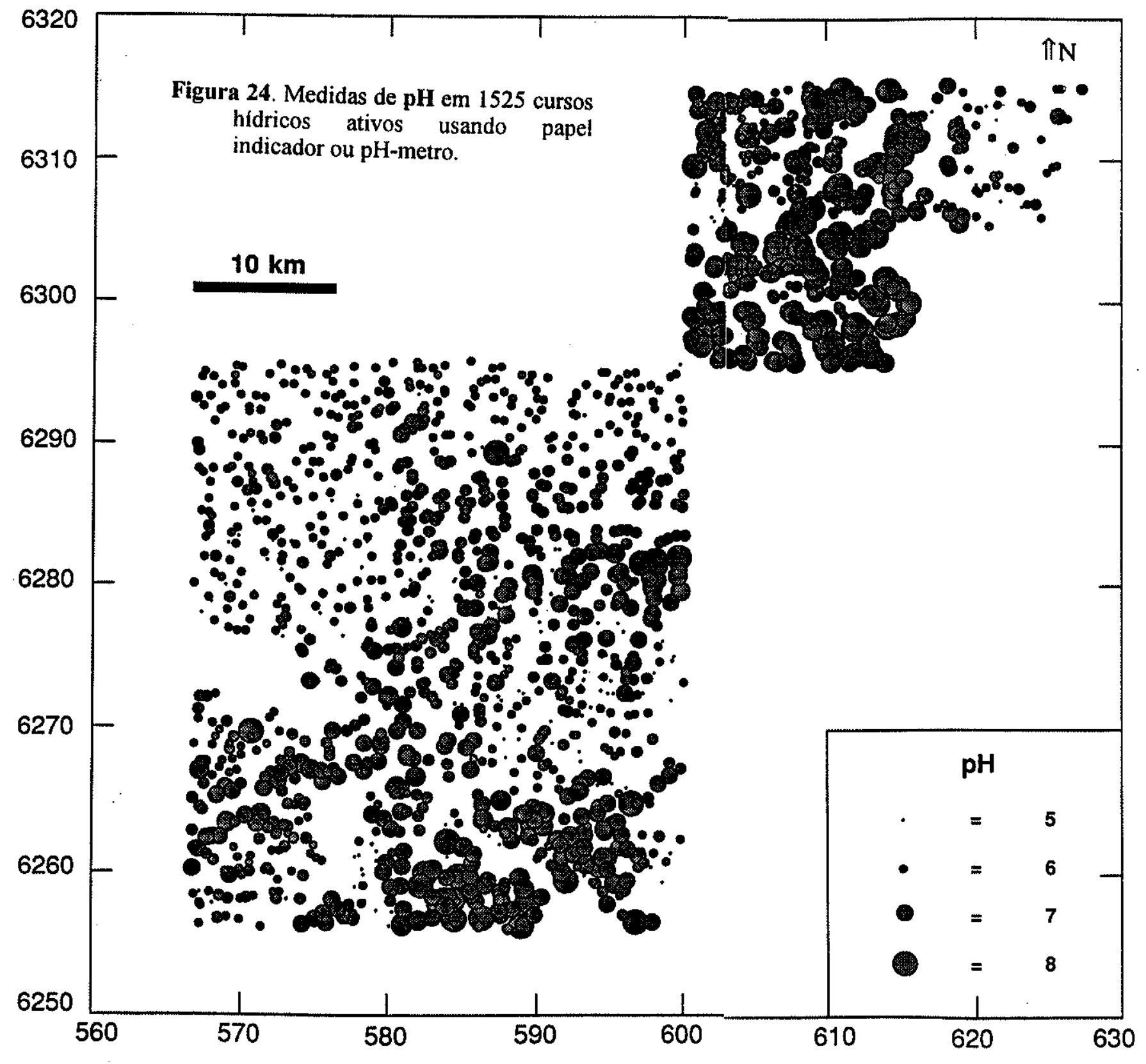




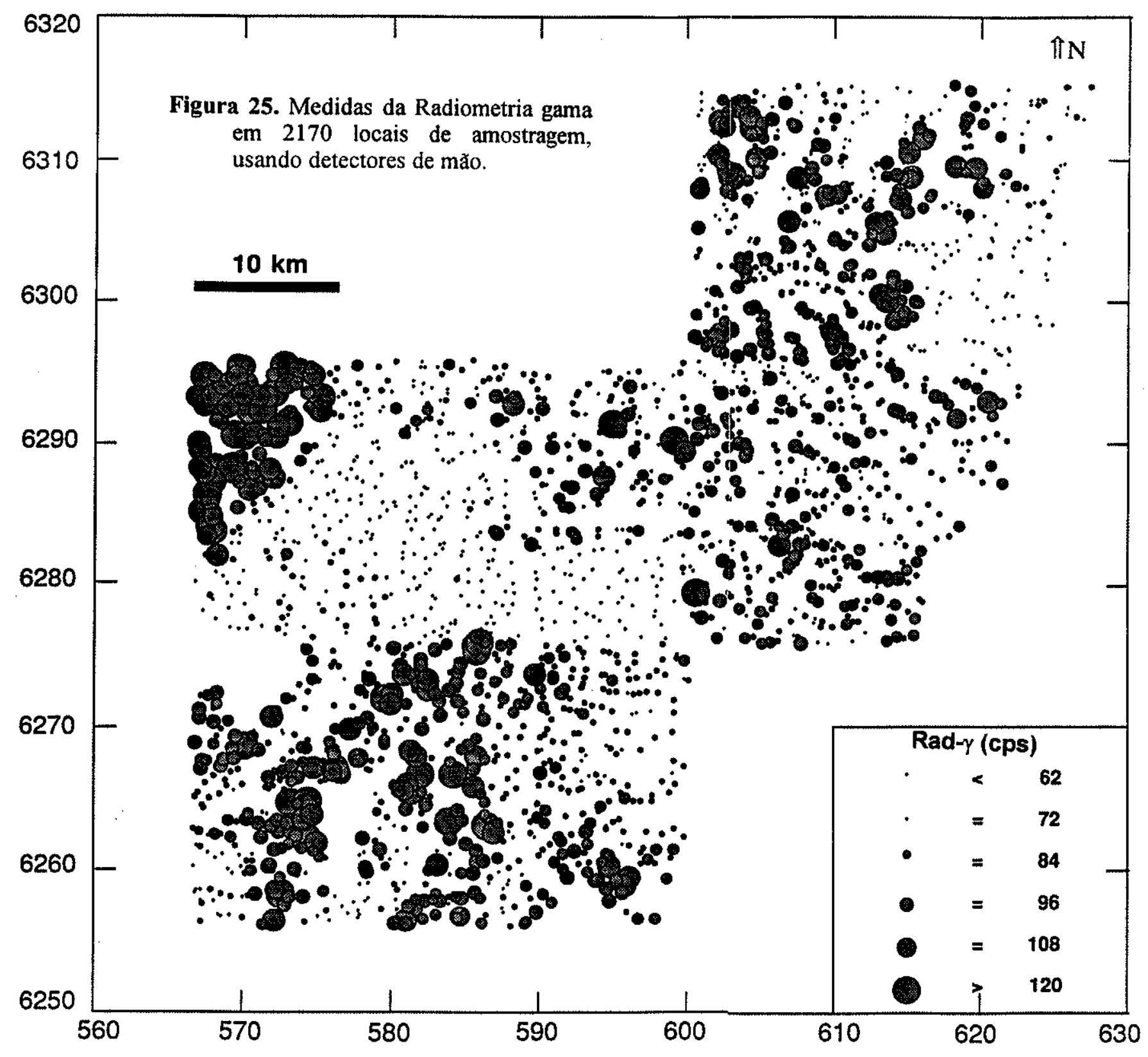




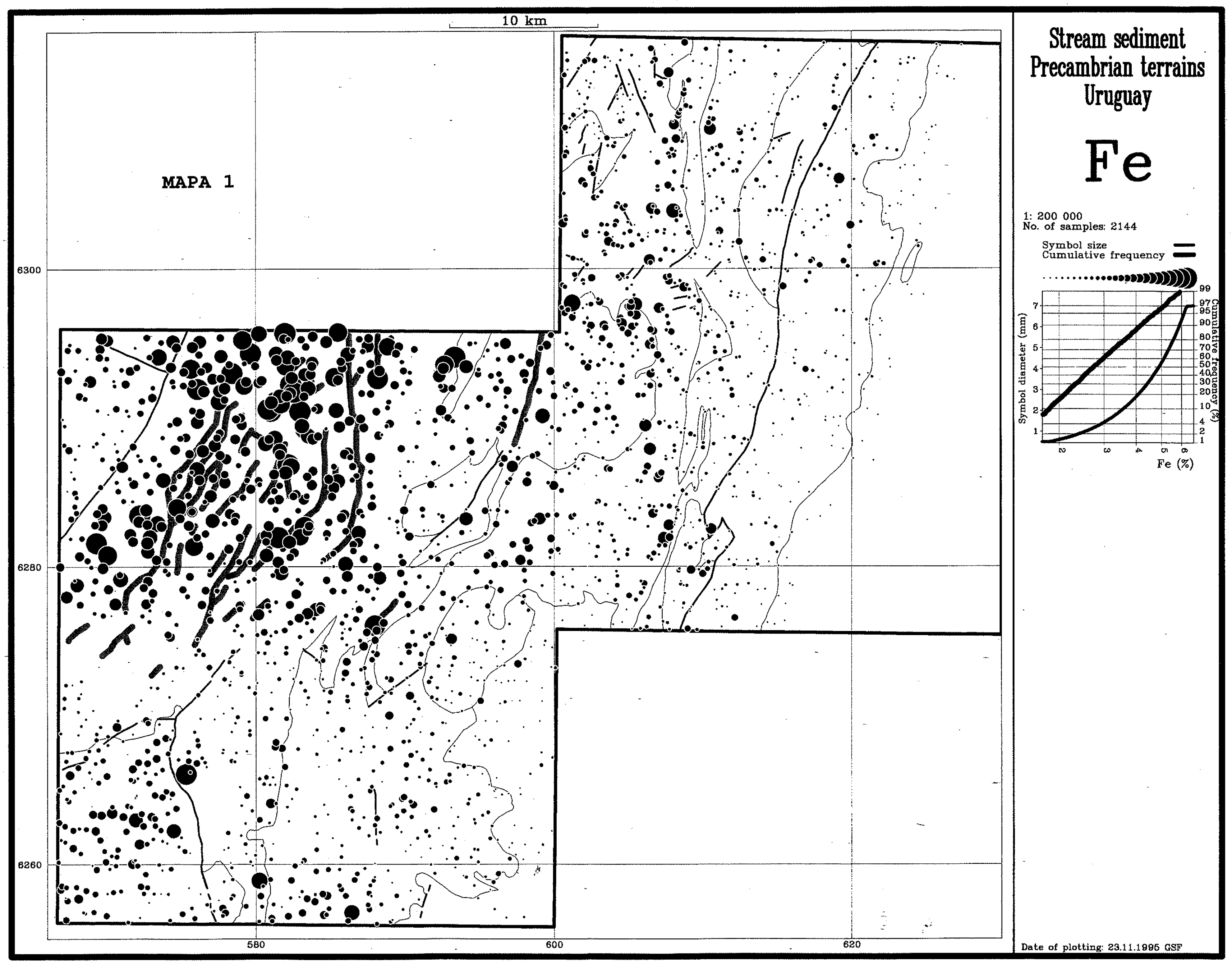




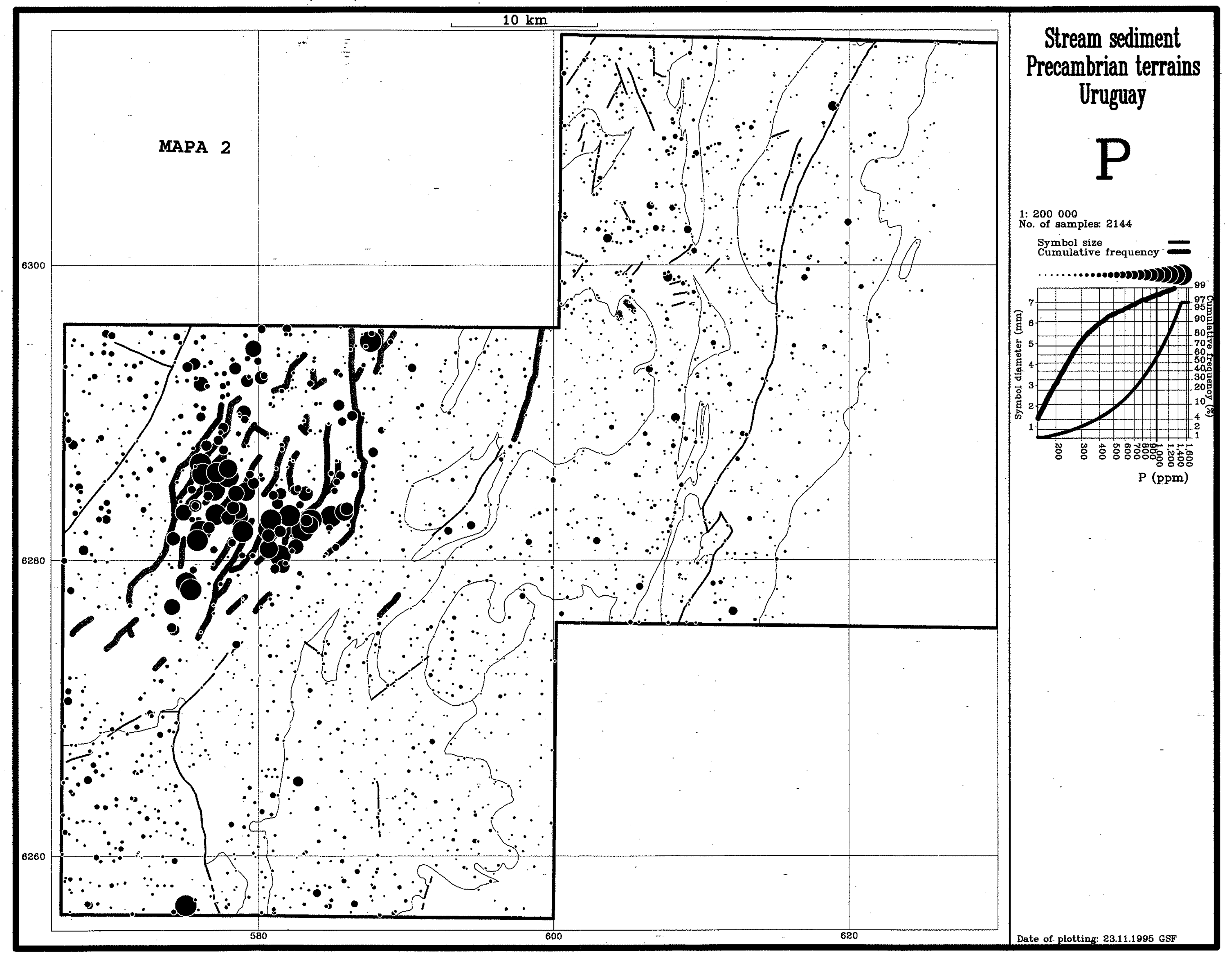




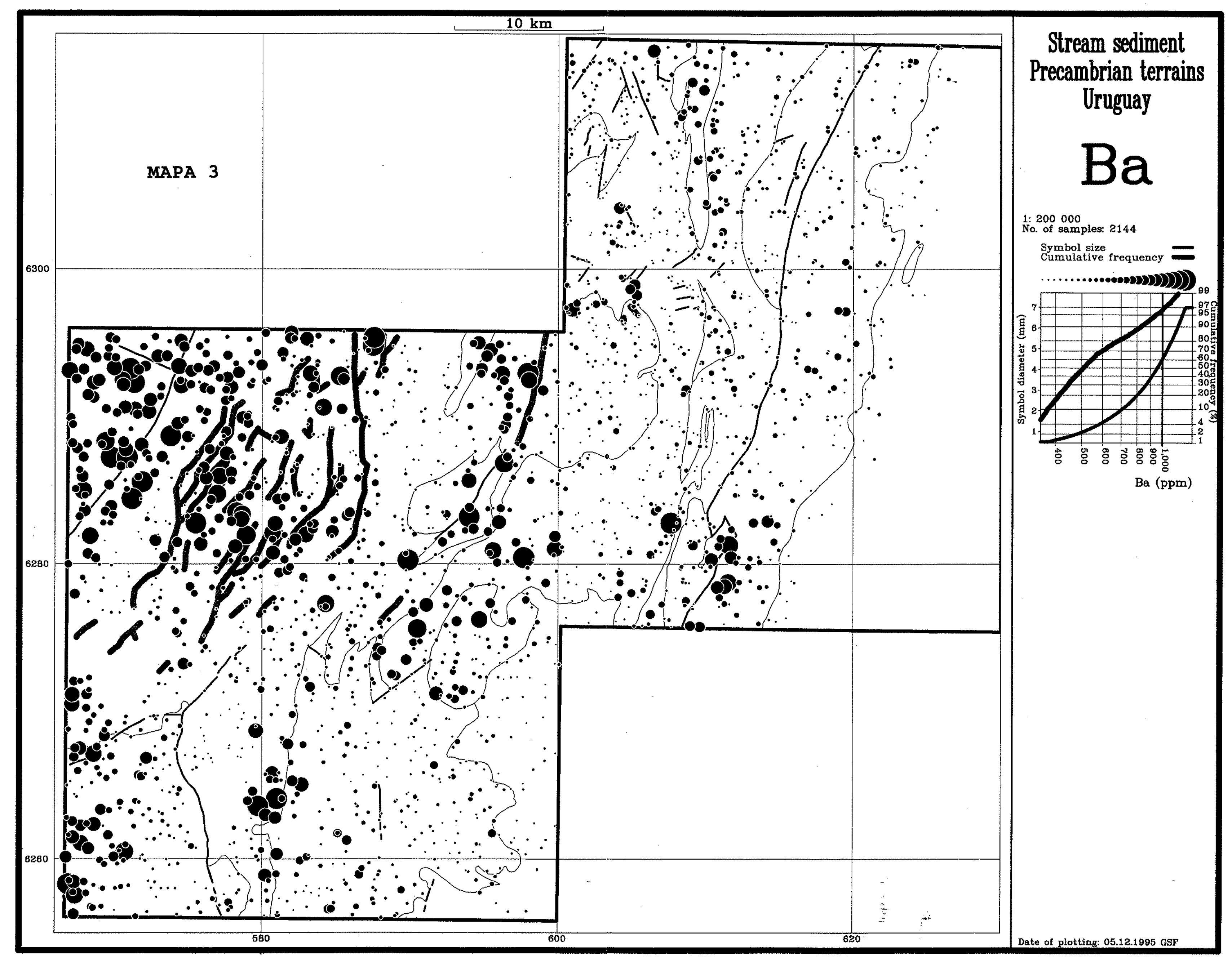




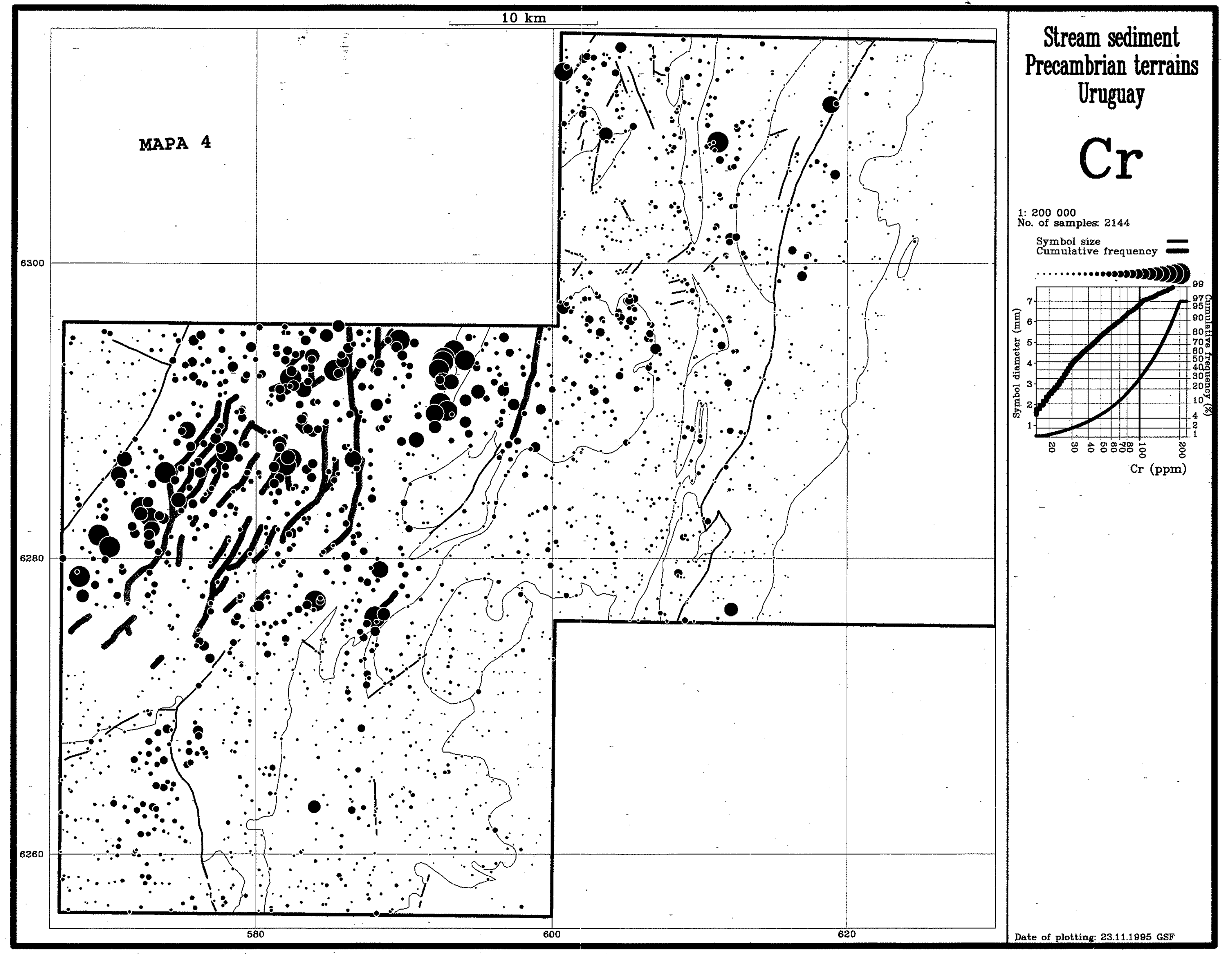


Geológico da Finlândia, foram elaborados de maneira que o raio dos círculos aumenta em forma proporcional ao teor do elemento mapeado. Para os elementos químicos foram considerados os teores brutos, sendo eliminadas as amostras de solos autóctones por serem as mais empobrecidas. Mapas desse tipo foram elaborados para todas as variáveis disponíveis.

\subsubsection{Análige das correlações}

Na Tabela 11 são expostos os coeficientes de Pearson e de Spearman, multiplicados por 100, dos doze elementos escolhidos para o tratamento estatístico multivariado. Ambos representam uma medida do grau de dependência entre duas variáveis, porém o coeficiente de Spearmam usa um método não paramétrico. No caso de existir dependência entre as duas variáveis, $\circ$ valor do coeficiente de correlação será proximo de -1 ou $+1(-100$ ou +100 na Tabela 11), no caso de correlação negativa ou positiva, e será nulo ou próximo ao zero, no caso de independência.

Tabela 11. Coeficientes de correlaçăo de Pearson (acima da diagonal) e de Spearman (abaixo da diagonal) significativos ao nivel de $1 \%$ e expressos em percentagem (vezes 100). No caso de Pearson foram usados os dados em logaritmos, e divididos pelas medianas segundo o material amostrado, sendo consideradas 2172 amostras. Para Spearmam foram ellminadas 28 amostras de significancia de $1 \%$.

\begin{tabular}{|c|c|c|c|c|c|c|c|c|c|c|c|}
\hline $\mathrm{Fe}$ & $\mathrm{Mn}$ & P & $\mathbf{B a}$ & Co & Cr & $\mathrm{Cu}$ & N1 & $\mathrm{Pb}$ & v & $\mathbf{Y}$ & zn \\
\hline 100 & 40 & 37 & 36 & 73 & 71 & 66 & 74 & -15 & 81 & 60 & 71 \\
\hline 39 & 100 & 15 & 31 & 73 & 14 & 27 & 30 & 13 & 28 & 10 & 39 \\
\hline 30 & 11 & 100 & 37 & 18 & 23 & 20 & 24 & -29 & 25 & 31 & 38 \\
\hline 35 & 33 & 29 & 100 & 29 & 13 & 18 & 19 & 7 & 28 & 30 & 38 \\
\hline 70 & 73 & 9 & 29 & 100 & 53 & 51 & 66 & Não & 66 & 30 & 50 \\
\hline 69 & 14 & 21 & 19 & 51 & 100 & 60 & 91 & -21 & 70 & 49 & 49 \\
\hline 67 & 25 & 21 & 18 & 48 & 60 & 100 & 64 & Não & 66 & 35 & 63 \\
\hline 72 & 30 & 22 & 23 & 63 & 91 & 64 & 100 & -15 & 68 & 48 & \\
\hline Não & 17 & -20 & 14 & 14 & -12 & Não & -9 & 100 & Nåo & -23 & Não \\
\hline 80 & 27 & 15 & 27 & 64 & 69 & 66 & 66 & Não & 100 & 49 & 47 \\
\hline 62 & 12 & 23 & 33 & 32 & 53 & 40 & 53 & -8 & 50 & 100 & 47 \\
\hline 70 & 38 & 40 & 38 & 47 & 49 & 64 & 56 & Não & 45 & 51 & 100 \\
\hline
\end{tabular}


Duas fontes de problemas podem complicar a interpretação dos coeficientes de correlação: (i)A existência de valores extremos. (ii) A ocorrência de duas ou mais sub-populações. O efeito dos valores extremos pode ser reduzido transformando os dados, eliminando as amostras extremas ou usando um método não paramétrico. Na Tabela 11 foram usados logaritmos no caso do método de Pearson, que foi comparado com $\circ$ método não paramétrico de Spearman. No primeiro caso foi corrigido o efeito do material amostrado. Quando se observa apenas a tabela dos coeficientes de correlação, a existência de duas ou mais subpopulações pode provocar falsas interpretações. Por esse motivo, é geralmente de utilidade analisar também os diagramas de dispersão. Alguns exemplos são apresentados nas Figuras 26 a 35 , considerando os dados brutos ou log-transformados.

Observe-se que os dois métodos usados para calcular os coeficientes de correlação produziram resultados semelhantes (Tabela 11). Para valores no intervalo $(40 \% ;-40 \%)$, os diagramas de dispersão sugerem ausência de correlação ou possibilidade de correlação para uma sub-população pequena, como no caso de P-Ba (Figura 32) e Zn-P (Figura 35). Para coeficientes de correlação variando entre 40-75\%, duas situações são possíveis: (i) A ocorrência de uma única nuvem, segundo um padrão elíptico, porém disperso, como no caso de Fe-Co (Figura 26), Fe-Y (Figura 29), Fe-zn (Figura 30) e Cu-Co (Figura 34). (ii) A ocorrência de um padrão "triangular", sugerindo a existência de pelo menos duas sub-populações, como no caso de Fe-Cr (Figura 27) e un-Co (Figura 31). Para coeficientes de correlação acima de 75\%, os diagramas de dispersão apresentaram um padrão elíptico com pouca dispersão lateral, como no caso de Fe-V (Figura 28) e Cr-Ni (Figura 33).

Parece portanto, provável que os pares de elementos efetivamente correlacionados seriam aqueles com coeficientes superiores a $40 \%$. Segundo esse critério, Mn, P, Ba e Pb não apresentam correlações entre si, sendo que a única correlação importante com outros elementos seria o par mn-Co. Os demais elementos, em geral, apresentaram correlações com $\circ$ Fe e entre eles. Por esse motivo, achou-se de interesse calcular os coeficientes de correlação parcial controlados pelo Fe para in, 


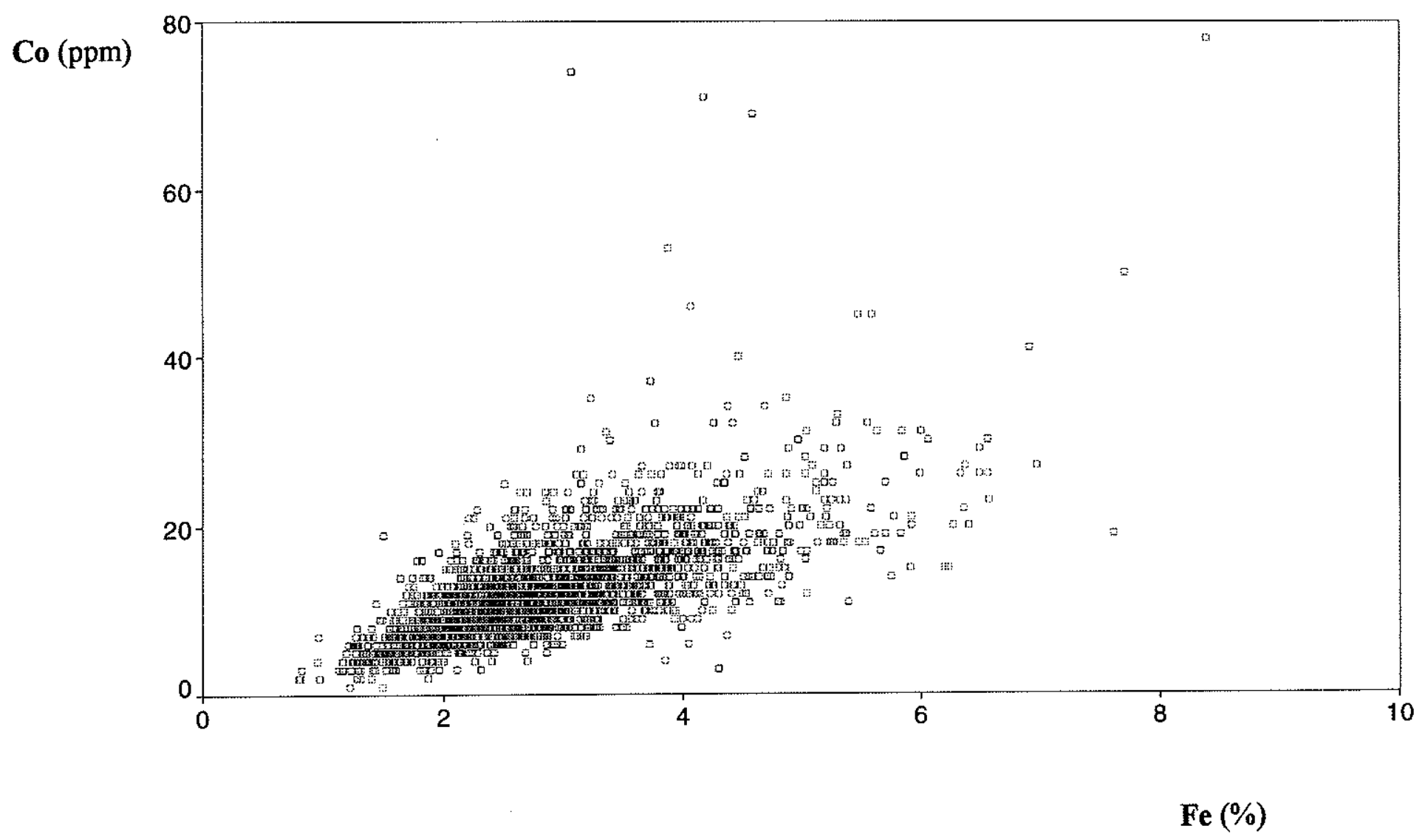

Figura 26. Diagrama de dispersão Fe - Co para os dados geoquímicos originais (2172 amostras) 


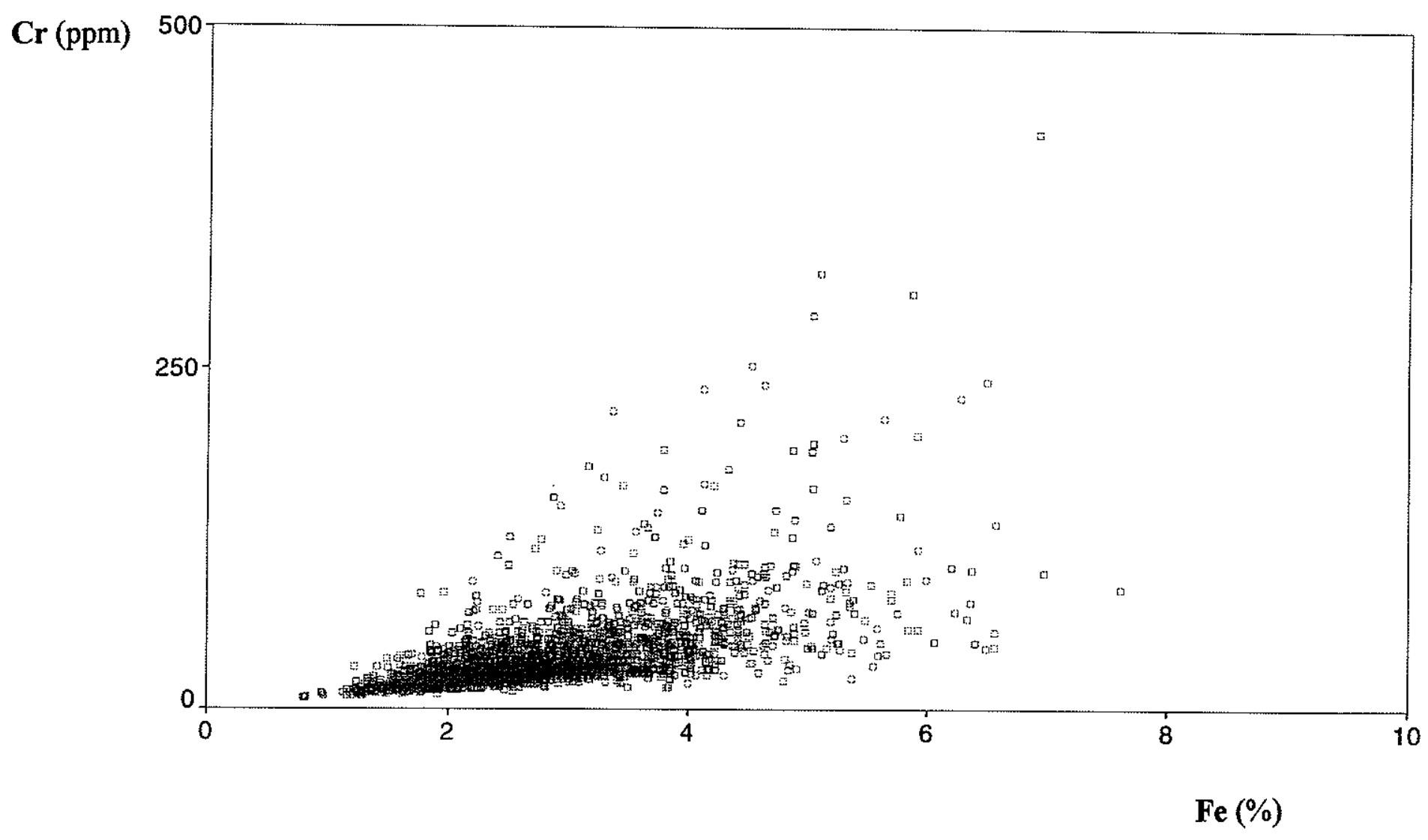

Figura 27. Diagrama de dispersão Fe - Cr para os dados geoquímicos originais (2172 amostras). 


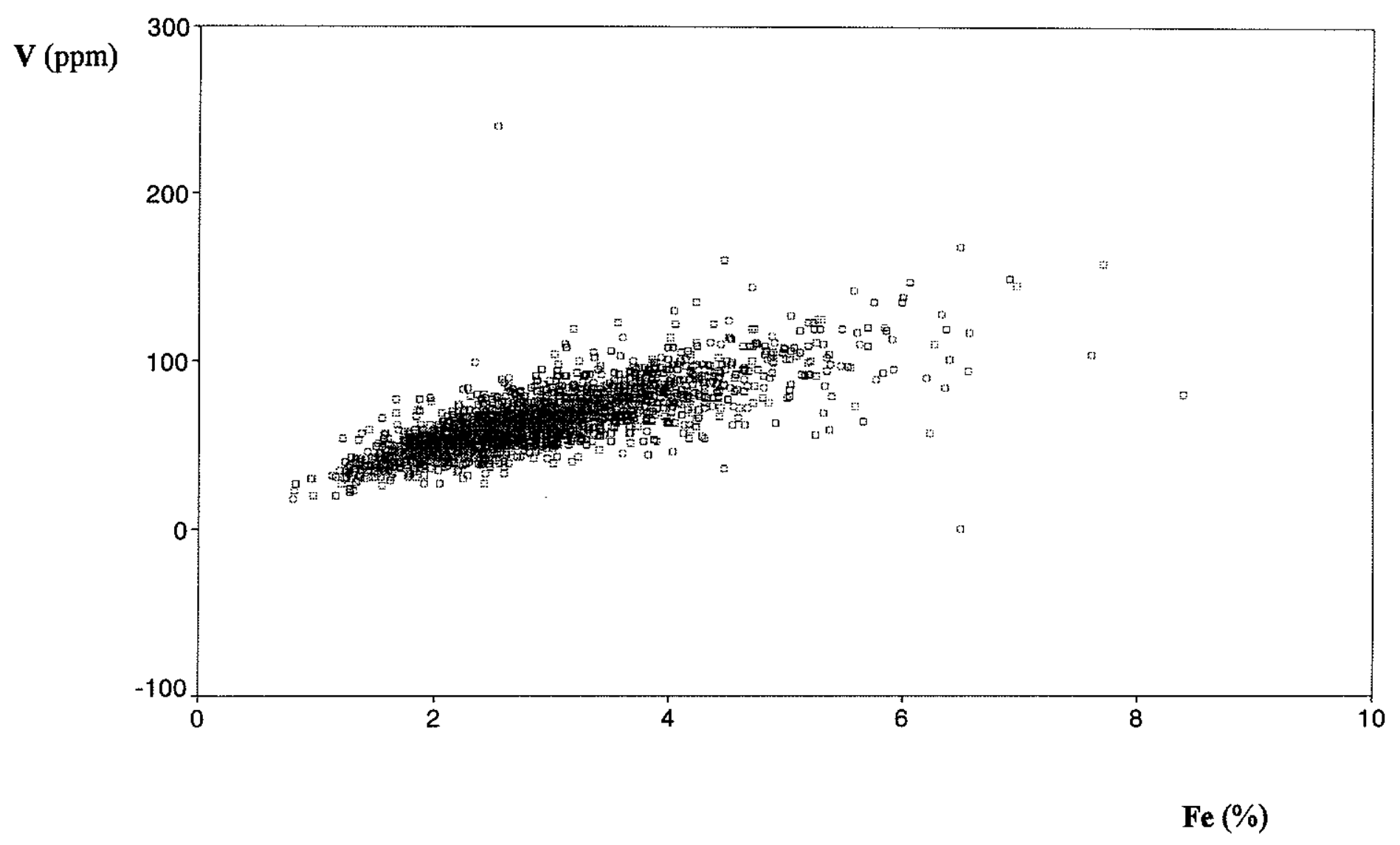

Figura 28. Diagrama de dispersão Fe - V para os dados geoquímicos originais (2172 amostras) 


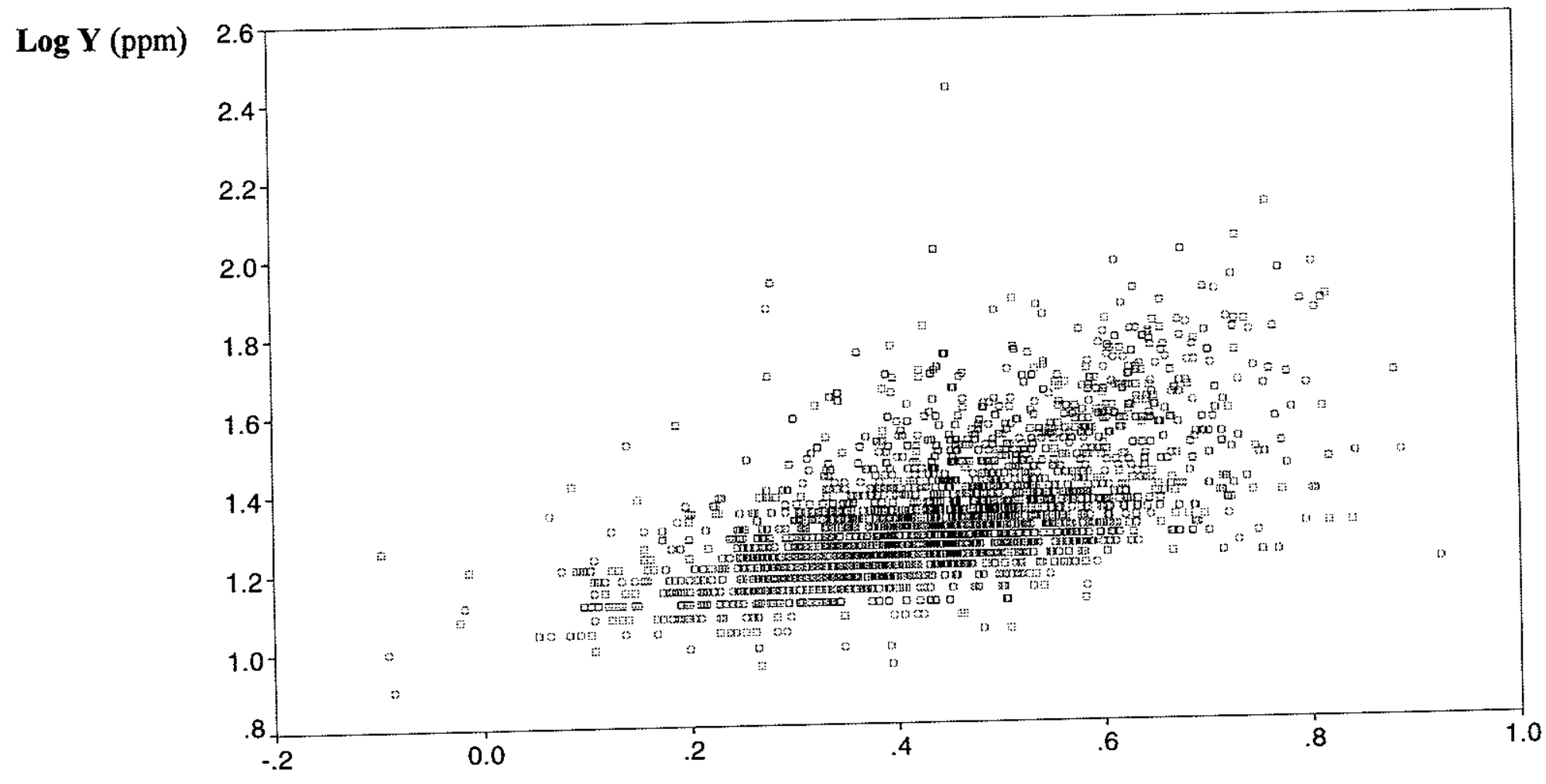

$\log \mathrm{Fe}(\%)$

Figura 29. Diagrama de dispersão Fe - Y para os dados geoquímicos em logaritmos (2172 amostras) 


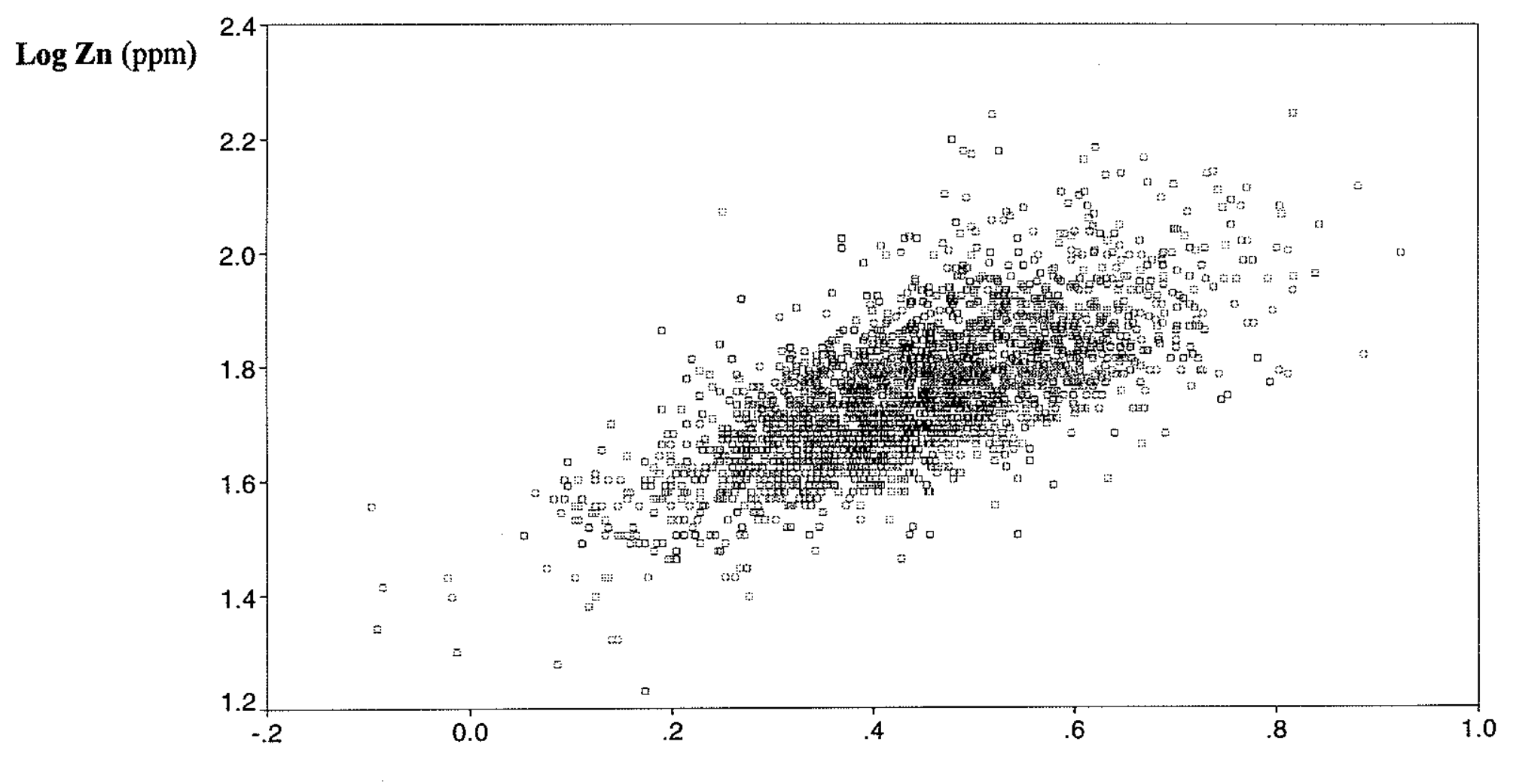

$\log \mathrm{Fe}(\%)$

Figura 30. Diagrama de dispersão Fe - Zn para os dados geoquímicos em logaritmos (2172 amostras) 


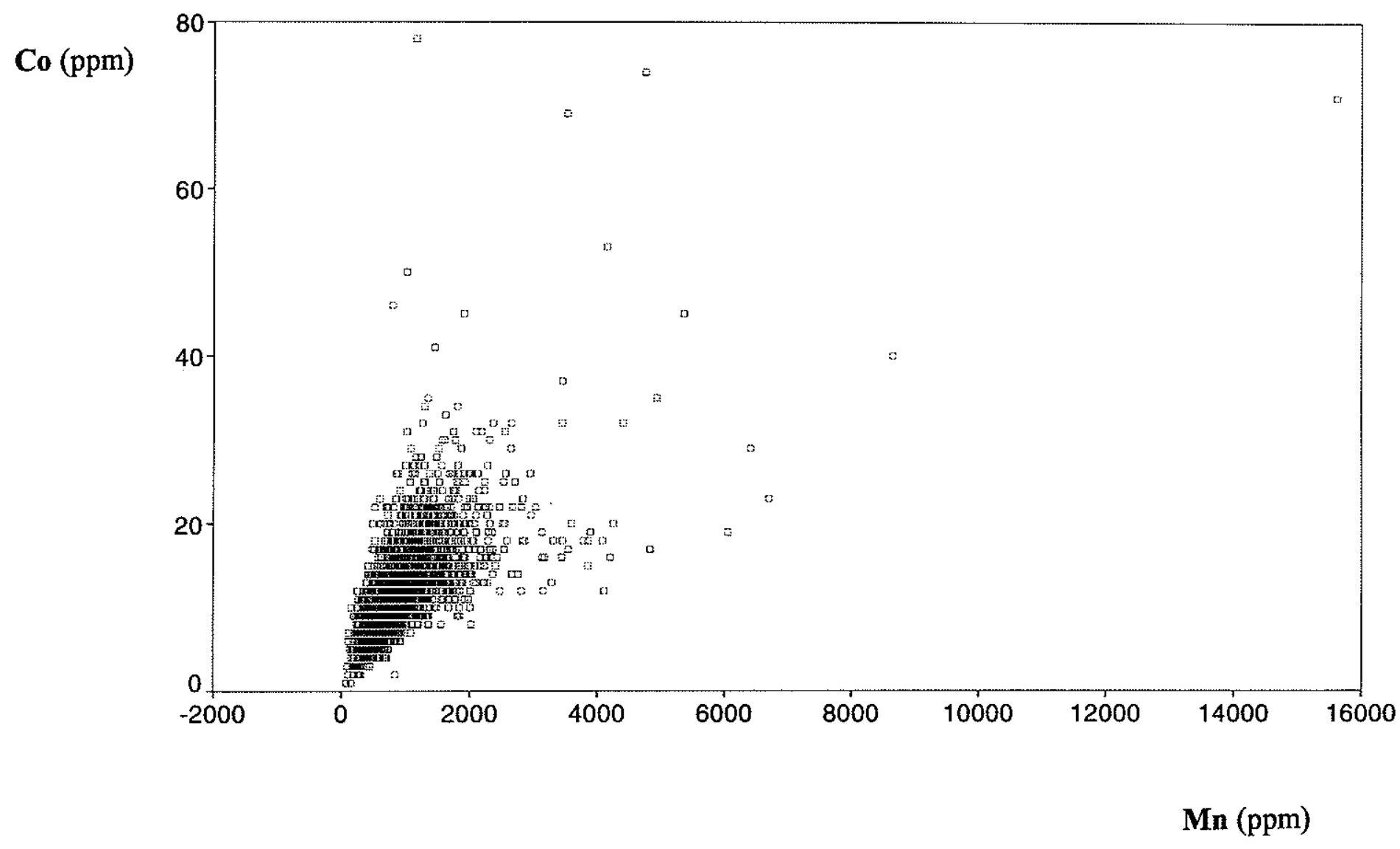

Figura 31. Diagrama de dispersão Co - Mn para os dados geoquímicos originais (2172 amostras). 


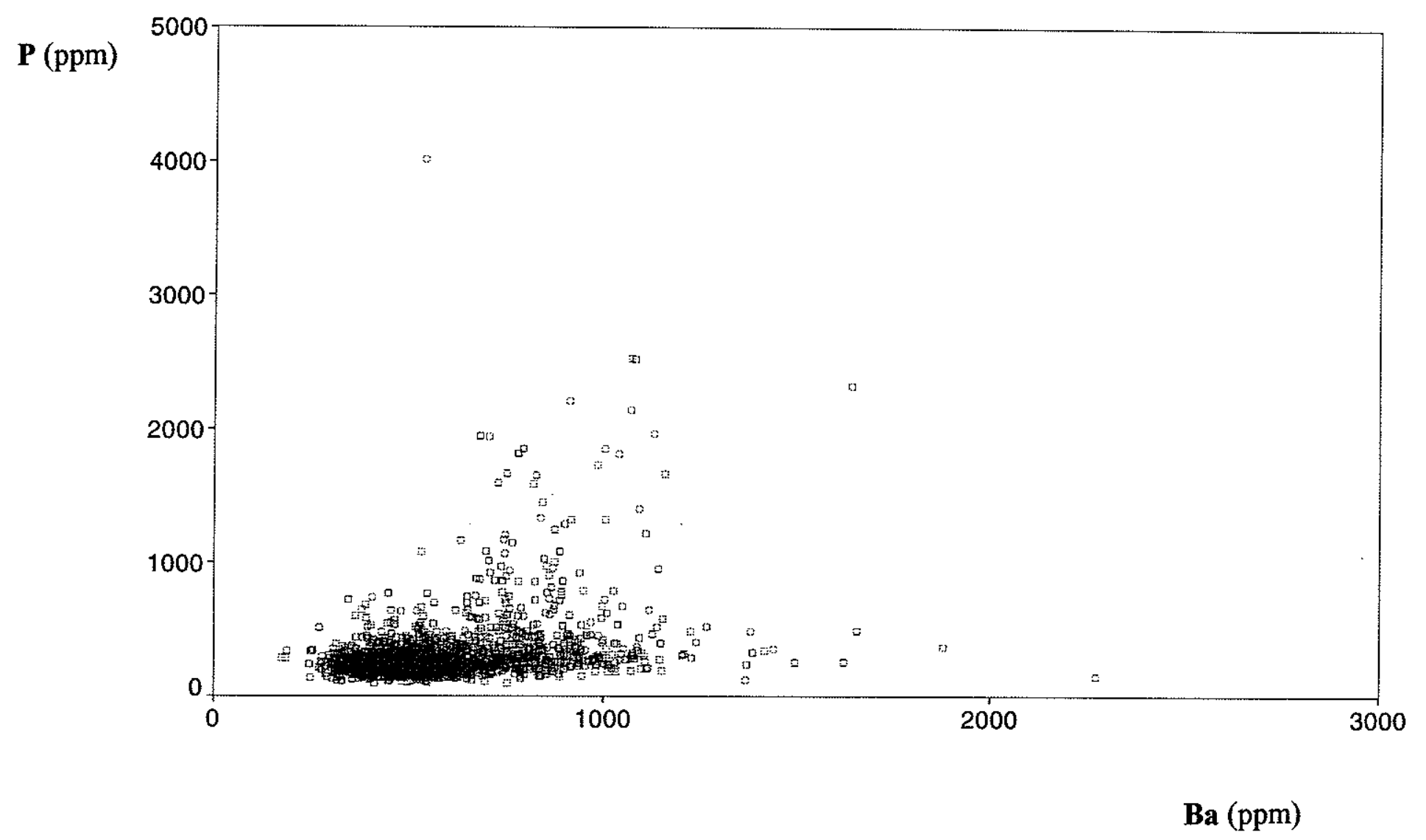

Figura 32. Diagrama de dispersão Ba - P para os dados geoquímicos originais (2172 amostras) 


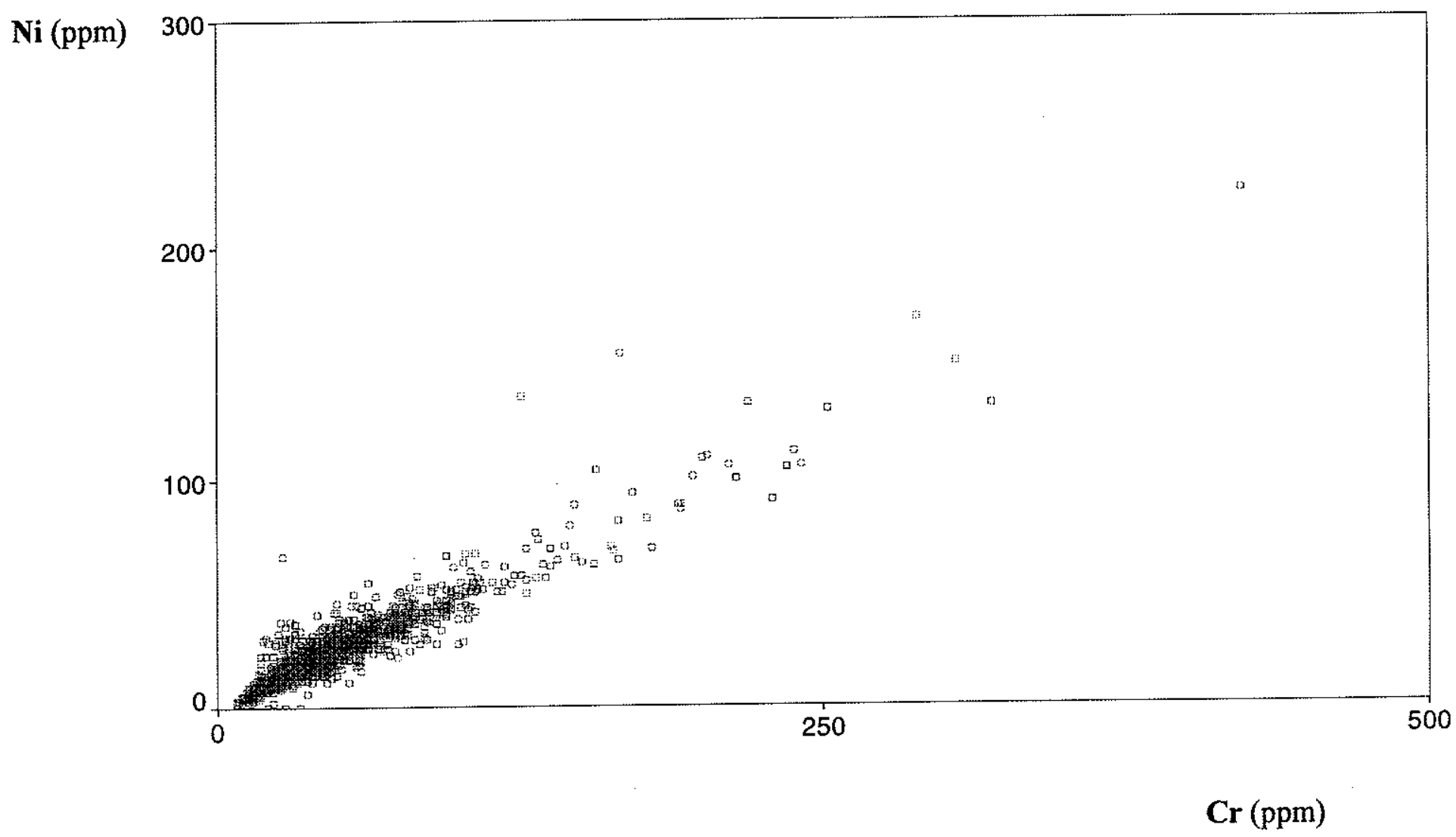

Figura 33. Diagrama de dispersão $\mathbf{C r}$ - Ni para os dados geoquímicos originais (2171 amostras). 


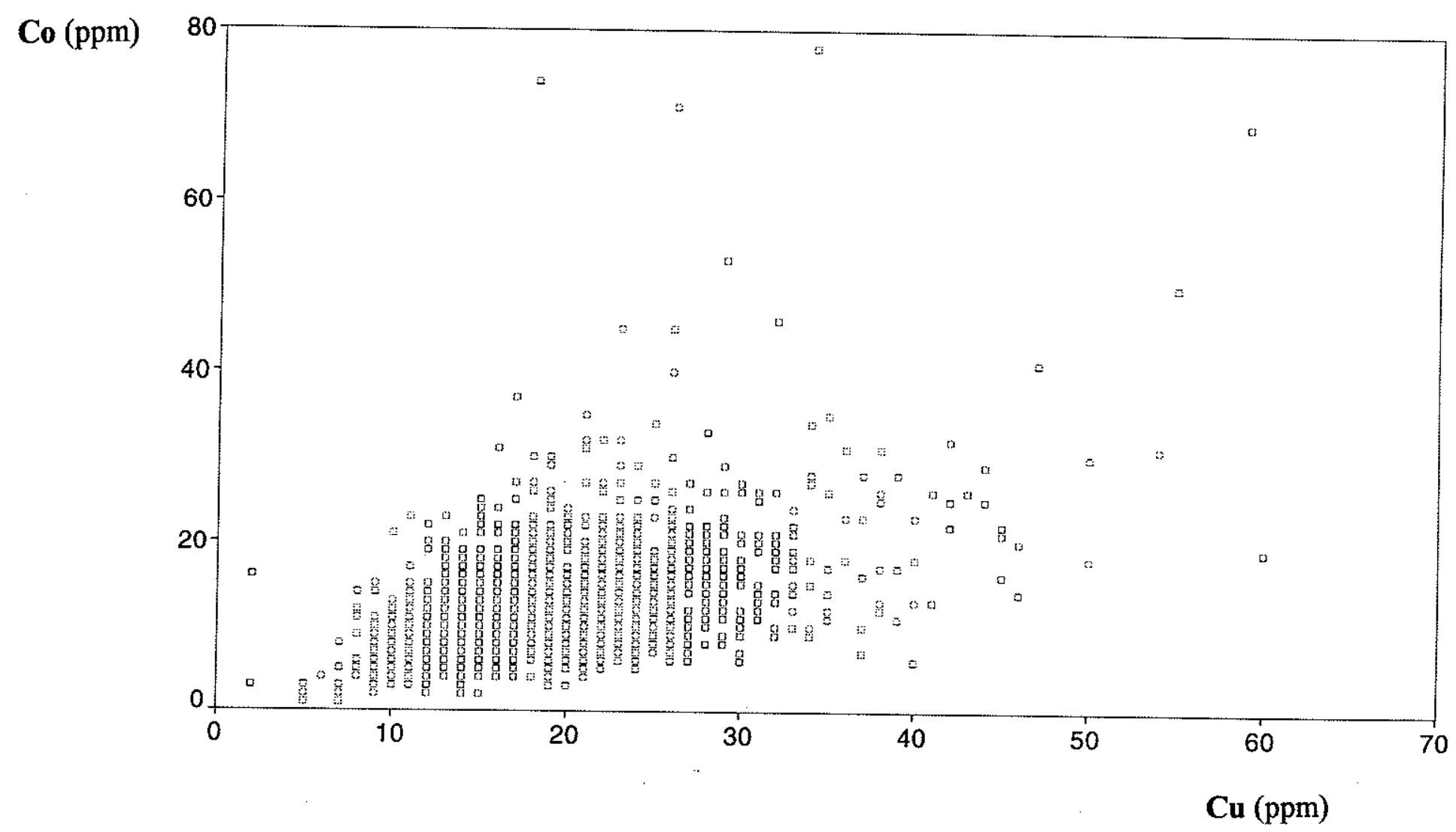

Figura 34. Diagrama de dispersão Cu - Co para os dados geoquímicos originais (2172 amostras). 


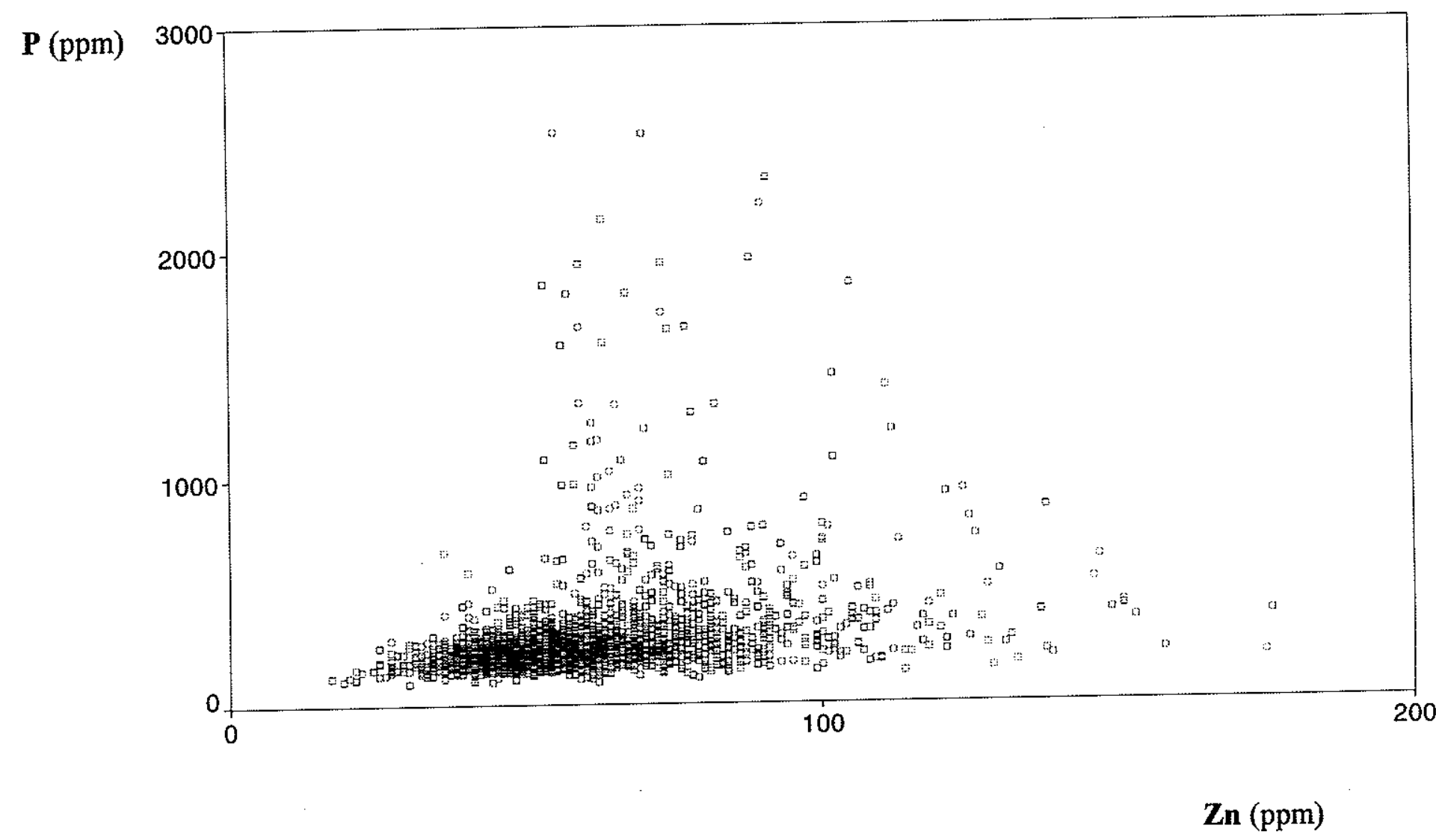

Figura 35. Diagrama de dispersão Zn - P para os dados geoquímicos originais (2172 amostras). 
Co, Cr, Cu, Ni, V, Y e zn (Tabela 12). Com exceção de Mn-Co e Cr-Ni, todos os coeficientes tiveram uma sensível diminuição, o que sugere um forte controle do $\mathbf{F e}$ sobre as correlações entre esses elementos.

Tabela 12. Coeficientes de correlação parcial controlados pelo Fe para $\mathrm{Mn}, \mathrm{Co}, \mathbf{C r}, \mathbf{C u}, \mathbf{N i}, \mathrm{V}, \mathbf{Y}$ e $\mathbf{z n}$. Os dados foram transformados em logaritmos e corrigidos pelo efeito do material amostrado. Os coeficientes foram multiplicados por 100. "Não"= não correlação ao nivel de significância de 1\%.

$\begin{array}{lrrrrrrrr} & \text { Mn } & \text { Co } & \text { Cr } & \text { Cu } & \text { Ni } & \text { V } & \text { Y } & \text { Zn } \\ \text { Mn } & 100 & & & & & & & \\ \text { Co } & 70 & 100 & & & & & & \\ \text { Cr } & -21 & \text { Nå } & 100 & & & & & \\ \text { Cu } & \text { Nå } & 6 & 24 & 100 & & & & \\ \text { Ni } & \text { Não } & 25 & 82 & 30 & 100 & & & \\ \text { V } & -8 & 18 & 30 & 29 & 21 & 100 & & \\ \text { Y } & -20 & -25 & 11 & -8 & 6 & \text { Nå } & 100 & \\ \text { Zn } & 17 & \text { Nå } & \text { Nå } & 30 & 8 & -26 & 8 & 100\end{array}$

\subsubsection{Regressão em função de Fe e Mn}

Em prospeção geoquímica geralmente é reconhecido que o conteúdo de elementos traços em sedimentos de correntes é afetado pelo conteúdo de $\mathbf{F e}$, kn e matéria orgânica (SELINUS, 1983). Neste trabalho não foi analisado o conteúdo de matéria orgânica, porém foi demonstrado que o Fe está correlacionado com vários elementos traços e, em menor proporção, também o Mn. Por isso foram ensaiados modelos de regressão de vários elementos em função do $\mathrm{Fe}$ e $\mathrm{m}$ do tipo:

$$
\mathrm{Z}=\mathrm{C}_{0}+\mathrm{C}_{\mathrm{Fe}} \cdot \mathrm{F}(\mathrm{Fe})+\mathrm{C}_{\mathrm{Mn}} \cdot \mathrm{F}(\mathrm{Mn})
$$

Sendo que: $F(A)=\operatorname{Ln}(A) / M_{A} ; \operatorname{Ln}(A)=$ Conteúdo do elemento $A$ em logaritmos naturais; $M_{A}=$ Mediana da variável $\operatorname{Ln}(A)$ em função do material amostrado; $\mathrm{C}_{0}=$ Coeficiente independente; $\mathrm{C}_{\mathrm{Fe}}=$ Coeficiente do Fe e $C_{M n}=$ Coeficiente do mn.

Foi aplicada uma técnica passo a passo, e os resultados são apresentados na Tabela 13. É evidente que existe uma relação com 
a análise das correlações efetuada acima. A variável de controle no caso do co é o Mn, e para Cu, Ni, Y e zn é o Fe. O $\mathbf{P b}$ não apresentou ajuste a nenhum modelo, fato esperado em função da ausência de correlações positivas com os demais elementos. Para visualizar a distribuição espacial estipulada pelo modelo, foram elaborados os mapas de círculos para as residuais do Co (Figura 36) e do $\mathbf{Z n}$ (Figura 37). A residuais são as diferenças entre 0 teor real e o teórico para cada amostra.

Tabela 13. Parâmetros dos modelos de regressăo em função de Fe e Mn. $\mathrm{VEX}=$ Variancia explicada pelo modelo, $\mathrm{C}_{0}=$ Coeficiente independente, $\mathrm{C}_{\mathrm{Fe}}=$ Coeficiente do $\mathrm{Fe}$ e $\mathrm{C}_{\mathrm{Mn}}=$ Coeficiente do $\mathrm{Mn}$.

$\begin{array}{lrrrl}\text { Elemento } & \text { VEX } & C_{0} & C_{\text {Fe }} & C_{\text {Mn }} \\ \text { Co } & 50 \% & -0,67 & 0 & 1,66 \\ \text { Co } & 74 \% & -0,53 & 0,30 & 1,22 \\ \mathbf{C u} & 43 \% & 0,78 & 0,23 & 0 \\ \mathbf{C u} & 43 \% & 0,74 & 0,22 & 0,039 \\ \mathbf{N i} & 53 \% & 0,51 & 0,49 & 0 \\ \mathbf{P b} & 7 \% & -- & -- & - \\ \mathbf{X} & 34 \% & 0,80 & 0,23 & 0 \\ \mathbf{Y} & 36 \% & 1,04 & 0,25 & -0,26 \\ \mathbf{Z n} & 47 \% & 0,84 & 0,16 & 0 \\ \mathbf{Z n} & 49 \% & 0,73 & 0,14 & 0,13\end{array}$

\subsubsection{Definição das outliers}

As outliers foram definidas utilizando a distância de Mahalanobis-DM. A DM de uma amostra é um escalar definido pela seguinte equação:

$$
\mathbf{M D}^{2}=(\mathrm{x}-\mu) \cdot \mathrm{S}^{-1}(\mathrm{x}-\mu)
$$

Onde $x$ é o vetor amostra de $\mathrm{N}$ dimensões ( $\mathrm{N}=12$ no caso), $\mu$ é o vetor das médias e $\mathbf{S}$ é a matriz de variância-covariância.

A forma ideal de trabalhar com as DMs seria elaborar o gráfico de probabilidade teórica das $\mathrm{DM}^{2}$, eliminar as outliers e reprocessar os dados, até ter uma população 12-normal no caso, ou seja sem outliers. Porém, considerando os dados originais ou log-transformados, esse procedimento eliminaria mais de 50\% das amostras no primeiro processamento (Figura 38). Observe-se que ambas as curvas estão muito afastadas do comportamento linear, que indicaria ajuste ao comportamento 12-normal ou 12-lognormal. Isso sugere que existem varias sub-populações no 


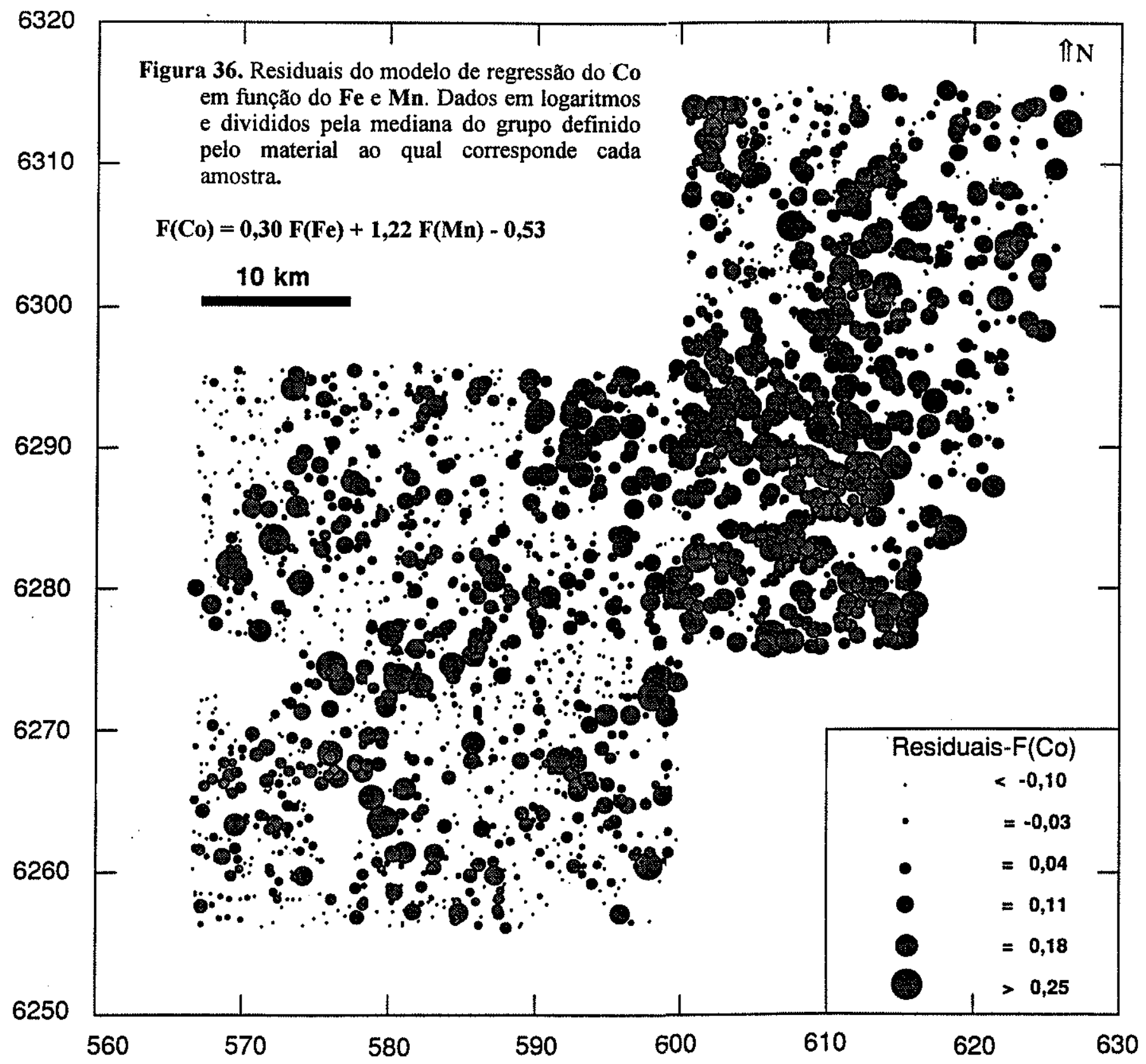




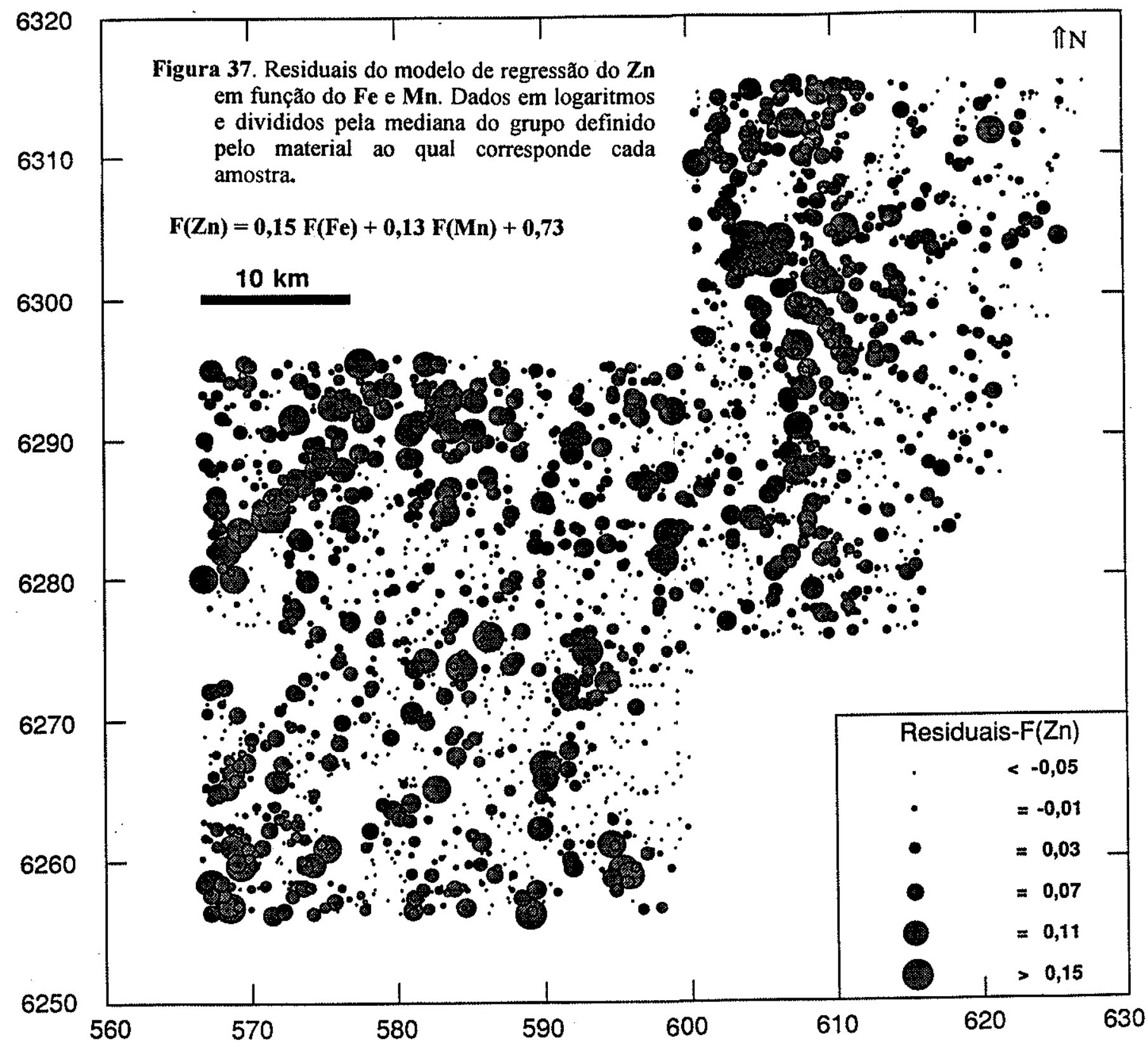




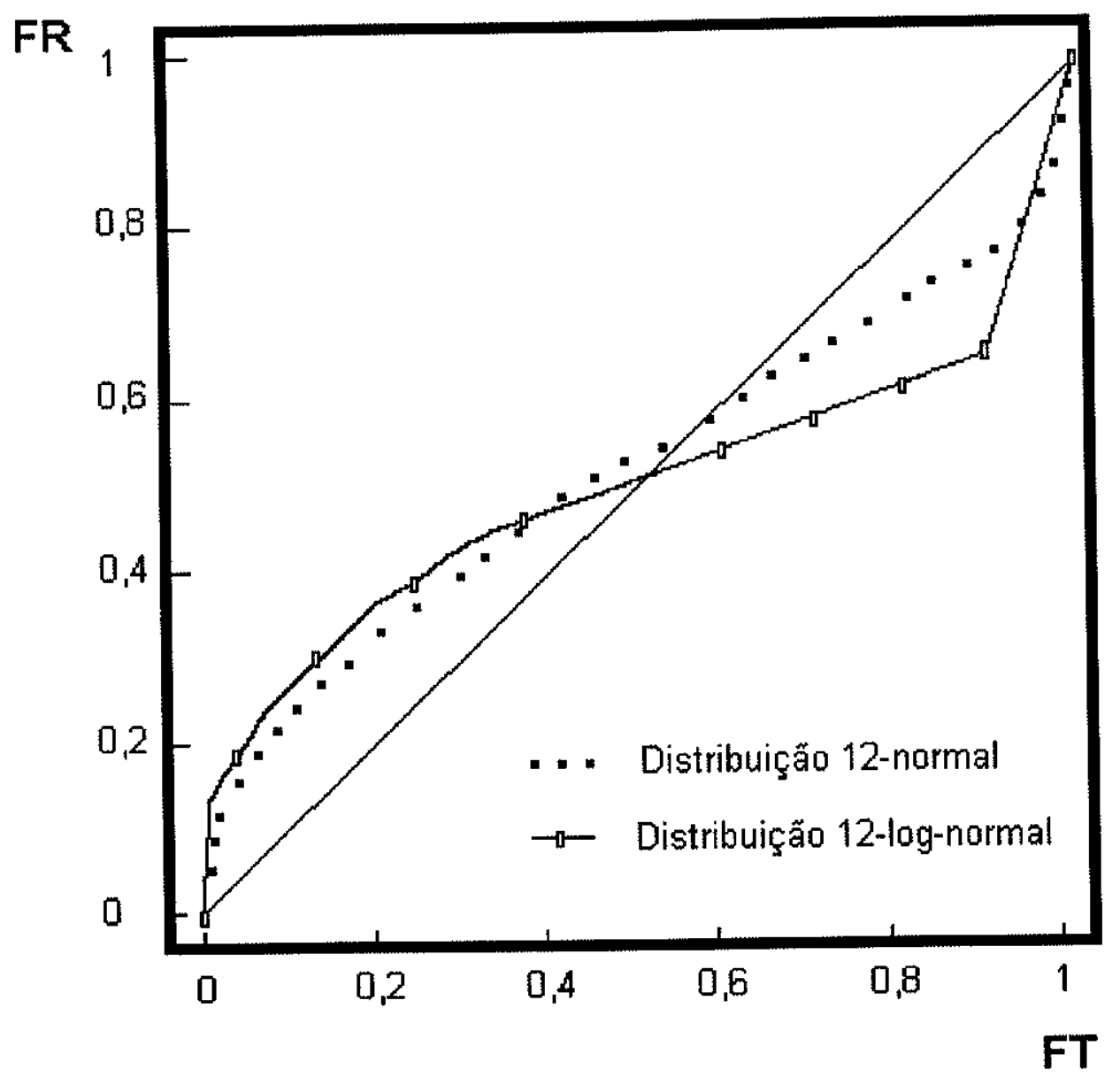

Figura 38. Gráfico de probabilidade teórica para as $\mathrm{DM}^{2}$ considerando uma distribuição 12normal ou uma distribuição 12-log-normal. $F T=$ Freqüência teórica e FR= Freqüência real. 
conjunto dos dados. Por esse motivo, decidiu-se trabalhar com as DM sem considerar esses aspectos. Assim, os procedimentos multivariados foram considerados segundo uma visão aplicada e não puramente estatística.

As DM foram calculadas considerando os dados transformados em logaritmos naturais, divididos pelas medianas dos grupos definidos pelo tipo de material amostrado. As estatísticas básicas foram: Amplitude $=1,1-14,2$; Média $=3,6$ e Desvio padrão= 3,6. A distribuição espacial das DM e apresentada no Mapa 5 . Os valores elevados das DM (acima de 50) aparecem relacionados às rochas máficas da Formação Pavas no setor NW da área. Outra anomalia regional (DM elevadas) aparece ao $\mathrm{N}$ da área, sem uma relação evidente com feições geológicas. As ocorrências de Au e de Fe-Cu foram indicadas por valores elevados de DM, más as ocorrências de $\mathbf{P b}$ foram indicadas por valores intermediários.

Do ponto de vista estatístico, as outliers devem ser eliminadas, pois prejudicam os procedimentos multivariados. porém, se isso fosse rigorosamente realizado, se perderiam as anomalias geoquímicas, que são o alvo principal de todo estudo prospectivo. Por esse motivo, para os demais procedimentos multivariados que serão utilizados neste trabalho, optou-se por eliminar apenas $2 \%$ da população original (44 amostras), que corresponderiam às outliers mais aberrantes. Essa eliminação deve tornar as técnicas mais sensíveis, sem perder as anomalias.

\subsubsection{Procedimentos que usam os autovetores (ACP e AFR)}

Nesta seção serão apresentados os resultados obtidos com a Análise em Componentes Principais-ACP e a Análise Fatorial em modo R-AFR. Ambos os procedimentos extraem os autovalores e autovetores da matriz de correlação ou de variância-covariância, definindo variáveis fictícias (componentes principais-CPs na ACP e fatores na AFR) que são combinações lineares das variáveis originais (DAVIS, 1986). Assim, as CPs ou fatores representam associações multivariadas que podem ser relacionadas a fenômenos naturais, permitindo reduzir $\circ$ número de variáveis a ser interpretadas. A ACP é um procedimento matemático, segundo o qual parte-se de $\mathrm{N}$ variáveis e geram-se $\mathrm{N}$ novas variáveis (as 


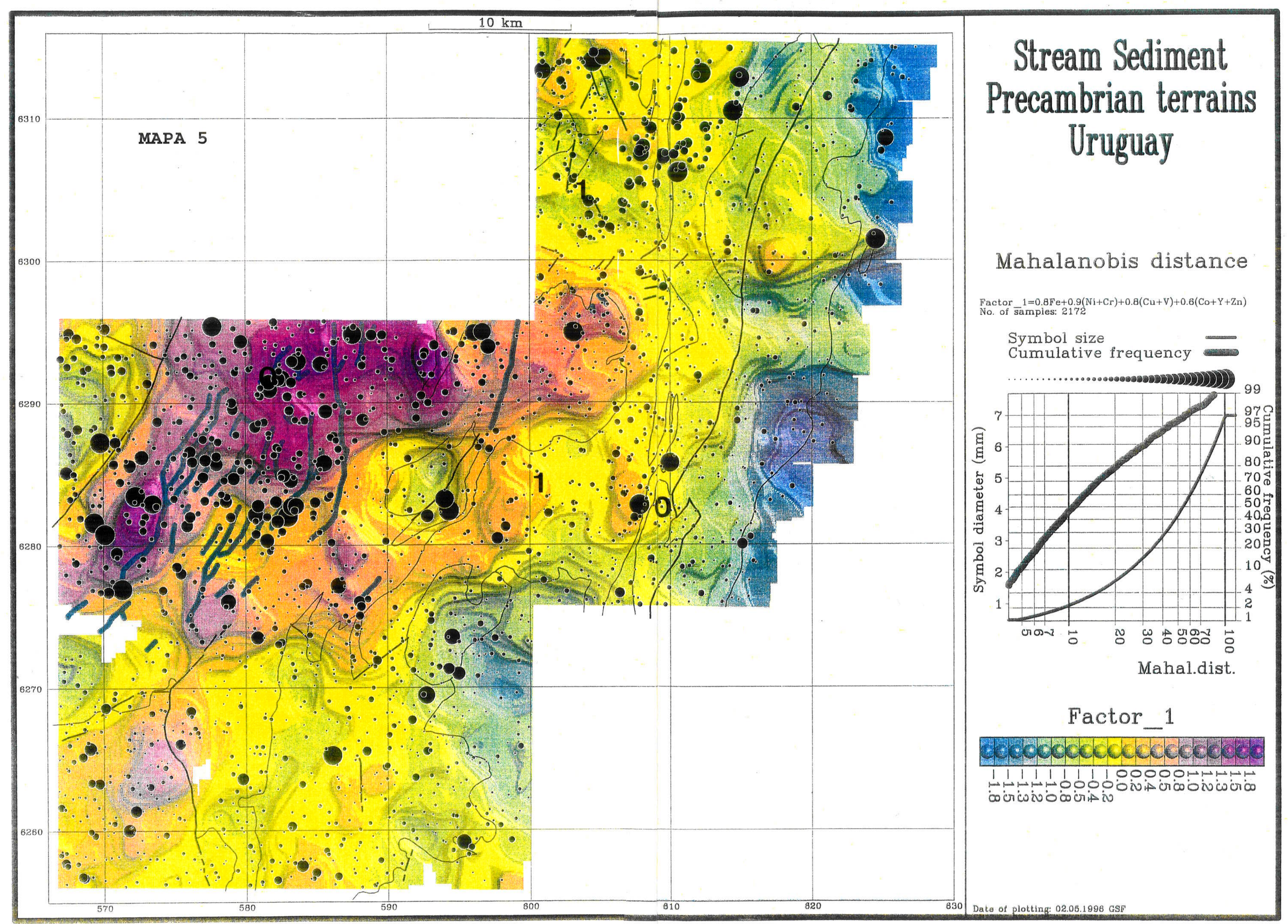


CPs), conservando a variância original. A AFR introduz conceitos estatísticos na sua concepção, gerando um número de fatores inferior ao das variáveis originais e descartando parte da variância. Em geral a AFR usa as CPs para gerar os fatores, O que leva ambas técnicas a produzirem resultados semelhantes. Porém, segundo JÖRESKOG et al. (1976), devido à forma de cálculo envolvida em cada procedimento, a ACP é orientada pelas variâncias e a AFR pelas correlações. A ACP e AFR tem sido extensamente utilizađas em prospeção geoquímica (HOWARTH, 1983).

Semelhanças nos resultados entre ACP e AFR justificaram utilizar dois procedimentos: (i) Aplicação da ACP ou AFR sobre a população total. (ii) Aplicação da ACP sobre as sub-populações definidas pelos litotipos das rochas de procedência.

\subsubsection{Aplicação da ACP-AFR sobre a população total}

Foram realizados seis tratamentos diferentes, considerando - descarte de 44 outliers definidas pelas DM, valores transformados em logaritmos e a correção pelo efeito do material amostrado (Tabela 14). Os quatro primeiros tratamento foram com ACP, e os dois últimos com AFR, sendo extraídos 5 fatores (tratamento 5) e quatro fatores (tratamento 6).

Tabela 14. Detalhes dos tratamentos realizados Com ACP e AFR para a população total. CEMA = Correção pelo efeito do material amostrado, ou seja, divisåo dos dados pela mediana dos grupos classificados pelo material amostrado.

$\begin{array}{clclll}\text { Tratamento } & \text { Típo } & \text { Amostras } & \text { Log } & \text { CEMA } & \text { Comentários } \\ 1 & \text { ACP } & 2172 & \text { Nåo } & \text { Nåo } & \text { Dados originais } \\ 2 & \text { ACP } & 2172 & \text { Sim } & \text { Não } & \text { Divisão pela mediana geral } \\ 3 & \text { ACP } & 2172 & \text { Sim } & \text { Sim } & \text { Nenhum } \\ 4 & \text { ACP } & 2128 & \text { Sim } & \text { Sim } & \text { Sem } 44 \text { outliers } \\ 5 & \text { AFR } & 2128 & \text { Sim } & \text { Sim } & \text { Sem } 44 \text { outliers - } 5 \text { fatores } \\ 6 & \text { AFR } & 2128 & \text { Sim } & \text { Sim } & \text { Sem } 44 \text { outliers - } 4 \text { fatores }\end{array}$

Para avaliar os resultados dos diferentes tratamentos efetuados com a ACP, foram comparadas as porcentagens de variância explicada $e$ as loadings de cada CP para cada 
tratamento (Tabelas 15-19). As loadings são os coeficientes que multiplicam as variáveis originais nas combinações lineares que constituem as CPs, e variam no intervalo $(-1 ; 1)$. Sua elevação ao quadrado representa a variância explicada pelo elemento para aquela CP. Por exemplo, uma loading de 0,4 (40 nas tabelas), significa $16 \%$ de variância explicada.

Tabela 15. Variancia explicada (VEX \%) e loadings (vezes 100) da CP1 para os tratamentos 1-4.

\begin{tabular}{|c|c|c|c|c|c|c|c|c|c|c|c|c|}
\hline Tratamento & VEX & $\mathbf{F e}$ & un & $\mathbf{P}$ & $\mathbf{B a}$ & Co & Cr & Cu & $\mathbf{N 1}$ & $\mathbf{P b}$ & $\mathbf{V}$ & $\mathbf{x}$ \\
\hline 1 & 38,9 & 91 & 43 & 40 & 41 & 79 & 60 & 73 & 65 & -1 & 79 & 50 \\
\hline 2 & 47,9 & 93 & 48 & 42 & 42 & 79 & 81 & 76 & 86 & -14 & 84 & 63 \\
\hline 3 & 46,9 & 92 & 45 & 44 & 39 & 77 & 81 & 76 & 86 & -17 & 83 & 61 \\
\hline 4 & 46,9 & 92 & 45 & 43 & 41 & 76 & 81 & 77 & 86 & -12 & 83 & 62 \\
\hline
\end{tabular}

Tabela 16. Variancia explicada (VEX \%) e loadings (vezes 100) da CP2 para os tratamentos 1-4.

$\begin{array}{clrllllllllllr}\text { Tratamento } & \text { VEX } & \text { Fe } & \text { Mn } & \text { P } & \text { Ba } & \text { Co } & \text { Cr } & \text { Cu } & \text { N1 } & \text { Pb } & \text { V } & \text { X } & \text { Zn } \\ 1 & 14,6 & 4 & 47 & 27 & 59 & 7 & -70 & -3 & -66 & 31 & 2 & 9 & 26 \\ 2 & 12,6 & -3 & 67 & -26 & 25 & 42 & -28 & 0 & -12 & 72 & -2 & -35 & 7 \\ 3 & 12,6 & -3 & 70 & -20 & 26 & 44 & -29 & 2 & -14 & 69 & -2 & -36 & 9 \\ 4 & 12,6 & -3 & 69 & -23 & 27 & 45 & -28 & -1 & -13 & 70 & -2 & -36 & 6\end{array}$

Tabela 17. Variancia explicada (VEx \&) e loadings (vezes 100) da CP3 para os tratamentos 1-4.

$\begin{array}{clrlrrrrrrrrrr}\text { Tratamento } & \text { VEX } & \text { Fe } & \text { Mn } & \text { P } & \text { Ba } & \text { Co } & \text { Cr } & \text { Cu } & \text { N1 } & \text { Pb } & \text { V } & \text { Y } & \text { Zn } \\ 1 & 12,0 & -15 & 50 & -52 & -7 & 37 & 15 & 2 & 19 & 68 & -11 & -48 & -5 \\ 2 & 10,8 & 0 & 16 & 67 & 66 & -11 & -32 & -23 & -29 & -18 & -19 & 18 & 20 \\ 3 & 11,0 & 0 & 13 & 67 & 66 & -14 & -31 & -23 & -28 & -21 & -19 & 21 & 20 \\ 4 & 11,0 & 0 & 17 & 68 & 63 & -12 & -3.2 & -24 & -28 & -22 & -21 & 19 & 22\end{array}$

Tabela 18. Variância explicada (VEx \%) e loadings (vezes 100) da CP4 para os tratamentos $1-4$.

$\begin{array}{crrllrrrrrrrrr}\text { Tratamento } & \text { VEX } & \text { Fe } & \text { Mn } & \text { P } & \text { Ba } & \text { Co } & \mathbf{C r} & \mathbf{C u} & \mathbf{N 1} & \text { Pb } & \text { V } & \mathbf{Y} & \mathbf{Z n} \\ 1 & 8,3 & 13 & -31 & -48 & -33 & -16 & -24 & 42 & -24 & 26 & 24 & 23 & 21 \\ 2 & 6,9 & 2 & -45 & -14 & 32 & -30 & 2 & 14 & -4 & 55 & 11 & 26 & 13 \\ 3 & 7,0 & 2 & -44 & -14 & 31 & -30 & 2 & 16 & -4 & 58 & 11 & 23 & 14 \\ 4 & 7,2 & 0 & -45 & -11 & 35 & -30 & 3 & 12 & -2 & 58 & 9 & 22 & 13\end{array}$


Tabela 19 Variância explicada (VEX \%) e loadings (vezes 100) da CP5 para os tratamentos 1-4.

$\begin{array}{crrrrrrrrrrrrr}\text { Tratamento } & \text { VEX } & \text { Fe } & \text { Mn } & \mathbf{P} & \mathbf{B a} & \mathbf{C o} & \mathbf{C r} & \mathbf{C u} & \mathbf{N 1} & \mathbf{P b} & \mathbf{V} & \mathbf{Y} & \mathbf{Z n} \\ 1 & 6,3 & 0 & -30 & 0 & 30 & -20 & 20 & -10 & 10 & 50 & 0 & 20 & 0 \\ 2 & 5,3 & -5 & -8 & 31 & -20 & -15 & -4 & 40 & -2 & 8 & -11 & -41 & 34 \\ 3 & 5,3 & -5 & -5 & 25 & -23 & -16 & -5 & 39 & -2 & 3 & -17 & -36 & 41 \\ 4 & 5,4 & -5 & -3 & 19 & -22 & -16 & -6 & 40 & -4 & 4 & -18 & -35 & 44\end{array}$

Descartando as loadings no intervalo $(-25 ; 25)$, as cinco primeiras CPs mostraram, em geral, parâmetros (VEX ou loadings) diferentes para o Tratamento 1 em relação aos outros. Por exemplo, para a CP2 (Tabela 16), segundo o Tratamento 1, ter-seia uma associação entre un e Ba, com participação secundária de $\mathbf{P}, \mathbf{P b}$ e $\mathbf{z n}$, além de uma associação entre $\mathbf{C r}$ e $\mathbf{w i}$ em oposição. Os outros tratamentos sugerem uma associação entre $\mathbf{M n}, \mathbf{P b}$ e Co com leve oposição de $\mathbf{Y}, \mathbf{P}$ e $\mathbf{C r}$.

o comportamento acima para as loadings dos tratamentos 2-4 foi reiterado para as CP6-11. Assim, as diferentes transformações realizadas para esses tratamentos foram equivalentes, sendo 0 uso dos logaritmos de fundamental importância. Finalmente, foi escolhido o tratamento 4 como 0 mais adequado, pois ao eliminar 44 outliers, melhorou a resposta, em especial para as últimas CPs. Na Tabela 20 são apresentadas as loadings das CPs 6-11 para esse tratamento. A CP12 não foi calculada pelo programa utilizado (SPSS, 1993).

Tabela 20. Variancia explicada (VEX \&) e loadings (vezes 100) das CP611 para o tratamento 4.

$\begin{array}{lrrrrrr}\text { Var1áve1 } & \text { CP6 } & \text { CP7 } & \text { CP8 } & \text { CP9 } & \text { CP10 } & \text { CP11 } \\ \text { Fe } & -6 & -3 & 17 & -24 & -3 & 5 \\ \text { Mn } & -16 & 4 & -8 & 17 & 15 & 3 \\ \text { P } & 33 & 31 & 17 & 17 & -2 & -19 \\ \text { Ba } & 17 & -33 & -20 & 0 & -2 & 22 \\ \text { Co } & 3 & 4 & 7 & -10 & -22 & 16 \\ \text { Cr } & 21 & 11 & -27 & 2 & 9 & 6 \\ \text { Cu } & -5 & -25 & 12 & 28 & -10 & -40 \\ \text { N1 } & 16 & 10 & -30 & 4 & -4 & 4 \\ \text { Pb } & 8 & 31 & 6 & 3 & 0 & -4 \\ \text { V } & 16 & -13 & 36 & -2 & 19 & 18 \\ \mathbf{Y} & -47 & 19 & 5 & 16 & -4 & 35 \\ \text { Zn } & -29 & 4 & -14 & -22 & 7 & -44 \\ \text { VEX } & 5 \% & 48 & 48 & 28 & 1 \% & 18\end{array}$


Em função do valor das loadings dos elementos, pode-se tentar uma interpretação para cada $C P$, visando relacionar cada uma delas à fenômenos naturais. A CP1 apresenta loadings altas para os elementos incompatíves (Co, Cr, Cu, Ni...), o que sugere uma relação com a ocorrência de minerais ferro-magnesianos nas rochas de procedência. A distribuição das scores das CP1, mostra efetivamente (Figura 39), uma grande anomalia relacionada as rochas máficas da Formação Pavas, em especial onde há abundância de afloramentos (setor NW). A CP2 (Mn-Co-Pb...) estaria relacionada a ocorrência de óxidos de un, a CP3 (P-Ba...) poderia indicar a geração de fosfatos supérgenos, a CP4 (Ba, Pb, -mo, -Co...) estaria associada à ocorrência de granitóides. A observação da distribuição das scores dessas CPs deixa algumas dúvidas em relação a essas questões. A interpretação resulta complicada a partir da CP5, por falta de significado geoquímico para as associações ou pelo fato de as loadings possuírem valores pouco definidos. Por exemplo, a CP9 apresenta uma relação entre $\mathrm{Cu}$ em oposição a $\mathrm{Fe}-\mathrm{zn}$, que poderia ser interpretada como relacionada a ocorrência de mineralizações. As scores da CP9 apresentaram valores elevados próximos as ocorrências minerais conhecidas (Figura 40). Mas, também ocorrem valores elevados da CP9 em alguns setores onde os mapas das variáveis originais não mostraram anomalias. Assim, achou-se necessario introduzir uma nova forma de trabalhar com as CPs.

JOLLIFFE (1986) descreveu algumas aplicações da ACP, que trabalham com a soma dos quadrados das scores das CPs. Do ponto de vista geoquímico, as primeiras CPs estariam relacionadas a processos regionais e as últimas a fenômenos locais, porém, isso não significa que as últimas CPs, não possuam certa relação com fenômenos litológicos ou supergénicos. Por esses motivos e para trabalhar com um número menor de variáveis, decidiu-se agrupar as CPs em dois parâmetros:

$$
\begin{aligned}
& \mathrm{D}^{2} \mathrm{cp} 1-5=\mathrm{CP}^{2}+\mathrm{CP}^{2}+\ldots+\mathrm{CP}^{2} \\
& \mathrm{D}^{2} \mathrm{cp} 6-11=\mathrm{CP} 6^{2}+\mathrm{CP}^{2}+\ldots+\mathrm{CP}^{2} 1^{2}
\end{aligned}
$$

Um passo crítico desse procedimento seria a escolha da CP de separação entre as primeiras e as últimas CPs. Esse tópico, 


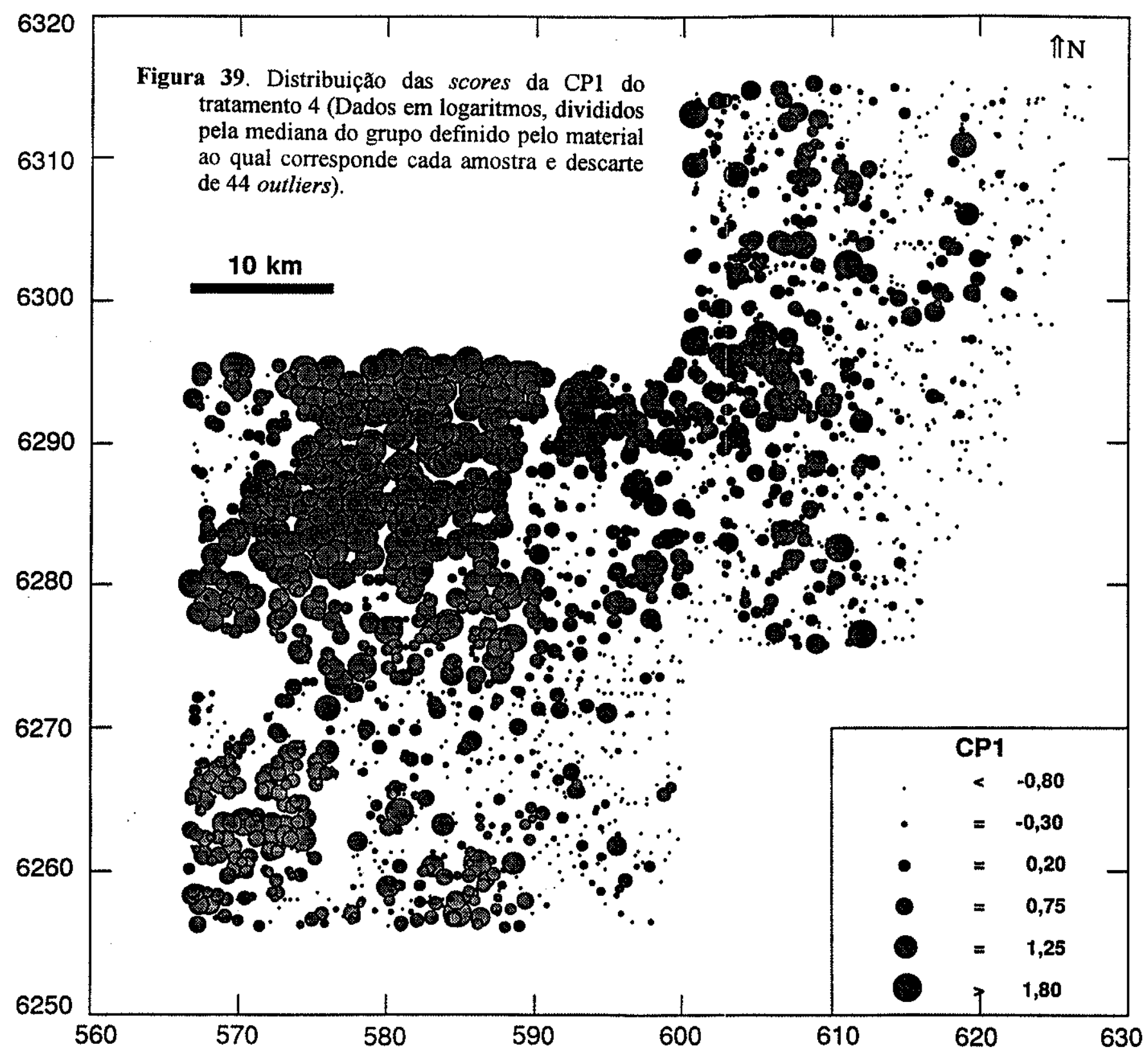




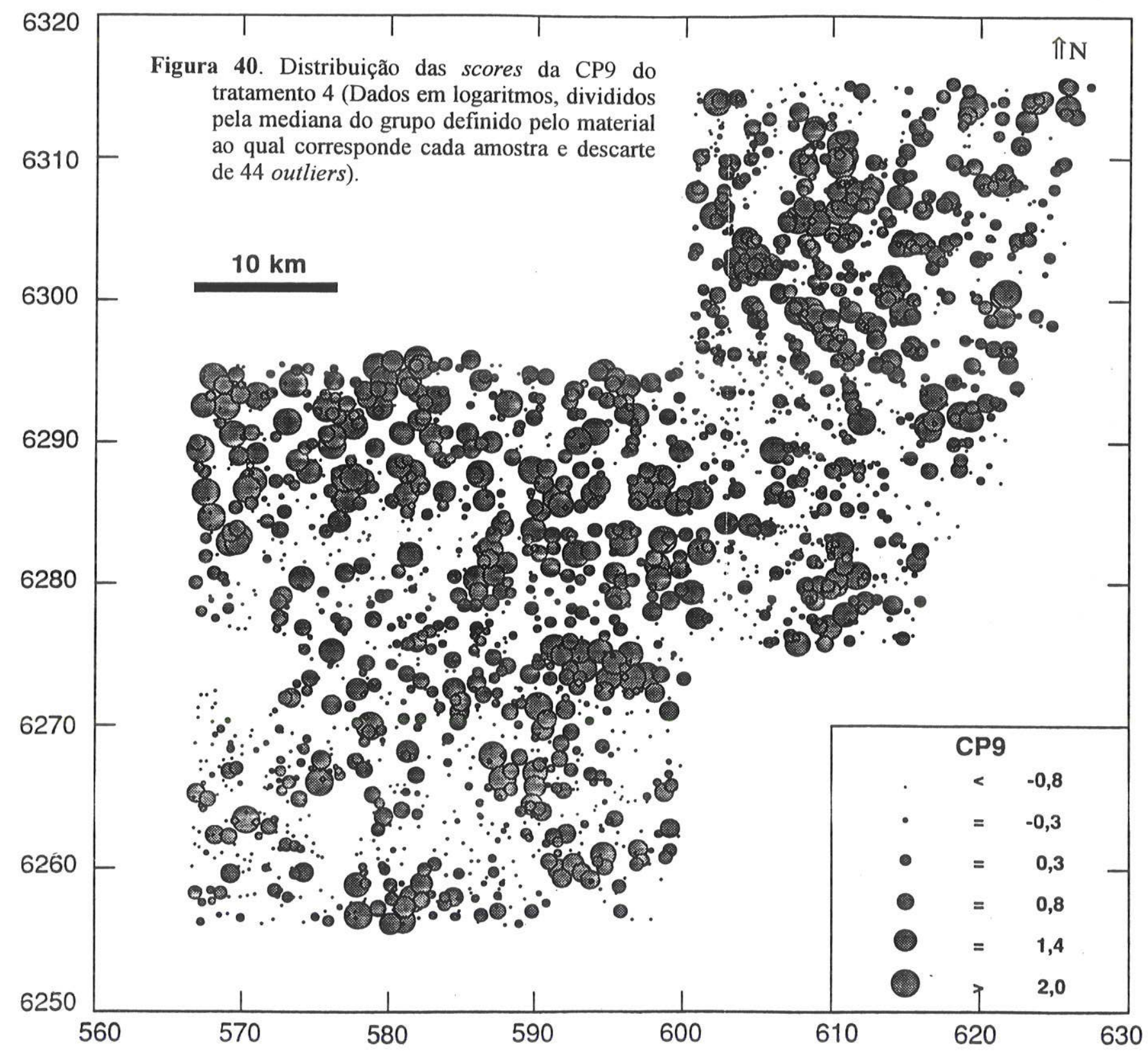


foi encarado em forma semelhante à escolha do número de fatores a serem extraídos na AFR. Algumas regras empíricas para ajudar nesse tópico foram indicadas por JöRESKOG et al. (1976):

(1) Quantidade de variância acumulada.

(2) Gráficos da variância explicada para cada CP (a parte plana da curva forneceria o número ideal de CPs).

(3). Se a variância explicada para uma CP fosse inferior à variância de uma variável, $100 / 12=8,3 \frac{0}{6}$ no caso, a CP não teria significação.

(4) O valor das loadings, de modo que as CPs com menos de três loadings significativas seriam descartadas. Essas regras indicariam a extração de 4-6 fatores como o número ideal, levando isso em conta, escolhou-se a CP5 para o corte.

No Mapa 6 foram representadas a $\mathrm{D}^{2} \mathrm{cp} 1-5 \mathrm{em}$ escala de cores e a $D^{2}$ cp6-11 como mapa de círculos. Em ambos os casos foram evidenciadas duas anomalias regionais, uma no setor NW e a outra no setor $N$. A $D^{2}$ cp6-11 mostrou-se mais eficiênte na detecção das ocorrências minerais conhecidas, estando associadas a círculos de bom tamanho, localizados a 2-3 km de distância.

o problema do número de fatores a ser extraídos na AFR já foi introduzido acima. Em função disso, foram comparados os resultados da AFR com rotação varimax e extração de cinco (Tabela 21) ou quatro fatores (Tabela 22), correspondendo aos Tratamentos 5 e 6, respectivamente (Tabela 14).

Tabela 21. Loadings (vezes 100) para a AFR com extraçăo de cinco fatores depois da rotaçăo. Usaram-se as mesmas condiçðes do Tratamento 4.

$\begin{array}{crrrrr}\text { Variavel } & \text { Fator-1 } & \text { Fator-2 } & \text { Fator-3 } & \text { Fator-4 } & \text { Fator-5 } \\ \text { Fe } & 76 & 29 & 27 & 30 & -11 \\ \text { Mn } & 6 & 93 & 13 & 13 & 4 \\ \text { R } & 4 & 9 & 52 & 45 & -52 \\ \text { Ba } & 9 & 20 & 86 & 13 & 12 \\ \text { Co } & 56 & 77 & 8 & 9 & 6 \\ \text { Cr } & 89 & 4 & 0 & 18 & -12 \\ \text { Cu } & 64 & 12 & -6 & 62 & 8 \\ \text { Ni } & 86 & 19 & 1 & 23 & -8 \\ \text { Pb } & -12 & 8 & 7 & 4 & 93 \\ \text { V } & 83 & 21 & 17 & 12 & 3 \\ \text { Y } & 62 & -12 & 51 & -3 & -22 \\ \text { Zn } & 40 & 19 & 29 & 74 & -3\end{array}$




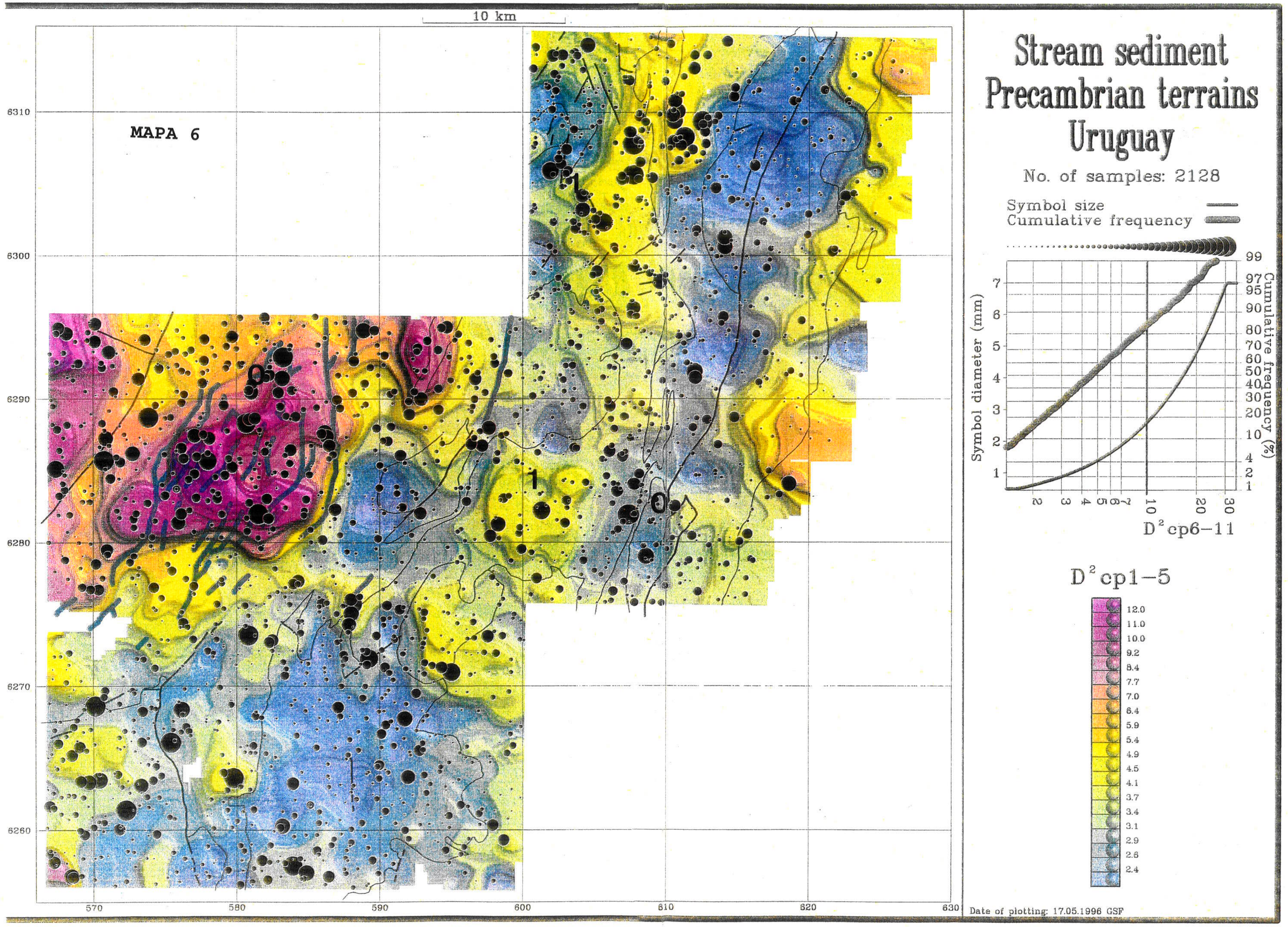


Do ponto de vista interpretativo, foram consideradas expressivas as loadings inferiores a -40 ou superiores a 40 , intermediárias aquelas nos intervalos $(-40,-20)$ e $(20,40)$, e descartadas aquelas no intervalo $(-20,20)$. Para o fator 1 (Tabela 21) aparece um maior contraste entre as loadings dos diferentes elementos, em comparação a CP1 (Tabela 15). Esse fato, que se repete para todos os fatores, é produto da rotação varimax. A escolha do modelo mais adequado para a AFR (extração de quatro ou cinco fatores) foi feita em forma subjetiva. Foi escolhido o modelo com quatro fatores (Tabela 22), pois as associações $\mathbf{P}, \mathbf{B a}$ e $\mathbf{Y}($ Fator-3) e $\mathbf{P}, \mathbf{C u}$ e $\mathbf{Z n}$ (Fator-4) do tratamento 5 (Tabela 21) parecem pouco coerentes, já que em ambos os casos aparece o $\mathbf{P}$ associado a metais traços. Essa duas associações foram unificadas no fator 2 para 0 tratamento 6 . A distribuição espacial das scores dos fatores 1,3 e 4 para 0 tratamento 6 foram apresentadas em escala de cores nos Mapas 5 , 7 e 8. Nos dois últimos, foram sobrepostos os mapas de círculos de $\mathrm{Mn}$ e $\mathrm{Pb}$.

Tabela 22. Loadings (vezes 100) para a AFR com extração de quatro fatores depois da rotação. Usaram-se as mesmas condiçoes do tratamento 4.

$\begin{array}{ccccc}\text { Variável } & \text { Fator-1 } & \text { Fator-2 } & \text { Fator-3 } & \text { Fator-4 } \\ \text { Fe } & 80 & 33 & 28 & -10 \\ \text { Mn } & 10 & 18 & 93 & 6 \\ \mathbf{P} & 12 & 69 & 10 & -47 \\ \mathbf{B a} & 9 & 83 & 16 & 20 \\ \mathbf{C o} & 56 & 8 & 75 & 5 \\ \mathbf{C x} & 90 & 2 & 2 & -15 \\ \mathbf{C u} & 79 & 12 & 15 & 7 \\ \mathbf{~ N i} & 89 & 5 & 18 & -10 \\ \mathbf{P b} & -8 & 1 & 9 & 94 \\ \mathbf{V} & 83 & 15 & 19 & 3 \\ \mathbf{Y} & 57 & 45 & -17 & -20 \\ \mathbf{Z n} & 56 & 51 & 23 & -1\end{array}$

\subsubsection{Aplicação da ACP sobre sub-populações}

A deformação das curvas de freqüencia teórica das $\mathrm{DM}^{2} \mathrm{em}$ relação ao comportamento linear (Figura 38), sugiriu que existe um grande número de outliers. Porém, além das outliers deve-se considerar que podem existir varias sub-populações, como foi 


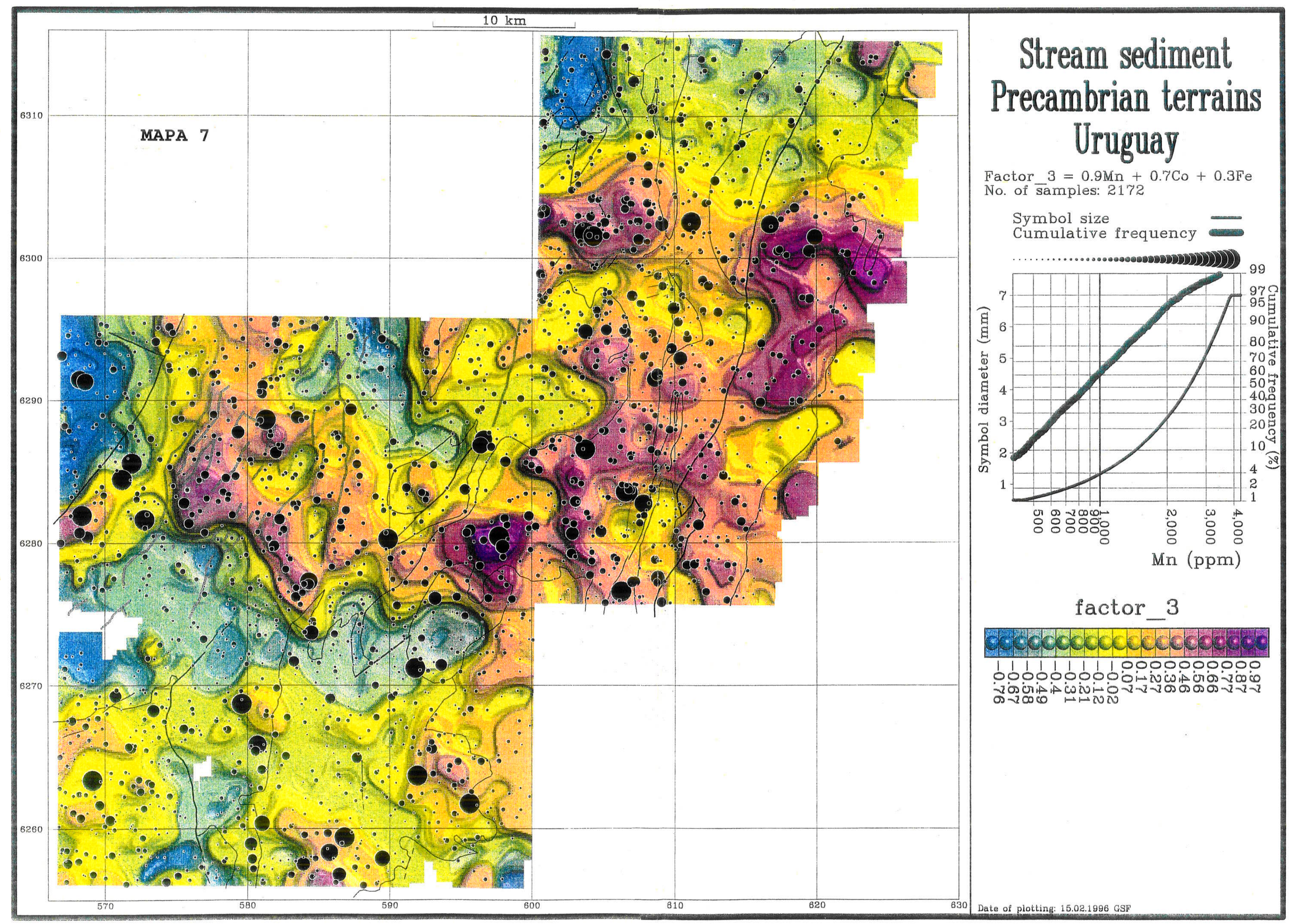




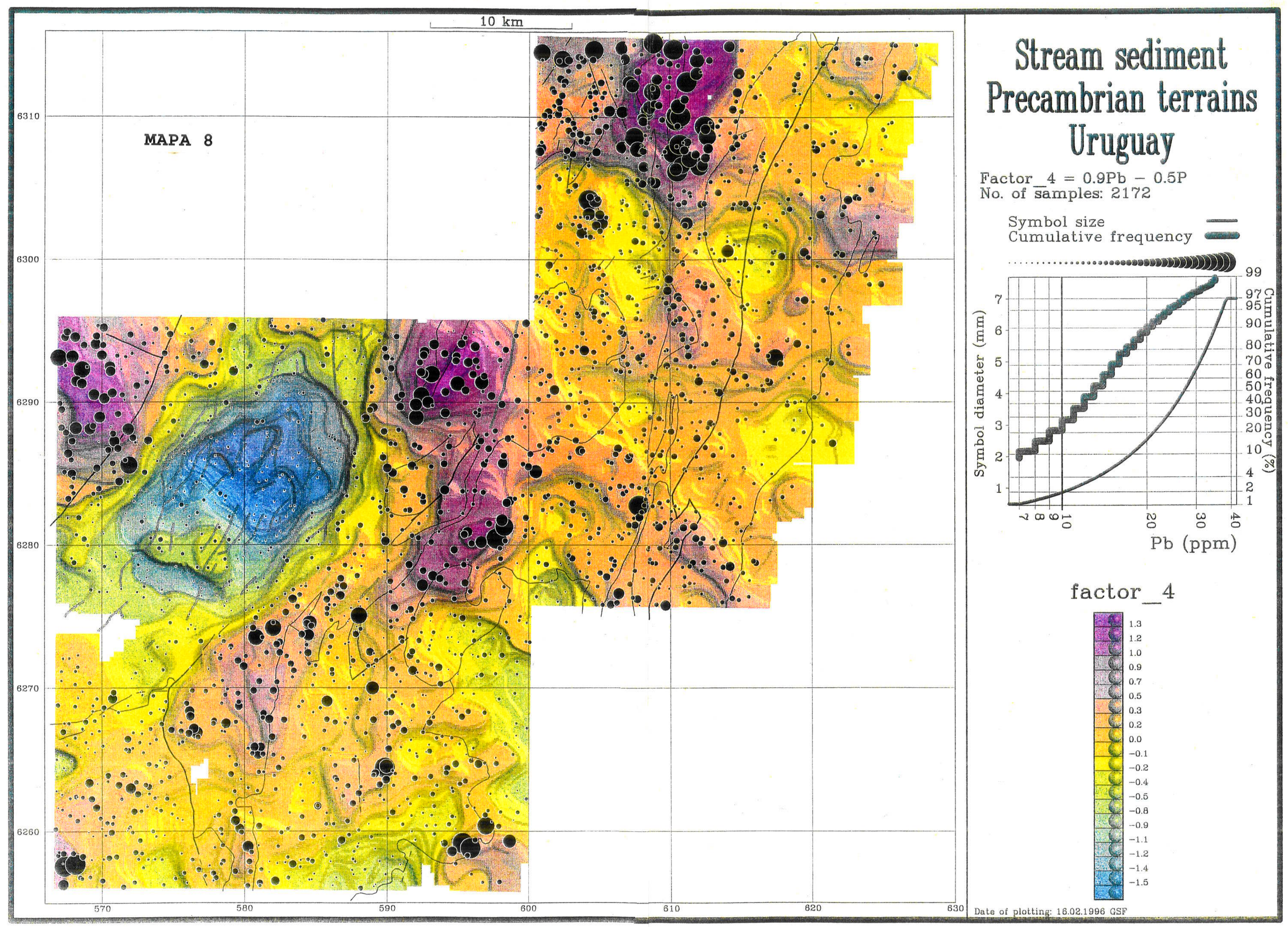


sugerido pelos histogramas e pela ANOVA. Um dos fatores de control dessas sub-populações seria o litotipo das rochas de procedência (Seção 3.2.2). Por isso, foi considerada a ACP para sub-populações de amostras classificadas em função dos tipos litológicos que, a princípio, representariam grupos mais homogêneos. Os seis grupos escolhidos foram: os granitóides tardi-, sin- e pós-tectônicos (Granito Maria Albina, Granito de Pirarajá, Granito-K e Granito Zócalo del Este), o Grupo Barriga Negra, o Grupo Lavalleja, a Formação de Anfibolitas-Leptitas e a Formação Pavas. Nas Tabelas 23-27 são comparados os resultados das CP1-CP5 para cada um dos referidos grupos litológicos. Foram usadas as mesmas condições do tratamento 4 (Tabela 14). Para as três primeiras CPs, é observado comportamento diferente em pelo menos um grupo litológico. Por exemplo, na CP1 a Formação Pavas apresentou comportamento característico, com loading negativa para $\circ \mathrm{Pb}$. A partir da $\mathrm{CP} 4$, parece difícil encontrar um significado geoquímico às CPs relacionadas a cada um dos grupos litológicos.

Tabela 23. Porcentagem de variância explicada e loadings (vezes 100) da CP1 para a ACP considerando os grupos litologicos. GRAN= Granitoides sin-, tardi- e pos-tectônicos; $\mathrm{GBN}=$ Grupo Barriga Negra, $\mathrm{A} A \mathrm{~V}=$ Grupo Lavalleja; $\mathrm{ANLE}=$ Formą̧ăo de Anfibolitas-Leptitas; $\mathrm{PAV}=$ Formação Pavas; VEX = Variância explicada e $N=$ Número de amostras.

$\begin{array}{llllrllllllllll}\text { Grupo } & \text { VEX } & \text { Fe } & \text { Mn } & \text { P } & \text { Ba } & \text { Co } & \text { Cr } & \text { Cu } & \text { N1 } & \text { Pb } & \text { V } & \text { Y } & \text { Zn } & \text { N } \\ \text { GRAN } & 46 & 89 & 41 & 28 & 41 & 78 & 81 & 79 & 88 & 47 & 81 & 41 & 78 & 172 \\ \text { GBN } & 43 & 90 & 58 & 9 & 25 & 83 & 69 & 77 & 83 & 57 & 83 & 34 & 59 & 145 \\ \text { LAV } & 37 & 83 & 54 & 25 & 43 & 77 & 59 & 73 & 75 & 42 & 66 & 52 & 60 & 556 \\ \text { ANLE } & 37 & 89 & 38 & 3 & 39 & 74 & 67 & 66 & 76 & 46 & 79 & 50 & 49 & 145 \\ \text { PAV } & 45 & 91 & 54 & 38 & 23 & 81 & 79 & 74 & 82 & -38 & 84 & 43 & 76 & 782\end{array}$

Tabela 24. Porcentagem de variância explicada e loadings (vezes 100) da CP2 para a ACP considerando os grupos litologicos. GRAN= Granitoides sin-, tardi- e pos-tectônicos; GBN= Grupo Barriga Negra; LAV= Grupo Lavalleja; ANLE= Formaçåo de Anfibolitas-Leptitas; PAV= Formaçåo Pavas; VkX = Variância explicada e $\mathbf{N}=$ Número de amostras.

\begin{tabular}{|c|c|c|c|c|c|c|c|c|c|c|c|c|c|c|}
\hline Grupo & VEX & $\mathrm{Fe}$ & $\mathrm{mn}$ & $\mathbf{p}$ & $\mathbf{B a}$ & Co & $\mathrm{Cr}$ & $\mathrm{Cu}$ & NN & $\mathbf{P b}$ & $\mathbf{v}$ & $\mathbf{Y}$ & $\mathbf{Z n}$ & $\mathbf{N}$ \\
\hline GRAN & 12 & 65 & 65 & -55 & 15 & 47 & -39 & -17 & -19 & 32 & 8 & -34 & -11 & 172 \\
\hline GBN & 17 & -11 & 40 & 68 & 70 & 18 & -56 & 15 & -32 & 0 & -34 & -14 & 60 & 145 \\
\hline IAAV & 13 & 0 & 60 & 47 & 22 & 17 & -59 & -13 & -33 & 22 & -47 & -8 & 46 & 556 \\
\hline ANLE & 17 & -2 & 68 & -33 & 67 & 43 & -59 & -31 & -42 & 45 & -5 & -3 & -10 & 145 \\
\hline PAV & 15 & 12 & 18 & 72 & 77 & -7 & -44 & -29 & -41 & -15 & -3 & 29 & 20 & 782 \\
\hline
\end{tabular}


Tabela 25. porcentagem de variancia explicada e loadings (vezes 100) da CP3 para a ACP considerando os grupos litologicos. GRAN= Granitoides sin-, tardi - e pos-tectônicos; GBN= Grupo Barriga Negra; LAV= Grupo Lavalleja; ANLE= Formaçăo de Anfibolitas-Leptitas; PAV= Formaçăo Pavas; VEX = Variância explicada e $\mathbf{N}=$ Número de amostras.

$\begin{array}{lrrrrrrrrrrrrrr}\text { Grupo } & \text { VEX } & \text { Fe } & \text { Mn } & \text { P } & \text { Ba } & \text { Co } & \text { Cr } & \text { Cu } & \text { N1 } & \text { Pb } & \text { V } & \text { Y } & \text { Zn } & \text { N } \\ \text { GRAN } & 10 & -2 & 56 & 60 & 1 & 18 & -8 & -16 & 5 & -50 & -37 & -20 & 31 & 172 \\ \text { GBN } & 12 & 17 & -58 & 33 & 13 & -39 & 11 & 25 & 10 & -37 & -9 & 73 & 23 & 145 \\ \text { IAAV } & 11 & 8 & -29 & 64 & -17 & -30 & 19 & 13 & 21 & -55 & -31 & 20 & 34 & 556 \\ \text { ANLE } & 11 & 13 & -30 & 30 & 31 & -33 & 1 & -42 & 5 & 34 & -30 & 73 & 11 & 145 \\ \text { PAV } & 11 & -5 & 56 & -19 & 29 & 36 & -17 & 12 & -5 & 69 & -10 & -50 & 14 & 782\end{array}$

Tabela 26. Porcentagem de variância explicada e loadings (vezes 100) da CP4 para a ACP considerando os grupos litologicos. GRAN= Granitóides sin-, tardi- e pos-tectônicos; GBN= Grupo Barriga Negra; LAV= Grupo Lavalleja; ANLE= Formação de Anfibolitas-Leptitas; $\mathrm{PAV}=$ Formação Pavas; VEX = Variância explicada e $\mathbf{N}=$ Número de amostras.

$\begin{array}{lcrrrrrrrrrrrrr}\text { Grupo } & \text { VEX } & \text { Fe } & \text { Mn } & \text { P } & \text { Ba } & \text { Co } & \text { Cr } & \text { Cu } & \text { Ni } & \text { Pb } & \text { V } & \text { Y } & \text { Zn } & \text { N } \\ \text { GRAN } & 8 & 0 & 10 & 2 & 64 & -16 & -13 & -24 & -15 & 12 & 18 & 62 & 11 & 172 \\ \text { GBN } & 9 & -6 & -3 & -44 & 42 & -12 & -20 & -8 & -30 & 52 & 18 & 45 & -7 & 145 \\ \text { LAV } & 9 & -8 & 27 & 27 & 26 & 27 & 32 & -36 & 33 & -29 & -6 & -53 & -33 & 556 \\ \text { ANLE } & 9 & -4 & 20 & 60 & 31 & -11 & -18 & 28 & -19 & -32 & -9 & -14 & 58 & 145 \\ \text { PAV } & 7 & 2 & -55 & 9 & 33 & -32 & 15 & 30 & 7 & 35 & 11 & -17 & 19 & 782\end{array}$

Tabela 27. Porcentagem de variância explicada e loadings (vezes 100) da CP5 para a ACP Considerando os grupos litologicos. GRAN= Granitoides sin-, tardi $-e$ pos-tectônicos; GBN= Grupo Barriga Negra; LAV= Grupo Lavalleja; $\mathrm{ANLE}=$ Formação de Anfibolitas-Leptitas; $\mathrm{PAV}=$ Formaça Pavas; VEX = Variância explicada e $\mathbf{N}=$ Número de amostras.

$\begin{array}{lrrrrrrrrrrrrrr}\text { Grupo VEX } & \mathbf{F e} & \mathbf{M n} & \mathbf{P} & \mathbf{B a} & \mathbf{C o} & \mathbf{C r} & \mathbf{C u} & \mathbf{N 1} & \mathbf{P b} & \mathbf{V} & \mathbf{Y} & \mathbf{Z n} & \mathbf{N} \\ \text { GRAN } & 7 & 9 & 8 & 20 & -59 & 7 & -24 & -3 & -19 & 37 & -6 & 37 & 18 & 172 \\ \text { GBN } & 5 & -6 & 10 & 38 & 7 & -10 & 28 & -39 & 16 & 31 & -15 & 12 & -16 & 145 \\ \text { LAV } & 7 & -25 & -11 & -7 & 72 & -27 & 15 & -15 & 8 & 13 & -15 & 33 & 3 & 556 \\ \text { ANLE } & 7 & -4 & 32 & 55 & -2 & 23 & 15 & 17 & 24 & -9 & -15 & 3 & -51 & 145 \\ \text { PAV } & 6 & 3 & 3 & -37 & -3 & -9 & -15 & 13 & -12 & 24 & -11 & 61 & 29 & 782\end{array}$

\subsubsection{Regressão em função dos fatores}

Os modelos de regressão em função dos conteúdos de $\mathrm{Fe}$ e em particular de in não foram eficientes no prognóstico da distribuição dos traços. Por isso, foram ensaiados novos modelos considerando os fatores do tratamento 6 como variáveis independentes. A variância explicada pelo modelo $e$ os coeficientes das equações são apresentados na Tabela 28. 
Tabela 28. Variância explicada-Vex e coeficientes dos modelos de regressão para $\mathbf{C u}, \mathbf{P b}$ e $\mathbf{z n}$ em funçăo dos fatores do Tratamento 8 . Os teores dos traços foram expressados em logaritmos e divididos pelas medianas dos grupos definidos segundo os materiais amostrados.

$\begin{array}{crrllll}\text { Var1ável } & \text { VEX } & \text { Fator-1 } & \text { Fator-2 } & \text { Fator-3 } & \text { Fator-4 } & \text { Constant } \\ & & & & & & \\ \mathbf{C u} & 66 \% & 0,0846 & 0,0125 & 0.0166 & 0,0072 & 1,009 \\ \mathbf{P b} & 89 \% & -0,0140 & & 0,0156 & 0.1700 & 0,993 \\ \mathbf{Z n} & 63 \% & 0,0409 & 0,0371 & 0,0164 & & 1,004\end{array}$

No Mapa 9 os valores do $\mathrm{Cu}$ estimados pelo modelo foram representados segundo uma escala de cores e as residuais de $\mathrm{Cu}$ (Cu real - Cu estimado) foram representadas como mapa de círculos. A anomalia regional de $\mathrm{Cu}$ no setor $\mathrm{NW}$ foi bem representada pelo $\mathrm{Cu}$ estimado e as residuais de $\mathrm{Cu}$ aparecem associados ao Grupo Barriga Negra e ao Grupo Lavalleja. Uma anomalia de residuais de $\mathrm{Cu}$ com várias amostras associadas, ocorre nas proximidades da antiga Mina de Au. A ocorrência de Fe-Cu perto do povoado de Zapicán, também foi evidênciada pelas residuais de $\mathrm{Cu}$. O modelo de regressão também funcionou bem para - zn, más o $\mathbf{P b}$ mostrou residuais elevadas em regiões empobrecidas em $\mathrm{Pb}$, o que gera desconfiança no modelo. Observese que a variância explicada foi alta nos três casos, em especial para o $\mathrm{Pb}$. Pelo que o fracasso na estimação dos teores de $\mathrm{Pb}$ seria conseqüência da ineficiência das PCs para explicar a variância desse elemento.

\subsection{Processamento digital das imagens Landsat-TM}

Na Tabela 29 são apresentadas as características das seis bandas refletidas Landsat5-TM e alguns dados estatisticos para a área de pesquisa. A intensidade de cada banda é expressa em 256 níveis de cinza, de modo que a amplitude esta restrita ao intervalo 0 (preto) - 255 (branco). As médias mostram as diferenças entre as intensidades para cada banda espectral, sendo o desvio e o coeficiente de variação uma medida do contraste entre os pixels para cada faixa. Com exceção da banda TM4, que mostrou coeficientes de correlação baixos com as outras bandas $(0,09-0,51)$, as restantes apresentaram entre elas valores superiores a 0,69 . 


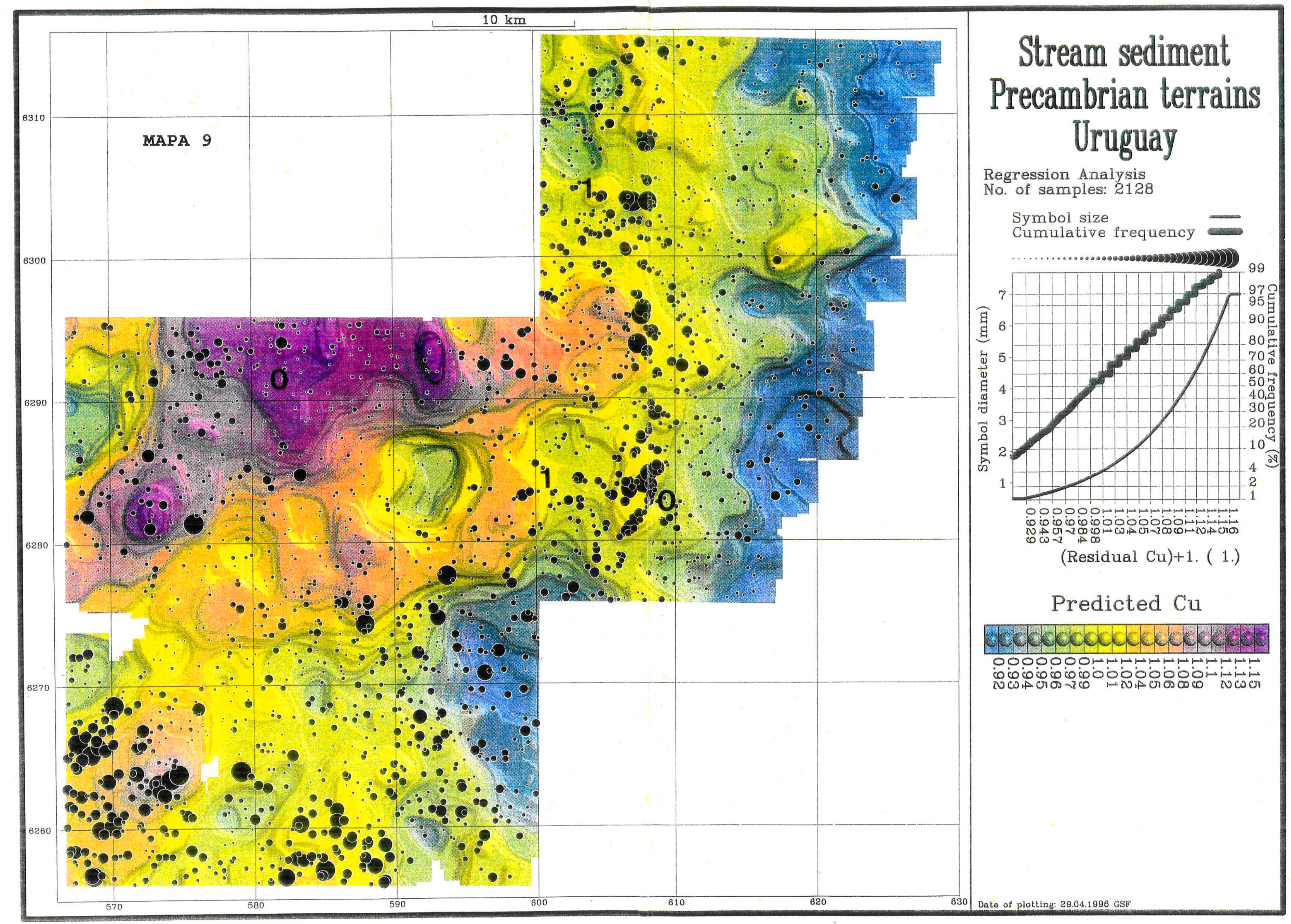


Tabela 29. Características das bandas Landsat-TM5 e estatisticas básicas na área de pesquisa. C.V. = Coeficiente de variação; I.V. = Infravermelho.

$\begin{array}{clrrrr}\text { Banda } & \text { Faixa Espectral } & \text { Amplitude } & \text { Media } & \text { Desvio } & \text { C.v. } \\ \text { TM1 } & \text { Azul } & 34-255 & 62 & 3,4 & 6 \% \\ \text { TM2 } & \text { Verde } & 8-175 & 31 & 2,8 & 9 \% \\ \text { TM3 } & \text { Vermelho } & 13-255 & 31 & 4,6 & 15 \% \\ \text { TM4 } & \text { I.V. proximo } & 3-206 & 83 & 13,7 & 16 \% \\ \text { TM5 } & \text { I.V. medio } & 1-255 & 108 & 17,7 & 16 \% \\ \text { TM7 } & \text { I.V. medio } & 1-255 & 30 & 7,0 & 23 \%\end{array}$

Foram geradas diversas composições coloridas com 0 software ER-MAPPER (1995). Uma das funções desse programa permite sobrepor três bandas, sendo atribuída uma cor para cada uma (red-R, green-G e blue-B), o que é denominado composição RGB. Assim, pode ser observada uma imagem próxima à cor natural com uma composição RGB das banđas TM3, TM2 e TM1 ( $R=T M 3 / G=T M 2 / B=T M 1)$. Varias outras combinações de bandas foram usadas para reconhecer as feições da área, $\mathrm{R}=\mathrm{TM} 3 / \mathrm{G}=\mathrm{TM} 4 / \mathrm{B}=\mathrm{TM} 1$ para destacar a vegetação, $R=T M 4 / G=T M 3 / B=T M 2$ para diferenciar óxidos e vegetação, $R=T M 5 / G=T M 3 / B=T M 1$ ou $R=T M 7 / G=T M 4 / B=T M 1$ para obter alguma discriminação de litologias. Um exemplo é apresentao na Figura 41 ( $R=T M 4 / G=T M 5 / B=T M 3)$. Observe-se que os afloramentos de rochas aparecem em azul claro e a vegetação em tons vermelhados. As imagens foram analisadas no monitor, considerando as bandas uma a uma ou combinações delas, utilizando os recursos de aumento do contraste, de aumento de tamanho (zoom) e de coloração (pseudo-cor, monocromatismo, etc.). Isso permitiu uma visão sinóptica da área e a descrição de diversos aspectos geográficos e geológicos. Os afloramentos de rochas foram diferenciados, porém sem discriminação das litologias. Pequenos corpos, como os veios máficos, não foram detectados, devido a limitação da resolução dos dados LandsatTM.

Foi também utilizada a técnica de Abrams (ABRAMS, 1977), que usa razões de bandas para diferenciar filosilicatos ( $R=T M 5 / T M 7), ~ \sigma ́ x i d o s ~(G=T M 3 / T M 2)$ e vegetação (B=TM4/TM3). Previamente foram corrigidos os efeitos atmosféricos pelo método do pixel escuro (CRÓSTA, 1993a). Nesse método, consideram-se 


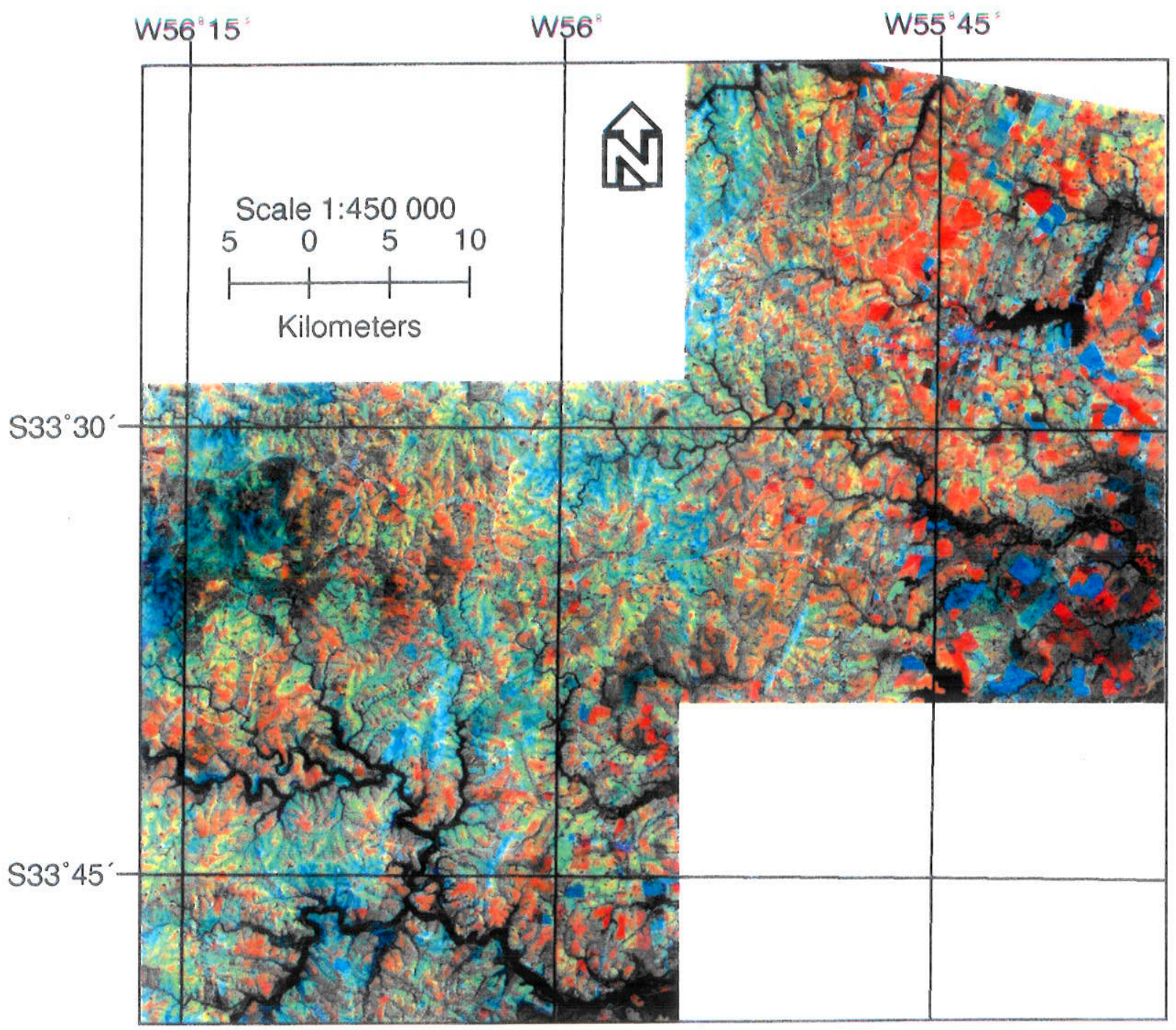

Figura 41. Composição RGB das bandas Landsat TM4, TM5 e TM3 da área de pesquisa. 
alguns pixels onde é certa a presença de água limpa. No caso, foi considerada uma lagoa perto da vila de J.P. Varela, que fornece a agua para o consumo dos seus habitantes. Esses pixels são considerados como sendo reflectância nula. Assim o valor médio de intensidade para esses pixels é atribuída ao efeito atmosférico e subtraido das bandas. Os valores obtidos para a correção foram $T M 1=45, T M 2=14, \quad T M 3=12, \quad T M 4=5$ e $T M 5=T M 7=1$. Observe-se que o valor da correção diminui ao passar da banda TM1 à banda TM6. Assim, se a correção não for efetuada, os valores das razões, e em conseqüência a imagem da técnica de Abrams, estariam incorretas. A técnica de Abrams evidenciou uma anomalia de filosilicatos ao norte da área de pesquisa e vários afloramentos com teores elevados de óxidos no Grupo Lavalleja e na Formação Pavas.

Na Figura 42 são apresentadas as dez classes da classificação não supervisionada dos dados originais das seis bandas, sendo atribuídas cores diferentes para cada uma. Algumas classes parecem ocorrer associadas, por exemplo, Classe 4 Classe 5 e Classe 7 - Classe 8, ao menos em certos setores. Na Tabela 30 são expostas as razões entre as médias das bandas para as 10 classes, a área ocupada e uma interpretação aproximada desses resultados. Usaram-se razões semelhantes às da técnica de Abrams para simplificar a interpretação. A razão TM3/TM1 é equivalente à TM3/TM2. As classes 7 e 8 , interpretadas como afloramentos de óxidos e outros afloramentos (com maior conteúdo de quartzo ou feldspatos em relação à óxidos), apresentam uma distribuição equivalente à dos óxidos na técnica de Abrams.

A ACP também foi utilizada para processar a informação Landsat-TM da área. As loadings das CPs da matriz de correlação são apresentadas na Tabela 31. A CP1 acumulou 71\% da variância total e evidencia uma forte correlação entre todas as bandas, com a exceção da banda TM4, fato normal em imagens multiespectrais de sensoriamento remoto. A CP2 está ligada à vegetação, o que foi indicado pela sua loading expressiva para a banda TM4, acompanhada pelas bandas TM2 (verde) e TM5. A CP3 representa os corpos de agua, alta reflexão no azul e no verde (bandas TM1 e TM2) e baixa no infra-vermelho médio (bandas TM5 e TM7). A CP4 e a CP5 estariam relacionadas à ocorrência de óxidos 

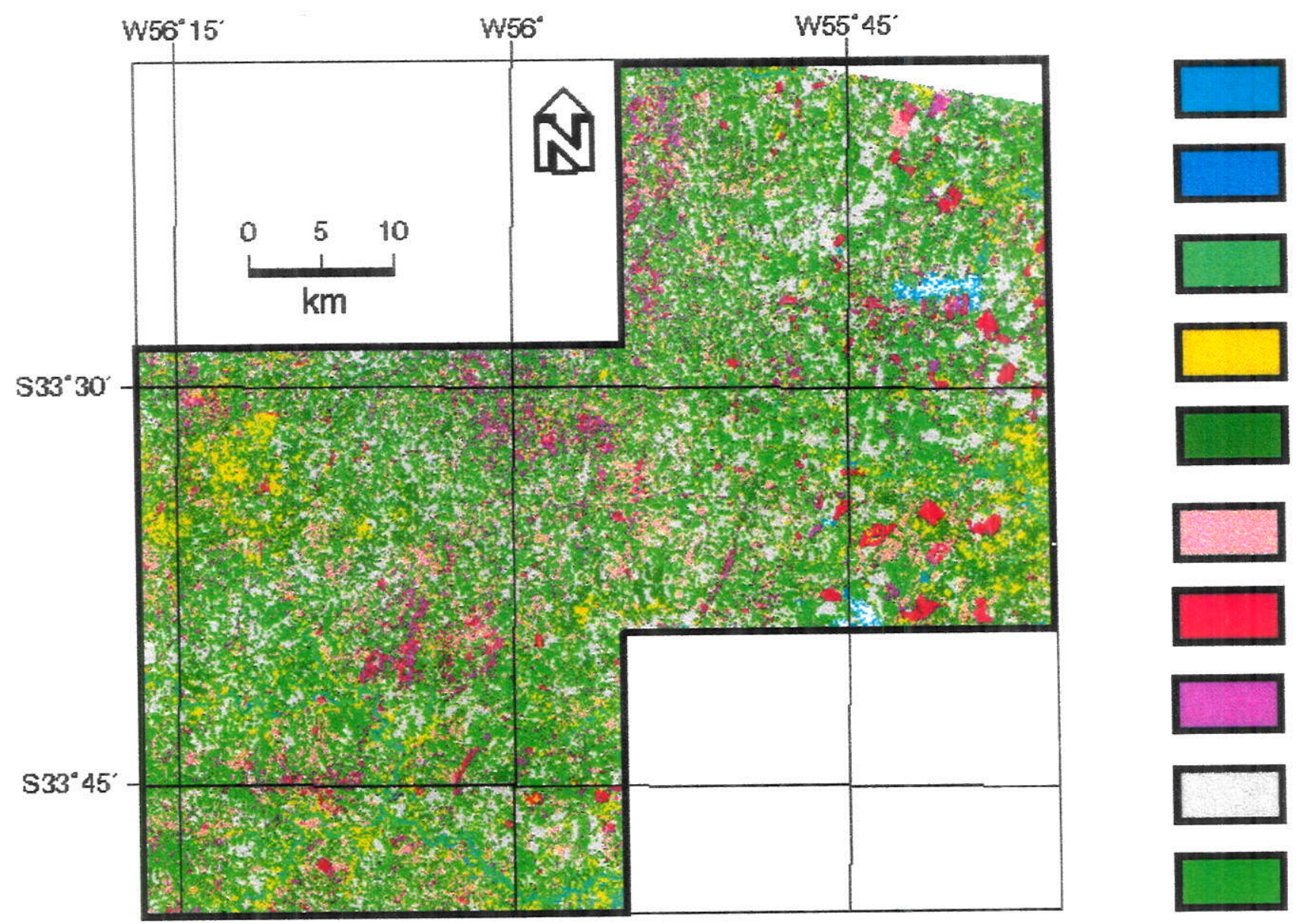

Água

Água turva

Florestas

Vegetação média

Vegetação média

Pastagens-solos

Afloramentos óxidos

Outros afloramentos

Pastagens

Pastagens-solos

Figura 42. Classificação não supervisionada usando as seis bandas refletidas Landsat-TM. A interpretação das classes é aproximada. 
(solos expostos) e de minerais com o grupo-OH (filosilicatos), evidenciadas pela resposta oposta entre as bandas TM3 e TM1, e entre as bandas TM5 e TM7, respectivamente. A CP6 não pôde ser interpretada, devido à presença de grande quantidade de ruído, o que é normal na ACP de imagens Landsat-TM. Na Figura 43 é apresentada uma composição RGB da CP5, da CP2 e da CP1. Os signos da CP2 e da CP5 foram trocados para destacar as regiões com vegetação intensa e com resposta alta da TM3 e da TM5. Observe-se que a CP5 representa rochas que possuem filosilicatos e também óxidos. A imagem obtida é aproximada a cor natural.

Tabela 30. Razбes entre as medias das bandas Landsat-TM corrigidas pelo efeito atmosférico, área coberta e interpretaça aproximada para as classes definidas pela classificação não supervisionada. Area em $\frac{\circ}{b}$ da área de pesquisa.

\begin{tabular}{cccccl} 
Classe & TM3/TM1 & TM4/TM3 & TM5/TM7 & Area,8 & Interpretaçå \\
1 & 1,00 & 2,44 & 3,71 & \multicolumn{1}{l}{0,8} & Água \\
2 & 1,00 & 3,45 & 3,56 & 1,1 & Agua turva \\
3 & 1,00 & 5,00 & 3,87 & 5,0 & Florestas (autoctones) \\
4 & 1,07 & 3,93 & 3,61 & 7,1 & Vegetação media \\
5 & 1,20 & 4,00 & 3,70 & 15,3 & Vegetaça media \\
6 & 1,11 & 3,80 & 3,53 & 20,3 & Pastagens-solos \\
7 & 1,27 & 2,29 & 2,88 & 2,7 & Afloramento de oxidos \\
8 & 1,14 & 3,24 & 3,38 & 4,6 & Outros afloramentos \\
9 & 1,12 & 4,89 & 3,89 & 19,5 & Pastagens \\
10 & 1,17 & 4,09 & 3,64 & 21,9 & Pastagens-solos
\end{tabular}

Tabela 31. Loadings das CPs da matriz de correlação das seis bandas refletivas Landsat-TM na área de pesquisa. VEX = Variancia explicada por cada CP.

$\begin{array}{crrrrrr}\text { Banda } & \text { CP1 } & \text { CP2 } & \text { CP3 } & \text { CP4 } & \text { CP5 } & \text { CP6 } \\ \text { TM1 } & 0,43 & 0,21 & 0,46 & -0,74 & 0,00 & 0,09 \\ \text { TM2 } & 0,45 & -0,14 & 0,38 & 0,52 & 0,28 & 0,53 \\ \text { TM3 } & 0,44 & 0,29 & 0,20 & 0,39 & -0,41 & -0,60 \\ \text { TM4 } & 0,19 & -0,87 & 0,10 & -0,13 & 0,12 & -0,41 \\ \text { TM5 } & 0,44 & -0,20 & -0,55 & -0,09 & -0,57 & 0,37 \\ \text { TM7 } & 0,44 . & -0,23 & -0,54 & -0,04 & 0,64 & -0,22 \\ \text { VEX } & \mathbf{7 1 8} & \mathbf{1 8 8} & \mathbf{5 8} & \mathbf{3 8} & \mathbf{1 8} & \mathbf{1 8}\end{array}$

Foram feitas diversas composições RGB das CPs, produzindo imagens com boa nitidez, porém nenhuma pareceu indicar aspectos específicos relacionados à exploração mineral, o que constituiu um dos principais objetivos desse trabalho. Por esse motivo, aplicou-se a técnica Feature-oriented Principal Components 


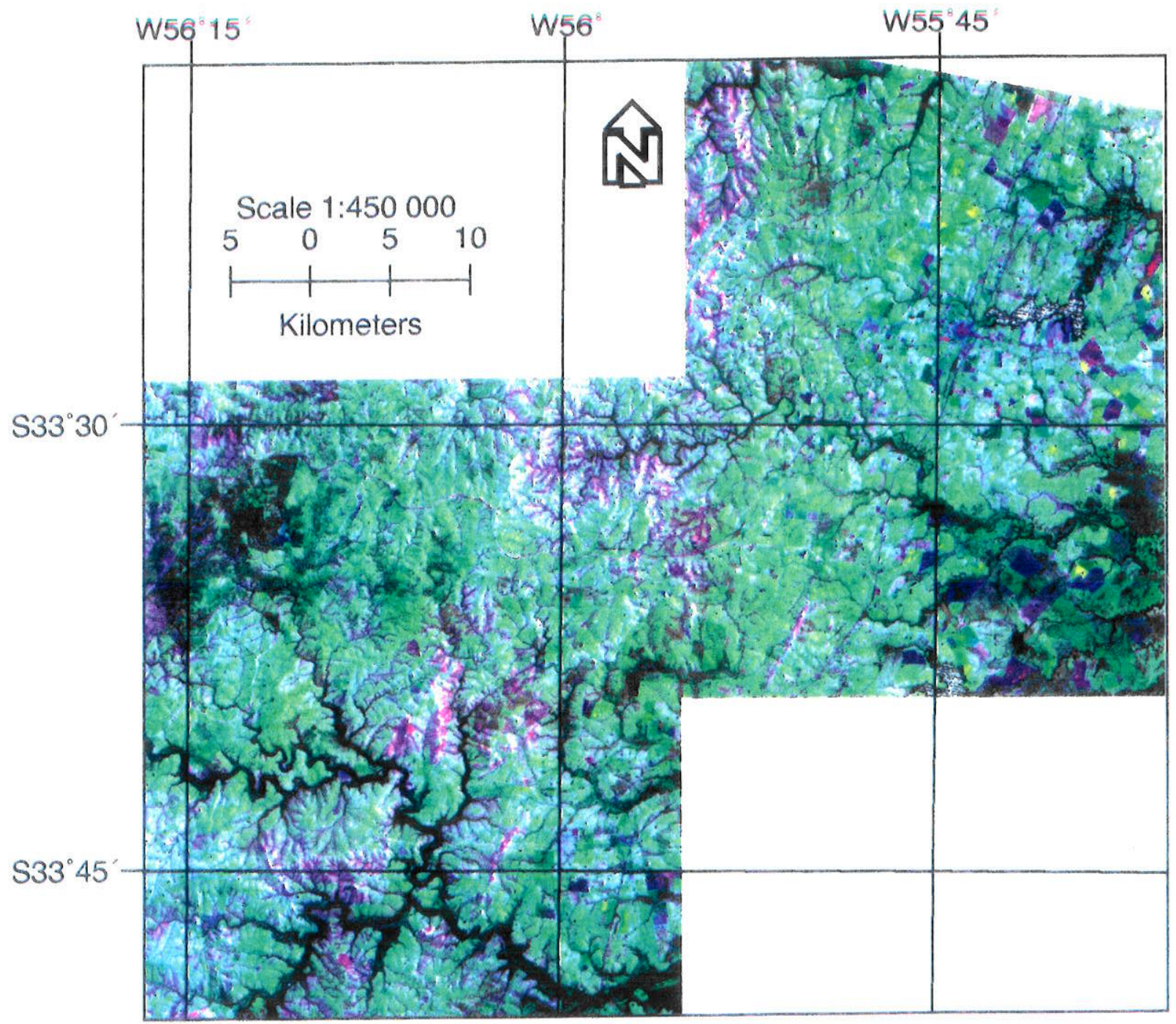

Figura 43. Composição RGB da CP5 (óxidos-filosilicatos), CP2 (vegetação) e CP1 (feições morfológicas). 
Selection-FPCS (CRÓSTA \& MOORE, 1989). As equações correspondentes ao Fator $-\mathrm{F}$ (relacionado aos óxidos) e do Fator-H (relacionado aos minerais que contém o grupo-OH) foram as seguintes :

$$
\begin{aligned}
& \text { Fator }-\mathrm{F}=-0,22 . \mathrm{TM} 1+0,38 . \mathrm{TM} 3+0,15 . \mathrm{TM} 4-0,25 . \mathrm{TM} 5 \\
& \text { Fator }-\mathrm{H}=0,04 . \mathrm{TM} 1-0,17 . \mathrm{TM} 4+0,41 . \mathrm{TM} 5-0,37 . \mathrm{TM} 7
\end{aligned}
$$

Nessas equações, as loadings foram divididas pela soma das loadings de cada fator, consideradas sempre em valor absoluto. A composição colorida gerada, $\mathrm{R}=$ Fator $-\mathrm{H}, \mathrm{G}=$ (Fator $-\mathrm{F}+\mathrm{Fator}-\mathrm{H}$ ) $\mathrm{e}$ $B=F a t o r-F$, mostrou uma imagem pouco nítida, pois a técnica extrai muito ruído junto com a informação dos minerais. Foram destacados os principais cursos hídricos e os afloramentos de rochas, em especial aqueles com conteúdo de óxidos mais alto. De qualquer maneira, $\circ$ Fator $F$ e $\circ$ Fator-H foram incluíos na integração com os dados geoquímicos, em função da sua importância do ponto de vista prospectivo.

\subsection{Integração dos dados}

A integração dos dados foi realizada considerando três métodos:

i. Sobreposição simples

ii. Classificação

iii. Técnicas de SIG.

os métodos são descritos a seguir.

\subsubsection{Sobreposição simples}

Este procedimento foi composto de duas etapas: definição dos setores anômalos pela avaliação do tratamento estatístico dos dados geoquímicos e sobreposição desses setores digitalizados em formato vetorial, a composições RGB dos dados Landsat-TM. 
Para a definição dos setores anômalos foram usados os mapas de teores brutos de Fe (Mapa 1), Mn (Mapa 6), Ag, As, Cr (Mapa 4), Cu, Ni, Pb (Mapa 7), Sn, $\mathbf{w}$ e $\mathbf{Z n}$, O mapa de residuais de $\mathrm{Cu}$ (Mapa 8), o mapa das $\mathrm{DM}$ e o fator-1 (Mapa 5), e o mapa de contraste entre as $D^{2}$ das primeiras e últimas CPs (Mapa 9). Esses mapas destacaram algumas anomalias poli-metalicas em relação ao fundo geoquímico, permitindo definir setores anômalos retangulares, com áreas de $16-60 \mathrm{~km}^{2}$, que foram numerados do 01 ao 09 (Figura 46).

Os setores anômalos e as principais falhas e limites geológicos todos eles em formato vetorial, foram superpostos às composições RGB das imagens Landsat-TM. Os setores anômalos 02 , 03, 04, 05 e 06 mostraram coincidência ou proximidade com relação a diques máficos que não foram visualizados nas imagens Landsat-TM, devido a suas pequenas dimensões. Existiram três casos nos quais a integração dos setores anômalos com as composições RGB pareceram ser úteis do ponto de vista de recursos minerais: (1) 0 setor 01 apresentou anomalias de $\mathbf{P b}$ ou Zn que pareceram estar relacionadas às porções de quartzito evidenciadas pelas imagens Landsat-TM (Figura 44). (2) No setor 04 as imagens Landsat-TM mostraram feições estruturais relacionadas às anomalias poli-metalicas. (3) 0 setor 07 inclui uma antiga Mina de Au e apresentou uma anomalia poli-metalica Ag-Cu-Pb-As. As imagens Landsat-TM não evidenciaram feições relacionadas à mineralização, porém mostraram um corpo aflorante caracterizado pela associação das classes 7 e 8 na Figura 42 . 0 setor 09 mostrou um corpo aflorante de características semelhantes e uma anomalia moderada de $\mathbf{A s - C u}-\mathbf{P b}$. $O$ ambiente geológico foi similar em ambos casos, de modo que o setor 09 foi definido por padrão de semelhança com o setor 07 (Figura 45).

\subsubsection{Classificação}

Na Figura 46 são expostos os resultados da classificação não supervisionada. A relação das doze classes com as catorze variáveis envolvidas é apresentada na Tabela 32 . As medianas de cada classe foram expressas como porcentagem da classe 1, que 


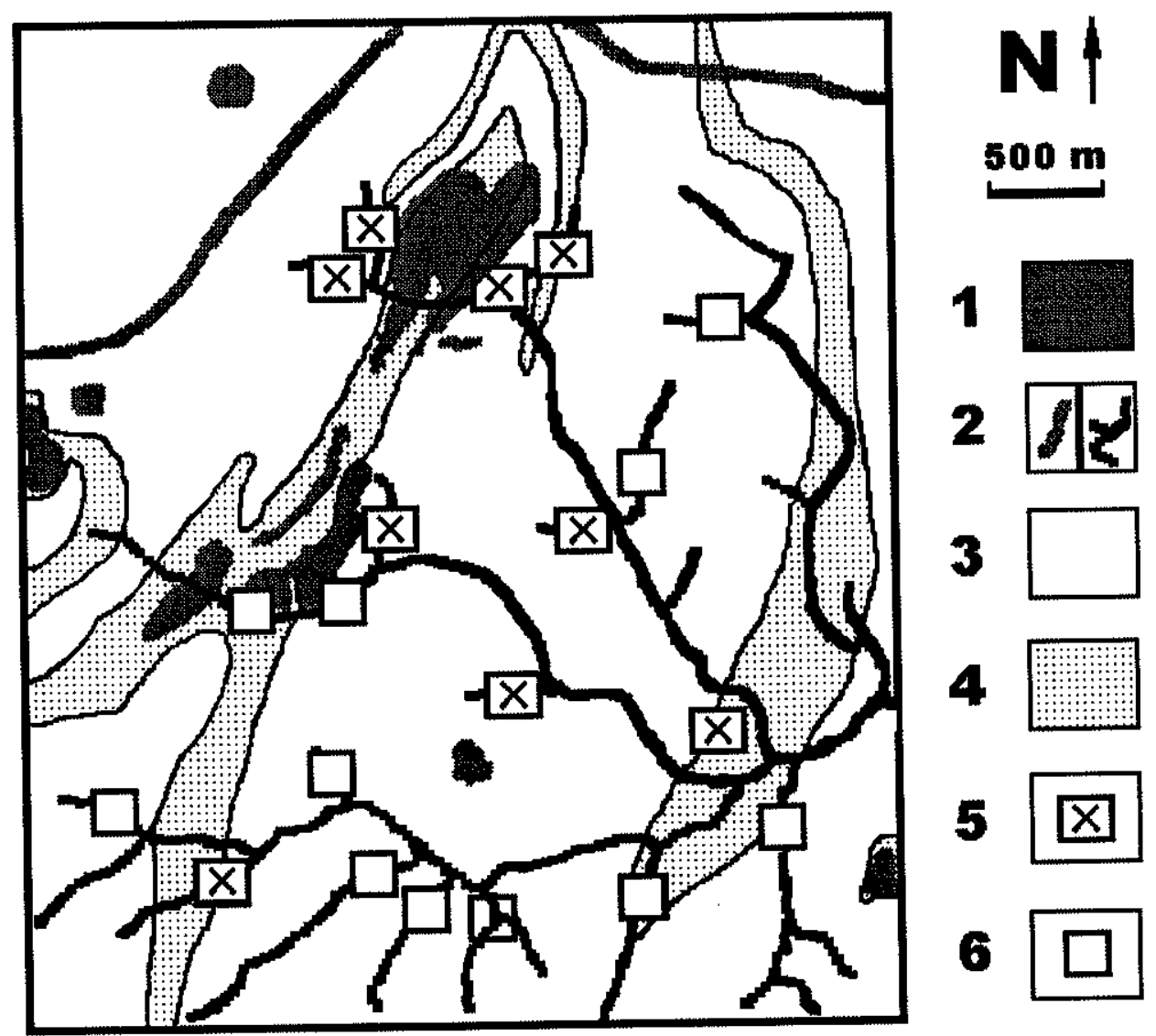

Figura 44. Relação espacial de amostras geoquímicas com feições geológicas para anomalia Pb-Zn. 1 = Rocha exposta em imagem Landsat-TM; 2 = Caminho/Cursos hídricos; 3 = rochas carbonáticas em mapa geológico; 4 = Quartzitos em mapa geológico; $\mathbf{5 / 6}=$ Amostras com teor de $\mathbf{P b}$ ou $\mathbf{Z n}$ superior/inferior a 1,5 vezes a mediana. 


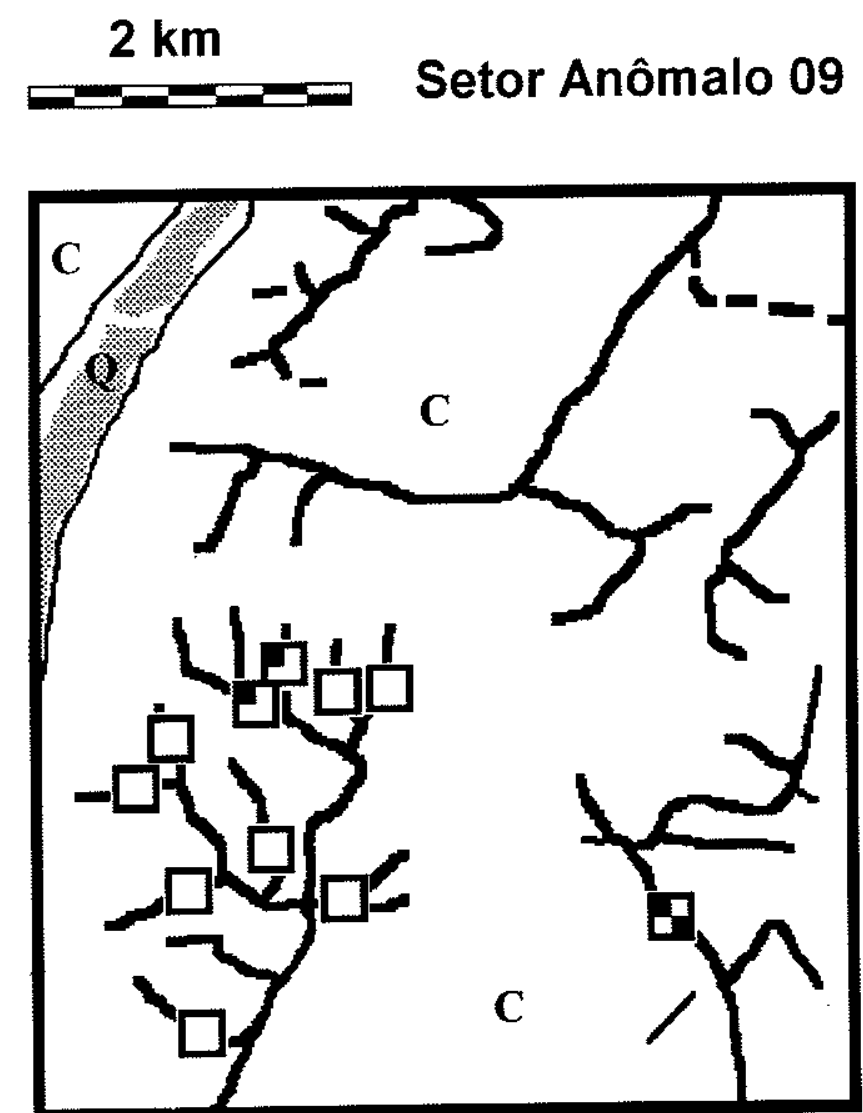

Mn-As घ $\mathrm{Pb}$

$\square$ Amostras background (ambos setores)

Afloramento em imagem Landsat-TM
$1 \mathrm{~km}$

Setor Anômalo 07

$M$

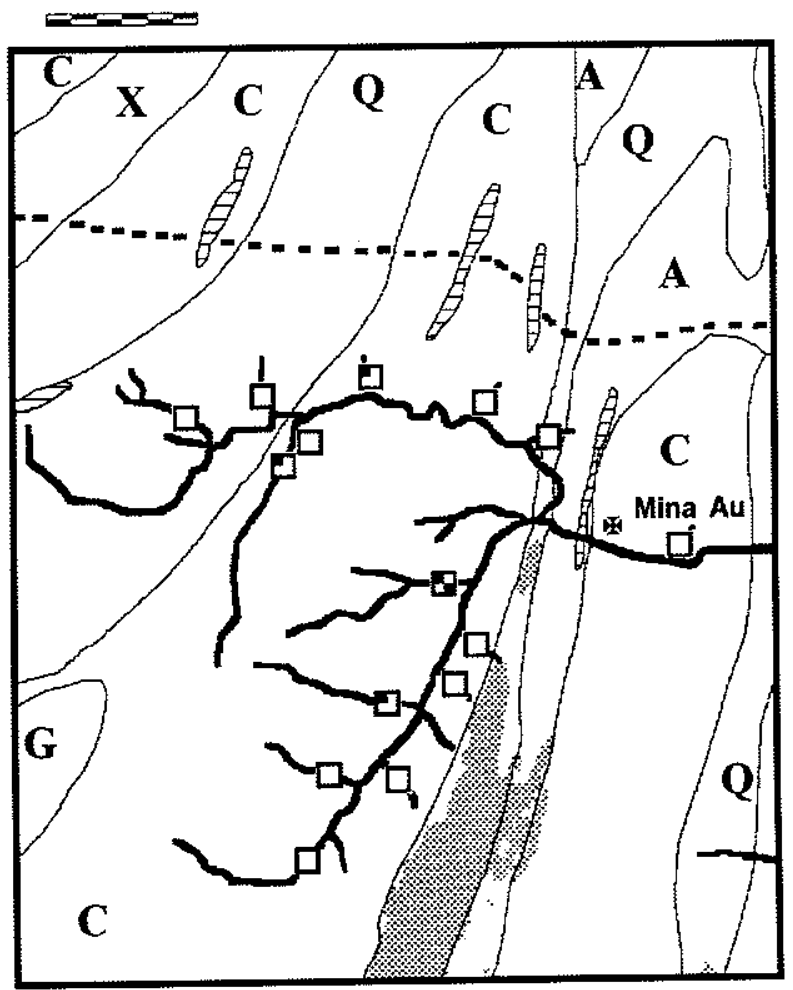

(Mn-Ag-Co-Cu-Pb

च As ou $\mathrm{Cu}$

月 Veios máficos

Figura 45. Esquema representativo dos setores anômalos 07 e 09. Para as amostras anômalas são indicados os elementos associados (quadrados recheios). $\mathbf{A}=$ Anfibolitos e leptitos; $\mathbf{C}=$ Calcário; $\mathbf{G}=$ Gnaiss; $\mathbf{Q}=$ Quartzitos e $\mathbf{X}=$ Xistos. 


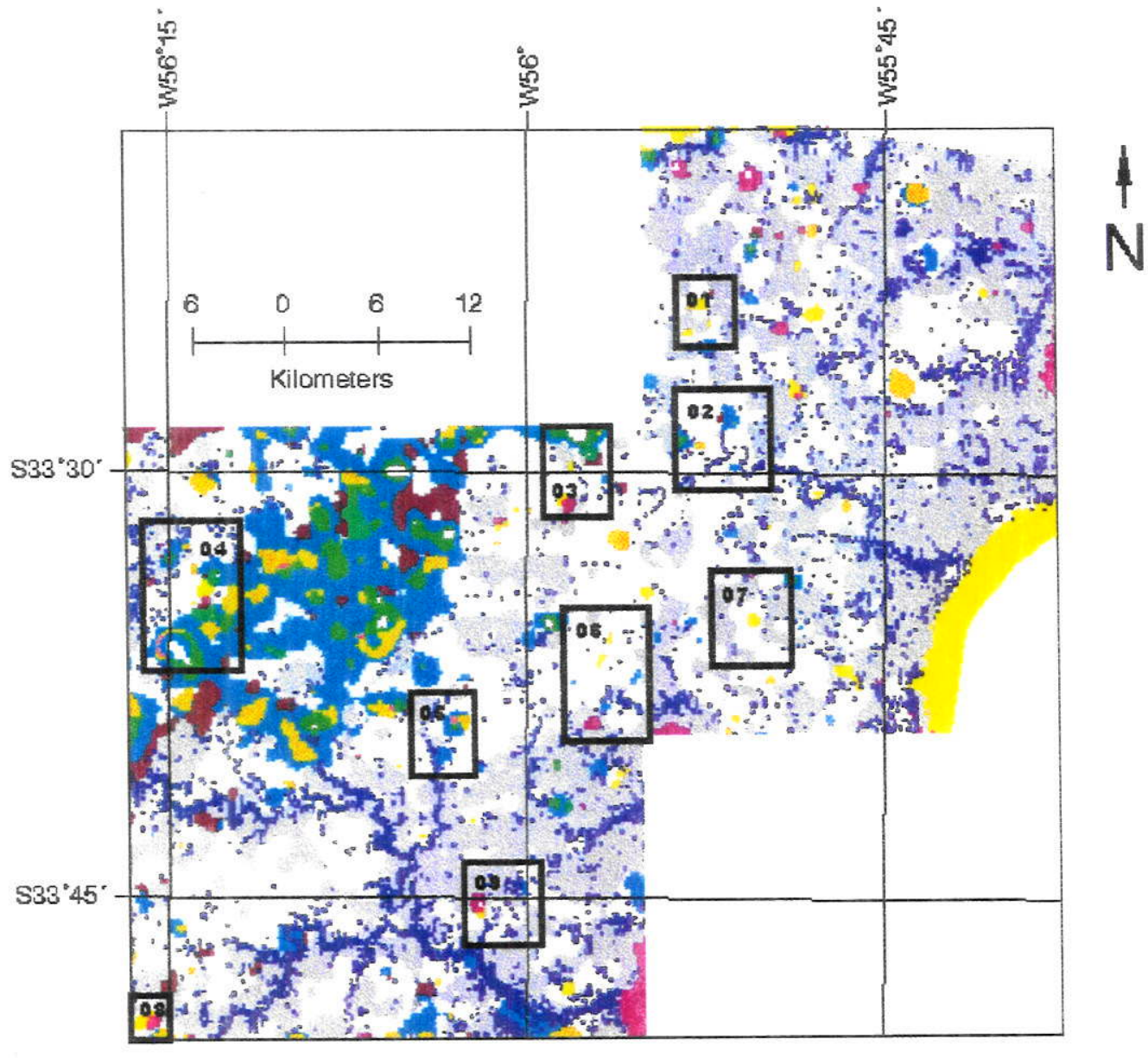

Anomalias definidas pelo tratamento estatístico

\begin{tabular}{|c|c|}
\hline Classe & Interpretação \\
\hline 1 & "Background baixo" \\
\hline 2 & "Background alto" \\
\hline 5 & Rios e florestas \\
\hline 4 & Possiveis mineralizações \\
\hline 6 & " \\
\hline 3 & Anomalias litológicas \\
\hline 7 & $"$ \\
\hline 8 & $"$ \\
\hline 9 & $"$ \\
\hline 10 & $"$ \\
\hline 11 & $"$ \\
\hline 12 & \\
\hline
\end{tabular}

Figura 46. Classificação não supervisionada usando 14 variáveis (TM4, Fator-F, Fator-H, Ba, Co, Cu, Mn, Ni, Pb, P, Rad- $\gamma, \mathbf{V}, \mathbf{Y}$ e Zn). 
foi usada como referência por mostrar-se geralmente empobrecida em relação às demais. o critério de discriminação foi o afastamento de mais de um desvio padrão da classe 1. As classes 8 a 12 apresentaram padrão de comportamento semelhante, podendo ser interpretadas, na verdade, como uma única classe.

A classificação supervisionada foi utilizada para comparar as características de todos os pixels da área com os de quatro polígonos escolhidos em locais estratégicos. Na Tabela 33 são apresentadas as coordenadas centrais, a área, o setor anômalo associado e as médias expressas como porcentagem da média da área de pesquisa para os pixels dos polígonos teste, que foram denominados com as letras $\mathbf{A}, \mathbf{C}, \mathbf{M}$ e $\mathbf{T}$. Os polígonos $\mathbf{A}$ e $\mathbf{T}$ estão associados a ocorrências minerais conhecidas e o polígono $\mathbf{M}$ às rochas máficas da Formação Pavas. O polígono c refere-se a uma anomalia moderada de $\mathrm{Cu}$, localizada na porção sul do setor 04 . Foram realizadas várias classificações supervisionadas, variando entre um e seis o número de desvios-padrões usados para discriminar as classes. Na Figura 47 é apresentado $\circ$ mapa considerando cinco desvios.

Tabela 32. Mediana de cada classe (CC) expressa como porcentagem da mediana da Classe 1, porcentagem de area ocupada e desvio padråo para a classe 1 (DPC1). $\mathbf{F =}$ Fator $-\mathrm{F}$ e $\mathrm{H=}$ Fator-H. Para facilitar a interpretacão o valor 100 foi substituido por "*".

\begin{tabular}{|c|c|c|c|c|c|c|c|c|c|c|c|c|c|c|c|}
\hline CC & TM4 & $F$ & H & $\mathbf{B a}$ & Co & $\mathbf{C u}$ & in & $\mathbf{N 1}$ & $\mathbf{P b}$ & $\mathbf{P}$ & $\operatorname{Rad}-\gamma$ & $\mathbf{V}$ & $\mathbf{X}$ & $\mathrm{Zn}$ & Área \\
\hline-- & --- & --- & -- & --- & -- & $\cdots$ & --- & -- & -- & $-\cdots$ & $---\cdots$ & --- & --- & --- & --- \\
\hline 1 & * & $\star$ & $\star$ & $\star$ & * & $\star$ & * & $\star$ & * & * & $\star$ & $\star$ & * & $\star$ & $28 \%$ \\
\hline 2 & * & * & * & * & 125 & 112 & * & 120 & $\star$ & $\star$ & * & 108 & $\star$ & 107 & $28 \%$ \\
\hline 3 & * & * & * & 105 & 116 & 131 & * & $\star$ & 80 & 111 & * & 111 & 142 & 119 & $4 \%$ \\
\hline 4 & 81 & 111 & 94 & 94 & * & * & * & 31 & 114 & $\star$ & * & * & $\star$ & 91 & $5 q$ \\
\hline 5 & 83 & 21 & 89 & * & * & * & $\star$ & $\star$ & $\star$ & $\star$ & $\star$ & * & * & * & $8 \%$ \\
\hline 6 & 88 & * & 96 & * & 149 & $\star$ & 127 & 76 & 150 & 95 & 106 & $\star$ & * & 94 & $5 \%$ \\
\hline 7 & $\star$ & * & * & * & 169 & 135 & 126 & * & 51 & 114 & * & 113 & 123 & 125 & $3 \%$ \\
\hline 8 & * & * & * & 105 & 132 & 119 & 107 & 139 & 67 & 108 & * & 111 & 116 & 113 & $12 \%$ \\
\hline 9 & $\star$ & * & * & 105 & 130 & 116 & 107 & 161 & 30 & 105 & * & 109 & 114 & 109 & $2 \%$ \\
\hline 10 & * & * & * & 107 & 144 & 136 & 123 & 223 & 24 & $\star$ & 92 & 116 & 125 & * & $1 \%$ \\
\hline 11 & * & * & * & 105 & 132 & 118 & 111 & 177 & 82 & 106 & * & 112 & 123 & * & $2 \%$ \\
\hline 12 & * & * & * & 104 & 162 & 155 & 124 & 169 & 49 & 107 & 94 & 116 & * & 111 & $2 \%$ \\
\hline P1 & 13 & 7 & 3 & 4 & 16 & 11 & 7 & 16 & 13 & 5 & 5 & 6 & 10 & 7 & \\
\hline
\end{tabular}




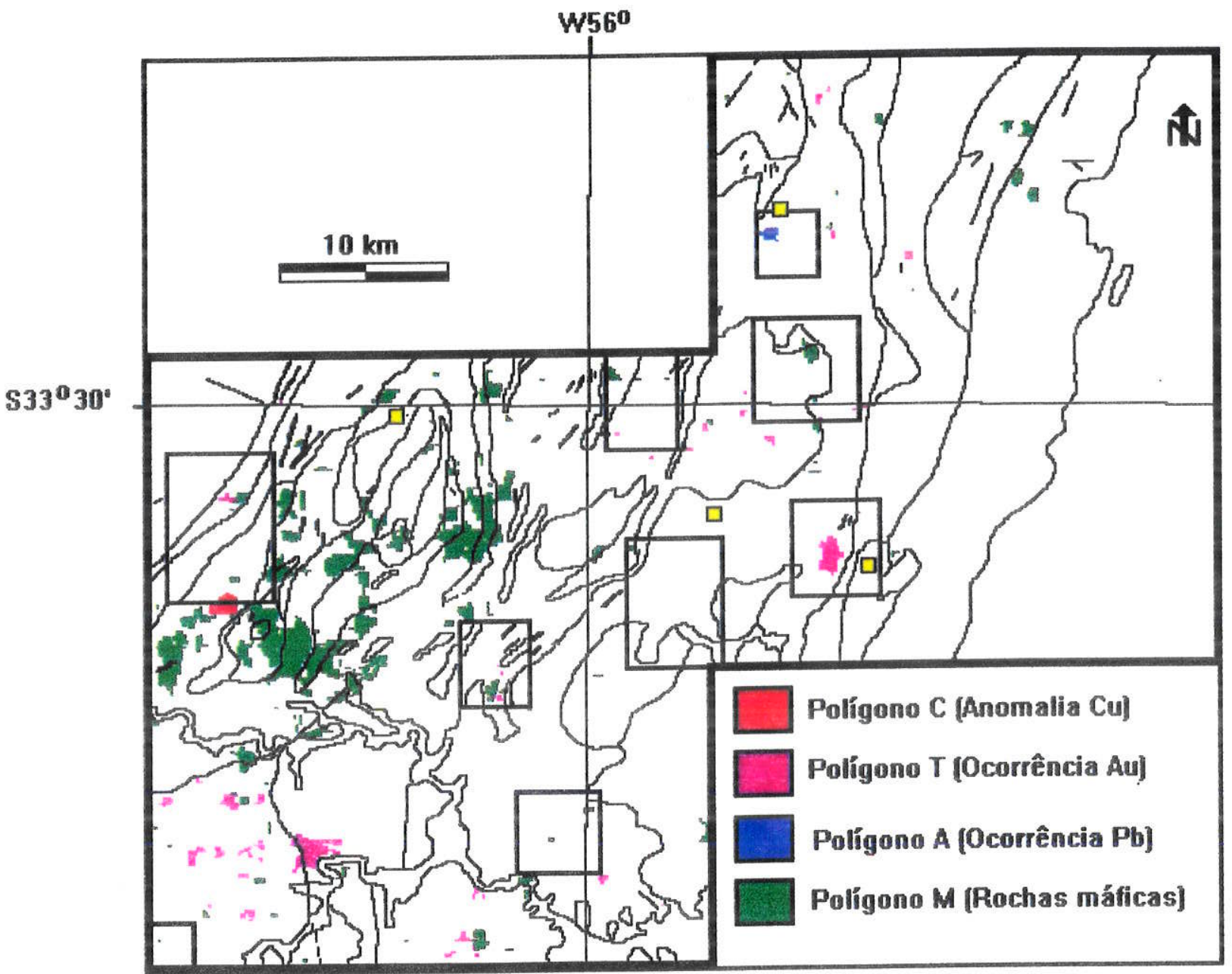

Figura 47. Resultados da classificação supervisionada considerando 14 variáveis (TM4, Fator-F, Fator-H, Ba, Co, Cu, Mn, Ni, Pb, P, Rad- $\gamma, \mathbf{V}, \mathbf{Y}$ e $\mathbf{Z n}$ ) e cinco desvios-padrões para discriminar as classes. As cores vermelho, magenta, azul e verde representam os pixels associados a cada polígono. Entre parênteses foram indicadas as feições características de cada um deles. As linhas pretas representam as principais falhas e contatos geológicos, os retângulos os setores anômalos definidos pelo tratamento estatístico dos dados geoquímicos e os quadrados amarelos as ocorrências minerais conhecidas. 
Tabela 33. Características dos grupos-teste da classificação supervisionada. As variáveis (TM4, Fator-F, Fator-H, Ba, Co, Cu...) foram expressas como porcentagem da media da área de pesquisa.

\begin{tabular}{|c|c|c|c|c|}
\hline Caracteristica & Poligono A & Poligono C & Rolígono $\mathrm{M}$ & Polígono \\
\hline UTM - X $\quad \mathrm{km}$ & 603,6 & 571,7 & 575,0 & 607,4 \\
\hline UTM-Y $\quad \mathrm{km}$ & 6303,6 & 6278,7 & 6277,0 & 6282,4 \\
\hline Area $\mathrm{km}^{2}$ & 0.32 & 0,56 & 2,20 & 0,48 \\
\hline Setor & 01 & 04 & Nenhum & 07 \\
\hline TM4 \% & 111 & 104 & 107 & 105 \\
\hline Fator $-F \div$ & 96 & 95 & 99 & 98 \\
\hline Fator $-\mathrm{H} \%$ & 103 & 102 & 101 & 102 \\
\hline Ba $\%$ & 106 & 90 & 103 & 113 \\
\hline Co \% & 99 & 89 & 93 & 163 \\
\hline $\mathrm{Cu}$ & 96 & 113 & 93 & 137 \\
\hline $\min$ & 108 & 86 & 101 & 114 \\
\hline $\mathrm{Ni}$ & 78 & 113 & 153 & 117 \\
\hline $\mathrm{Pb} \quad \frac{\circ}{6}$ & 157 & 16 & 67 & 139 \\
\hline $\mathbf{P} \%$ & 99 & 93 & 115 & 103 \\
\hline $\operatorname{Rad}-\gamma \div$ & 101 & 90 & 99 & 108 \\
\hline V 8 & 100 & 114 & 104 & 104 \\
\hline$Y \div$ & 102 & 126 & 117 & 118 \\
\hline Zn & 125 & 87 & 105 & 99 \\
\hline
\end{tabular}

\subsubsection{Técnicas de SIG}

Foram adotados critérios baseados em modelos exploratórios teóricos (GOVETT, 1983; GOVETT \& ATHERDEN, 1988), que permitiram hierarquizar os pixels da área de estudo em duas categorias (procedimento não ponderado) ou em quatro categorias (procedimento ponderado). Na Figura 48 são apresentados com símbolos dos principais setores selecionados pelo procedimento não ponderado. O tamanho dos setores não foi considerado ao reproduzir a figura.

$\mathrm{Na}$ Tabela 34 são indicados os parâmetros usados no procedimento ponderado. O programa GRASS gerou 41 classes que foram reagrupadas em quatro categorias (descarte, prioridade baixa, média e alta). A atribuição de tons de cinza a essas classes resultou no mapa da Figura 49. 


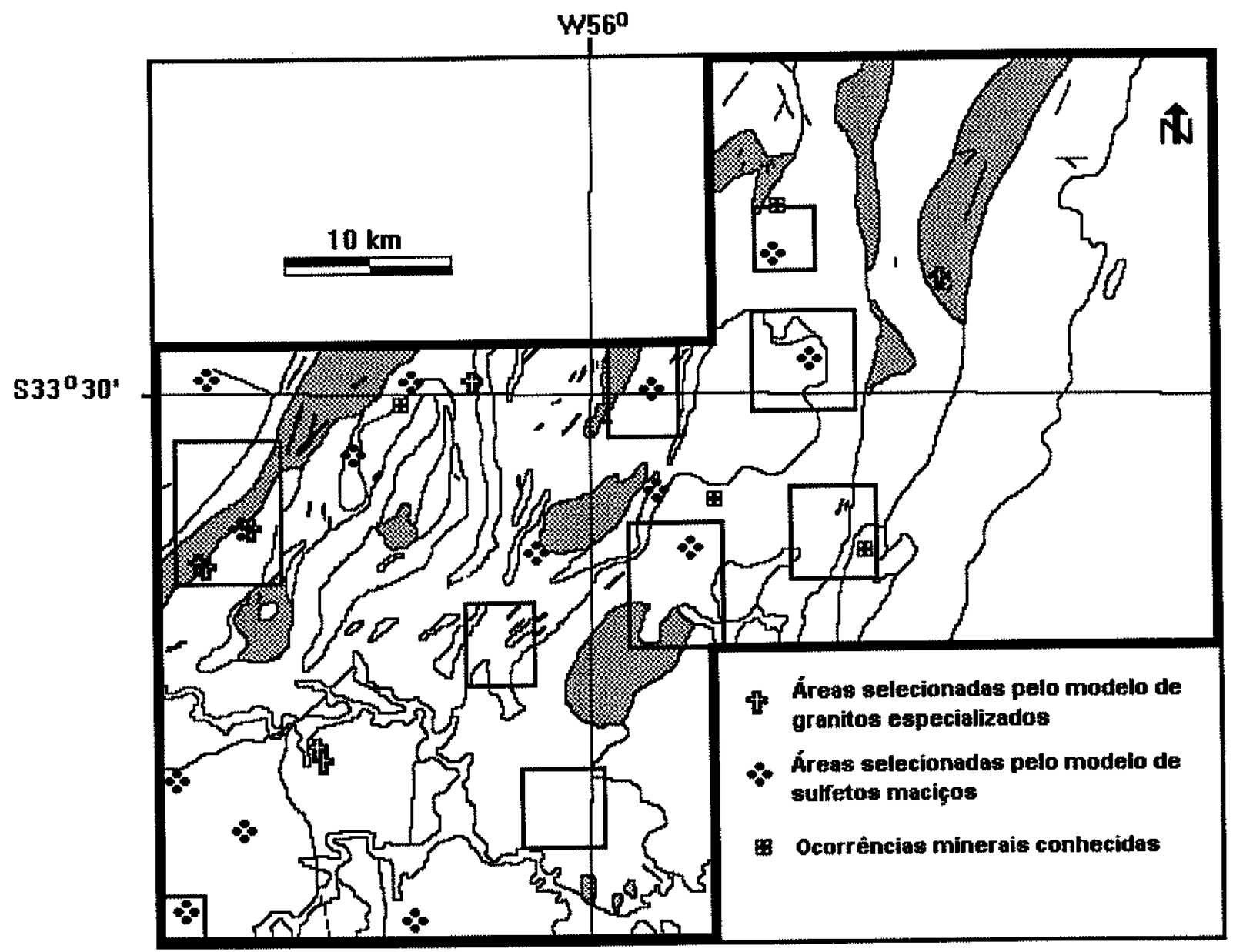

Figura 48. Principais áreas selecionadas pelo SIG (GRASS, 1991), através de um processamento não ponderado baseado nos modelos de granitos especializados e de depósitos de sulfetos maciços. Os corpos graníticos foram destacados em cinza para uma melhor apreciação. 


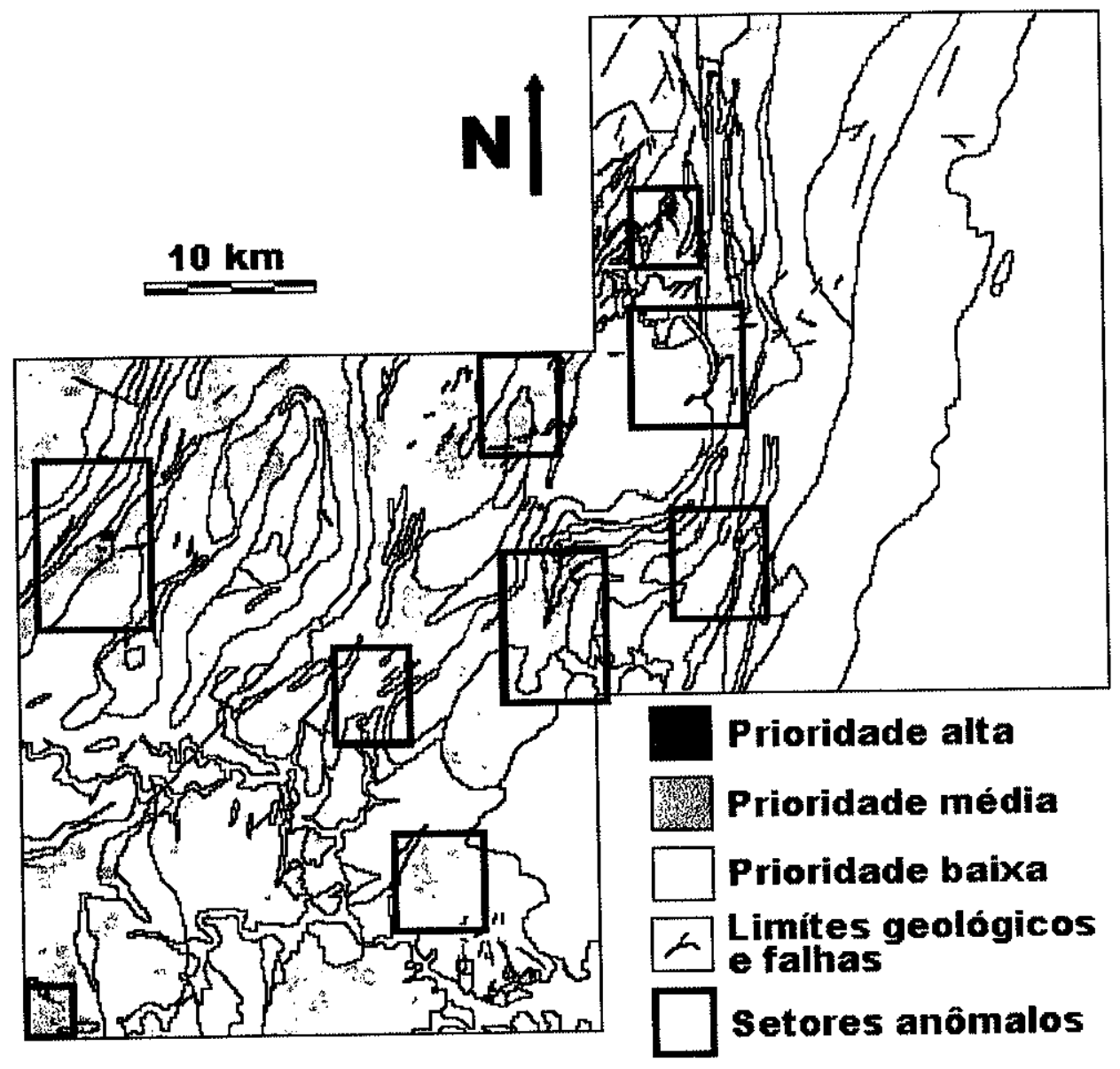

Figura 49. Zonas selecionadas pela análise espacial ponderada. As prioridades foram estimadas segundo um modelo exploratório teórico, incluíndo variáveis geoquímicas e aquelas extraídas pela aplicação da FPCS sobre os dados Landsat-TM. 
Tabela 34. Seqüencia logica final com ponderadores (Po) e indice aditivo. As variáveis foram transformadas segundo explicação apresentada no texto. SOPF $=(\mathbf{A g}+\mathbf{A} \mathbf{s}+\mathbf{C u}+\mathbf{P b}) / 10$. Intervalo que contém a mediana sublinhado.

\begin{tabular}{|c|c|c|c|c|c|c|c|c|c|}
\hline N1 & & $\mathbf{z n}$ & & SOPF & & Fator-F & & Fator-H & \\
\hline & & & & & & & & & \\
\hline iaçăo & Po & Variaçăo & PO & Variaçao & Po & $\begin{array}{l}\text { Varıaçao } \\
. . . . . . . . .\end{array}$ & PO & Varıaçá & \\
\hline $0-50$ & 9 & $115-156$ & 12 & $50-69$ & 12 & $120-255$ & 12 & $200-255$ & \\
\hline $51-85$ & 7 & $108-114$ & 8 & $35-49$ & 9 & $100-119$ & 9 & $185-199$ & \\
\hline $86-110$ & 3 & $101-107$ & 4 & $25-34$ & 5 & $70-99$ & 7 & $\underline{175-184}$ & \\
\hline $111-235$ & 0 & $0-100$ & 0 & $20-24$ & 3 & $50-69$ & 3 & $0-174$ & \\
\hline & & & & $0-19$ & 0 & $0-49$ & 0 & & \\
\hline
\end{tabular}

\subsection{Tratamento estatístico dos dados das sub-bacias}

Um dos objetivos de utilizar o método das sub-bacias foi avaliar e comparar a variância interna de cada sub-bacia em relação à variância geoquímica. Se essa variância fosse inferior à variância geoquímica, seria válido considerar as médias das variáveis como representativas da area de cada sub-bacia, constituindo verdadeiras amostras compostas.

No cálculo das sub-bacias foram consideradas 1943 amostras, pois as amostras de solos autóctones foram descartadas e as de solos aluviais foram utilizadas apenas no caso de haver poucas amostras ou quando houve semelhanças com as restantes amostras da sub-bacia. O tamanho médio das sub-bacias foi calculado de duas maneiras:

i. Pelo número médio de amostras por sub-bacia, que foi 6,5 , com intervalo de variação entre 3 e 10 .

ii. Dividinco a área total coberta pelo número total de sub-bacias $2210 / 332=6,7$.

Na Tabela 35 são apresentados os resultados da ANOVA, considerando as 332 sub-bacias como fator para o teste $F$ e teste não paramétrico de Kruskall-Wallis. Considerando um nível de significação de $2,5 \%$, os dois testes foram significativos para todos os elementos, indicando que a variância geoquímica foi superior à variância interna de cada sub-bacia em todos os casos. 
Tabela 35. Resultados da ANOVA de um nível, considerando como fator de influência as 332 sub-bacias. Foram ensaiados $\circ$ Teste $F e \circ$ Teste de Kruskall-Wallis. F=Coeficiente-F; SIg $(\mathbf{F})=$ Significancia de $F$; $\mathbf{K W = e s t a t i s t i c a ~}$ de Kruskall-Wallis, SIg(KW)= Significância de $\mathbf{K W}$ e GL=Graus de liberdade.

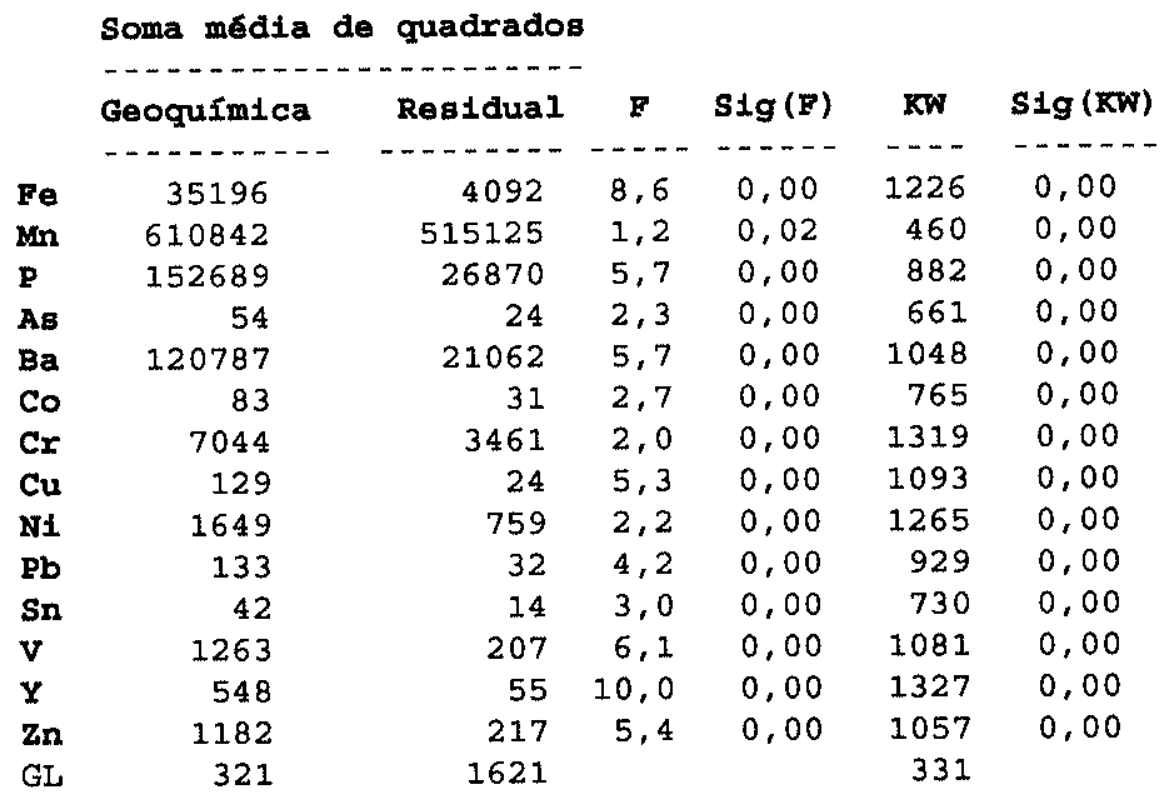

Na Tabela 36 são apresentados alguns dados estatísticos básicos para as sub-bacias. Existe uma diminuição da variabilidade em função de que os dados são médias de 3-10 amostras originais. Isso permitiu uma classificação em função da média mais um ou dois desvios-padrões. Para As e Sn somente foi considerado o limiar superior. Foram selecionadas 95 sub-bacias, que foram classificadas em sete grupos $\left(L_{a}, L_{S}, R_{0}, R_{C}, R_{i}, R_{m}\right.$ e Un) em função dos teores de Fe, Mn, As, Ba, Co, Cr, Cu, Ni, Pb, Sn, V e $\mathbf{z n}$ (Tabela 37). Na Figura 50 é apresentada a distribuição espacial das sub-bacias características. Considerando as feições geoquímicas das sub-bacias e sua localização, os grupos $R_{0}, R_{C}, R_{j}$ e $R_{m}$ parecem corresponder a anomalias regionais. $O$ grupo $R_{0}$ estaria associado a rochas félsicas enriquecidas em feldspato-K no vértice $\mathrm{NW}$ da área. $\mathrm{O} \mathbf{B a}$ e o $\mathrm{Pb}$, enriquecidos nessas sub-bacias, podem substituir ao $\mathbf{K}$ dos feldspatos. As sub-bacias do grupo Rc constituem um grupo heterogêneo. As sub-bacias localizadas mais ao norte estão sobre a Formação de Anfibolitas-Leptitas e apresentam teores elevados de $\mathrm{Pb}$ e $\mathrm{Sn}$. As outras, localizadas ao sul do povoado de María Albina e na Folha Pirarajá, apresentam associações incluíndo no 


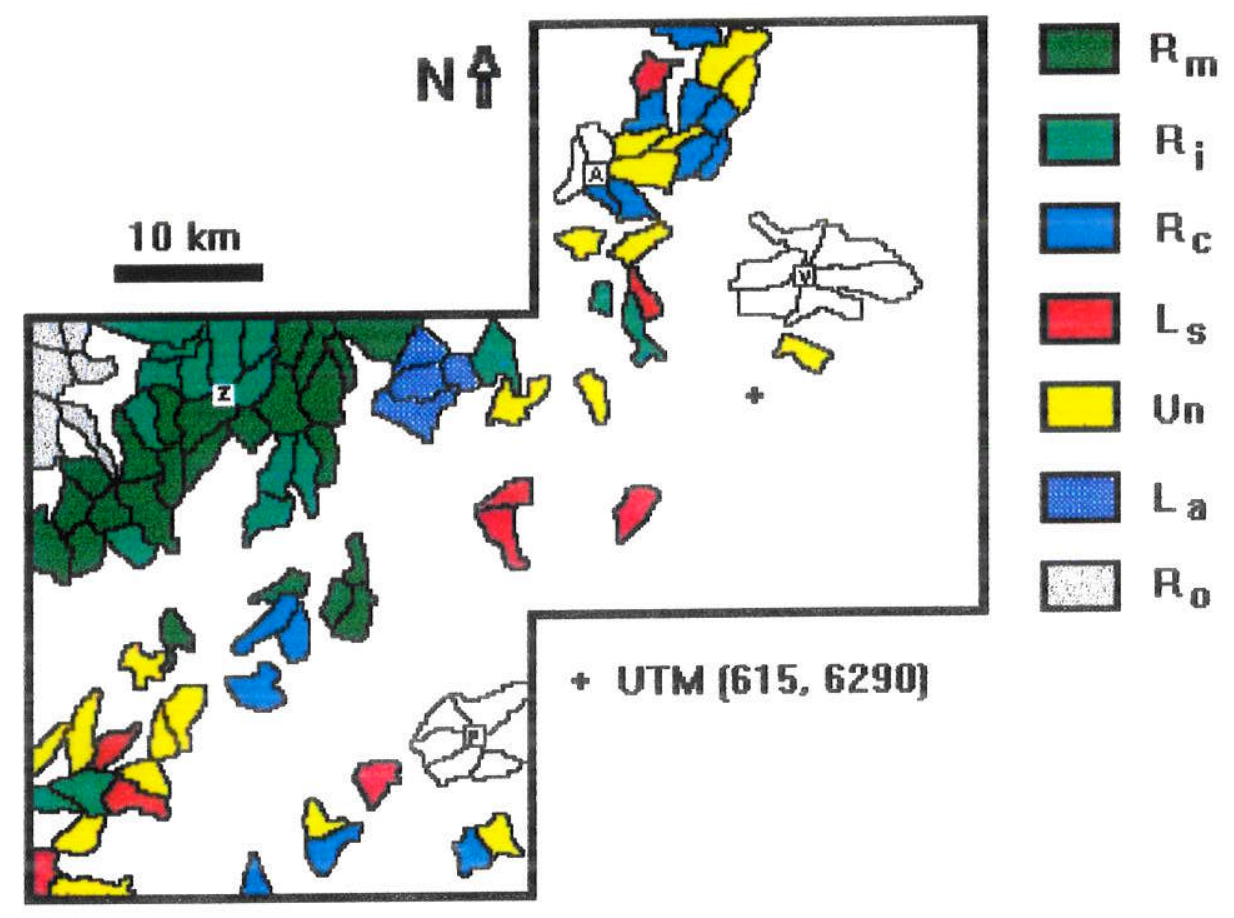

Figura 50. Sub-bacias características definidas em função dos teores e das associações geoquímicas. As sub-bacias em branco não apresentaram feições particulares, so foram indicadas como referência. $\mathbf{A}=$ María Albina, $\mathbf{V}=$ José $P$. Varela, $\mathbf{P}=$ Pirarajá e $\mathbf{Z}=$ Zapicán.

Nota: .O grupo $\mathrm{R}_{\mathrm{m}}$ representa sub-bacias enriquecidas em $\mathbf{C r}$-Ni e empobrecidas em $\mathbf{P b}$. $\mathrm{O}$ grupo $\mathrm{R}_{\mathrm{i}}$ representa sub-bacias com teores moderados de $\mathbf{C r}-\mathbf{N i}$, enriquecidas em $\mathbf{F e}, \mathbf{C u}, \mathbf{V}$ ou $\mathbf{Z n}$ e empobrecidas em $\mathbf{P b}$. $\mathbf{R}_{\mathrm{c}}$ é um conjunto de sub-bacias enriquecidas em $\mathbf{C u}$ ou $\mathbf{P b}$, também apresentando teores anômalos para $\mathbf{M n}, \mathbf{Z n}$ ou $\mathbf{S n} . \mathrm{L}_{\mathrm{s}}$ representa sub-bacias com anomalias de pelo menos dois elementos calcófilos (As, $\mathbf{C u}, \mathbf{P b}$ ou $\mathbf{Z n}$ ) e $\mathbf{L}_{\mathbf{a}}$ são sub-bacias enriquecidas em $\mathbf{C r}$, Ni e $\mathbf{P b}$. O grupo $\mathbf{R}_{0}$ representa sub-bacias ricas em $\mathbf{B a}$ e $\mathbf{P b}$, e o grupo Un sub-bacias com anomalias univariadas. Mais detalhes na Tabela 37. 
mínimo dois dos seguintes elementos $\mathbf{m} \mathbf{n}-\mathbf{C u}-\mathbf{P b}-\mathbf{V}-\mathbf{Z n}$, e estariam relacionadas às rochas carbonáticas do Grupo Lavalleja. Os grupos $R_{i}$ e $R_{m}$ estariam relacionados às rochas máficas da Formação Pavas, sendo as sub-bacias de $R_{i}$ representantes de rochas intermediárias ou da mistura de rochas félsicas e máficas. As sub-bacias do grupo $\mathrm{I}_{\mathrm{a}}$ apresentam enriquecimento em Cr, Ni e Pb, fato anômalo em função do observado para o total da área, e que foi interpretado como uma anomalia local. o grupo $R_{S}$ apresenta associações típicas de sulfetos (As, $\mathbf{C u}, \mathbf{P b}$ ou $\mathbf{Z n}$ ), e as sub-bacias estão relacionadas ao Grupo Barriga Negra ou ao Grupo Lavalleja. Considerando essa interpretação, 19\% das subbacias totais seriam anomalias regionais, 4 옹 anomalias locais e 6음 anomalias univariadas.

Tabela 36. Estatísticas básicas para os dados (médias) dos 332 subbacias definidos. $\mathrm{C} . \mathrm{V} .=$ coeficiente de variaçă. $(\mu+\sigma) ;(\mu+2 \sigma)=$ média mais um ou dois desvios.

\begin{tabular}{|c|c|c|c|c|c|c|c|}
\hline & Mínimo & Máximo & MédIa & Desvio & C.V. & $\mu+\sigma$ & $\mu+2 \sigma$ \\
\hline $\mathrm{Fe}, \frac{\mathrm{O}}{6}$ & 1 & 6 & 3 & 1 & $26 \%$ & 3,7 & 4,4 \\
\hline $\mathrm{kn}, \mathrm{ppm}$ & 373 & 2786 & 1026 & 319 & $31 \%$ & 1350 & 1665 \\
\hline P, ppm & 154 & 1611 & 290 & 170 & $59 \%$ & 460 & 630 \\
\hline As, ppm & 0 & 18 & 6 & 3 & $54 \%$ & & 12 \\
\hline $\mathrm{Ba}, \mathrm{ppm}$ & 342 & 1253 & 564 & 144 & $26 \frac{\circ}{\circ}$ & 710 & 850 \\
\hline Co, ppm & 6 & 29 & 13 & 4 & $28 \%$ & 17 & 20 \\
\hline Cr,ppm & 13 & 390 & 42 & 33 & $79 \%$ & 75 & 108 \\
\hline Cu, ppm & 9 & 37 & 19 & 5 & $24 \%$ & 24 & 28 \\
\hline $\mathbf{N 1}, \mathrm{ppm}$ & 6 & 188 & 22 & 16 & $72 \%$ & 38 & 54 \\
\hline $\mathrm{pb}, \mathrm{ppm}$ & 3 & 58 & 14 & 5 & $36 \%$ & 19 & 24 \\
\hline $\mathrm{sn}, \mathrm{ppm}$ & 0 & 20 & 4 & 3 & $72 z$ & & 9 \\
\hline V, ppm & 30 & 117 & 65 & 14 & $22 \frac{\circ}{6}$ & 79 & 93 \\
\hline $\mathbf{Y}, \mathrm{ppm}$ & 13 & 68 & 24 & 9 & 398 & 33 & 43 \\
\hline $\mathbf{z n}, \mathrm{ppm}$ & 36 & 116 & 60 & 14 & $23 \%$ & 74 & 88 \\
\hline
\end{tabular}


Tabela 37. Caracteristicas das sub-bacias classificadas em grupos, em função dos teores de $\mathbf{F e}, \mathbf{M n}, \mathbf{A s}, \mathbf{B a}, \mathbf{C o}, \mathbf{C r}, \mathbf{C u}, \mathbf{N i}, \mathbf{P b}, \mathbf{S n}, \mathbf{v}$ e $\mathbf{z n} . \mu, \mu+\sigma$, $\mu+2 \sigma$ referem-se à media, a media mais um desvio-padråo e a media mais dois desvios-padroes.

\begin{tabular}{|c|c|c|c|}
\hline Sub-bacia & Follha & Teores caracteristicos & Grupo \\
\hline $1,2,5,6,7,19$ & Zapicán & $\mathrm{Ba}>800 \mathrm{ppm} ; \mathrm{pb}>19 \mathrm{ppm}$ & $R_{0}$ \\
\hline $\begin{array}{l}3,9-13,29,38 \\
41,47,82,116\end{array}$ & $\begin{array}{c}\text { Zapicán } \\
" ~\end{array}$ & $\begin{array}{l}\mathbf{C x}<70 ; \mathbf{N 1}<35 ; \mathbf{P b}=4-15 \\
\mathbf{P e}, \mathrm{Cu}, \mathrm{V} \text { ou } \mathrm{Zn} \text { iguais ou }\end{array}$ & $R_{i}$ \\
\hline 133 & $"$ & acima de $(\mu+\sigma)$ & \\
\hline 223,224 & Piraraja & & \\
\hline 92,238 & Varela & & \\
\hline $14-17,21,22$ & Zapicán & $\mathrm{Cr}>67 ; \mathrm{Ni}>35 ; \mathrm{Pb}=5-13$ & $\mathrm{R}_{\mathrm{m}}$ \\
\hline $24-28,36,37$ & " & Pode acontecer Fe, $\mathbf{m}$, Co, & \\
\hline $39,40,44,48$ & $"$ & Cu, v ou Zn acima $(\mu+\sigma)$ & \\
\hline $51,52,74,75$ & $"$ & & \\
\hline 77,330 & $"$ & & \\
\hline 135,174 & Piraraja & & \\
\hline $71,78-80$ & Zapican & $\mathbf{C r}>70 ; \mathbf{N 1}>35 ; \mathrm{Pb}>20$ & $L_{a}$ \\
\hline 63,65 & Zapicán & Verificam-se pelo menos duas & $I_{s}$ \\
\hline 127 & Gutierrez & das seguintes condiços: & \\
\hline $\begin{array}{l}179,192,221 \\
228\end{array}$ & $\begin{array}{c}\text { Piraraja } \\
" ~\end{array}$ & 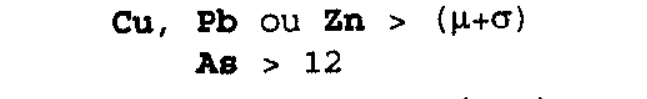 & \\
\hline 240,285 & Varela & As vezes Fe ou $\mathrm{Mn}>(\mu+\sigma)$ & \\
\hline $139,165,171$ & Piraraja & Cu ou $\mathrm{Pb}>=(\mu+\sigma)$ & $\mathbf{R}_{\mathrm{C}}$ \\
\hline $198,206,211$ & $"$ & $\operatorname{Mn}$ ou $\mathbf{Z n}>\boldsymbol{\mu}$ ou $\mathbf{S n}>9$ & \\
\hline $271,276,279$ & Varela & & \\
\hline $283,287,301$ & $"$ & & \\
\hline 302,314 & $"$ & & \\
\hline $\begin{array}{l}69 \\
84,105\end{array}$ & $\begin{array}{l}\text { Zapicán } \\
\text { Gutierrez }\end{array}$ & $\begin{array}{l}\text { Anomalias univariadas As, Cu, } \\
\text { Pb, } \mathbf{S n} \text { ou } \mathbf{Z n}\end{array}$ & Un \\
\hline $176,181,182$ & Piraraja & As vezes Fe ou $\mathrm{Mn}>\mu$ & \\
\hline $200,207,217$ & " & & \\
\hline $222,226,230$ & $"$ & & \\
\hline 234 & $"$ & & \\
\hline $267,268,278$ & $"$ & & \\
\hline $281,282,306$ & $"$ & & \\
\hline 308 & $"$ & & \\
\hline
\end{tabular}




\section{DISCUSSÃO}

\subsection{Qualidade da informação geoquímica}

$\mathbf{F e}, \mathbf{M n}, \mathbf{P}, \mathbf{B a}, \mathbf{C o}, \mathbf{C r}, \mathbf{C u}, \mathbf{N i}, \mathbf{P b}, \mathrm{V}, \mathbf{Y}$ e $\mathbf{Z n}$ apresentaram erros analíticos inferiores a $10 \%$ e muitos valores acima dos limites de detecção analítica-LIDAs, pelo que foram escolhidos para o tratamento estatístico. $\mathbf{A g}, \mathbf{A s}, \mathbf{B}, \mathbf{B e}, \mathbf{C d}, \mathbf{M o}, \mathbf{M b}, \mathbf{S b}$, $\mathbf{S n}$ e $W$ apresentaram erros analíticos elevados, acima de 15\%. Sendo considerados apenas os valores acima ou próximos aos LIDAs. Em relação à exatidão das análises, SPANGENBERG (1983) mencionou que algumas amostras de padrões secundários analisadas na DINAMIGE (Uruguai) e no BRGM (França), simultaneamente, mostraram correlação pobre para $\mathbf{P}, \mathbf{C o}, \mathbf{C u}, \mathbf{P b} e \mathbf{Y}$.

Alguns dos elementos com erros analíticos baixos apresentaram erros de amostragem elevados (P, Co, $\mathbf{Y} . .$. ). Como foi discutido na seção 3.1, esses erros seriam explicados por três fatores: (i) Mudanças rápidas da litologia em distâncias curtas. (ii) Efeito pepita provocado pela ocorrência de óxidos de un-Fe. (iii) Erros na metodologia de coleta das amostras (amostragem muito restrita em relação à área de influência e forma inadequada de coletar as duplicatas).

No método das sub-bacias, a variância interna das subbacias foi sempre inferior à variância geoquímica global (Tabela 34), o que sugere, de forma indireta, que existiram problemas no método de amostragem. A influência das mudanças rápidas da litologia foram constatadas nos mapas de distribuição das diferenças relativas entre as duplicatas de amostragem, que apresentaram diferenças elevadas relacionadas à Formação Pavas, onde ocorrem faixas alternadas de rochas félsicas e máficas de largura quilométrica. A ocorrência de duplicatas com diferenças elevadas para mn e co sugeriu a possibilidade do efeito pepita, pela geração de nódulos (ou micronódulos) de óxidos de $\mathbf{m}$. Poderia ser concluído que os erros de amostragem foram superestimados, devido à forma como foi efetuada a coleta e à ocorrência de modificações rápidas da litologia.

Dois problemas de ordem analitica não foram avaliados:

(1) A ausência de replicatas inter-folhas. 
(2) A ocorrência de interferências.

- tópico (1) poderia ser resolvido considerando padrões secundários, isto é, amostras que fossem sempre intercaladas durante a análise de cada uma das folhas. As amostras foram coletadas em um período de cinco anos e isso poderia produzir variações de ordem instrumental ou dos reagentes utilizados. segundo o laboratório da DINAMIGE, essas variações foram verificadas como de pequena magnitude. Os mapas de círculos, das replicatas de amostragem ou dos teores brutos não sugeriram a existência de variações inter-folhas. Em relação ao problema (2), não há informações sobre interferências nas análises da DINAMIGE. TRESCASES (1984) indicou interferências nas linhas de absorção atômica para vários elementos, por exemplo, Al, Fe, Co e Ni interferem na linha $2795 \AA$ do $\mathbf{M n}$, Ni e Fe com a linha $2407 \AA$ do co. Porém, no mesmo texto, DUTRA (1984) não mencionou interferências desse tipo na espectrometria de emissão. SKOOG \& LEARY (1994) indicaram ausência de interferências para soluções preparadas de $\mathbf{B e}, \mathbf{C d}, \mathbf{C r}, \mathbf{P b} \mathbf{e} \mathbf{z n}$ analisadas por espectrometria ICP.

A $\operatorname{Rad}-\gamma$ e $\circ$ pH foram determinados no campo, de modo que a sensibilidade da medida pode ser inferior à dos elementos químicos. De qualquer forma, foram de utilidade na descrição do ambiente geoquímico (Figuras 24 e 25).

\subsection{Sobre os métodos de processamento}

Os métodos utilizados para processar os dados relativos a este trabalho podem ser sintetizados em quatro modalidades:

(1) Tratamento estatístico dos dados geoquímicos originais

(2) Tratamento estatístico dos dados das sub-bacias

(3) Métodos de classificação (dados digitais)

(4) Procedimentos que usaram SIG (dados digitais)

- método (1) considerou procedimentos estatísticos univariados e multivariados, e diversas formas de mapeamento da informação geoquímica. A maioria das variáveis mostrou um melhor ajuste ao comportamento log-normal (Tabela 8 e Figuras 13-16). 
Por esse motivo, no caso univariado, foram preferidos os métodos não paramétricos ou trabalhou-se por comparação.

GARRETT (1989) mostrou que, se um conjunto de dados multivariados apresenta distribuição $\mathrm{N}$-normal/N-log-normal, o gráfico de probabilidade teórica para as $\mathrm{DM}^{2}$ mostrará uma reta, ao se utilizar escala linear/logarítmica. No presente trabalho, esses gráficos resultaram completamente deformados para os dados geoquímicos originais (Figura 38), sugerindo a existência de um grande número de outliers. Do ponto de vista estatístico, as outliers devem ser descartadas, pois prejudicam os resultados dos procedimentos multivariados. Porém, do ponto de vista geoquímico devem ser considerados dois aspectos:

(1) Grande parte das outliers são, na verdade, anomalias geoquímicas.

(2) Em prospecção geoquímica regional, o conjunto original de amostras pode estar constituído por várias sub-populações de resposta característica, produzindo deformação nos resultados dos métodos multivariados, em forma adicional à provocada pelas outliers.

Em função dos resultados da ANOVA (Tabela 10 e Figuras 19 23), constatou-se que um dos fatores de controle da variância geoquímica foi o litotipo das rochas de procedência. Assim, as sub-populações mencionadas acima estariam definidas pelas amostras relacionadas a cada litotipo. Por isso, os procedimentos multivariados ( $A C P, A F, A R .$. ) foram aplicados comparando diversas formas de tratamento (Tabela 14), analisando a distribuição espacial dos mapas das CPs, dos fatores ou residuais (Figuras 36-40, Mapas 5-8), ou aplicando esses métodos para as sub-populações definidas pelo litotipo das rochas de procedência (Tabelas 23-27).

No método (2) foram aplicados procedimentos simples, como a determinação das sub-bacias em função da amostragem, o relevo e a hidrografia, o cálculo das médias de cada sub-bacia e alguns tratamentos estatísticos univariados. A resposta geoquímica foi menos sensível, mas suficiente para detectar as principais anomalias locais, sendo discriminadas as anomalias regionais. 0 mapa das sub-bacias características (Figura 50) apresentou semelhanças com o da classificação não supervisionada (Figura 
46). Nessa comparação as sub-bacias representam celas de tamanho médio de $6-7 \mathrm{~km}^{2}$, e na classificação não supervisionada as celas foram de $0,04 \mathrm{~km}^{2}$. Assim, procedimentos diferentes, produziram resultados semelhantes. Um comentário análogo poderia ser realizado considerando a imagem do fator-1 (Mapa 5).

Os métodos (3) e (4) precisaram da gridagem dos dados geoquímicos. Mapas elaborados pela gridagem de dados geoquímicos de sedimentos de corrente aparecem com freqüência na literatura especializada (HOWARTH, 1983; HOWARTH \& THORNTON, 1983; DARNLEY et al., 1995...). Devido à natureza vetorial da geoquímica de sedimentos, ao efetuar a interpolação, pode acontecer uma mistura de materiais em algumas celas, sendo introduzidos erros no mapa. Para evitar esses erros, BOHAM-CARTER (1994) apresentou uma forma de interpolar dados de geoquímica de sedimentos, considerando as unidades geológicas $e$ as sub-bacias simultaneamente. No presente trabalho, esse problema foi resolvido fazendo com que a distribuição das variáveis nos mapas interpolados fosse semelhante à dos mapas de círculos e comparando malhas geradas em condições diferentes.

Finalmente deve-se mencionar que uma das vantagens dos métodos do tipo (3) e (4), que usam a gridagem dos dados, é a possibilidade de avaliar o total da área, pixel por pixel, permitindo uma avaliação objetiva, que elimina, ao menos em parte, os erros introduzidos pela apreciação puramente visual.

\subsection{Fundo geoquímico e anomalias regionais}

Alguns autores dividem uma população de amostras geoquímicas em duas sub-populações: uma relacionada ao fundo geoquímico e a outra, às anomalias (LEPELTIER, 1969; MIESCH, 1981; SINCLAIR, 1989). Outros autores consideram $\circ$ fundo geoquímico como uma superfície que varia com a posição, em função das caracteristicas geológicas e ambientais (DI ZHOU, 1985; ROQUIN \& ZEEGERS, 1987). O segundo conceito parece mais adequado para estudos regionais, como o presente. Em relação ao tamanho das anomalias, uma anomalia regional pode variar entre A-100A km², enquanto que uma anomalia local cobriria $0, A-A \mathrm{~km}^{2}$ (DARNLEY et al. , 1995). 
Considerando a abundância de alguns elementos em rochas ígneas (GOVETT, 1983), observou-se que Co, $\mathbf{C r}$ e $\mathbf{N i}$ estão enriquecidos nas rochas máficas, $\mathrm{Cu} e \mathrm{~V}$ nas rochas intermediárias e $\mathrm{Pb}$ nas rochas félsicas. $\mathrm{Na}$ seção 1.3 (mapeamento geoquímico) apresentaram-se vários casos da Iiteratura, nos quais a geoquímica de sedimentos ou regolitos reflete a composição das rochas de procedência. Por exemplo, HOWARTH \& THORNTON (1983) descreveram uma anomalia de Ni em sedimentos de correntes na Península de Gaspe (Canada) associada a serpentinitos, sendo que os teores de $\mathbf{N i}$ caíram de 2000-1000 ppm no centro do maciço, para 500-100 ppm a distâncias de 1-2 km da borda do corpo.

No presente trabalho, uma forma de analisar o teor de fundo foi através dos mapas de círculos (Mapas 1-7). O Fe (Mapa 1) apresenta anomalias relacionadas às rochas máficas da Formação Pavas, incluindo o Granito a anfibólio. Na Formação Barriga Negra, no Grupo Lavalleja e nos gnaisses da Formação Pavas ocorrem teores intermediários de Fe. As restantes unidades são as mais empobrecidas em Fe. A correlação positiva Fe-v (Tabela 11) é resultado de uma distribuição muito semelhante dos teores de ambos elementos. Co, $\mathrm{Cu}$ e $\mathrm{zn}$ possuem uma distribuição espacial semelhante à do Fe na Formação Pavas, mas não no Grupo Lavalleja e no Grupo Barriga Negra, onde os três elementos apresentam anomalias, algumas vezes sobrepostas, que em geral parecem possuir caráter local. O Cr (Mapa 4) e o Ni apresentam distribuições quase idênticas, sendo que as principais anomalias aparecem em geral associadas às rochas máficas da Formação Pavas. O Y também apresenta teores altos na Formação Pavas, em particular nas proximidades do povoado de zapicán, porém nesse setor existe um leve deslocamento em relação às anomalias de CrNi, que parece relacionado ao Granito a anfibólio, onde $0 \mathbf{Y}$ apresenta teores muito baixos. Esse efeito de deslocamento acontece com vários elementos, como por exemplo o P (Mapa 2), que apresenta uma anomalia com padrão arredondado ao sul do povoado de Zapicán. As anomalias de Fe (Mapa 1), Ba (Mapa 3 ) e Cr (Mapa 4) mostram padrões mais alongados, o que sugere certa relação com as estruturas geológicas.

A distribuição dos teores de co e Mn (Mapa 7) foi. 
semelhante no Grupo Lavalleja, mas não na Formação Pavas, onde o un apresentou teores intermediarios. Isso explica a forma apresentada pelo diagrama de dispersão $\mathbf{m}$-Co, que sugere a existência de pelo menos duas sub-populações. O Pb (Mapa 8) apresenta distribuição característica, com empobrecimento nas proximidades do povoado de Zapicán. Ba e $\mathbf{P b}$ ocorrem associados no vértice $\mathrm{NW}$ da área e nas proximidades ou sobre os granitos potássicos e o corpo mais ocidental dos granitos zócalo del Este.

Alguns elementos com problemas analíticos mostraram distribuições interessantes. O As mostrou seu caráter calcófilo acompanhando, com teores acima do LIDA, as anomalias de $\mathrm{Cu}, \mathrm{Pb} e$ Zn no Grupo Lavalieja e no Grupo Barriga Negra. O B também apresentou enriquecimento nessas formações, porém mostrando um padrão contínuo, diferente daquele apresentado pelo $\mathbf{A s}, \mathbf{C u}, \mathbf{P b}$ e zn. O Be mostrou teores característicos relacionados a alguns granitos ou rochas félsicas.

Os padrões de distribuição descritos acima sugerem um contraste entre elementos compatíveis (Co, $\mathbf{C r}, \mathbf{C u}, \mathbf{N i} . .$. ) e incompatíveis ( $\mathbf{B a}$ e $\mathbf{P b})$ na Formação Pavas, que seria conseqüência da alternância de faixas quilométricas de rochas félsicas e máficas. Por outra parte, no Grupo Lavalleja predominam elementos com caráter calcófilo ( $\mathbf{m}, \mathbf{C o}, \mathbf{C u}, \mathbf{P b} e$ za). Isso foi corroborado pelos modelos de regressão em função de Fe-Mn ou das CPs, pois as residuais de Co (Figura 36), de zn (Figura 37) e de Cu (Mapa 9) apresentaram teores elevados relacionados ao Grupo Lavalleja. Assim, existiria uma "fração calcófila" para esses elementos, que não foi explicada pelo modelo, em contraposição a uma "fração" relacionada aos processos litológicos e superficiais, que foi explicada. O Grupo Barriga Negra apresentou comportamento característico e diferente dos expostos acima, com teores intermediarios de Fe, Mn, Co, Cr, Ni, $\mathbf{V}$ e $\mathbf{Z n}$, teores altos de $\mathbf{C u}$ e algumas anomalias de $\mathrm{Pb}$. As formações restantes apresentaram resposta fraca, tendo destaque somente algumas anomalias isoladas de $\mathbf{m}$-Co.

os fatos mencionados acima são sintetizados pelos mapas elaborados com as primeiras CPs $e$ os fatores. O mapa da distribuição da $\mathrm{D}^{2} \mathrm{Cp} 1-5$ divide a área em dois extensos domínios 
(Mapa 6), o setor oriental com valores baixos-intermediários de $\mathrm{D}^{2} \mathrm{cp} 1-5$ e o setor ocidental com valores altos. Observando em detalhe, percebe-se que alguns setores foram bem caracterizados:

(1) A anomalia de $\mathbf{P b}-\mathbf{S n}$, com teores intermediários de $\mathbf{B a}$ ao norte da area, aparece com tonalidades amareladas.

(2) O empobrecimento das Formações de Anfibolitas-Leptitas e da Formação Sierra Ballena, que aparece na forma de uma mancha azul sobreposta às referidas formações.

(3) A anomalia de elementos compatíveis (Co, Cr, Cu, $\mathbf{N i} .$. ) em cor violácea perto de zapicán.

(4) O vértice $\mathrm{NW}$ da área com anomalias de $\mathrm{Ba}-\mathrm{Pb}$, também em cor violácea.

As cinco primeiras CPs explicam $83{ }^{\circ}$ da variância total (Tabelas 15-19), o que sugere que a $D^{2} \mathrm{cp} 1-5$ está associada a fenômenos de natureza regional. Os setores acima descritos têm área superior a $20 \mathrm{~km}^{2}$. Os setores descritos em (1) e (3) constituem duas das principais anomalias regionais caraterizadas neste trabalho e serão denominadas María Albina e zapicán, respectivamente.

A CP1, que contém um $47 \%$ da variância total, representa uma associação entre todos os elementos incluíaos no tratamento estatístico, com exceção do Pb (Tabela 15). Na Figura 39, valores altos da CP1 evidenciam a anomalia regional Zapicán e valores intermediários estão relacionados ao Grupo Barriga Negra e ao Grupo Lavalleja. o fator 1 foi obtido ao se efetuar a rotação Varimax da CP1, o que explica a semelhança entre as duas variáveis. O fator 1 representa uma associação entre elementos compatíveis (Fe-Co-Cr-Cu-Ni-V-Y-Zn), que se concentram em minerais ferro-magnesianos. Por esse motivo, as scores do fator 1 apresentam valores elevados relacionados às rochas máficas da Formação pavas (Mapa 5). Os setores onde aparecem cores mais claras estariam associados às rocha félsicas dessa formação. 0 vértice $\mathrm{NW}$ aparece empobrecido, pois $\mathrm{Ba}$ e $\mathrm{Pb}$ possuem loadings baixas para este fator. Por esse motivo a anomalia María Albina não foi caracterizada. A Formação Puerto Gómez, alguns corpos graniticos e a Formação sierra Ballena possuem um sinal fraco devido ao empobrecimento em minerais ferromagnesianos. O Grupo Lavalieja está integrado por rochas carbonáticas, xistos e 
alguns termos vulcânicos (PRECIOZZI 1987a/b; PRECIOZZI \& FAY, 1988) sendo, portanto, restrita a ocorrência de minerais ferromagnesianos. Assim, nesse Grupo, o fator 1 poderia estar representando um fenômeno diferente, como a adsorção de elementos traços sobre óxido-hidróxidos de Fe.

- fator 2 está representado por uma associação P-Ba-Y-Zn que estaria relacionada à geração de fosfatos superficiais. Sua distribuição espacial não é apresentada, mas é semelhante com à distribuição $D^{2} \mathrm{cpl-5}$ (Mapa 6). A anomalia Zapicán apareceu restrita ao setor anômalo em $\mathbf{P}$ (Mapa 2) e a anomalia María Albina apresenta-se tênue. Seu padrão de distribuição espacial sugere certa relação com a geologia.

Ao contrário do que aconteceu com os fatores anteriores, o fator 3 não parece relacionado às estruturas geológicas (Mapa 7). Trata-se de uma associação un-co com participação secundária do Fe, o que sugere uma relação com a formação de óxidos de Mn mixturados com pequenas quantidades de óxido-hidróxidos de $\mathbf{F e}$. Representa um fenômeno controlado por condições supérgenas (Eh, pH...), porém o padrão de distribuição do pH (Figura 24) não evidencia de forma clara uma relação entre essas variáveis (fator 3 e pH). De qualquer maneira, a distribuição desse fator sugere maior importância para o fenômeno no setor oriental, o que parece confirmar os resultados obtidos com as replicatas de amostragem para o in e o co nesse setor.

o fator $4, \mathrm{~Pb}$ em oposição ao $\mathbf{P}$, está regido pela distribuição dos teores de $\mathbf{P b}$, ou seja, scores altas para o fator ocorrem onde há teores elevados desse elemento (Mapa 8). Isso é devido a que esse fator explica $88 \%$ da variância do $\mathbf{P b}$ (Tabela 22). A oposição de $\mathbf{P}$ e $\mathbf{P b}$ é evidenciada em vários setores, com um desses elementos aparecendo sempre com teores altos e o outro com teores baixos.

As imagens coloridas Landsat-TM (Figura 41 e 43) e a classificação supervisionada das seis bandas (Figura 42) mostram três grandes domínios $\left(D_{1}, D_{2}\right.$ e $\left.D_{3}\right)$, que são caracterizados por feições texturais, isto é, por relações espaciais entre os pixels das classes, e não por feições cromáticas.

o domínio $\mathrm{D}_{1}$ aparece no setor oriental da área através de uma faixa de direção $\mathrm{N}-\mathrm{S}$ e largura de $20 \mathrm{~km}$, onde observa-se um 
padrão típico de locais usados para produção agrícola ou atividades florestais. Isso é caracterizado por manchas retangulares de pixels da classe 7 (óxidos), que indicam locais de solo exposto ou de bosques artificiais já explorados.

- domínio $\mathrm{D}_{2}$ é representado por uma faixa que cobre a porção ocidental das folhas J.P.Varela e Gutiérrez, a porção oriental da folha zapicán e a parte central da folha pirarajá, onde destacam-se os afloramentos de rochas (em azul claro na Figura 41). Os pixels das classes 7 e 8 da classificação não supervisionada dos dados de satélite ocorrem associados indicando a posição desses afloramentos.

o domínio $\mathrm{D}_{3}$ ocorre no setor $\mathrm{NW}$ da área representado por uma mancha característica, integrada por pixels das classes 4 e 5, que foram interpretados como devidos a vegetação média dada a alta razão TM4/TM3. As Figuras 41 e 43 também sugerem a relação dessa mancha com vegetação. Varios setores da área (vértice SE da folha Gutiérrez, proximidades do rio Cebollatí) apresentam semelhanças com a referida mancha (associação das classes 4 e 5), mas em todos os casos trata-se de locais baixos nas proximidades de cursos hídricos, diferentemente do que acontece no vértice $\mathrm{NW}$.

De alguma forma, os três domínios mencionados acima foram também caracterizados pela geoquímica, como se observa no mapa de distribuição das scores do fator 1 (Mapa 5). Os domínios $\mathrm{D}_{1}$, $\mathrm{D}_{2} \mathrm{e} \mathrm{D}_{3}$ estariam caracterizados por scores baixas, intermediárias e altas, respectivamente. Na Figura 46 observa-se que, ao se integrarem os dados geoquímicos e das bandas Landsat$T M$, continuam existindo três grandes domínios, sendo imperfeita sua sobreposição com os domínios $D_{1}, D_{2}$ e $D_{3}$. Os três grandes domínios caracterizados pela classificação não supervisionada foram o de teor de fundo baixo, o de teor de fundo alto e o das anomalias litológicas que coincide com a anomalia regional zapicán. Os três dominios encontram-se inter-misturados, evidenciando que a resposta geoquímica possui variações em diferentes níveis: aquelas associadas às unidades geológicas como um todo e aquelas dentro das unidades. A cobertura sedimentar indiferenciada (Cenozóico), a Formação Puerto Gómez e a Formação Sierra Ballena apresentam maior afinidade pelo 
domínio de baixo teor de fundo. O Grupo Barriga Negra, o Grupo Lavalleja e os gnaisses da Formação Pavas possuem mais afinidade pelo domínio de teor de fundo alto. Os anfibolitos e as rochas máficas da Formação pavas foram caracterizadas pelas classes 3 e de 7 a 12 interpretadas como anomalias litológicas, enriquecidas em elementos compatíveis (Co, Ni, V...). As diferentes classes ligadas à anomalia Zapicán estariam vinculadas com os deslocamentos observados entre as anomalias dos diversos elementos. O domínio de teor de fundo alto, com conteúdos intermediários em $\mathbf{C o}, \mathbf{C u}, \mathbf{N i}, \mathbf{v}$ e $\mathbf{z n}$, por apresentar certa associação com os Grupos Barriga Negra e Lavalleja, intensifica o interesse prospectivo dessas unidades.

o método das sub-bacias caracterizou as mesmas anomalias regionais mencionadas acima. O grupo de sub-bacias $R_{0}$ apresentou teores de $\mathbf{B a}$ acima de $800 \mathrm{ppm}$ e de Pb acima de 19 ppm (Tabela 37). Na Figura 50 observa-se que todas essas sub-bacias estão localizadas no vértice $\mathrm{NW}$ da área, onde uma anomalia $\mathrm{Ba}-\mathrm{Pb}$ já foi caracterizada. Nesse setor a $\operatorname{Rad}-\gamma$ apresentou teores elevados (Figura 25). A associação geoquímica existente seria explicada pela ocorrência de rochas félsicas ricas em feldspato- $K$, onde $\mathrm{Ba}$ e $\mathrm{Pb}$ podem ocorrer por substituição. A anomalia zapicán foi caracterizada pelos grupos $R_{m}$ e $R_{j}$ (Figura 50). As sub-bacias do tipo $R_{m}$ apresentam teores mais elevados em $C r$ e Ni em relação às $\mathrm{R}_{i}$, o que sugere um maior grau de associação com rochas máficas. Ambos os tipos apresentaram empobrecimento em $\mathbf{P b} e$ teores anômalos para $\mathrm{Fe}, \mathrm{Cu}, \mathrm{V}$ ou $\mathrm{Zn}$ (Tabela 37). Na classificação não supervisionada (Figura 46) as rochas mafico-intermediárias apareceram relacionadas à classe 8 , que foi caracterizada por uma associação geoquímica Co-Cu-Mn-Ni-V...(Tabela 32 ). Agrupamentos de pixels pertencêntes à classe 8 ocorrem distantes da anomalia Zapicán e estão sobrepostos às sub-bacias dos grupos $R_{i}$ ou $R_{m}$. Na região sul da folha Piraraja, os pixels da classe 8 estão sobrepostos às sub-bacias do grupo $R_{C}$ que, como já foi mencionado, constituem um grupo um pouco heterogêneo. Essas subbacias (grupo $R_{C}$ ) caracterizam muito bem a anomalia regional de María Albina, que apresenta teores elevados de Pb e Sn (Tabela 37). Várias sub-bacias com anomalias univariadas de $\mathbf{P b}$ ou $\mathbf{S n}$ aparecem próximas das sub-bacias características da anomalia 
María Albina (Grupo Un, Figura 50).

\subsection{Anomalias locais}

Uma primeira definição das anomalias locais foi realizada através da observação dos mapas de círculos para $\mathbf{A g}, \mathbf{A s}, \mathbf{C u}, \mathbf{P b}$, $\mathrm{Sn}, \mathrm{w}$ e $\mathrm{Zn}$. Alguns desses elementos apresentaram problemas analíticos (Ag, As, Sn e W), e por esse motivo apenas foram consideradas as amostras com teores acima ou muito próximas dos limites de deteç̧ão. Valores anômalos positivos dos sete elementos podem aparecer associados a diversos tipos de depósitos minerais (Govett, 1983). O mesmo autor indica que os depósitos de sulfetos maciços estão associados a anomalias negativas de Ni, sem uma explicação teórica para o fato. No presente trabalho $\mathbf{C r}$ e $\mathbf{N i}$ apresentaram uma excelente correlação (Figura 33). Parece razoável pensar que essa associação é de origem litológica, ou seja, seria herdada das rochas de procedência dos sedimentos, que seriam rochas máficas com teores elevados de Cr-Ni. Assim, a ocorrência de teores elevados de CrNi indicaria uma anomalia litológica. Teores anômalos de Fe-Cu-V poderiam indicar rochas máfico-intermediarias, porém, no caso de sedimentos de corrente, diversos autores mostram que a adsorção de elementos traços sobre b́xidos de $\mathrm{Fe}$ (e $\mathrm{Mn}$ ) provocaria falsas anomalias desse tipo (Howarth, 1983). Esses aspectos foram considerados ao interpretar os mapas de círculos, sendo utilizados como apoio os mapas das DM (Mopa 5), das residuais de Cu (Mapa 9) e $\mathrm{Zn}$ (Figura 37), e das $\mathrm{D}^{2}$ das primeiras $\mathrm{e}$ as ultimas CPs (Mapa 6).

As primeiras CPs acumularam 83\% da variância total e, como foi mostrado em função dos fatores, que são as CPs depois de aplicar a rotação varimax, elas estão associadas fundamentalmente a fenômenos regionais. As últimas CPs estão relacionadas aos $17 \%$ restante da variância, e seriam as mais interessantes do ponto de vista prospectivo. Dessa forma, a $\mathrm{D}^{2} \mathrm{cp} 1-5$ teria maior afinidade por fenômenos regionais, enquanto que a $D^{2} \mathrm{cp} 6-11$ seria associada a efeitos locais. Em função disso, elas constituiriam mais um critério para discriminar anomalias regionais e locais. As DMs poderiam ser usadas no mesmo sentido. 
Porém, no presente estudo, por não ter sido realizado um segundo cálculo eliminando as outliers, as DMS seriam menos sensíveis que as últimas CPs para detectar anomalias locais.

o setor anômalo 01 (Figura 44) corresponde a uma anomalia de $\mathbf{M n}-\mathbf{P b}-\mathbf{z n}$ localizada a Sw da anomalia María Albina. Os teores anômalos de Mn (Mapa 7) ocorrem um pouco deslocados em relação aos de $\mathbf{P b}-\mathbf{z n}$. Foi observada uma relação das amostras anômalas com um corpo aflorante evidenciado nas imagens Landsat-TM (Figura 41). No mapa dos teores de $\mathbf{P b}$ (Mapa 8), no Mapa 6 e na Figura 50 observa-se uma separação entre a anomalia regional e a local. A Classe 6 da classificação não supervisionada evidenciou essa anomalia (Figura 46). Essa classe apresentou teores elevados de $\mathbf{M n}$, Co, $\mathbf{P b}$ e $\operatorname{Rad}-\gamma$, e teores abaixo da mediana da classe 1 (baixo teor de fundo), para $\mathbf{P}$, Ni e $\mathbf{z n}$. Próximo à mancha da classe 6 , ocorre uma pequena mancha da classe moderadamente enriquecida em P, Ba, Co, Cu, V, $\mathbf{Y}$ e $\mathbf{Z n}$ (classe 3). Deve-se destacar que as classes $3,4,6,7,9,10,11$ e 12, por abrangerem áreas pequenas (Tabela 32), podem ser interpretadas como anomalias locais. A tentativa de procurar outros pixels da área de pesquisa, com características semelhantes, não deu resultado (Figura 47). O setor 01 parece coincidir com as mineralizações de galena em calcário, encontradas por uma empresa argentina na década de 80 (PRECIOZZI, 1987a).

o setor anômalo 02 mostrou teores elevados de Cu-v, com teores secundários de $\mathbf{F e}-\mathbf{C r}-\mathbf{N i}$. As residuais de $\mathbf{C u}$ apareceram deslocadas em relação à anomalia das amostras originais (Mapa 9). A DM (Mapa 5) e a $D^{2} \mathrm{Cp} 6-11$ (Mapa 6) mostraram valores geralmente intermediários ou baixos. Nessa região existe uma intrusão máfica que foi bem caracterizada pela classe 8 da classificação não supervisionada (Figura 46) e também, com certo deslocamento, pelo grupo $M$ da classificação supervisionada (Figura 47). Na Figura 50 observa-se duas sub-bacias do grupo $R_{i}$ e uma sub-bacia do grupo $\mathrm{L}_{\mathbf{S}}$, que apresenta teores elevados para Cu e zn. Parece estar bem caracterizada uma anomalia de origem litológica nesse local.

o setor anômalo 03 apresenta uma associação característica Fe-Ag-Cr-Ni-Pb-V, que poderia ser explicada em função da 
ocorrência de pequenos afloramentos de rochas máficas próximos a um granito-k. As sub-bacias do grupo $\mathrm{I}_{\mathrm{a}}$ corroboraram a associação $\mathrm{Cr}-\mathrm{Ni}-\mathrm{Pb}$. As anomalias de Ag estão relacionadas, na sua maior parte, a uma das sub-bacias. A classificação não supervisionada mostrou uma integração dos pixels das classes 3 , 4,6 e 7 (Figura 46). A classe 4 evidenciou anomalias secundárias de $\mathrm{Pb}$, relacionadas a pixels com valores acima do nível de fundo para o fator-F.

o setor 04 apresenta uma associação poli-metalica Fe-Ag-CrCu-Ni-Sn-W-Zn com teores secundários de As e está localizado sobre uma zona de falha (Figura 2). As imagens de satélite mostraram alguns lineamentos espacialmente relacionados às amostras anômalas. O método das sub-bacias não caracterizou nenhum fenômeno particular, mas algumas sub-bacias mostraram teores anômalos de $\mathrm{Sn}$. A classificação não supervisionada novamente mostrou a integração de um grande número de classes (Figura 46). A tentativa de procurar pixels semelhantes aos do grupo $C$, que representa uma anomalia na porção sul do setor, não deu bons resultados. Mas no setor norte apareceram alguns pixels semelhantes aos do grupo $\mathrm{T}$, que caracterizou uma anomalia $\mathrm{Cu}-\mathrm{Pb}$ localizada próxima à antiga Mina de Au da folha Gutiérrez (Figura 47).

- setor 05 apresenta teores anômalos em $\mathrm{Fe}-\mathrm{Cr}-\mathrm{Cu}-\mathrm{Ni}$ e teores secundários de $\mathrm{Pb}$. As rochas maficas que ocorrem na área foram caracterizadas pela classificação não supervisionada (Figura 46), pela classificação supervisionada (Figura 47) e pelo método das sub-bacias (Figura 50). Várias anomalias locais de $\mathrm{Pb}$ no setor e nas vizinhanças seriam explicadas pelo contato entre rochas félsicas da Formação Pavas e rochas carbonáticas do Grupo Lavalleja (Mapa 8). Este setor foi interpretado como uma anomalia litológica.

o setor 06 apresenta anomalias de $\mathbf{M n}$, Ag, Co e $\mathbf{P b}$ e teores secundários de Fe e As. Um pequeno veio de rochas máficas ocorre na porção NW do setor. A classificação não supervisionada e a supervisionada caracterizaram rochas maficas a alguns quilômetros ao norte desse veio (Figuras 46-47). PRECIOZzI (1987b) mencionou a ocorrência de um chapéu de Fe na porção norte do setor, que foi caracterizado pela classe 6 (Figura 46). 
Duas sub-bacias mostrando associações típicas de ocorrência de sulfetos são mostradas na Figura 50 .

No setor 07 ocorre uma antiga mina de Au que apresentou uma anomalia de Au-Ba-Cu-Mn-P-Pb em solos, a poucos metros do veio mineralizado (FILIPPINI ALBA, 1990). Nas vizinhanças da mina aparecem várias amostras de sedimentos anômalas, porém as duas amostras mais próximas não apresentaram anomalias (Figura 45), mas empobrecimento em $\mathrm{m}$ (teores inferiores a $400 \mathrm{ppm}$ ). A anomalia poli-metalica $\mathbf{m}-\mathbf{A g}-\mathrm{Co}-\mathrm{Cu}-\mathrm{Pb}$ com valores secundários de As-Ba ocorrem em uma única amostra. No entanto, algumas amostras apresentaram teores anômalos de $\mathbf{m}$, As e Cu. A média de $\mathbf{C u}$ considerando 27 amostras no setor, foi de $26 \mathrm{ppm}$ e a de Pb de 16 ppm, sendo para o Cu bastante superior à média geral (19 ppm). As residuais de Cu melhoraram a resposta em relação aos teores brutos (Mapa 9). Alguns pixels da classe 6, sem dúvida relacionados à amostra com resposta poli-metalica, aparecem quase no centro do setor (Figura 46). O método das sub-bacias mostrou uma anomalia m-As-Co-Cu-Pb, mas a mina de Au está localizada em uma sub-bacia adjacente (Seção 4.6).

No vértice SW da área, ocorre uma anomalia Ag-As-Pb-Zn com teores secundários de $\mathrm{Cu}$ (setor 08). As residuais de $\mathrm{Cu}$ contrastaram melhor a anomalia em relação aos teores originais, como aconteceu com o Grupo Barriga Negra como um todo (Mapa 9). A classificação não supervisionada mostrou uma associação entre pixels das classes 4 e 6 (Figura 46). A classificação supervisionada mostrou vários pixels semelhantes aos do grupo $T$, relacionados ao Grupo Barriga Negra (Figura 47). Uma sub-bacia com associação característica de sulfetos aparece no vértice sw, e outras duas sub-bacias do mesmo grupo aparecem próximas, junto com várias sub-bacias com anomalias univariadas de $\mathbf{A s}$ ou $\mathbf{C u}$ (Figura 50). Isso sugere que não somente o setor 08, mas o Grupo Barriga Negra como um todo, deveria ser estudado em detalhe.

o setor 09 apresentou semelhanças geológicas, geoquímicas e nas imagens de sensoriamento remoto com o setor 07 . Do ponto de vista geológico, em ambos os casos predominam rochas carbonáticas do Grupo Lavalleja nas quais alternam-se faixas de quartzitos. A anomalia de $\mathrm{Cu}$ é um pouco mais fraca, sendo de 22 ppm a média de dez amostras, o que supera a média geral, porém 
sem ter significação estatística. As médias de As e Pb foram 16 ppm e 21 ppm, respectivamente. O máximo de As e de $\mathrm{Cu}$ para o setor foi $28 \mathrm{ppm}$, e para $O \mathrm{~Pb}$ foi $58 \mathrm{ppm}$. Em ambos os casos ocorreram teores de $\mathrm{Mn}$ extremamente anômalos (acima de 3000 $\mathrm{ppm}$ ). As imagens de sensoriamento remoto mostraram dois corpos aflorantes, um associado a cada setor, de características espectrais, tamanho e orientação muito semelhantes (Figura 41 e Figura 45). Os dados litológicos da área permitiram caracterizar esses afloramentos como de quartzito. A classificação supervisionada não detectou pixels do grupo $\mathrm{T}$ no setor 09 (Figura 47), possivelmente em função do empobrecimento em $\mathbf{C u} e$ do enriquecimento em $\mathrm{Pb}$ demonstrado pelas médias do setor 09 em relação ao setor 07 .

GOVETT (1983), baseado em estudos litogeoquímicos em diversos depósitos do mundo, concluiu que Fe e un são indicadores regionais de depósitos de sulfetos maciços, produzindo halos 2-10 vezes mais extensos que os produzidos pelos elementos do minério. Porém, em estudos com sedimentos de corrente, seriam geradas falsas anomalias, em função dos processos de adsorção dos metais traços sobre óxidos e hidróxidos de $\mathbf{F e}$ e Mn (HOWARTH, 1983). Neste trabalho os fenômenos de adsorção foram caracterizados pelo fator 1 (Mapa 5), que também caracterizou a ocorrência de minerais ferromagnesianos nas rochas de procedência, e pelo fator 3 (Mapa 7), que mostrou uma correlação mn-Co e Fe secundário. Várias amostras com teores elevados de $\mathrm{Mn}$, às vezes acompanhados por Co ocorreram nos setores $01,06,07$ e 09. Três desses setores incluíram ocorrências minerais conhecidas. No setor 07, duas amostras empobrecidas em Mn próximas à mina de Au não apresentaram valores anômalos para nenhum elemento. Uma anomalia polimetálica $\mathbf{M n - A g - C o - C u - P b}$ foi observada em um curso hídrico mal localizado em relação à mina. Essa associação apresenta pontos comuns com uma anomalia em solos obtida perto do minério (FILIPPINI ALBA, 1990). A classe 6 da classificação não supervisionada foi interpretada como ligada a mineralizações, e esteve relacionada a sete dos nove setores anômalos discutidos acima. Em particular, essa classe não apareceu nos setores 02 e 05, que foram interpretados como anomalias litológicas. A classe 
6 apresentou enriquecimento em $\mathbf{M n}, \mathrm{Co}, \mathrm{Pb} e \operatorname{Rad}-\gamma$, $\mathrm{e}$ empobrecimento em Ni, $\mathbf{P}$ e $\mathbf{z n}$. Por esses motivos, pensa-se que os teores elevados em Mn-Co estão associados a mineralizações e não representariam portanto falsas anomalias.

Algumas anomalias podem não ter sido notadas no procedimento de determinação dos setores anômalos. Parece que foi o caso da anomalia ao norte do povoado de María Albina, que foi caracterizada pela classe 4 da classificação não supervisionada (Figura 46) e por uma sub-bacia anômala em As-Pbzn (Figura 50). Essa anomalia foi mascarada pela anomalia regional María Albina, fato que também aconteceu em relação às outras anomalias regionais (Zapicán e Grupo Barriga Negra).

Nas borda leste da área ocorrem várias anomalias das classes 4 e 6 da classificação não supervisionada (Figura 46). Estas são falsas anomalias, geradas pelos processos de interpolação, em função da ausência de dados nesses setores. Ao norte da Formação Sierra Ballena, foi identificada uma anomalia Mn-Co-v, com teores intermediários de $\mathbf{F e}-\mathbf{C r}-\mathbf{C u}-\mathbf{N i}$, que é bem descrita por uma mancha amarelada das scores do fator 1 (Mapa 5). Na Figura 46 essa anomalia parece estar associada a variações da borda da lagoa próxima à cidade de J.P.Varela. Uma mancha cinza clara (teor de fundo alto) aparece nas vizinhanças da lagoa, sendo que todo o conjunto está localizado dentro de uma mancha cinza escura, representando o baixo teor de fundo.

Duas das técnicas utilizadas para evidenciar os contrastes entre anomalias regionais $e$ locais foram $\circ$ uso das $\mathrm{D}^{2}$ das primeiras e últimas CPs (Mapa 6) e os modelos de regressão em função dos fatores. Como ambas as técnicas foram processadas em condições idênticas, isto é, eliminando 44 outliers, corrigindo os dados pelo efeito do material amostrado e usando logaritmos, achou-se interessante realizar uma comparação entre os dois procedimentos. Uma primeira observação que surge em relação aos mapas interpolados, é que representariam aspectos regionais. A regressão foi mais eficiente para caracterizar os diferentes domínios. No Mapa 6 foram caracterizados o vértice NW da área, a anomalia regional María Albina e a anomalia regional zapicán. Os outros domínios aparecem, em geral, com tonalidades verdeazuladas. O Mapa 9, por sua vez, caracterizou a cobertura 
sedimentar indiferenciada no setor oriental da área $e$ os basaltos de puerto Gómez em tonalidade azulada, a formação Sierra Ballena em tonalidade esverdeada, o Grupo Lavalleja e a Formação de Anfibolitas-Leptitas em cores verde-amareladas e o Grupo Barriga Negra em tonalidades rosa-violáceas. A Formação Pavas foi representada por uma mancha violácea sobreposta aos anfibolitos $e$ cores mais claras para as rochas félsicas. A anomalia María Albina apareceu muito tênue para o $\mathbf{C u}$ estimado e um pouco melhor para o $\mathbf{z n}$ estimado. O $\mathbf{z n}$ estimado apresentou um panorama semelhante ao do $\mathrm{Cu}$ estimado. $0 \mathrm{~Pb}$ estimado mostrou uma grande anomalia negativa sobre os anfibolitos de Pavas, caracterizou o setor NW, os granitos-x e a anomalia María Albina, mas o resto da área não aparece bem definido.

Os valores de $\mathrm{D}^{2} \mathrm{cp} 6-11$ (Mapa 6) aparecem como círculos de tamanho razoável nas quatro ocorrências minerais conhecidas. As anomalias regionais María Albina e zapicán também foram destacadas. As residuais de $\mathrm{Cu}$ aparecem relacionadas aos Grupos Barriga Negra e Lavalleja, e ocorre um grupo de amostras anômalas próximo à antiga mina de Au. As outras ocorrências são marcadas com teores intermediários ou um pouco deslocados, como no caso da ocorrência de $\mathrm{Pb}$ ao norte. O padrão geral apresentado pelas residuais de $\mathrm{Cu}$ no Grupo Barriga Negra é diferente do apresentado no Grupo Lavalleja. No primeiro caso, as residuais anômalas aparecem distribuídas em forma quase homogênea, sugerindo uma anomalia regional. No caso de Lavalleja, pequenos grupos de valores anômalos ocorrem isolados. No extremo sul, ocorre uma anomalia de residuais de $\mathrm{Cu}$ que apresenta semelhanças com a anomalia do Grupo Barriga Negra. As residuais de $\mathbf{z n}$ e $\mathbf{P b}$ não evidenciaram a ocorrência de $\mathbf{A u} e$, no caso do $\mathbf{P b}$, aparece uma anomalia das residuais sobre os anfibolitos de Pavas, o que parece um desajuste ao modelo.

o modelo de regressão do $\mathrm{Cu}$ em função dos fatores (Mapa 9) pareceu o mais eficiente para discriminar anomalias regionais e locais. Isso seria conseqüencia da capacidade dos fatores em interpretar a variância do $\mathbf{C u}$, ○ que não aconteceu $\mathrm{com} \circ \mathbf{P b}$ e 0 zn. A distribuição espacial das scores (Mapas 5, 7 e 8) sugeriu que os fatores 2 e 4 não representaram uma boa definição dos fenômenos associados. $\mathbf{P b}$ e $\mathbf{z n}$ apresentaram boa porcentagem da 
variância associada a esses fatores, diferentemente do que aconteceu com o Cu, que está associado, em forma preferencial, ao fator 1 .

\subsection{Aspectos relacionados à geologia}

Ja foi mencionado que a resposta geoquímica apresenta variações em diferentes escalas, o que permite caracterizar grandes domínios, com domínios menores inseridos. A classificação das amostras em função do litotipo de procedência segundo os mapas geológicos 1/50.000 (FAY, 1982a-b-c, ILLANES, 1982) permitiu observar essas variações através da análise da variância e, em especial, pelos diagramas de box. No caso do Fe (Figura 19), as amostras relacionadas às rochas máficas da Formação Pavas apresentam teores altos, as amostras relacionadas aos Grupos Barriga Negra e Lavalleja mostram teores intermediários e as relacionadas à cobertura sedimentar indiferenciada estão empobrecidas. Variações locais estão relacionadas aos gnaisses da Formação Pavas, aos veios máficos e, considerando aos granitos como um todo, ao granito-k. O Mn apresenta uma resposta semelhante, porém mais moderada. Quase todas as classes mostram mediana de un muito próxima, o granito María Albina aparece empobrecido em relação aos outros e a cobertura sedimentar indiferenciada não está empobrecida (Figura 20) . O Ni apresenta um padrão semelhante ao do Fe (Figura 21). 0 $\mathrm{Pb}$ apresenta um padrão bastante diferente dos anteriores (Figura 22). As amostras relacionadas aos gnaisses da Formação Pavas estão enriquecidos em relação às amostras relacionadas aos anfibolitos da mesma formação, porém as amostras relacionadas às rochas máfico-ultramáficas não aparecem tão empobrecidas. Isso sugere que a ausência de $\mathrm{Pb}$ nas amostras relacionadas aos anfibolitos estaria vinculada aos processos metamórficos. Os outros grupos apresentam medianas de $\mathrm{Pb}$ próximas, destacando-se, no caso dos granitos, o empobrecimento nas amostras relacionadas ao granito de Pirarajá.

o gráfico de box do $Y$ (Figura 23) apresenta enriquecimento para as amostras relacionadas ao Proterozóico médio-inferior, teores intermediários para as amostras relacionadas à Formação 
de Anfibolitas-Leptitas, aos milonitos da Formação sierra Ballena, ao Grupo Lavalleja, ao Grupo Barriga Negra e aos granitos, e os teores mais baixos para as amostras relacionados às rochas pós-cambrianas. TAYLOR \& MCLENNAN (1985) consideram que alguns elementos traços, entre eles $\circ \mathrm{Y}$, apresentam teores em sedimentos muito semelhantes aos das rochas de procedência, em função dos seus baixos tempos de residência no oceano. Assim, os dados deste trabalho sugerem uma diferenciação dos teores de Y entre a crosta do proterozóico superior e a crosta do Proterozóico médio-inferior. Observe-se que para os elementos discutidos acima ( $\mathbf{F e}, \mathbf{M n}, \mathbf{N i}$ e $\mathrm{Pb}$ ) existem diferenças entre as rochas desses dois grandes domínios, que seriam explicadas por variações da resposta geoquímica em função dos litotipos associados. Porém esse não parece ser o caso do $\mathbf{Y}$.

outra forma de analisar as variações apresentadas pela resposta geoquímica em relação às diferentes unidades geológicas é considerando a ACP para os Granitóides, o Grupo Barriga Negra, - Grupo Lavalleja, a Formação de Anfibolitas-Leptitas e a Formação Pavas. Para a CP1 (Tabela 23), aparece uma diferença entre a resposta para a Formação Pavas e para as outras unidades. Isso foi indicado pela carga negativa do $\mathbf{P b}$, o que sugere um contraste entre esse elemento e os outros, que estariam associados aos minerais ferromagnesianos que ocorrem nas rochas dessa formação, em especial nos anfibolitos, que apareceram empobrecidos em $\mathbf{P b}$. Para as outras unidades essa componente poderia representar os processos de adsorção de traços sobre óxidos de Fe-kn.

A CP2 apresenta um comportamento mais heterogêneo para as diferentes unidades (Tabela 24). Os granitóides mostram uma oposição entre $\mathbf{M n}-\mathbf{C o}-\mathbf{P b}$ e $\mathbf{C r}-\mathbf{N i}-\mathbf{Y}$, o que sugere uma discriminação entre óxidos de $\mathrm{m}$ e minerais ferromagnesianos, que devem estar empobrecidos nessas rochas. O Grupo Barriga Negra e o Grupo Lavalleja apresentam semelhanças para a CP2. A associação Mn-P-Ba-zn mostrou-se em oposição a Cr-Ni-v. Em função dos mapas geológicos e de círculos, essa separação para o Grupo Barriga Negra seria devida a um maior enriquecimento em Cr-Ni-V no setor oriental, onde predominam conglomerados e siltitos, e a um enriquecimento nos outros elementos no setor 
ocidental, onde ocorrem rochas carbonáticas e arenitos. No Grupo Lavalleja, essa oposição seria explicada pela ocorrência de rochas carbonaticas por um lado, e filitos cloritosos ou veios máficos, por outro. Para a Formação de Anfibolitas-Leptitas a CP2 é representada pela oposição $\mathbf{m - B a - C o - P b}$ contra P-Cr-Cu-Ni, que poderia estar relacionada à anomalia regional Maria Albina que ocorre nessa formação. Finalmente a Formação Pavas apresenta uma oposição P-Ba contra $\mathbf{C r}-\mathbf{N}$, que é bem evidente na anomalia regional de $\mathbf{P}$ próxima a vila Zapicán (Mapa 2).

o principal aspecto a destacar para a CP3 é que $\mathbf{m}$-Co-Pb apresentam-se associados no Grupo Barriga Negra, no Grupo Lavalleja e na Formação Pavas. Essa associação sugere a ocorrência de óxidos de Mn, fato que foi discutido antes, em particular para o Grupo Lavalleja. A CP4 e a CP5 apresentam associações entre poucos elementos, o que torna difícil a sua interpretação.

A interpretação das CPs para cada grupo de amostras classificado em função do litotipo das rochas de procedência foi prejudicada em função da falta de mapas para as scores desses procedimentos. Essa carência foi parcialmente sanada pela análise dos mapas dos teores brutos, porém, para certo nível de detalhe, a interpretação é muito complicada. De qualquer forma, - importante foi destacar que cada unidade geológica apresenta resposta diferenciada em relação à ACP, em função das características dos litotipos envolvidos e, possivelmente, de parâmetros ambientais, como relevo, pH e Eh. Outros aspectos relacionados à resposta geoquímica em função da geologia já foram discutidos neste capítulo (Seção 4.3).

\subsection{Aspectos relacionados aos recursos minerais}

- potencial mineral da área foi avaliado a partir de modelos exploratórios litogeoquímicos teóricos (GOVETT, 1983; GOVETT \& ATHERDEN, 1988), através do uso de seqüências lógicas executadas utilizando Sistemas Geográficos de Informações (GRASS, 1991). Os modelos considerados foram o de depósitos de sulfetos maciços $e$ o de depósitos associados a granitos 
(granitos especializados), que foram adaptados às condições deste trabalho, em função da correlação existente entre a resposta geoquímica e as diversas litologias. Foram ensaiados procedimentos não ponderados e ponderados. Os ponderadores permitem atribuir maior ou menor hierarquia às variáveis e às classes definidas pelos seus valores.

No caso não ponderado, para os depósitos de sulfetos maciços foram usadas duas seqüencias lógicas diferentes, que foram integradas no final. Na primeira, escolheram-se os pixels enriquecidos em $\mathbf{F e} e$ em $\mathbf{z n}$, empobrecidos em $\mathbf{N i}$, e que apresentaram anomalias de pelo menos um dos seguintes quatro elementos: $\mathbf{m}, \mathbf{A s}, \mathbf{C u}$ ou $\mathbf{P b}$. Na segunda seqüência, escolheram-se os pixels anômalos em $\mathrm{Cu}-\mathbf{z n}$ ou $\mathrm{Pb}-\mathbf{z n}$, enriquecidos em $\mathrm{Fe} e$ empobrecidos em $\mathrm{Ni}$. Nos dois casos, os limiares foram escolhidos em função dos histogramas para as variáveis interpoladas, sendo menos restritivos para $\mathbf{F e}$, Ni e $\mathbf{z n}$, que constituíram indicadores regionais. As anomalias litológicas associadas à ocorrência de minerais ferro-magnesianos foram eliminadas pelos pixels empobrecidos em Ni. Existe um problema em relação aos pixels enriquecidos em Fe-zn pois, segundo alguns autores, no caso de amostras de sedimentos, eles indicariam falsas anomalias relacionadas a processos de adsorção (HOWARTH, 1983). Porém, em função da discussão sobre os fenômenos de adsorção (Seção 4.4.), e levando em consideração que se trata de um trabalho em escala regional, preferiu-se considerar esses elementos.

o modelo dos granitos especializados considerou pixels empobrecidos em $\mathrm{Ba}$ que foram relacionados com aqueles enriquecidos em Sn ou com teores altos de Rad- $\gamma$ (representando o conteúdo de $\mathrm{U}-\mathrm{Th}$ ). Esses setores foram sobrepostos àqueles com teores anômalos para $\mathbf{C u}, \mathbf{P b}$ ou $\mathbf{z n}$.

Em ambos os casos, a área selecionada foi muito pequena em relação ao todo (Figura 48 ). Seis dos nove setores indicados pelo tratamento estatístico dos dados geoquímicos originais apresentaram pixels relacionados a pelo menos um dos modelos. A inexistência de pixels característicos no setor 05 seria explicada pela ocorrência de uma anomalia litológica. Para os setores 07 e 09, que também não mostraram pixels caracteristicos, as anomalias existentes não se ajustariam a 
nenhum dos modelos. Os pixels relacionados aos granitos especializados ocorreram associados às rochas mais félsicas da Formação pavas ou à granitos.

Alguns pixels relacionados a ambos os modelos ocorreram fora dos setores definidos pelo tratamento estatístico. A maioria foram setores mascarados por anomalias regionais. Próximo do vértice $\mathrm{NE}$ do Grupo Barriga Negra, ocorreram alguns pixels relacionados aos modelos de granitos especializados, que seriam explicados pela existência de teores anômalos de Rad- $\gamma$, constituindo, possivelmente, uma anomalia litológica em rochas félsicas.

No caso ponderado, tentou-se produzir um modelo geral, baseado no modelos dos depósitos de sulfetos maciços e na experiência prévia do caso não ponderado. As variáveis foram ponderadas em função das suas características (Tabela 34). Assim, como não seriam de interesse pixels empobrecidos em Ni e com teores médios para as outras variáveis, os ponderadores do Ni foram diminuídos. Os fatores de ponderação da segunda, terceira e quarta categorias do $\mathbf{z n}$ foram reduzidos, por tratarse de um elemento muito móvel. O Fe foi representado pelo fator$F$ que, em geral, apareceu associado aos afloramentos de rochas. As regiões de prioridade alta foram muito restritas (Figura 49), sendo mais correta sua interpretação em conjunto com os setores de prioridade média. Os setores definidos pelo tratamento estatístico 01, 03, 04, 06 e 08 foram destacados. O Granito a anfibólio foi destacado por pixels de prioridade média-alta em quase toda sua extensão, inclusive fora do retângulo de demarcação do setor 04 . No setor 06 , os pixels prioritários aparecem relacionados a dobras e falhas em calcário e xistos na porção norte. A parte norte da anomalia zapicán e a porção ocidental da anomalia Maria Albina constituiriam novos alvos prospectivos. De forma menos intensa, os setores 07 e 09 também foram destacados.

Neste ponto, cabe realizar uma análise da precisão dos diferentes procedimentos para detectar as ocorrências minerais conhecidas. Na Tabela 38 são comparadas as distâncias mínimas anomalia-ocorrência para os mapas de círculos de $\mathrm{Cu}$ ou de $\mathrm{Pb}$ (Mapa 8), para o mapa das distâncias das últimas CPs (Mapa 6), 
para o mapa gerado pelo modelo ponderado do SIG (Figura 49) e para o mapa gerado pela classificação não supervisionada (Figura 46). Os mapas de círculos $\mathbf{C u}-\mathbf{P b}$ e das distâncias das CPs foram elaborados em escala $1 / 200.000$ e os mapas do SIG e da classificação foram produzidos em escala aproximada 1/400.000. Como as medidas foram feitas com régua em mapas de papel, e considerando uma precisão de $1 \mathrm{~mm}$, o erro seria de $0,2 \mathrm{~km}$ para a escala maior e de $0,4 \mathrm{~km}$ para a escala menor. Dessa maneira, os métodos que usaram interpolação (SIG e classificação) foram levemente prejudicados. A forma mais precisa de detectar as ocorrências conhecidas foi o uso dos mapas de círculos $\mathbf{C u - P b}$. Próximo a elas sempre foi verificada uma anomalia de $\mathbf{C u}$ ou de $\mathbf{P b}$ a uma distância média de $1,2 \mathrm{~km}$, variando entre 0,6-1,6 km. 0 procedimento mais impreciso foi $\circ$ que usou as distâncias das CPs, com desvios de $1,8-3,0 \mathrm{~km}$ em relação às ocorrências. Isso significaria que o processo de interpolação não influenciou de maneira muito drástica. Considerando a imprecisão da medida, a distância mínima anomalia-ocorrência para o SIG e para a classificação foi somente $0,2-0,3 \mathrm{~km}$ maior que a determinada pelos mapas $\mathbf{C u}-\mathbf{P b}$. Isso representa somente um pixel no caso da classificação.

Tabela 38. Comparação da distancia minima anomalia-ocorrência para diversos procedimentos. Para o SIG foram considerados como anômalos os pixels de prioridade alta e media do modelo ponderado. Na classificação supervisionada, a classe 3 indicou a ocorrência de $\mathbf{F e - C u}$ e a classe 6 as demais. DMM = Distância minima media.

$\begin{array}{cccccc}\text { Ocorrência } & \text { Coordenadas } & \text { Mapas Cum Pb } & \mathbf{D}^{2} \mathrm{Cps} & \text { SIG } & \text { Classiftcaçá } \\ \text { Au } & 609,0-6282,6 & 1,4 \mathrm{~km} & 1,8 \mathrm{~km} & 1,0 \mathrm{~km} & 1,5 \mathrm{~km} \\ \mathrm{~Pb} \text { (sul) } & 600,0-6284,7 & 0,6 \mathrm{~km} & 3,0 \mathrm{~km} & 2,0 \mathrm{~km} & 1,3 \mathrm{~km} \\ \mathrm{~Pb} \text { (norte) } & 603,9-6305,7 & 1,6 \mathrm{~km} & 1,9 \mathrm{~km} & 2,0 \mathrm{~km} & 1,9 \mathrm{~km} \\ \text { Fe-Cu } & 581,6-6291,8 & 1,0 \mathrm{~km} & 2,0 \mathrm{~km} & 2,0 \mathrm{~km} & 1,5 \mathrm{~km} \\ \text { DMM } & & 1,2 \mathrm{~km} & 2,2 \mathrm{~km} & 1,7 \mathrm{~km} & 1,6 \mathrm{~km}\end{array}$

No caso do método das sub-bacias, duas das quatro ocorrências minerais conhecidas localizaram-se no interior de sub-bacias características. No caso da ocorrência de $\mathrm{Au}$ e da ocorrência de $\mathbf{P b}$ mais ao sul, estas localizaram-se em sub-bacias adjacentes às sub-bacias características (Figura 50). Isso 
sugere várias possibilidades:

(1) Erros na localização das ocorrências minerais ou das amostras anômalas.

(2) Existência de ocorrências desconhecidas com melhor resposta geoquímica.

(3) Processos de geração de anomalias independentes da ação gravitacional (capilaridade?, migração aérea?,...).

(4) Relações geológico-estruturais desconhecidas entre a anomalia geoquímica e a ocorrência mineral.

\subsection{Aspectos relacionados ao meio ambiente}

No Capítulo 1 foram mencionados vários efeitos benéficos e prejudiciais dos elementos traços sobre os seres vivos (Tabela 1). Em relação à vegetação, tentou-se observar alguma correlação entre a banda TM4 $e$ os elementos químicos, através da classificação não supervisionada (Figura 46), porém observou-se somente um empobrecimento das classes 4,5 e 6 em relação às outras, indicando que predomina uma cobertura vegetal relativamente uniforme na maior parte da área. Isso é comprovado pela imagem RGB das CPs (Figura 43), onde a vegetação em verde sugere essas características. Na maior parte das imagens processadas (Figura 41 e 43), observou-se um padrão textural particular nas vizinhanças da vila Zapicán, sugerindo uma relação com a anomalia regional nessa região. Porém essa correlação não foi estabelecida em forma quantitativa.

ADRIANO (1986) menciona os efeitos cancerígenos de As-CoCr-Ni-V e outros elementos. Valores guias e valores limites para amostras de tilitos na Finlândia (TARVAINEN, 1996) e para amostras de sedimentos na América do Norte (BAUDO et al., 1990) foram agrupados na Tabela 39. Quando superados, os valores guias indicam a necessidade de estudos complementares. Se os valores limite são atingidos, alguma medida deve ser tomada. Os valores do Ontario Minister of Environment-OME (apud BAUDO et al., 1990) foram baseados em toxicidade evidente em invertebrados bentônicos e não consideraram efeitos de bioacumulação ou efeitos em espécies de vida longa. Para teores abaixo do $L_{3}$ 
(nível sem efeito) não apareceram efeitos, ao passo que valores acima de $\mathrm{L}_{4}$ (nível de efeitos moderados) mostraram efeitos moderados. O $\mathrm{L}_{5}$ representa 0 limite de tolerância. Os valores da Beak Consultants Ltd.-Beak (apud BAUDO et al., 1990) foram baseados em bio-ensaios ou em critérios que usam o background.

Na Tabela 40 são apresentadas as porcentagens de amostras do presente trabalho que superam os valores guias e limites da Tabela 39. Foram considerados os valores brutos das amostras geoquímicas originais. O valor de efeitos moderados do $\operatorname{OME}\left(\mathrm{L}_{4}\right)$ é superado por um grande número de amostras (Fe, $\mathbf{M n}, \mathbf{A s}, \mathbf{C r}, \mathbf{C u}$ e Ni). O que sugere que não se aplicariam, em função da escassa atividade industrial na região.

Tabela 39. Valores guia e valores limite para amostras de tilitos na Finlândia e para amostras de sedimentos no Canada. Forma considerados aqueles elementos disponiveis no presente trabalho. $\mathbf{G}_{1}$ e $\mathbf{G}_{6}=$ Valores guia; $\mathbf{L}_{2}=$ Valores Iimite; $I_{3}=$ Nivel sem efeito; $\mathbf{L}_{4}=$ Nivel de efeitos moderados $e \mathbf{L}_{5}=$ Limite de tolerância. GSF = Geological Survey of Finland (apud TARVAINEN, 1996); OME = Ontario Minister of Environment (apud BAUDO et al., 1990); Beak = Beak Consultants Ltd. (apud BAUDO et al., 1990).

\begin{tabular}{lcccccc} 
Elemento & \multicolumn{2}{c}{ GSF } & \multicolumn{3}{c}{ OME } & Beak \\
& $\mathbf{G}_{1}$ & $\mathbf{L}_{\mathbf{2}}$ & $\mathbf{L}_{\mathbf{3}}$ & $\mathbf{L}_{\mathbf{4}}$ & $\mathbf{L}_{5}$ & $\mathbf{G}_{\mathbf{6}}$ \\
$\mathbf{F e} \%$ & & & 2,0 & 3,0 & 4,0 & 5,9 \\
Mn ppm & & & 400 & 457 & 1110 & 1200 \\
As ppm & & & 4,0 & 5,5 & 33 & 17 \\
Co ppm & 50 & 200 & & & & \\
Cr ppm & 100 & 400 & 22 & 31 & 111 & 100 \\
Cu ppm & 100 & 400 & 15 & 25 & 114 & 85 \\
N1 ppm & 60 & 200 & 15 & 31 & 90 & 92 \\
Pb ppm & & & 23 & 31 & 250 & 55 \\
V ppm & 50 & 500 & & & & \\
Zn ppm & 150 & 700 & 65 & 110 & 800 & 143
\end{tabular}

Considerando os limites de tolerância do OME e os valores guia da Beak, existiriam problemas com Fe, Mn, As, Cr e v. Isso sugere a anomalia regional zapicán como um alvo para futuros estudos. Quanto ao $\mathrm{Co}, \mathrm{Pb}$ e $\mathbf{Z n}$, apenas poucas amostras 
apresentam valores superiores aos limites e seu efeito seria restrito. As e m apresentaram teores elevados associados ao Grupo Lavalleja.

Ao classificar as amostras em grupos em função dos litotipos que ocorrem na área, observou-se que alguns deles apresentaram médias superiores ou próximas aos valores guias da Tabela 39 (Tabela 41). TARVAINEN (1996) indica que o efeito de toxicidade de Co, $\mathbf{C r}, \mathbf{C u}, \mathbf{N i}, \mathbf{v}$ e $\mathbf{z n}$ é cumulativo. Por esse motivo foram consideradas as médias de $\mathrm{Cr}$, que em alguns casos, apresentaram valores próximos aos guias. O valor de 50 ppm para - $\mathrm{V}$ parece muito baixo, pois a maioria dos litotipos mostraram médias acima desse valor.

Tabela 40. Porcentagens de amostras acima dos valores guias ou limites (Tabela 39) para os teores brutos das amostras originais relacionadas ao presente trabalho. os valores para tilitos apenas foram considerados na ausência de outros criterios.

\begin{tabular}{|c|c|c|c|c|c|}
\hline Elementos & $>\mathbf{G 1}$ & $>\mathrm{I}_{2}$ & $>L_{3}$ & $>I_{4}$ & $>L_{5}$ \\
\hline Fe : & & & 83,4 & 38,2 & 12,4 \\
\hline $\operatorname{Mn} \div$ & & & 92,5 & 89,5 & 30,4 \\
\hline As $\%$ & & & 51,3 & 37,8 & 0,1 \\
\hline Co \% & 0,2 & 0,0 & & & \\
\hline $\mathrm{Cr} \%$ & & & 78,3 & 48,0 & 2,6 \\
\hline $\mathrm{Cu} \%$ & & & 70,3 & 15,0 & 0,0 \\
\hline Ni \% & & & 56,3 & 14,8 & $1,0 \%$ \\
\hline $\mathbf{P b} \div$ & & & 5,5 & 1,8 & 0,0 \\
\hline$v \div$ & 77,4 & 0,0 & & & \\
\hline Zn $\frac{9}{6}$ & & & 28,3 & 2,1 & 0,0 \\
\hline
\end{tabular}


Tabela 41. Grupos de amostras classificadas pelos litotipos associados que apresentaram teores proximos ou acima dos valores guias para os elementos indicados (valores medios).

$\begin{array}{ccccc}\text { Litotipo } & \text { Fe } & \text { Mn } & \text { Cr } & \text { V } \\ \text { Anfibolitos Pavas } & 4,2 \% & 1083 \mathrm{ppm} & 73 \mathrm{ppm} & 87 \mathrm{ppm} \\ \text { Granito a anfibolio } & 4,3 \% & 1463 \mathrm{ppm} & 88 \mathrm{ppm} & 90 \mathrm{ppm} \\ \text { Mático ultramáicas Pavas } & 4,9 \% & 1247 \mathrm{ppm} & 79 \mathrm{ppm} & 83 \mathrm{ppm} \\ \text { Veios máticos } & 3,7 \% & 1053 \mathrm{ppm} & 67 \mathrm{ppm} & 81 \mathrm{ppm} \\ \text { Xistos Lavalleja } & 2,9 \% & 1246 \mathrm{ppm} & 32 \mathrm{ppm} & 61 \mathrm{ppm}\end{array}$

Outra forma de analisar o problema é através do método das sub-bacias. Como valor guia será considerado o mínimo entre $\mathbf{L}_{5} e$ $\mathbf{G}_{6}$, ou $\circ \mathbf{G}_{1}$ para $\circ \mathbf{C o}$. $O \mathbf{V}$ mostrou médias superiores a $50 \mathrm{ppm}$ $\left(\mathbf{G}_{1}\right)$ para a maioria das sub-bacias. Por isso, para o $\mathbf{V}$ foi considerada a média geral das sub-bacias mais um desvio-padrão (Tabela 36) como valor guia, ou seja $80 \mathrm{ppm}$. Co, Cu e zn não apresentaram médias superiores aos valores guias para nenhuma sub-bacia. A porcentagem de sub-bacias com médias superiores aos valores indicados para Fe, $\mathbf{M n}, \mathbf{A s}, \mathbf{C r}, \mathbf{N i}, \mathbf{P b}$ e $\mathbf{V}$ é apresentada na Tabela 42.

Tabela 42. Porcentagens de sub-bacias com medias acima dos teores guias para as variáveis indicadas.

$\begin{array}{ccc}\text { Variável } & \text { Valor guia } & \text { Porcentagem } \\ \text { Fe } & 4 \% & 9 \% \\ \mathrm{Mn} & 1110 \mathrm{ppm} & 32 \% \\ \mathrm{As} & 17 \mathrm{ppm} & 0,3 \% \\ \mathrm{Cr} & 100 \mathrm{ppm} & 2 \% \\ \mathrm{NI} & 90 \mathrm{ppm} & 1 \% \\ \mathrm{~Pb} & 55 \mathrm{ppm} & 0,3 \% \\ \mathrm{~V} & 80 \mathrm{ppm} & 14 \%\end{array}$

As sub-bacias com médias acima dos valores guias para Fe, Cr, Ni e V coincidiram, em geral, com as classificadas nos 
grupos $R_{i}$ e $R_{m}$, ou mostraram-se espacialmente ligadas a elas. As sub-bacias com médias de Mn acima de 1110 ppm mostraram uma composição mais heterogênea: $20 \%$ relacionaram-se ao grupo anterior, 19\% integraram os grupos $L_{s}, R_{0}, R_{c}$ e Un, e 41\%, que não integraram nenhum dos grupos característicos, ocorreram sobrepostas ao Grupo Lavalleja, à Formação de AnfibolitasLeptitas e à Formação Sierra Ballena. O As mostrou média acima do valor guia em uma única sub-bacia, coincidindo com a subbacia próxima à ocorrência de Au na folha Gutiérrez. Para o Pb também só houve uma única sub-bacia com valor acima do guia, que integrou o grupo $R_{c}$ e localizou-se no vértice $S E$ da folha pirarajá, ao sul da vila do mesmo nome (Figura 50).

Analisando os quatro principais centros urbanos da região, observa-se que:

(1) A vila Zapicán está inserida em um ambiente enriquecido em Fe, Mn, $\mathrm{Cr}, \mathrm{Ni} e \mathrm{~V}$, superando com freqüência os limites recomendados na literatura sobre $\circ$ assunto. As sub-bacias adjacentes à vila não constituem os casos mais críticos, mas apresentam médias de Fe, un e V acima dos valores guias, com médias de Cr variando entre 56-93 ppm. Deve-se esclarecer que o nível de efeitos moderados do OME $\left(L_{4}\right)$ é superado em forma expressiva por vários elementos (Cr, Cu, Ni, v...). Localmente, as amostras originais apresentam valores extremamente altos.

(2) O povoado de María Albina localiza-se em uma região enriquecida em $\mathbf{P b}-\mathbf{z n}$, e existe ao norte uma anomalia regional $\mathbf{P b}-\mathrm{Sn}$. Os valores guia para $\mathbf{P b}$ não são superados pelas médias das sub-bacias. $O \mathbf{L}_{\mathbf{4}}$ do $\mathbf{P b}$ é superado em uma sub-bacia, imediatamente ao sul do povoado. Varias sub-bacias apresentam médias de Mn acima de $1110 \mathrm{ppm}$. Em alguns casos, as amostras originais superam o limite guia do $\mathbf{P b}$ (55 ppm).

(3) Em Pirarajá e José $P$. Varela, a resposta geoquímica aparece empobrecida, existindo apenas teores de $\mathrm{Mn}$ acima do valor guia de $1110 \mathrm{ppm}$. Isso confirma-se para as amostras originais e para as médias das sub-bacias. Porém, no caso de José $P$. Varela, existe uma sub-bacia próxima ao reservatório de água (lagoa ao leste) que apresentou média de $\mathrm{V}$ de $94 \mathrm{ppm}$.

Foram caracterizados três ambientes geoquímicos diferentes (J.P. Varela-Pirarajá, María Albina e Zapicán), mostrados na 
Figura 50. A situação em J.P. Varela e Pirarajá sugere que poderiam existir problemas relacionados à carência de traços, já que as médias das sub-bacias e os teores originais estão abaixo das médias gerais. Exemplos desse tipo parecem corroborar a idéia de que há empobrecimento em elementos traços em solos uruguaios (APPLETON, apud DARNLEY et al., 1995).

A situação em Zapicán é contrária à anterior. Existe um enriquecimento de metais pesados (Fe, Mn, Cr, Ni, V...), sendo superados os valores de efeito baixo e os valores guias. Isso sugere a necessidade de estudos para avaliar a ocorrência de problemas eco-toxicológicos nas populações de seres vivos autóctones. Seriam problemas de toxicidade crônica, produzidos pela influência de longo prazo dos referidos elementos sobre vegetação, animais e $\circ$ homem. A situação em María Albina não parece tão crítica. Deve-se considerar que, pelas informações disponíveis, não foram observađas evidências de contaminação antrópica, sendo os fenômenos discutidos relacionados a processos naturais. A realização de estudos comparativos nos diferentes locais, considerando dados sanitários, de produção agrícola, e de gado, além de outras variáveis, representaria uma boa iniciativa para esclarecer o problema. 


\section{CONSIDERAÇÕES FINAIS}

Informações extraídas de mapas geológicos, dados geoquímicos de sedimentos de corrente e solos coletados na década passada e dados digitais das seis bandas refletidas Landsat-TM, de um setor localizado em terrenos pré-cambrianos do Uruguai, foram analisados e integrados utilizando pacotes estatísticos, sistemas de PDI e SIGs. Foram aplicados métodos estatísticos sobre os dados geoquímicos originais ou transformados pelo método das sub-bacias. A integração da informação foi realizada por simples sobreposição das anomalias geoquímicas em formato vetorial, por classificação ou adotando critérios exploratórios através de técnicas de SIG.

As análises químicas foram realizadas por espectrometria DCP para 22 elementos (Fe, Mn, $\mathbf{P}$ e 19 traços), depois de digestão total com $\mathbf{B C l}-\mathrm{HClO}_{4}-\mathrm{HF}$. Teve-se especial cuidado para avaliar os erros de precisão através de procedimentos estatisticos (ANOVA), gráficos de dispersão e mapas simples, utilizando duplicatas de análise e de amostragem.

$\mathbf{F e}, \mathbf{M n}, \mathbf{P}, \mathbf{B a}, \mathbf{C o}, \mathbf{C r}, \mathbf{C u}, \mathbf{N i}, \mathbf{P b}, \mathbf{V}, \mathbf{Y}$ e $\mathbf{Z n}$ apresentaram variância adequada e erros analíticos inferiores a $10 \%$, sendo os elementos selecionados para o tratamento estatistico dos dados originais. Ag, As, $\mathbf{B}, \mathbf{B e}, \mathbf{C d}, \mathbf{M o}, \mathbf{M b}, \mathbf{S b}, \mathbf{S n} \mathrm{e} \mathbf{W}$ apresentaram erros analíticos relativos acima de $15 \%$, devido ao fato de muitas amostras estarem abaixo dos limites inferiores de detecção analítica (LIDAs). Por esse motivo, para esses elementos somente foram utilizados os valores próximos ou acima dos LIDAs.

Alguns dos elementos com erros analiticos baixos mostraram valores elevados para os erros de amostragem ( $P$, Co, $\mathbf{Y}$...). Esses erros seriam explicados por dois motivos:

(1) Problemas na forma de coleta das amostras e duplicatas.

(2) Variações devidas aos processos naturais.

É preciso levar em conta que, as amostras originais são, na realidade, amostras compostas considerando 3-5 pontos coletados a uma distância de 20-30 $\mathrm{m}$ ao longo do curso hídrico. Essa distância seria muito pequena em comparação à área que deveria ser representada (aproximadamente $1 \mathrm{~km}^{2}$ ). Por esse motivo, a 
distância de 150-200 m entre duplicatas de amostragem foi um pouco exagerada, em particular quando havia variações da litologia a distâncias curtas (Formação Pavas), provocando uma super-avaliação dos erros de amostragem. De qualquer maneira, outros processos afetaram a variância de amostragem, como a ocorrência de nódulos de Fe-Mn (efeito pepita). Assim, a amostragem deveria considerar amostras compostas abrangendo no mínimo 10 \% da área a ser representada $e$ as duplicatas de amostragem deveriam ser coletadas em forma diferente, de maneira de reduzir a influência dos processos naturais, em particular a variação de litologia. Essas considerações foram confirmadas quando usado o método das sub-bacias, pois ao considerar pequenos poligonos contendo 3-10 amostras originais, em função da hidrografia e morfologia, a variância geoquímica foi superior à variância interna dos polígonos (sub-bacias) para todos os elementos considerados. Por esse motivo, as sub-bacias constituíram verdadeiras amostras compostas geradas em função dos dados originais.

Foram amostrados quatro tipos de materiais: sedimentos em leito, seđimentos em flat, solos aluviais e solos autóctones. Em geral, as amostras de solos apresentaram teores inferiores aos das amostras de sedimentos. Assim, a comparação dos dados brutos na sua totalidade seria inviável, pois poderia provocar perda das anomalias indicadas por amostras de solos. Por esse motivo, cada amostra foi dividida pela mediana do grupo de amostras classificadas segundo o material amostrado. Outra fator que influencia a variância geoquímica, provocando resultados erráticos para os métodos multivariados, são as outliers (amostras inconsistentes). Utilizando gráficos e mapas produzidos com as distâncias de Mahalanobis-DMs, observou-se que as outliers eram, na sua maior parte, anomalias geoquímicas. Por esse motivo, sua completa eliminação, em função do indicado por critérios estatísticos, conduziria à perda da sub-população anômala, que é o alvo principal em todo estudo prospectivo. Assim, foram descartadas apenas as 44 outliers mais aberrantes, que representaram um $2 \frac{\circ}{6}$ das amostras totais. O conjunto de amostras resultante depois das correções (pelo material de 
amostragem e pelas outliers) apresentou um comportamento mais homogêneo.

- tratamento estatístico dos dados geoquímicos e a integração da informação permitiu visualizar varias anomalias regionais, sendo duas delas de particular destaque: zapicán e María Albina. A primeira delas está localizada na folha do mesmo nome e cobre mais de $100 \mathrm{~km}^{2}$ dentro da Formação Pavas, apresentando enriquecimento em Fe-Mn-P-Ba-Cu-Cr-Co-Ni-V-Zn e empobrecimento em $\mathrm{Pb}$, e está relacionada à ocorrência de anfibolitos e rochas máfico-ultramáficas. A anomalia regional María Albina possui dimensões menores e está localizada ao norte da folha J.P.Varela, possivelmente relacionada a uma das intrusões do Granito zócalo del Este. E caraterizada por teores elevados de $\mathbf{P b}$ e/ou de $\mathbf{S n}$, e está circundada por anomalias locais de As, Cu, $\mathbf{P b}$ e $\mathbf{z n}$.

As grandes unidades geológicas mostraram variações locais da resposta geoquímica, que foram controladas pelas características dos litotipos associados ou pela ocorrência de mineralizações. No caso da Formação Pavas, essas variações dependeram da existência de rochas máfico-ultramáficas (como na anomalia Zapicán) e no caso do Grupo Lavalleja, da ocorrência de mineralizações ou de pequenos afloramentos de litotipos especificos. As unidades geológicas de menor extensão mostraram resposta mais homogênea, destacando-se o Grupo Barriga Negra, pelos teores elevados de $\mathrm{Cu}$.

Os dados Landsat-TM são o produto de uma mixtura complexa de diversas variáveis (vegetação, morfologia, hidrografia, litologia, caracteristicas do solo, atividade antrópica e aspectos meteorológicos). Sua relação com a geologia é menos direta que no caso da geoquímica. Os grandes domínios geológicos foram evidenciados por feições texturais (relações espaciais entre pixels), porém as ocorrências pequenas, como os veios máficos, não foram identificadas. As diversas litologias apareceram, em geral, com cor uniforme, sem discriminação dos diversos litotipos. Isso seria explicado pela ausência de fenômenos intempéricos e hidrotermais importantes, e pela baixa ressolução das imagens Landsat. 
Vários procedimentos permitiram discriminar anomalias regionais e locais. Na analise fatorial dos dados geoquímicos, o fator 1 foi uma das variáveis que representou melhor comportamento do fundo. O Cu, estimado pelo modelo de regressão em função dos fatores, também caracterizou a resposta das principais unidades geológicas. Isso permitiu relacionar as anomalias locais com as residuais de $\mathrm{Cu}$. A representação do teor de fundo com a $D^{2}$ das primeiras CPS definiu as duas principais anomalias regionais (Zapicán e María Albina), mas mostrou resposta muito pobre para os outros domínios. A $D^{2}$ das últimas CPs detectou as quatro ocorrências minerais conhecidas, porém foi o procedimento mais impreciso, em termos da distância anomalia-ocorrência. Esses procedimentos, incluindo a análise dos mapas dos teores brutos, deram subsídios à definição de nove setores anômalos, porém não permitiram avaliar com precisão as dimensões dos setores. A sobreposição desses setores, digitalizados em formato vetorial, às imagens coloridas dos dados Landsat-TM, permitiu hierarquizar o interesse prospectivo de alguns desses setores anômalos. Nesse procedimento foram levandos em conta a observação de lineamentos ou a ocorrência de corpos aflorantes relacionados espacialmente às amostras anômalas.

No processo de integração de dados, a classificação não supervisionada, considerando a banda TM4, o Fator-F, o Fator-H, a $\operatorname{Rad}-\gamma$ e 10 elementos químicos, permitiu discriminar anomalias regionais e locais. Além disso, as últimas foram diferenciadas em anomalias litológicas e anomalias relacionadas às mineralizações (Figura 46). Nas bordas da área, devido à ausência de dados, a classificação não supervisionada apresentou alguns problemas. o melhor resultado mostrado pela classificação supervisionada foi destacar o interesse prospectivo do Grupo Barriga Negra. Os procedimentos que usaram SIG hierarquizaram os setores anômalos conhecidos e otimizaram seu tamanho. Porém, deve-se levar em consideração que a comparação da distância mínima anomalia-ocorrência mineral conhecida para quatro procedimentos que envolveram mapas de círculos e interpolados (Tabela 38) mostrou distância mínima média de $1,7 \mathrm{~km}$, variando 
no intervalo $0,6-3 \mathrm{~km}$. Isso sugere que o tamanho mínimo a ser pesquisado seria equivalente ao de uma sub-bacia.

Em prospeç̧ão geoquímica são conhecidos dois tipos de falsas anomalias, ou seja, anomalias locais que não estão relacionadas a ocorrências minerais. Os dois tipos seriam:

(1) Anomalias geradas por litotipos especificos (afloramentos de pequenas dimensões).

(2) Anomalias geradas por processos de adsorção de elementos traços sobre b́xidos de Fe-Mn.

Dois exemplos de anomalias do tipo (1), no presente trabalho, seriam o setor 02 e o setor 05 . Houve um único caso de anomalia possivelmente relacionada aos processos de adsorção, que foi uma anomalia $\mathbf{m - C o - v}$, com teores intermediarios de FeCr-Cu-Ni, que estaria associada a variações do nível da lagoa próxima à vila J.P. Varela. Por outro lado, várias amostras com teores elevados de Mn-Co mostram-se relacionadas à maioria das ocorrências minerais conhecidas, e também aos setores anômalos. Em particular, as classes 4 e 6 da classificação não supervisionada foram interpretadas como associadas a mineralizações e apresentaram valores altos para o Fator-F e o $\mathbf{P b}$, e para $\mathrm{Mn}$, $\mathrm{Co}, \mathrm{Pb}$ e $\mathbf{R a d}-\gamma$, respectivamente. GOVETT (1983) indica que $\mathrm{Fe}$, $\mathrm{zn}$ e às vezes $\mathrm{m}$ são indicadores regionais litogeoquímicos da ocorrência de depósitos de sulfetos maciços. Esses três elementos podem ocorrer também relacionados a fenômenos de adsorção em amostras de sedimentos de corrente, gerando falsas anomalias (HOWARTH, 1983). Porém, pelo observado neste trabalho, as anomalias de $\mathrm{m}$-Co $\mathrm{e}$ em eventualmente teores de Fe moderados, em especial relacionadas ao Grupo Lavalleja, representariam anomalias associadas a mineralizações, e não falsas anomalias.

Vários dos elementos enriquecidos na anomalia zapicán são tóxicos (Fe,un, Cr, Ni, V...) e seus efeitos são cumulativos. Isso poderia sugerir a existência de problemas de eco-toxicidade nessa região, ou seja, efeitos crônicos nos seres vivos autóctones, incluindo o próprio homem, devidos à influência dos metais mencionados durante periodos longos. Em Pirarajá e J.P. Varela a situação é oposta, pois há um empobrecimento nos teores da maioria dos traços. No povoado de María Albina ocorrem 
anomalias de $\mathbf{P b}$, mas a situação parece menos crítica que em Zapicán, pois os valores guias mencionados na bibliografia são superados em poucos casos. A sobreposição de dados de produtividade agrícola, problemas veterinários, de saúde pública e outros, considerando as quatro zonas urbanas de maneira comparativa, poderia constituir um antecedente para novos estudos, e também um exemplo para ser usado como referência.

No presente trabalho foi considerada uma pequena parte dos dados geoquímicos levantados pela DINAMIGE com a cooperação do BRGM na década passada. A criação de um banco de dados com o total da informação, viabilizariam o reprocessamento desses dados, em seu conjunto, o que abriria novos horizontes do ponto de vista ambiental ou geo-mineral. Nesse sentido, 0 uso do método das sub-bacias e de procedimentos relacionados ao PDI e aos SIGs oferecem boas possibilidades. Porém, para um estudo mais completo, dada a carência de informações em extensas áreas do país, seriam necessários dados novos, incluindo aspectos qualitativos (elementos químicos ainda não estudados, outros materiais...) e quantitativos (métodos anaĺticos com limites de deteç̧ão mais baixos, exatidão e precisão otimizadas). 


\section{BIBLIOGRAFIA}

ABACUS CONCEPTS (1992) Statview Manual. Berkeley, Abacus Concepts.

ABRAMS, M.; ASHLEY, R.; ROWAN, L., GOETZ, A. ; KAHLE, A. (1977). Mapping of hydrothermal alteration in the Cuprite mining district, Nevada, using aircraft scanner images for the spectral region 0.46 to $2.36 \mu \mathrm{m}$. Geology, v. 5, p. $713-718$.

ADRIANO, D. (1986) Trace Elements in the Terrestrial Environment. New York, Springer-Verlag, $533 \mathrm{p}$.

ALDUS (1993) Superpaint User Manual. Version 3.0 for use with Apple Macintosh computers. San Diego-CA, Aldus Corporation.

ALECRIM, J. ; ROYER, J. (1991) As outliers nas distribuicós monovariáveis: uma tecnica para o tratamento de dados em prospeccão geoquimica. In: CONGRESSO BRASILEIRO DE GEOQUIMICA, $3 . ;$ CONGRESSO DE GEOQUIMICA DOS PAISES DE LINGUA PORTUGUESA, 1., São Paulo, 1991. Resumos, v. 2, p. 468-473.

AFIFI, A. ; AZEN, S. (1972) Statistical Analysis: a Computer oriented Approach. New York, Academic Press. p. 228-230.

AHLSVED, C.; LAMPIO, E. ; TARVAINEN, T. (1991) ALKEMIA-a VAX minicomputer database program package for geochemical exploration. Journal of Geochemistry Exploration, v. 41, p. 23-28.

AUTODESK (1990) AUTOCAD Reference Manual, release 11. USA, Autodesk Inc., $640 \mathrm{p}$.

BARROS SILVA, A. (1993) Mineral Exploration in Northeastern Brazil; A Data Fusion Aproach and a GIS Strategy. In: Ninth Thematic Conference on Remote Sensing for Exploration Geology. Pasadena, Proceedings, p. 55-63.

BEUS, A. ; GRIGORIAN, S. (1977) Geochemical Exploration Methods for Mineral Deposits. Wilmette, Applied Publishing, 287p.

BONHAM-CARTER， G. (1994) Geographic Information Systems for Geocientists. Ontario, Pergamon. 398p.

BONHAM-CARTER， G. ; AGTERBERG， F. ; WRIQHT, D. (1988) Integration of Geological Datasets for Gold Exploration in Nova Scotia. Photogrammetric Engineering and Remote Sensing, v. 54, n. 11, p. 1585-1592.

BOSSI, J. (1987) Evidencias geologicas sobre la posible existencia de un Núcleo Cratónico de más de $2.000 \mathrm{ma}$ en el Noroeste del Uruquay. In: SIMPÓSIO SUL-BRASILEIRO DE GEOLOGIA, 3., Curitiba, 1987. Atas, v.2, Curitiba, p. $821-832$.

BOSSI, J (1989) Carta Geologica del Uruguay Escala 1/100.000. Prefacio. Montevideu, DINAMIGE-FA-FHC, 13p.

BOSSI, J. ; PRECIOZZI, F. ; CAMPAI, N. (1993) Predevoniano en el Uruquay. Tomo I: Terreno Piedra Alta. Montevideu, MIE-DINAMIGE, 50p. 
BOYLE, R. (1982a) Geochemical methods for the discovery of blind mineral deposits - Part 1. CIM Bulletin, 65 (844): 123-142.

BOYLE, R. (1982b) Geochemical methods for the discovery of blind mineral deposits - Part 2. CIM Bullet1n, v. 75, n. 845, p. 113-132.

BOWIE, S. ; THORNTON, I. (1985) Environmental Geochemistry and Health. Dordrecht, D. Reidel, 140p.

BÖLVIKEN, B.; BOGEN, J.; DEMETRIADES, A.; DE VOS, W.; EBBING, J.; HINDEL, R.; LANGEBAL, M.; LOCUTURA, J.; O'CONNOR, P.; OTTESEN, R.; PULKKINEN, E.; SALMINEN, R.; SCHERMANN, O.; SWENNEN, R.; VAN DER SLUYS, J.; VOLDEN, T. (1996) Regional geochemical mapping of Western Europe towards the vear 2000 . Journal of Geochemical Exploration, v. 56, p. 141-166.

BÖLVIKEN, B.; STOKKE, P.; FEDER, J. ; JÖSSANG, T. (1992) The fractal nature of geochemical landscapes. Journal of Geochemical Exploration, v. 43, p. 91109 .

BAUDO, R.; GIESY, J. ; MUNTAU, H. (1990) Sediments: Chemistry and Toxicity of In-Place Pollutants. Ann Arbor, Lewis Publishers, 405p.

CRÓSTA, A. (1991) High Resolution Geochemistry and Satellite Data Inteqration: Application to Mineral Exploration in a Tropical Environment. In: Eigth Thematic Conference on Geological Remote Sensing. Denver, Proceedings, $16 \mathrm{p}$.

CROSTA, A. (1993a) Processamento Digital de Imagens de Sensoriamento Remoto. Edição revisada. Campinas, IG-UNICAMP, 170 p.

CRÓSTA, A. (1993b) Caracterizaçăo epectral de minerais de interesse à prospeccão mineral e sua utilizaçåo em processamento digital de imagens. In: SIMPOSIO BRASILEIRO DE SENSORIAMENTO REMOTO, 7., Curitiba, 1993. Ana1s. Curitiba, INPE, p. 202-210.

CROSTA, A. ; MOORE, J. MCM (1989) Enhancement of Landsat Thematic Mapper imagery for residual soil mapping in SW Minas Gerais state, Brazil: a prospecting case history in greenstone belt terrain. Seventh Thematic Conference of Remote Sensing for Exploration Geology, Calgary. Proceedings, p. $1173-1187$.

CROSTA, A. ; RABELO, A. (1993) Assessing Landsat/TM for Hydrothermal Alteration Mapping in Central-Western Brazil. Ninth Thematic Conference on Geological Remote Sensing. Pasadena, Proceedings, p.1053-1061.

CROUNSE, R. ; PORIES, W.; BRAY, J. ; RICHARD, M. (1983) Geochemistry and Man: Health and Disease. In: THORNTON, I. (ed.) Applied Environmental Geochemistry. London, Academic Press. Capitulo 9-10, p. 267-333.

DARNLEY, A. (1990) International geochemical mapping: a new global project Journal of Geochemical Exploration, v. 39, p. 1-13.-

DARNLEY, A. (1993) International Geochemical Mapping. Journal of Geochemical Exploration, v. 48, p. 97-104.

DARNLEY, A. (1995) International Geochemical Mapping - a review. Journal of Geochemical Exploration, v. 55, p. 5-10. 
DARNLEY, A. ; BJŎRKLUND, A.; BÖLVIKEN, B.; GUSTAVSSON, N.; KOVAL, P.; PLANT, J.; STEENFELT, A.; TAUCHID, M. ; XIE XUEJING (1995) A global geochemical database for environmental and resource management. Final Report of IGCP Project 259. Paris, UNESCO Pub., 122p. (Earth Sciences 19)

DAVENPORT, P. (1993) Geochemical Mapping. Journal of Geochemical Exploration, v. $49,212 \mathrm{p}$.

DAVIS, J. (1986) Statistics and Data Analysis in Geology. New York, Wiley, $645 \mathrm{p}$.

DI zHOU, (1985) Adjustment of Geochemical Background by Robust Multivariate Statistics. Journal of Geochemical Exploration, v. 24, p. 207-222.

DRURY, S. (1990) A Guide to Remote Sensing. Oxford, Oxford University Press, $199 p$.

DUTRA, C. (1984) Espectrografia optica de emissão. In: GOMES, C.B. (Coord.). Técnicas analíticas instrumentais aplicadas à geologia. São Paulo, Edgard Blücher Ltda., p.121-158.

EDÉN, P. (1994) Wide-spaced sampling of overbank, till, humus and river water in Fennoscandia. Applicability for global geochemical mapping and environmental assessment. Abo, 49p. (Tese - Doutorado) - Abo Akademi University.

ER-MAPPER， (1995) ER-Mapper 5.0: Applications. West Perth, Earth Resource Mapping, 372p.

FAY, A. (1982a) Esbozo Geologico del Fotoplano Piraraja a la escala 1/50.000. Montevideu, DINAMIGE, 1 mapa.

FAY, A. (1982b) Esbozo Geologico del Fotoplano Zapicán a la escala 1/50.000. Montevideu, DINAMIGE, 1 mapa.

FAY, A. (1982C) Esbozo Geologico del Fotoplano Jose P. Varela a la escala $1 / 50.000$. Montevideu, DINAMIGE, 1 mapa.

FESEFELDT, K. (1988) Asesoramiento geologico y vacimentológico a la DINAMIGE. Hannover, BGR, $186 \mathrm{p}$.

FESEFELDT, K., VAZ, N. ; ARRIGHETTI, R. (1988) Interpretaçión geotectónica preliminar de la Faja de la Serie de Minas y áreas vecinas, 1 mapa. In: FESEFELDT, K. ( ed.) Asesoramiento geologico y vacimentolóico a la DINAMIGE, Hannover, BGR, $186 \mathrm{p}$.

FILIPPINI ALBA, J. (1990) prospección geoguimica en los alrededores de la Mina abandonada Presidente Terra. Montevideu, DINAMIGE, 30p.

FILIPPINI ALBA，J. (1991) Aplicação da analise fatorial em prospecção geoguímica: amostragem de sedimentos de corrente em terrenos Pré-cambrianos do Uruquai. CONGRESSO BRASILEIRO DE GEOQUIMICA, $3 . ;$ CONGRESSO DE GEOQUIMICA DOS PAISES DE LINGUA PORTUGUESA, 1,, Såo Paulo, 1991. Resumos. São Paulo, SBG v. 2, p. 546-550. 
FILIPPINI ALBA，J. (1992) Aplicaç̃o dos metodos estatísticos em prospeccão geoquímica de sedimentos de corrente e rochas na região de Isla Patrulla, Distrito de Treinta y Tres, Uruquai. Såo Paulo, 182p. (Dissertação Mestrado) - Instituto de Geociências, Universidade de são Paulo.

FRAGOSO CESAR, A. ; MACHADO, R. ; GOMEZ RIFAS, C. (1987) Observacóes sobre o Cinturão Dom Feliciano no Escudo Uruquaio e correlaç̃es com o Escudo do Rio Grande do SUl. In: SIMPOSIO SUL-BRASILEIRO DE GEOLOGIA, 3., Curitiba, 1987. Atas. v.2, Curitiba, SBG. v.2, p. 791-809.

GARRETT, R. (1983) Sampling Methodology. In: Howarth, R. (ed.) Statistics and data analysis in geochemical prospecting. Amsterdam, Elsevier Scientific, p. $83-110$.

GARRETT, R. (1989) The chi-square plot: a tool for multivariate outlier recognition. Journal of Geochemical Exploration, v. 32, p. 319-341.

Koljonen, T. (1992) The Geochemical Atlas of Finland, Part II: Till, Espoo, Geological Survey of Finland, 218p.

GNANADESIKAN, R. ; KETTENRING, R. (1972) Robust estimates, residuals and outliers detection with multiresponse data. Blometrics, v. 28, p. 81-124.

GOLDSCHMIDT, V. (1958) Geochemistry. Oxford, Clarendon Press. 730p.

GOMEZ-RIFAS, C. (1995) A zona de cisalhamento sinistral Sierra Ballena no Uruquai. São Paulo, IG-USP, 244p. (Tese - Doutorado) - Instituto de Geociências, Universidade de São Paulo.

GOVETT, , G. (1983) Rock Geochemistry in Mineral Exploration. Amsterdam, Elsevier, 461p. (Handbook of Exploration Geochemistry, 3).

GOVETT, , G. ; ATHERDEN, G. (1988) Application of rock geochemistry to productive plutons and volcanic sequences. Journal of Geochemical Exploration, v. 30, p. 223-242.

GRANIER， G. (1973) Introduction a la prospection qeochimique des gites metalliferes. Paris, Masson et Cie. $143 p$.

GRASS (1991) Geographic Resources Analysis Support System. Version 4.0., Champaign, U.S. Army Corps of Engineers, Construction Engineering Research Laboratory.

HARRIS, J. (1989) Data integration for gold exploration in Eastern Nova Scotia using a GIS. Seventh Thematic Conference on Remote Sensing for Exploration Geology. Calgary, Proceedings, p. 233-249.

HOWARTH, R. (1983) Statistics and data analysis in geochemical prospecting. Amsterdam, Elsevier. 437p. (Handbook of Exploration Geochemistry, 2).

HOWARTH, R. ; THORNTON, I. (1983) Regional Geochemical Mapping and its Application to Environmental Studies. In: THORNTON, I. (ed.) Applied Environmental Geochemistry. London, Academic Press, p. 41-73.

IGU-BRGM (1982) Inventario Minero del Uruquay - primera Fase - Informe final. Orleans, BRGM, 83p. 
ILLANES, L. (1982) Esbozo Geologico del Fotoplano Gutierrez a la escala $1 / 50.000$. Montevideu, DINAMIGE, 1 mapa.

JARVIS, I.; JARVIS, K. (1992) Inductively coupled plasma mass spectrometry in exploration geochemistry. Journal of Geochemical Exploration, v. 44, p. 189194 .

JOLLIFFE, I. (1986) Principal component analysis. New York, Springer-Verlag. 271 p.

JÖRESKOG, K.; KLOVAN, J. ; REYMENT, R. (1976) Geological Factor Analysis. Amsterdam, Elsevier, 178p.

Keckler, D. (1994) Surfer for Windows. Golden-Co, Golden Software,

KOVAL, P.; BURENKOV, E.; GOLOVIN, A (1995) Introduction to the program Multipurpose Geochemical Mapping of Russia. Journal of Geochemical Exploration, v. 55, p. 115-123.

KRYUSKOV, V. (1991) Heavy metal accumulation in spruce needles and changes of Nothern Taiga ecosystems. In: PULKKINEN, E. ( ed.) Environmental Geochemistry in Nothern Europe. Geological Survey of Finland, Spectal Paper , v. 9, p. 177-184.

KUOSMANEN, V.; ARKIMAA, H.; GAAL, G.; HUHTALA, T.; KOISTINEN, E.; LINDQVIST, E.; MURTONIEMI, S.; NIKANDER, J.; RUSKEENIEMI, K.; SALONEN, V.; TALVITIE, J.; TENHOLA, M.; TIAINEN, M. ; WARD, P. (1988) Exploration target selection by integration of geodata using statistical and image processing technigues: an example from central Finland". Part 1 (Text). Espoo, Geological Survey of Finland. Report of Investigation 80. 156p.

LÄG, J. (1983) Geomedicine in Scandinavia. In: THORNTON, I. (Ed.) Applied Environmental Geochemistry. London, Academic Press. p. 335-353.

LAG, J. (1991) Geomedical aspects of geochemical environments. In: PULKKINEN, E. (ed.) Environmental Geochemistry in Nothern Europe. Geological Survey of Finland, Special Paper, v. 9, p. 271-276.'

LEPELTIER, C. (1969) A simplified statistical treatment of geochemical data by graphical representation. Journal of Geochemical Exploration, v. 64, p. $538-550$.

LEVINSON, A. (1974) Introduction to Exploration Geochemistry. Calgary, Applied Publishing Ltd.. 600p.

LICHT, O. ; TARVAINEN, T. (1996) Multipurpose geochemical maps produced by inteqration of geochemical exploration data sets in the Parana Shield, Brazil. Journal of Geochemical Exploration, 56: 167-182.

LOUGHLIN, W. (1991) Principal Component Analysis for Alteration Mapping. Photogrammetric Engineering and Remote Sensing, v. 57, p. 1163-1170.

MIDOT, D. (1984) Etude Geologique et Diagnostic Metallogenique pour L'Exploration du Secteur de Minas (Uruguay). Paris, 175p. (Tese de Doutorado) - L'Universite Pierre et Marie Curie. 
MIESCH, A. (1981) Estimation of the Threshold and its Statistical Significance. Journal of Geochemical Exploration, v. 16, p. 49-76.

PLANT, J. ; RAISWELL, R. (1983) Principles of Environmental Geochemistry. In: THORNTON, I. (ed.) Applied Environmental Geochemistry. London, Academic Press. p. $1-39$.

PLUMMER, R. (1992) Using a Geographic Information System as a tool in mineral exploration. CIM Bullet1m, v. 85, n. 957, p. 67-71.

PEREZ, M. (1984a) Inventario Minero del Uruquay. Prospección Aluvionar en la Zona sur de Isla Patrulla. Montevideu, DINAMIGE, 7p.

PEREZ, M. (1984b) Inventario Minero del Uruquay. Prospección Aluvionar en la zona Central de Isla Patrulla. Montevideu, DINAMIGE, $6 \mathrm{p}$.

PRECTOZZI, F. (1987A) Carta Geologica del Uruquay Escala 1:100,000. Memoria Explicativa del Fotoplano Jose $P$. Varela (E-21). Montevideu, DINAMIGE-FAFHC, 11 p., 1 mapa.

PRECIOZZI, F. (1987b) Carta Geologica del Uruquay Escala 1:100.000. Memoria Explicativa del Fotoplano Zapicán (E-22). Montevideu, DINAMIGE-FA-FHC, 12 p., I mapa.

PRECIOZZI, F. ; FAY, A. (1988). Carta Geologica del Uruquay Escala 1:100.000. Memoria Explicativa del Fotoplano Pirarajá (F-23). Montevideu, DINAMIGE-FAFHC, 15 p., 1 mapa.

PRECIOZZI, F., SPOTURNO, J., HEINZEN, W. \& ROSSI, P. (1985). Carta Geologica del Uruquay Escala 1:500.000. Montevideu, DINAMIGE, I mapa.

PRECIOZZI, F., SPOTURNO, J., HEINZEN, W. \& ROSSI, P. (1988). Memoria Explicativa de la Carta Geologica del Uruquay Escala 1:500.000. Montevideu, DINAMIGE, $92 \mathrm{p}$.

ROQUIN, C. \& ZEEGERS, H. (1987). Improving Anomaly Selection by Statistical Estimation of Backqround Variations in Regional Geochemical Prospecting. Journal of Geochemical Exploration, v. 29, p. 295-316.

ROSE, A., HAWKES, H. \& WEBB, J. (1979) - Geochemistry in Mineral Exploration. New York, Academic Press, 657p.

SALOMONS, W. \& FÖRSTNER, U. (1984). Metals in the Hydrocycle. Berlin, Springer-Verlag, p. 259-286

SELINUS, O. (1983). Regression analysis applied to interpretation of geochemical data at the Geological survey of Sweden. In: Statistics and Data Analysis in Geochemical Prospecting. I. HOWARTH, (Ed.), Amsterdam, Elsevier. p.293-301.

SERVIÇO GEOGRÁFICO MILITAR (1982). Carta Geografica de la Hoia 1/50.000 Jose p. Varela. Monteviđéu, 1 mapa.

SERVIÇO GEOGRÁFICO MILITAR (1989). Carta Geografica de la Hoja 1/50.000 Piraraja. Montevidé, I mapa. 
SERVIÇO GEOGRÁFICO MILITAR (1990a). Carta Geografica de la Hoja 1/50.000 Gutierrez. Montevideu, 1 mapa.

SERVIÇO GEOGRÁFICO MILITAR $(1990 \mathrm{~b})$. Carta Geografica de la Hoja 1/50.000 Zapicán. Montevidé, 1 mapa.

SPANGENBERG, J. (1986). Metodos de exploracion geoquímica empleados en el Inventario Minero Nacional. Boletín DINAMIGE, nro. 39, 34-104.

SHACKLETTE, H., SAUER, H. \& MIESH, A. (1970). Geochemical environments and cardiovascular mortality rates in Georgia. U.S. Geological Survey Professional paper $574-\mathrm{C}$. Washington, 39p.

SHAW, D. (1964). Interpretation Geochimique des Elements em Traces dans les Roches Cristalines. Paris, Masson et Cie., $237 \mathrm{p}$.

SINCLAIR, A. (1991). A fundamental approach to threshold estimatino in exploration geochemistry. Journal of Geochemical Exploration, 41: 1-22.

SKOG, D. \& LEARY, J. (1994). Análisis Instrumental. $4^{a}$ edição, Madrid, MC Graw-Hill, p. 285-286.

SPSS (1993). SPSS for Windows: Professional Statistics. Realese 6.0. ChicagoUSA, SPSS InC.

SYSTAT (1992). SYSTAT: StatistiCS, Version 5.2 Edition. SYSTAT, InC., Evanston, II. $724 \mathrm{p}$.

TARVAINEN, T. (1996). Environmental Aplications Geochemical Databases in Finland. Espoo, Geological Survey of Finland, 75p. (Dissertação Acadêmica).

TAYLOR, S. \& MC LENNAN, S. (1985). The Continental Crust: Its Composition and Evolution. Oxford, Blackwell Sc. Pub., 312p. (Capitulo 2).

THORNTON, I. (1983) Geochemigtry Applied to Agriculture. In: THORNTON, I. (ed.) Applied Environmental Geochemistry. London, Academic Press, p. $231-$ 266.

TIAINEN, M. ; VIITA, H. (1994) Determination of ore potential areas in the Häme Belt, Southwestern Finland, by integration of geoloqical, geophysical and till geochemical data. Espoo, Geological Survey of Finland. Report of Investigation $125.49 \mathrm{p}$.

TRESCASES, J. (1984) Análise química por espectrometria de absorcão atômica. In: GOMES, C.B. ( coord.) Técnicas analfticas instrumentais aplicadas à geologia. Så Paulo, Edgard Blücher, p.44-83.

VAZ, N.; PIRELli, H. ; OYHANÇABAL, P. (1985) Geologla à escala 1/10.000 de los alrededores de Isla Patrulla. Montevideu, DINAMIGE, $49 \mathrm{p}$.

XIE XUEJING (1990) Some problems, strategical and tactical, in international geochemical mapping. Journal of Geochemical Exploration, v. 39, p. 15-33. 